Portland State University

PDXScholar

\title{
A Historical and Archaeological Study of the Nineteenth Century Hudson's Bay Company Garden at Fort Vancouver: Focusing on Archaeological Field Methods and Microbotanical Analysis
}

Elaine C. Dorset

Portland State University

Follow this and additional works at: https://pdxscholar.library.pdx.edu/open_access_etds

Part of the Biological and Physical Anthropology Commons, Inequality and Stratification Commons, and the Social and Cultural Anthropology Commons Let us know how access to this document benefits you.

\section{Recommended Citation}

Dorset, Elaine C., "A Historical and Archaeological Study of the Nineteenth Century Hudson's Bay Company Garden at Fort Vancouver: Focusing on Archaeological Field Methods and Microbotanical Analysis" (2012). Dissertations and Theses. Paper 869.

https://doi.org/10.15760/etd.869

This Thesis is brought to you for free and open access. It has been accepted for inclusion in Dissertations and Theses by an authorized administrator of PDXScholar. Please contact us if we can make this document more accessible: pdxscholar@pdx.edu. 
A Historical and Archaeological Study of the Nineteenth Century Hudson's Bay Company Garden at Fort Vancouver:

Focusing on Archaeological Field Methods and Microbotanical Analysis

\author{
by \\ Elaine C. Dorset
}

A thesis submitted in partial fulfillment of the requirements for the degree of

Master of Arts

in

Anthropology

Thesis Committee:

Kenneth M. Ames, Chair

Douglas C. Wilson

Virginia L. Butler

Portland State University

(C)2012 


\begin{abstract}
The Hudson's Bay Company (HBC), a British fur-trading enterprise, created a large garden at Fort Vancouver, now in southwest Washington, in the early- to mid-19th century. This fort was the administrative headquarters for the HBC's activities in western North America. Archaeological investigations were conducted at this site in 2005 and 2006 in order to better understand the role of this large space, which seems incongruous in terms of resources required, to the profit motive of the $\mathrm{HBC}$.

Questions about the landscape characteristics, and comments by 19th century visitors to the site provided the impetus for theoretical research of gardens as representations of societal power, and, on a mid-range level, the efficacy of certain archaeological methods in researching this type of space. Documentary research related to the history of the HBC Garden was also conducted, including previous archaeology completed at the site. The results of these lines of inquiry are presented, providing insight as to the diverse roles this Garden fulfilled in the survival of the HBC in the region - as a commercial enterprise, as a microcosm of western societal practice, and in the health of its employees.
\end{abstract}




\section{DEDICATION}

For my husband, family and friends

who were ever patient and supportive. 


\section{ACKNOWLEDGEMENTS}

This project was completed with the support of the Portland State University

Department of Anthropology staff and faculty, the National Park Service,

the Northwest Cultural Resources Institute, the North Coast and Cascades Science Learning Network, and the Oregon Archaeological Society.

Special thanks to my fellow employees, field school students, and volunteers at Fort Vancouver National Historic Site, my thesis advisor Douglas Wilson and committee members Ken Ames and Virginia Butler. 


\section{TABLE OF CONTENTS}

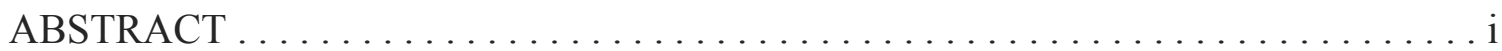

DEDICATION ........................................ ii

ACKNOWLEDGEMENTS $\ldots \ldots \ldots \ldots \ldots \ldots \ldots \ldots \ldots \ldots \ldots \ldots \ldots \ldots \ldots \ldots$ iii

LIST OF TABLES . . . . . . . . . . . . . . . . . . . . . . . . v

LIST OF FIGURES $\ldots \ldots \ldots \ldots \ldots \ldots \ldots \ldots \ldots \ldots \ldots \ldots \ldots \ldots \ldots \ldots \ldots \ldots$

CHAPTER 1. Introduction and Background . . . . . . . . . . . . . . . . 1

CHAPTER 2. Methods and Results of Archival Research ................. 10

CHAPTER 3. Summary of Research, Article and Publication Review Relating to

Garden Archaeology Projects and Methods .................... 31

CHAPTER 4. Previous Archaeology at the Site of the Hudson's Bay Company Garden at Fort Vancouver.............................. 35

CHAPTER 5. Archaeological Research Design and Methods for the Fort Vancouver Garden Project ............................... 43

CHAPTER 6. Archaeological Testing Results. . . . . . . . . . . . . . 52

CHAPTER 7. Artifacts and Archaeobotanical Remains ..................... 60

CHAPTER 8. Discussion. . . . . . . . . . . . . . . . . . . . . 85

CHAPTER 9. Conclusions and Recommendations.................... 106

SOURCES CITED . . . . . . . . . . . . . . . . . . . . . . . . 111

APPENDIX A: A Review of Research, Articles and Publications Relating to Garden Archaeology Projects and Methods ................ 123

APPENDIX B: Results of Excavations by Unit . . . . . . . . . . . . . . . . . 144

APPENDIX C: WWI and Later Features Found at TA1 .............. 148

APPENDIX D: Phytolith Analysis of Samples from Fort Vancouver National Historic Site, Washington . . . . . . . . . . . . . . . 152

APPENDIX E: Pollen and Phytolith Analysis of a Historic Garden at Fort Vancouver National Historic Site, Vancouver, Washington. . . . . . . 161

APPENDIX F: An Analysis of Pollen from Fort Vancouver Washington. . . . . . . . 177

APPENDIX G: A Pollen Analysis of a Hudson's Bay Company Non-Garden Provenience, Fort Vancouver, Washington . . . . . . . . . . 235

APPENDIX H: Macrobotanical Analysis of Hand-picked and Wetscreen Samples from Fort Vancouver, Washington ................. 280 


\section{LIST OF TABLES}

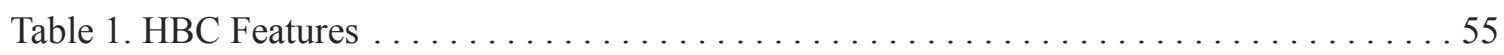

Table 2. HBC Garden and Village Artifact Count Comparison (artifacts per $\mathrm{m}^{3}$ ) $\ldots \ldots \ldots 63$

Table 3. Primary modes of flat glass thickness and corresponding thickness $\ldots \ldots \ldots \ldots 69$

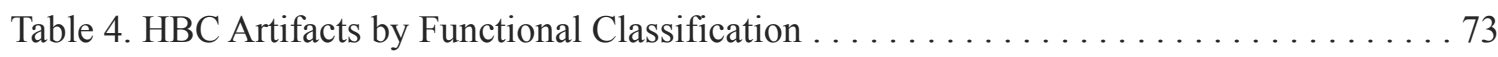

Table 5. Introduced plants not previously known to have been grown at Fort Vancouver from historical documents, based on pollen analysis of Garden

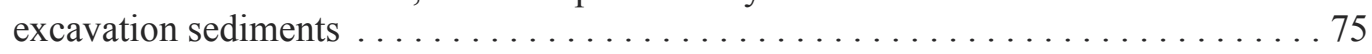

Table 6. Native plants with economic uses growing in the garden, or nearby $\ldots \ldots \ldots \ldots 76$ 


\section{LIST OF FIGURES}

Figure 1. Looking northwest from the site of the WWI spruce mill at temporary housing

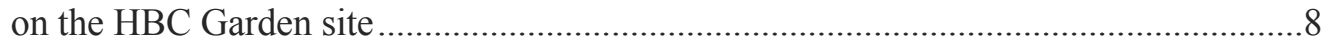

Figure 2. Detail of 1844 Line of Fire map with author's annotations..........................................11

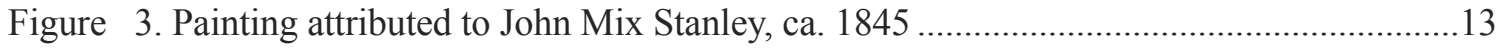

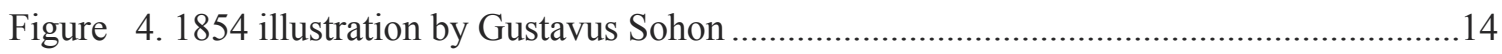

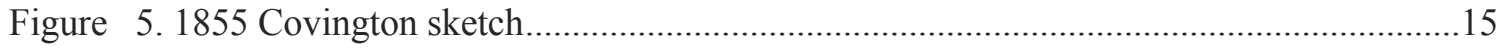

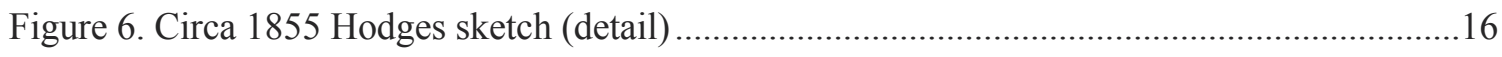

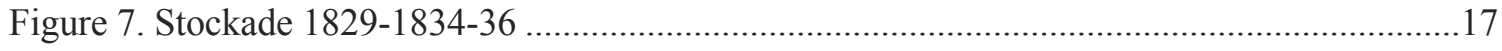

Figure 8. Original stockade 1829 to1834-36 (green line) imposed over 1844 Line of Fire map ....18

Figure 9. Duke of Devonshire's garden at Chiswick ..............................................................17

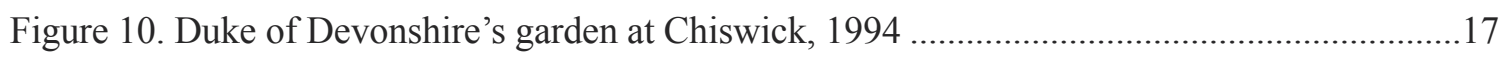

Figure 11. Horticultural Society of London arboretum..............................................................18

Figure 12. A ca. 1870 photo of English Camp, with the formal garden in lower right corner .........32

Figure 13. Map of previous archaeology projects conducted within, and on the margins

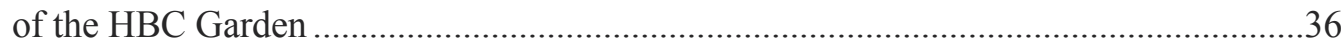

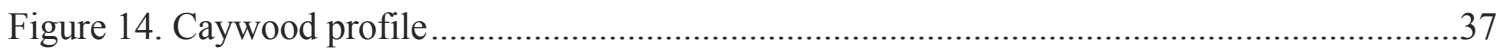

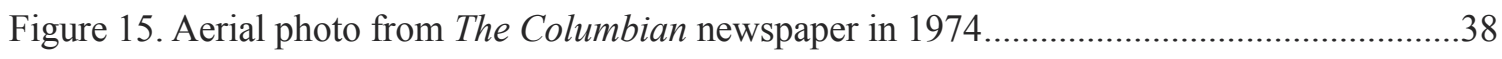

Figure 16. Cultural aspects of the modern landscape with 1991 Remote Sensing Results .............40

Figure 17. The relationship of anomalies found during remote sensing ........................................41

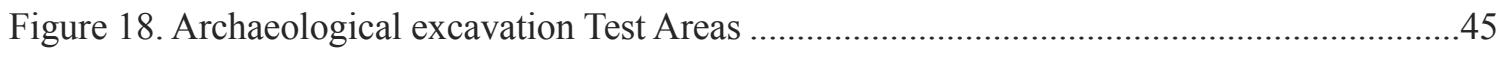

Figure 19. A typical profile of sediments at the HBC Garden site ...............................................54

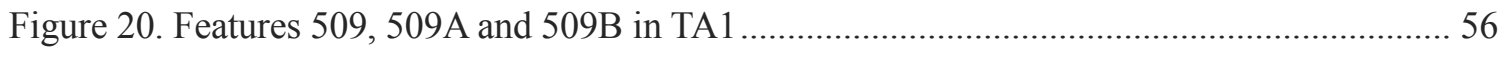


Figure 21. Profile of west wall of TA8, showing Feature 621 post on right (VII) .58

Figure 22. Spatial distribution of all artifacts 61

Figure 23. Locations of excavation units used for artifact quantity comparison . .62

Figure 24. Samples of beads from the HBC Garden excavations..................................................64

Figure 25. Brass button illustrating effect of dezincification process .............................................65

Figure 26. Emerald-colored glass trade ring inset....................................................................65

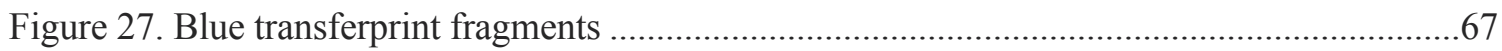

Figure 28. Chinese handpainted porcelain fragment, possibly the rim of a flower pot, Nanking pattern. .67

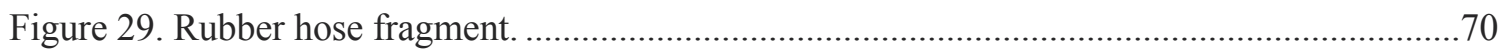

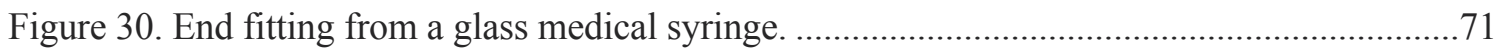

Figure 31. Spatial distribution of aster and marigold pollen found in HBC deposits ....................77

Figure 32. Spatial distribution of dahlia and zinnia pollen found in $\mathrm{HBC}$ deposits .......................78

Figure 33. Spatial distribution of Senecio and Solidago pollen found in HBC deposits .................79

Figure 34. Spatial distribution of tansy and Poaceae pollen found in $\mathrm{HBC}$ deposits .....................80

Figure 35. Early-20th century activities on the site of the HBC Garden....................................93

Figure 36. Mid-20th century activities on the site of the HBC Garden ........................................94

Figure 37. Combes' illustration of the linear trench dug during 1966 investigations to expose stockade wall post butts remaining in the ground ............................................98

Figure 38. Location of king bost butts indicated in Figure 44 ....................................................99 


\section{CHAPTER 1. Introduction and Background}

The products of the kitchen-garden form important articles of human food for all ranks of society; and furnish the chief luxuries of the tables of the rich, and a main support of the families of the poor. One of the first objects of a colonist on arriving at a new settlement is to plant a garden, as at once a proof of possession, and a pledge of immediate enjoyment; and indeed the history of the civilisation of mankind bears evidence, that there are few benefits which a cultivated people can bestow on savage tribes, greater than that of distributing among them the seeds of good fruits and oleraceous herbs, and teaching them their culture.

John Claudius Loudon, An Encyclopedia of Gardening, 1824

Resource exploitation and settlement by European peoples began in the late 18th century in the Pacific Northwest. The first non-indigenous group to make a significant and lasting impact on the natural and cultural resources of the region was the Hudson's Bay Company (HBC), a British fur-trade organization. In the 19th century, John McLoughlin, Chief Factor (1828-1845) of Fort Vancouver, in now-Washington state, and the surrounding Columbia District, was one of the most powerful colonial leaders on the west coast of North America. His power was sanctioned and capitalized by the HBC's fur-trading empire, which stretched across most of Canada and included the modern states of Washington, Oregon, Idaho, and portions of California and Montana (Taylor 1992:5). While functioning as chief administrator of the Columbia District, McLoughlin developed an extensive garden at Fort Vancouver. It is proposed that this Garden was a symbol of the power of the HBC, and had an important material influence on the economic and social development of the Pacific Northwest, before and during the time of American settlement. The presence of the garden also influenced the success of the HBC's enterprise in the region by providing food and treatments for disease and maladies, and influenced changes in the subsistence behavior of American Indians in the Pacific Northwest in the 19th century (Taylor 1992, Deur 2011). It is also possible that this space represented the changes occurring within the HBC and British class systems. 
While historical documentation on the activities and influences of the $\mathrm{HBC}$ in this region is available, it is incomplete, at times inaccurate and often biased. The archaeological investigations of the HBC Garden at Fort Vancouver increase our understanding of this highly dynamic period in the Pacific Northwest, also providing information for reconstruction, management and public interpretation of this designed landscape. This project was implemented by a joint Portland State University, Washington State University and National Park Service (NPS) team, and expanded previously employed landscape approaches from around the globe to archaeology in the Pacific Northwest.

Paleobotanical studies were employed, specifically plant pollen, phytolith and macrofloral analysis. These studies are vital aspects of landscape archaeology (including garden archaeology), as the land itself is the primary focus of the investigation. They can provide otherwise unobtainable information relating to environment, nutrition and diet. Several North American sites, including Williamsburg, Virginia (Samford 1986, 1999, Franklin 2004), and Jefferson's Poplar Forest (Heath et al. 2004), have successfully employed paleobotanical analysis to test the accuracy of historic documentation and obtain knowledge of the inhabitants that has been lost through written history. This landscape information can aid in reconstruction decisions and enhance the public's interpretive experience. These data are particularly pertinent at Fort Vancouver as the records common at other posts, which would normally provide information on which crops were planted and other garden specifics, are missing for Fort Vancouver (Hussey 1976:233).

To augment the extant cultural landscape study by Erigero and Taylor (1992), and to further the exploration of Fort Vancouver's landscape, samples of sediment from the HBC Garden contexts were collected during the investigation. The pollen, phytolith and macrofloral remains present in the samples were identified. These analyses provide physical evidence contributing to our understanding of the Garden's role in the subsistence and economic development of those involved in the European and American colonization of the Pacific 
Northwest, and of Fort Vancouver's contribution to regional history. For example, the HBC's practice of shipping fruit trees to other posts and settlers in the region provided the materials and expertise for what has become one of the region's leading economic sectors (Hussey [197?]).

The primary goals of this historical archaeology project were to enhance the information provided to visitors at Fort Vancouver National Historic Site, both through verbal interpretation and reconstruction of at least a portion of the Garden (Orser 2004:68), and to provide information to the National Park Service that would aid in said reconstruction. According to the National Park Service's Standards for Reconstruction as stated by Technical Preservation Services (NPS 2004), in order to move forward with a reconstruction, it "will be preceded by a thorough archeological investigation to identify and evaluate those features and artifacts which are essential to an accurate reconstruction." Also, historical documents can be incomplete, inaccurate, and biased, so archaeological investigation, which is based on things people left behind, rather than words, provides a more fully documented past, and is particularly valuable in understanding the story of common men and women (Orser 2002:50), who are generally missing from the written record.

This thesis presents the methods, including theoretical positions, that shaped the goals, content and scope of the project. These methods include: historical document research, a review of garden archaeology both in the Pacific Northwest and relevant projects around the world, previous archaeological project research at the site, and the 2005, 2006 and 2007 excavations in the HBC Garden. The results are discussed, and recommendations for further work are made. 


\section{THEORETICAL BACKGROUND}

The archaeological investigation of geographic landscapes, employed for many decades, is increasingly being understood as also descriptive of the passage of human lives, referred to as the cultural landscape. However, landscape archaeology is considered by many (but not all - see Schiffer 1988 for a discussion of method as theory) to be methodological in nature. This is precisely its potential for providing information to fill the gap between material remains and ideological concepts. Studies in this discipline (De Conzo et al. 1996; Erickson 1994; Kelso 1994; Leone 2005), have made attempts, of varying success, to connect archaeological data to these concepts, with the most successful projects using a deductive approach-asking questions related to ideology-before determining an archaeological sampling strategy. This thesis project, therefore, asks some questions on an ideational level, then researches and applies methodological strategies intended to provide information related to those questions.

At the inception of this project, the most puzzling aspect of the HBC Garden, as it was known from historical documents, was its large size - about 8 acres at its maximum in the mid-to-late 1840s (Erigero 1992, Peers 1844). Access to food has long been a manifestation of the power of certain segments of society over others, and knowing that even at its height of activity, those with "power" living at Fort Vancouver numbered only around 40, (allowing for Company officers from other posts, ship's officers, and other visitors [Roberts 1838; Jessett 1959]), an eight acre garden was significantly larger than that required to provide fresh produce for those relatively few powerful people (Loudon 1824). Based on HBC policy, only the Company officers were allowed to enjoy the Garden's food and aesthetic products (Hamilton 2000, Monks 1992). As the HBC was only a quasi-colonial entity which primarly focused on realizing profit, how was this over-sized space justified? These questions prompted a theoretical approach to this project that involved the possibility that the HBC Garden represented much more than just nutrition and health. 
Perhaps the Garden was a statement of power by the recently arrived Europeans to a region that was already well-populated by socially stratified indigenous people (Ames and Maschener 1999:254). Historical research conducted during this project led to the conclusion that certainly, as in most colonial occupations, mastery of the landscape was a representation of power of the colonist over the indigenous, or "other." It will also be shown, however, that the Garden at Fort Vancouver was unique in its also having an overarching practical purpose-a purpose that was perceived to ensure Company profits.

Mark Leone's (2005) work in William Paca's garden in Annapolis, Maryland (see Chapter 7 Discussion) provides a comparative analysis framework for colonial-period gardens, attempting to connect the methodological with the ideational. Leone theorizes that the intent of Paca's formal garden layout was to create optical illusions leading the observer to understand the garden as being much larger than it actually was, resulting in an increased perception of the level of power at Paca's command. Leone's hypotheses are intriguing when considering the seemingly oversized HBC Garden at Fort Vancouver.

On an additional level, research shows that very little landscape and garden archaeology has been conducted in the western United States. It is clear that this project is valuable as a testing ground for methods employed in other regions of the United States, and around the world. Such mid-range theoretical concepts were incorporated into the archaeological research design.

\section{HISTORICAL BACKGROUND}

The Hudson's Bay Company was a British commercial enterprise based in what is now eastern Canada. Their main business was the buying and selling of furs. First chartered in 1670 to have exclusive access to the Hudson's Bay drainage system, as time passed the Company expanded its activities across the North American continent and by 1825 began to set up operations in the Pacific Northwest, primarily focusing on beaver furs (Erigero 
1992:3, 11). The HBC as a company was highly stratified socially, employing several methods of maintaining the hierarchy, including differential access to food (Hamilton 2000; Monks 1992; Nelson 2007).

Dr. John McLoughlin arrived in the Pacific Northwest in 1825, tasked with the management of the vast region known as the Columbia Department, which encompassed lands from Russian Alaska to Mexican California, and from Hawaii to the Rocky Mountains. The administrative headquarters for this Department was established in 1829 at the current location of Fort Vancouver National Historic Site, in Vancouver, Washington (Erigero 1992:52).

The HBC Garden was apparently established very quickly. George Simpson, Governor of HBC operations in North America, noted in his 1829 report on crop production "extensive Gardens," although the location of the Garden at this time is not known (Erigero 1992:24). Company documents show shipments of seeds of a variety of fruits, vegetables, herbs and flowers dating to 1829 , the year of the Fort's establishment on Fort Plain, where the Garden was located on the north side of the Fort stockade (Taylor 1992). Besides these frequent seed orders, there are comments from several visitors indicating the types of plants that were grown, and other characteristics of the Garden. Many visitors referred to the Garden as belonging to Dr. McLoughlin, as exemplified by Henry Spalding, a missionary who arrived with the Whitmans in 1836:

We were soon conducted by the Doct. to his Garden, \& be assured we were not a little surprised to see west of the Rocky Mountains, where we did not expect to meet scarcely the first buddings of civilization, such perfection in gardening. About 5 acres laid out in good order, stored with almost every species of vegetables, fruit trees and flowers. A greater variety indeed than is often met with in the States...Everything produces well.

Curiously, based on research conducted to date, Dr. McLoughlin never spoke directly about the Garden in his correspondence with friends, family or the Company 
Committee in London. There are no planting plans, lists of plants, accounts for expenditures, or records of what happened to the produce. It is clear, however, from comments made by visitors, that Dr. McLoughlin was quite proud of his agricultural accomplishments at the post, ultimately providing food in the form of agricultural field crops and livestock products to the 24 outlying posts in the Department, increasing the Company's profits significantly for its operations in the Pacific Northwest (Erigero 1992). However, there is no evidence that the produce of the Garden was distributed to other forts. Dr. McLoughlin did provide seeds and plant starts to incoming American pioneers (Erigero 1992:140), and to the local American Indian people (Hussey [197?]). This represents the roots of a long-standing agricultural focus in the region (Hussey [197?]).

In 1846, after the United States boundary, (the current Canadian border), was established, the HBC began to move its operations to the north, and the Garden was reduced in size and care (Erigero 1992). Three-fourths of the garden was leased to the U.S. Army, which had established a post in 1852 on the terrace to the north of the Fort stockade (Erigero 1992:246). Late in the 19th century the Garden was converted to pasture (Map of Fort Vancouver, 1870). In WWI a spruce mill was built on Fort Plain (Figure 1), with the Garden site providing temporary housing for some of the thousands of soldiers working at the mill, and having several railroad spurs crossing it (U.S. Army Signal Corps 1918).

The Civilian Conservation Corps (CCC) set up regional headquarters on the site of the HBC Village in the 1930s, placing several buildings on the Garden site, along with a complex of buildings for the Bureau of Public Roads and an Army Polo Clubhouse (Erigero 1992:326). These buildings were largely removed in the 1940s, and the site was used for various U.S. Army training exercises during WWII, then as a runway for Pearson Air Field (Erigero 1992:327). In 1948 the Garden site was included as part of Fort Vancouver National Monument, and in 1960-61 the National Park Service planted the majority of the site (the northwest corner was still owned by the U.S. Army) with standard-size fruit trees, some of 


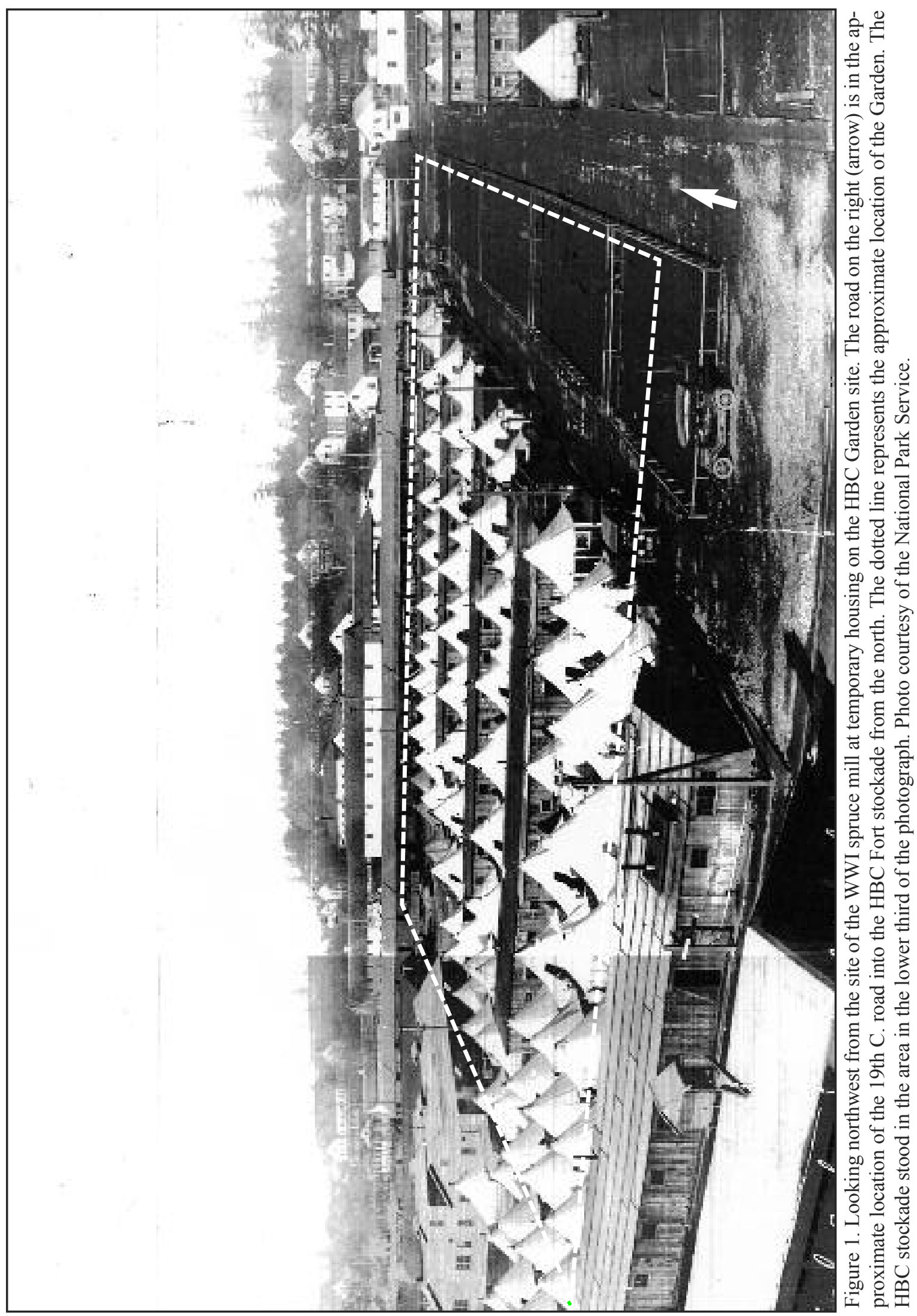


which are still growing today (Erigero 1992:346).

In the late 1970 s volunteers spearheaded a program of living history that, initially, demonstrated the agricultural aspects of the HBC occupation on Fort Plain. By the 1980s this program also included growing garden plants that were accurate, based on historical documents, to the original HBC Garden (The Sunday Oregonian, 1974:36; The Columbian, 1990:Section C). This interpretive garden is located just east of the HBC Garden site, and has grown considerably in size and scope since its inception. It continues to be managed by a large group of dedicated volunteers.

This historical background section indicates that the Hudson's Bay Company, a British fur-trade enterprise, built Fort Vancouver in the early 1800s as an administrative base for its activities in the region. The HBC created a large garden at this post to provide fresh produce for company elites and their families. The site became U.S. territory in 1846 and the HBC left in 1849. The Garden site had various uses during the U.S. Army occupation, including pasture, garden, temporary housing for soldiers working at a Spruce Cut-Up Plant during WWI, and various military training exercises. After WWII a portion of the Garden site, along with other lands on the Army post, was transferred to the National Park Service for preservation. Activities on the Garden site since that time include an orchard being planted and partially removed, and volunteer groups conducting living history events to inform the public on agricultural activities, including gardening, at Fort Vancouver. 


\section{CHAPTER 2. Methods and Results of Archival Research}

Archival research involved compiling information from both primary and secondary sources to determine such things as the physical characteristics of the HBC Garden and how the space changed over time; the aesthetic style; horticultural practice; gender, ethnicity, age and number of laborers; impressions of visitors; and the role of the Garden as related by employees of the Company.

The Diverse Role of Dr. McLoughlin's Garden

While the HBC Garden was briefly described by several of its visitors, there is very little information generated from $\mathrm{HBC}$ records. Logically, all of the posts throughout North America would have had a kitchen garden. Self-sufficiency was a primary goal for the HBC enterprise, as noted by Simpson (Merk 1968:50), which was driven by profit margin (as is every commercial operation). The information that we do have about this particular garden, though, indicates that it was more sizable and elaborate than a kitchen garden. Erigero (1992) provides a thorough review of primary source documents which contain descriptions

of the various flowers seen, of the unusual fruits and vegetables grown, indications of state-of-the-art approaches to horticultural practice, and a use of space that represented HBC status and power.

Physical Characteristics

The HBC Garden was located on the north side of the palisade, running from the palisade itself to Upper Mill Road (East 5th Street), in a north/south direction, with its eastern boundary at the western edge of the back gate road to the post-1836 (extended) stockade (Erigero 1992). The western boundary appears to have been fluid, anywhere from the west edge of the bastion to quite some distance further west (Erigero 1992). Figure 2 is 


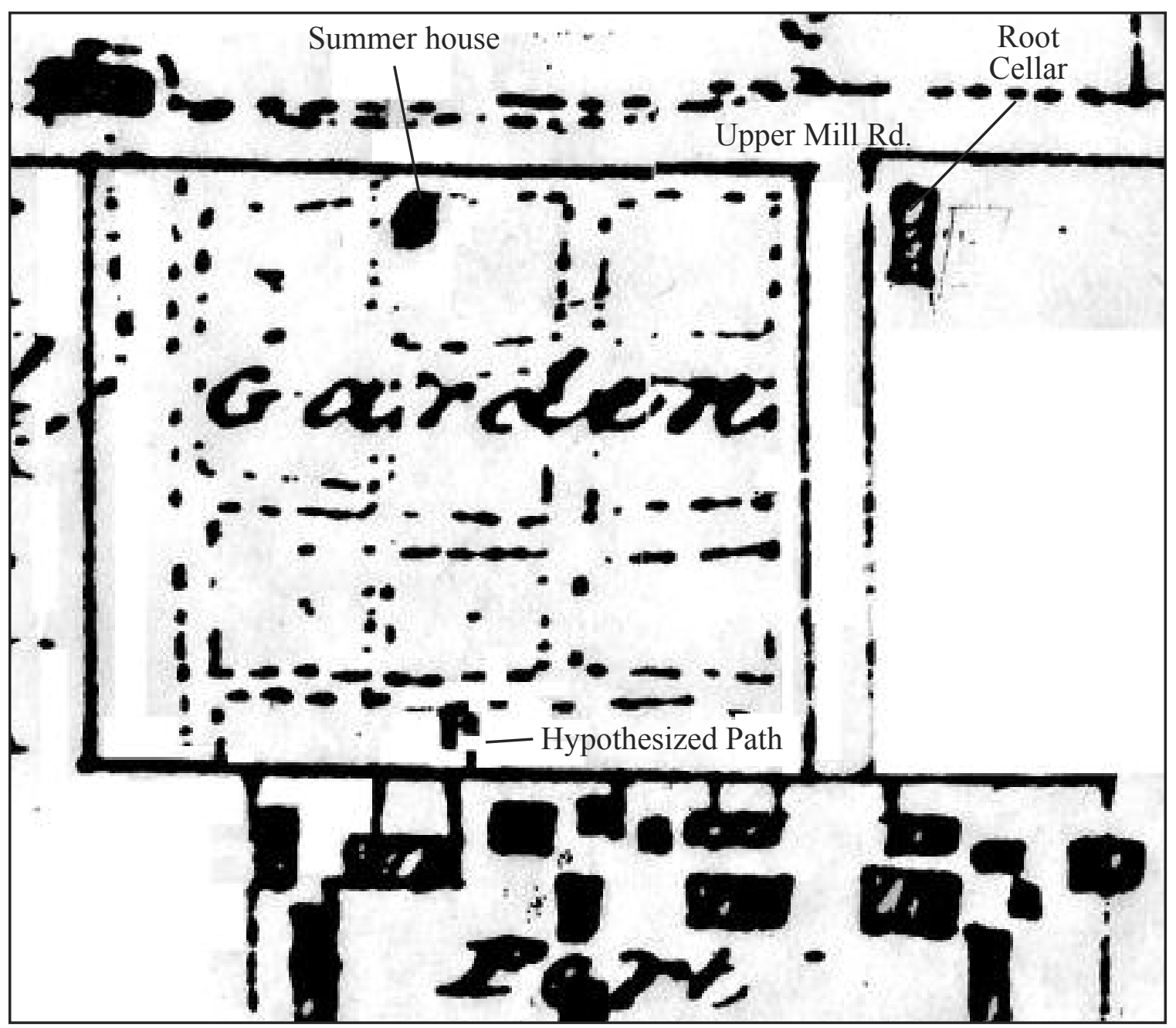

Figure 2. Detail of 1844 Line of Fire map with author's annotations.

a detail of the 1844 Line of Fire map, drawn by Henry Peers, a clerk with the HBC. It is the only know representation of the layout of the Garden. There are a few other maps showing the Garden during the 1840s and 50s (Erigero 1992):

- Sketch of Fort Vancouver and Adjacent Plains by Mervyn Vavasour, 1845

- Sketch of Environs of Fort Vancouver by Henry Peers, 1844

- Plan of Fort Vancouver by Richard Covington, 1846

- Map of the Government Reserve at Fort Vancouver, W.T. by Brvt. Captain J. R. McConnell, based on a survey to Lt. Col. B. L. E. Bonneville and referred to as the "Bonneville Map," 1854 
- Fort Vancouver and U.S. Military Post and Town Environs by Richard Covington, 1859

The 1840s maps are consistent in delineating an approximately square area on the north side of the fort stockade, extending from Upper Mill Rd. on the north to the stockade wall on the south, east to the western edge of the north road into the fort and variable placements of the western garden boundary, as described above. The Vavasour and Peers maps do not label this area, and the Covington map labels it as "Orchard." The 1854 Bonneville Map shows the Fort stockade completely surrounded by agricultural fields, other than the Garden site, which has geometrically space dots, most likely representing trees. The 1859 map, again drawn by Covington, is fairly detailed in showing agricultural fields, but the Garden is neither identified or delineated, nor is the space identified as an agricultural field.

Figures 3 through 6 are illustrations which provide the most context for the site at from the mid 1840s to mid 1850s. Previous to these illustrations, there are only written comments, providing cursory information. Fort Vancouver's Cultural Landscape Report, Vol. II, by Patricia Erigero (1992), does a thorough job of compiling this information. The maps and illustrations, while having some consistencies from one to another, also leave much to speculation. The Orchard was generally located to the west of the Garden proper, however, the presence of fruit trees in the Garden has provided confusion when interpreting contemporary writings and maps as to what was Garden and what was Orchard (Erigero 1992).

The "Line of Fire" map (Figure 2) is the only known map that shows a layout of paths and beds within the garden. If the proportions are essentially correct, and it has been stated that this map is quite accurate in other respects (Erigero 1992:127), the paths would be approximately 30 feet wide. The map is inaccurate in that Upper Mill Road and the fort stockade were not parallel. So in actuality, the western Garden boundary was longer than the eastern. The map seems to account for that within the Garden, showing that the east-west running paths in the western portion of the Garden did not align. 


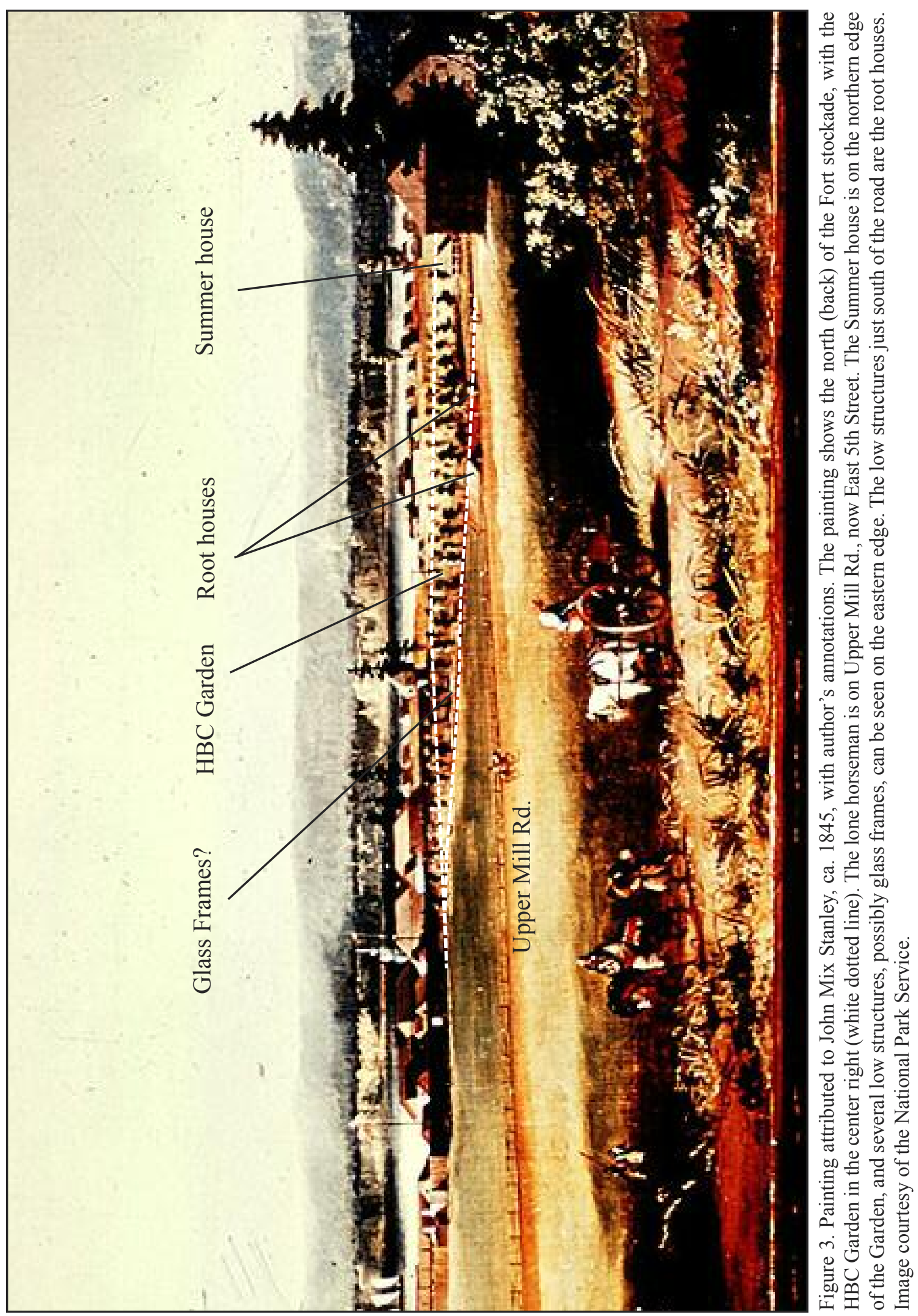




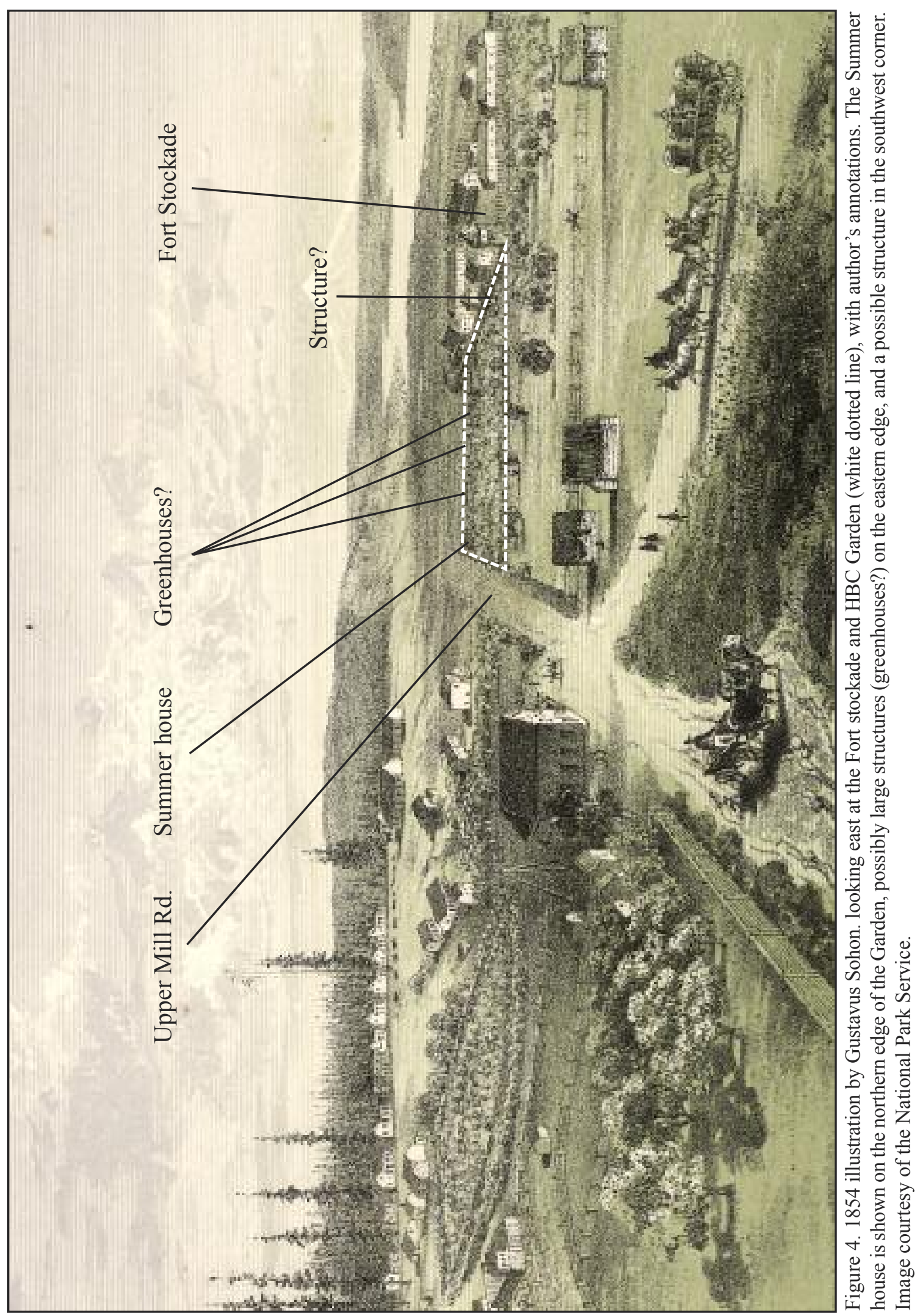




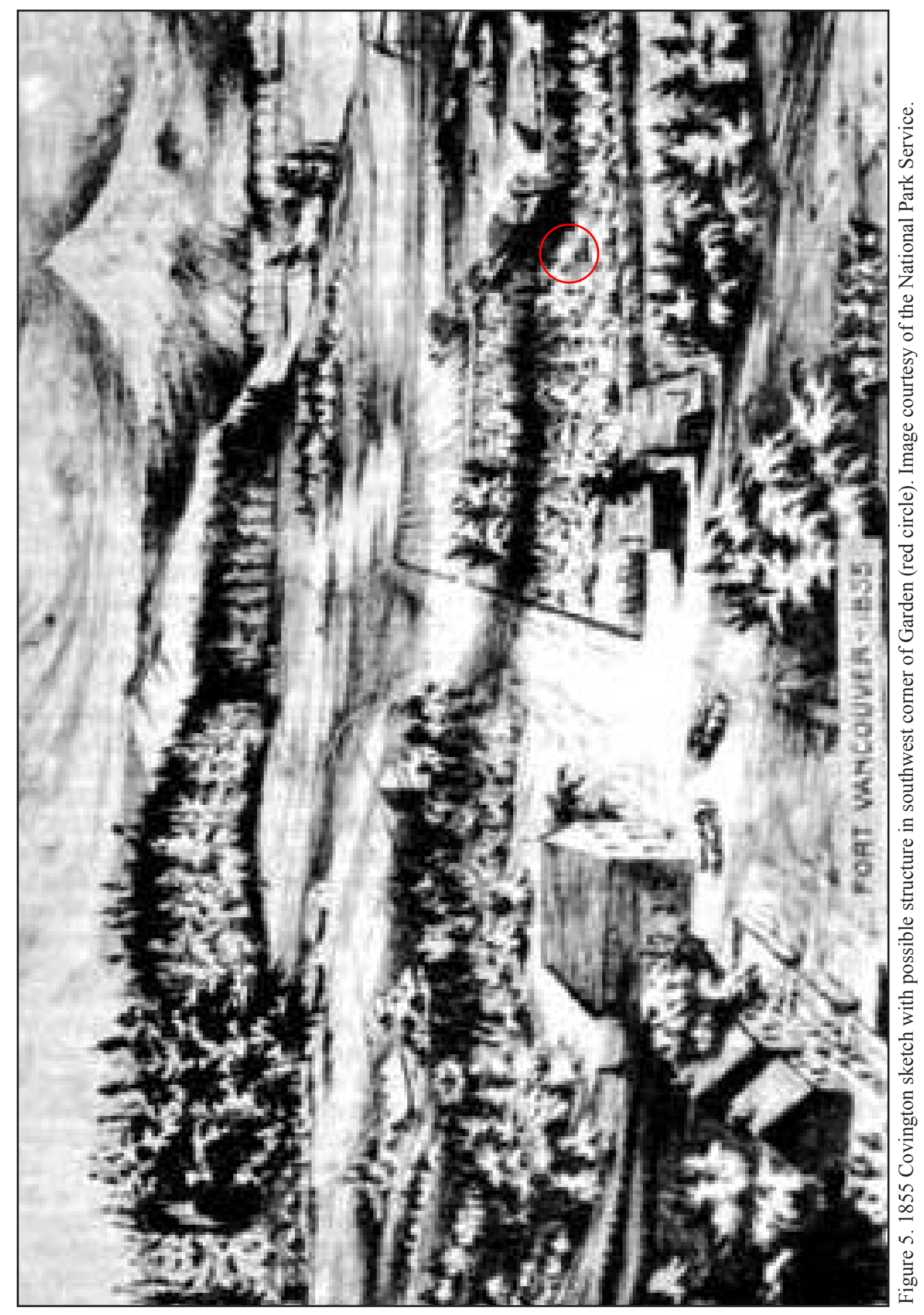




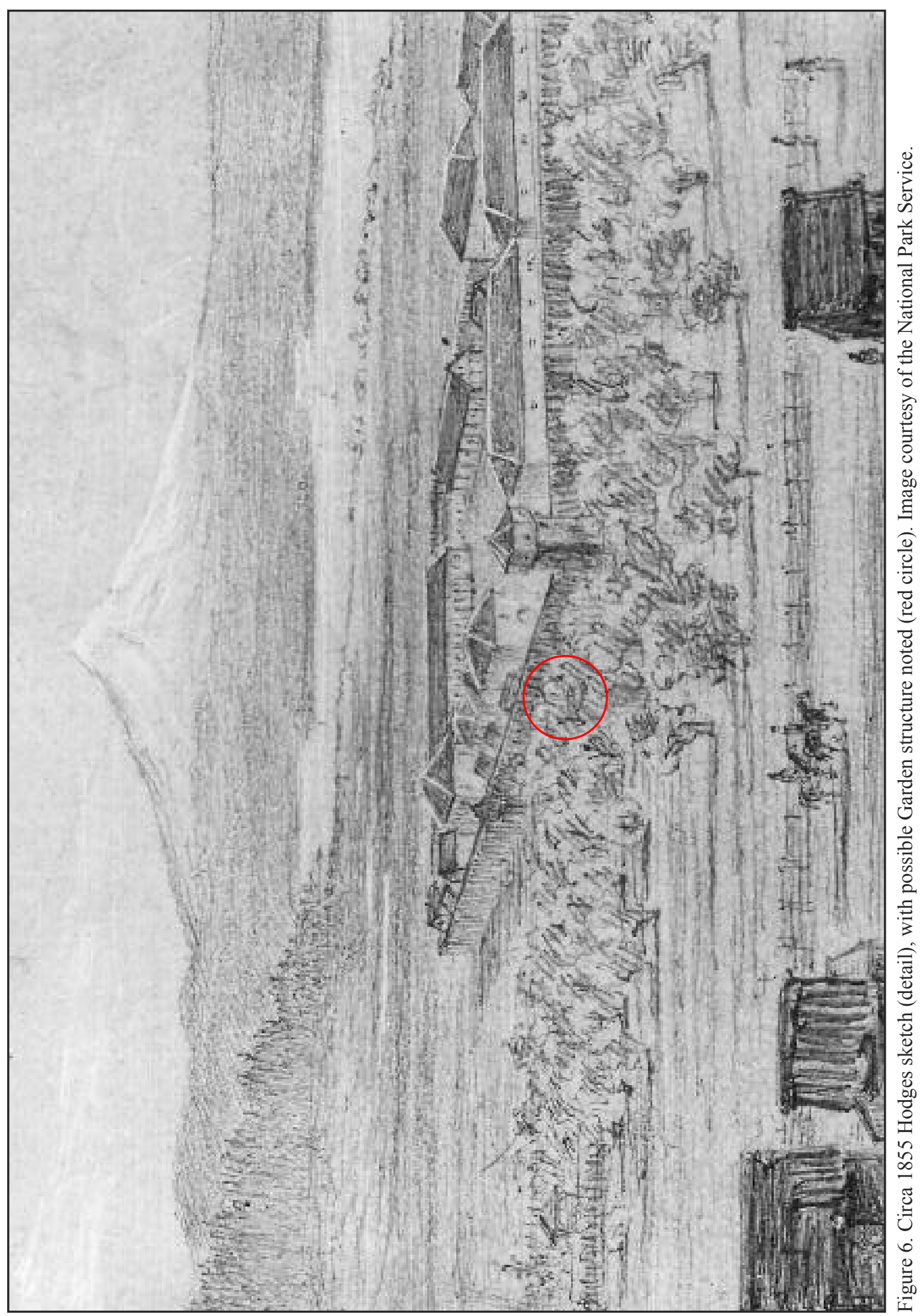




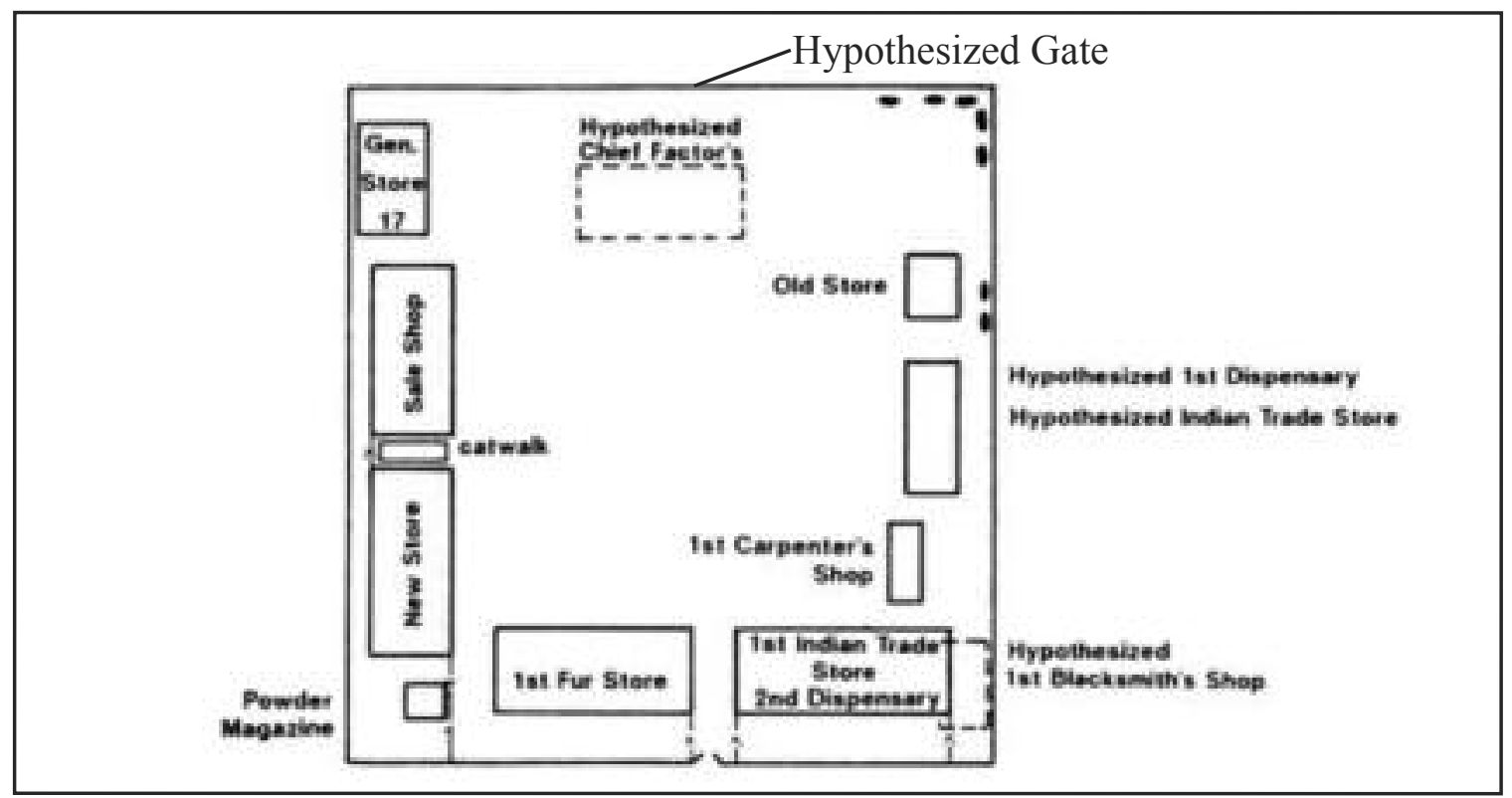

Figure 7. Stockade from 1829 to1834-36 (Erigero 1992:189).

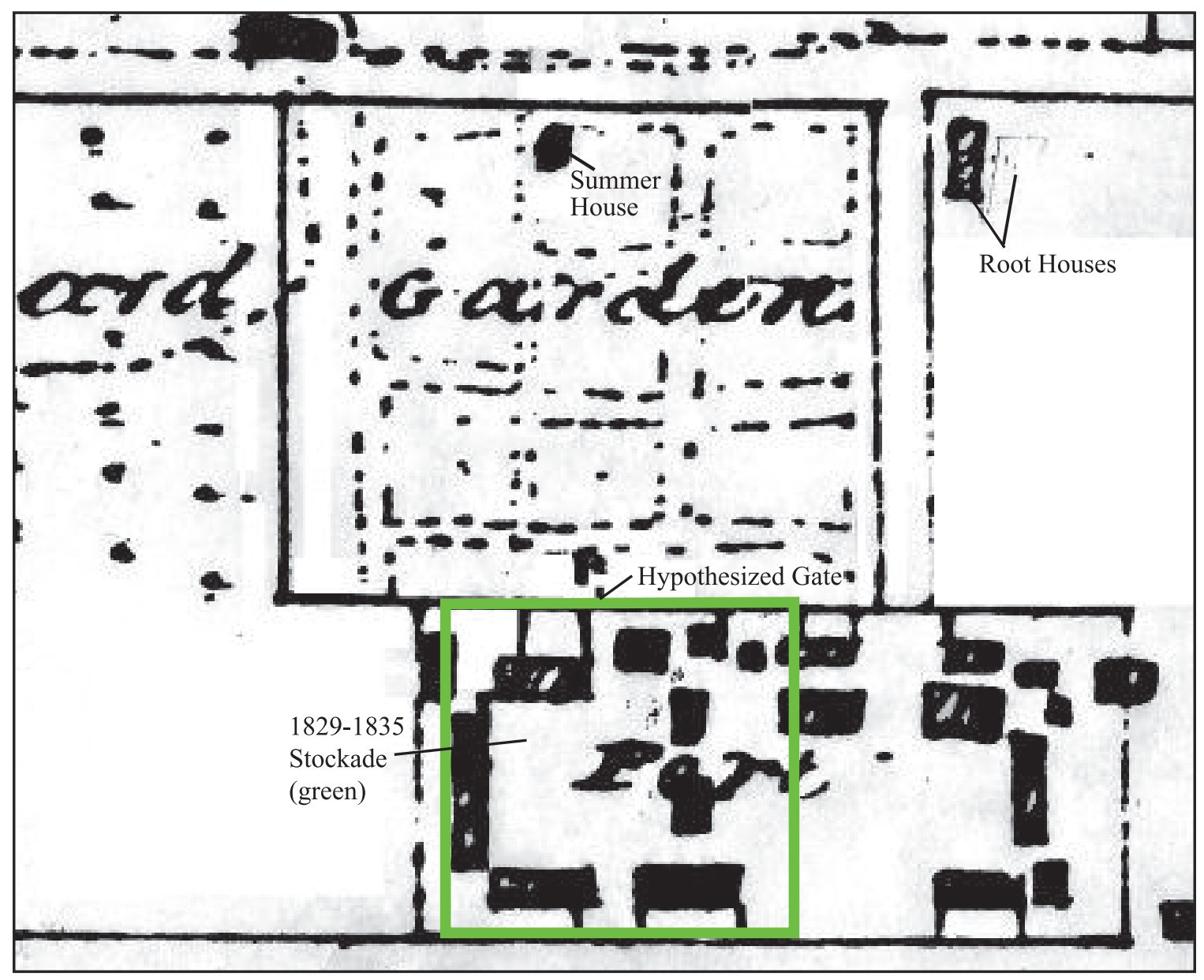

Figure 8. Original stockade from 1829 to 1834-36 (green line) imposed over 1844 Line of Fire map, showing symmetrical relationship to Garden layout. 
The 1844 map also shows what has been interpreted as the "Summer house" on the northern edge (Erigero 1992:130), some other enigmatic symbol on the southern edge, near the palisade, and possibly a path leading to a gate in the palisade (Figure 2). Oral history indicates that there was a well in the Garden and it is possible that the symbol seen near the palisade is related. The Covington sketch (Figure 5), shows a possible structure in this location (red circle) as interpreted by Erigero (1992:128). The circa 1855 Hodges sketch (Figure 6) also may show a structure in this location. A modern map (Figure 7) indicates a hypothetical location for the Chief Factor's House in the early stockade, opposite this portion of the Garden (Erigero:1992:189). If there was a garden gate in the stockade it would have been to the right (or perhaps just behind) this building. As the Garden was an "invitation only" area (Erigero 1992), this would seem a logical place for the gate (behind the original location of the Chief Factor's House). Figure 8 shows the original stockade (1829 to 1834-36) imposed over the 1844 Garden. The hypothesized gate appears to be centered on the northern east-west stockade wall, and the 1844 Garden is relatively symmetrical to this earlier stockade. Erigero (1992:127) speculates that the placement of the north gate and road related to the later, extended stockade was determined by the extant eastern edge of the Garden. The 1844 map (Figure 2) also shows a structure (possibly two) to the east of the Garden, near Upper Mill Road. Contemporary accounts indicate that these were probably root houses, (Erigero 1992:115), which are also seen in the Stanley painting (Figure 3).

The site of Fort Vancouver became U.S. territory in 1846, with U.S. Army personnel establishing a military post in 1849. Records are sketchy on the fate of the Garden during this early U.S. Army period. Due to the California gold rush, it was impossible to hire enough employees to cover all of the commercial activities of the Fort. The total number of "servants" (employees) was reduced by "over two-thirds" from 1846 to 1849 (Erigero 1992:204). It is likely that the maintenance of an extensive Garden became a low priority. Archibald McKinley commented that by $1849-50$, "the orchards and two or three hundred 
acres of enclosed land, was in the occupation of settlers and the military" (Erigero 1992:221). Apparently portions of the Garden were leased to the Army for most of this decade (Erigero 1992; Taylor 1992). The Mansfield map, prepared in 1854, labels the area of the HBC Garden as "soldiers garden" (Erigero 1992:246). The area was also used as pasture by 1869 (Erigero 1992:300). Map evidence currently available does not show that any structures were built on the Garden site until the WWI Spruce Mill construction (Covington 1859; Lydecker 1889; McConnell 1854; McCrea 1892; Quartermaster Map 1879).

\section{Garden Style}

The Line of Fire map (Peers 1844) indicates an orderly garden layout, with relatively evenly sized and spaced beds and wide paths. This provides a starting point for discussion of garden design, and what ideas and events directly influenced the style of the HBC Garden at the height of its significance.

Garden design in the early 19th century was undergoing a fashion change. The pastoral landscape which had been de rigeur for a large part of the 18th century was being revised to provide for more "gardenly" spaces. This new style, termed the Transition, or Landscape style, had three elements. According to Price, Knight and Repton (three renowned English garden designers), "The foreground should be Beautiful and well kept like a Garden scene..., [t]he middleground should be a Picturesque parkland scene... farm animals will make it more picturesque... [t]he background should be a Sublime scene." The term "sublime" alludes to wild and untamed (Turner 1986:119). While it is doubtful that Dr. McLoughlin utilized this plan when he determined land use at Fort Vancouver, the resulting view to the north from the stockade, across the Garden, fulfilled the three components of the Transitional style. The background was certainly wild with its hills covered with dense forest, the middleground was filled with cultivated fields and farm animals, and the HBC Garden, up close to the palisade, provided the foreground "Garden scene." While the background and middleground uses are 
also typical of the Pastoral landscape, the HBC Garden is most definitely representative of the Transitional style with its "gardenly" space in the foreground.

Formal gardens require someone knowledgeable, trained, and experienced in not only garden design, but also horticulture. At Fort. Vancouver, from the late 1820s (or early 1830s) to 1849 , the principal gardener was William Bruce, a Scotsman. He was first employed by the HBC as a laborer in 1825 and arrived at Fort Vancouver in 1826. By 1833 he was "regularly listed as gardener" (Hussey, [197?]:36). In 1838, Bruce either "retired" (Hussey [197?]:36) or returned to England with Dr. McLoughlin as his servant (Erigero 1992:133). Apparently, after arriving in England, Bruce had a change of heart, and begged Dr. McLoughlin to have his job back. Before returning to Fort Vancouver however, the Hudson's Bay Company Directors requested that Bruce be allowed to visit Chiswick (the Duke of Devonshire's estate outside of London) in order to learn to properly care for plants that Joseph Paxton, (principal gardener at Chatsworth, also an estate of the Duke of Devonshire), had given to the HBC for Fort Vancouver (HBCA 1838:A5/12 fo. 212).

Bruce's initial employment status as an HBC laborer, the lowest position on the HBC hierarchical scale, (usually due to a lack of education) (Erigero 1992), and the fact that there were two gardens known as Chiswick, requires some discussion of which garden Bruce actually visited. Status was extremely important, even in the garden setting. Bruce's personal status should have prohibited a visit to the Duke's private estate (Loudon 1824). It was highly unusual for someone of Bruce's social status to be the head gardener for such a prestigious establishment as Fort Vancouver. It is possible that Bruce visited The Horticultural Society of London's experimental and educational garden, leased from the Duke of Devonshire, also located at Chiswick and referred to as "Chiswick." Joseph Paxton had been trained at this other "Chiswick." However, the letter asking permission for the garden visit is specifically addressed to the Duke of Devonshire. It is important to further research the details of this event, as Bruce commented that he compared his work at Fort 
Vancouver to Chiswick, intending to mirror its style (Erigero 1992:139).

There are illustrations available of both of the above-mentioned Chiswick gardens. Figures 9 and 10 represent the Duke of Devonshire's gardens in 1753 and 1994 (Harris 1994). The western portion of the garden (Figures 9 and 10, within the blue line) has not changed significantly in that time (Figure 9 illustration is truncated on the east). The Italian Garden (Fig. 10, green line) was added in 1812 (Bluffton n.d.A). As the Italian Garden still existed in 1994, Bruce must have seen it on his visit. This garden has essentially rectangular beds with straight paths in between, similar to the Line of Fire map (Peers 1844) of Fort Vancouver. Significantly, the reconstructed garden at the Duke's Chiswick garden incorporates dwarf trees within garden beds as has been represented in the Covington sketch (Figure 5). Erigero (1992:133) notes that a number of visitors to Fort Vancouver commented on the "fruit trees in the Garden." In 1841, Eugene Duflot de Mofras states that, "A large vegetable garden filled with fruit trees adjoins the fort" (Erigero 1992:133).

The other "Chiswick" garden, the Horticultural Society of London's garden, (Figure 11) was created in 1821 from lands leased from the Duke of Devonshire (Colquhoun 2003:14), and retained the same design for many years. The main focus of this garden was science, (particularly fruit culture), not display, and as such garden design was not addressed for many years, other than criticism by John C. Loudon, who was attempting to bring a more orderly look to garden design at the time (Elliot 2004). Plants were grouped by botanical nomenclature, not to be pleasing to the eye (Elliot 2004:62). Figure 11 shows the informal style of the arboretum in 1826. While this is only part of the total garden, it does indicate less emphasis on the aesthetic. This design remained in place until the $1840 \mathrm{~s}$, after Bruce would have visited (Elliot 2004).

In comparing these two Chiswick gardens, it appears that Bruce intended to emulate the Italianate Garden at Chiswick, the Duke of Devonshire's private estate, rather than the Horticultural Society's experimental garden at Chiswick, however more appropriate (both 

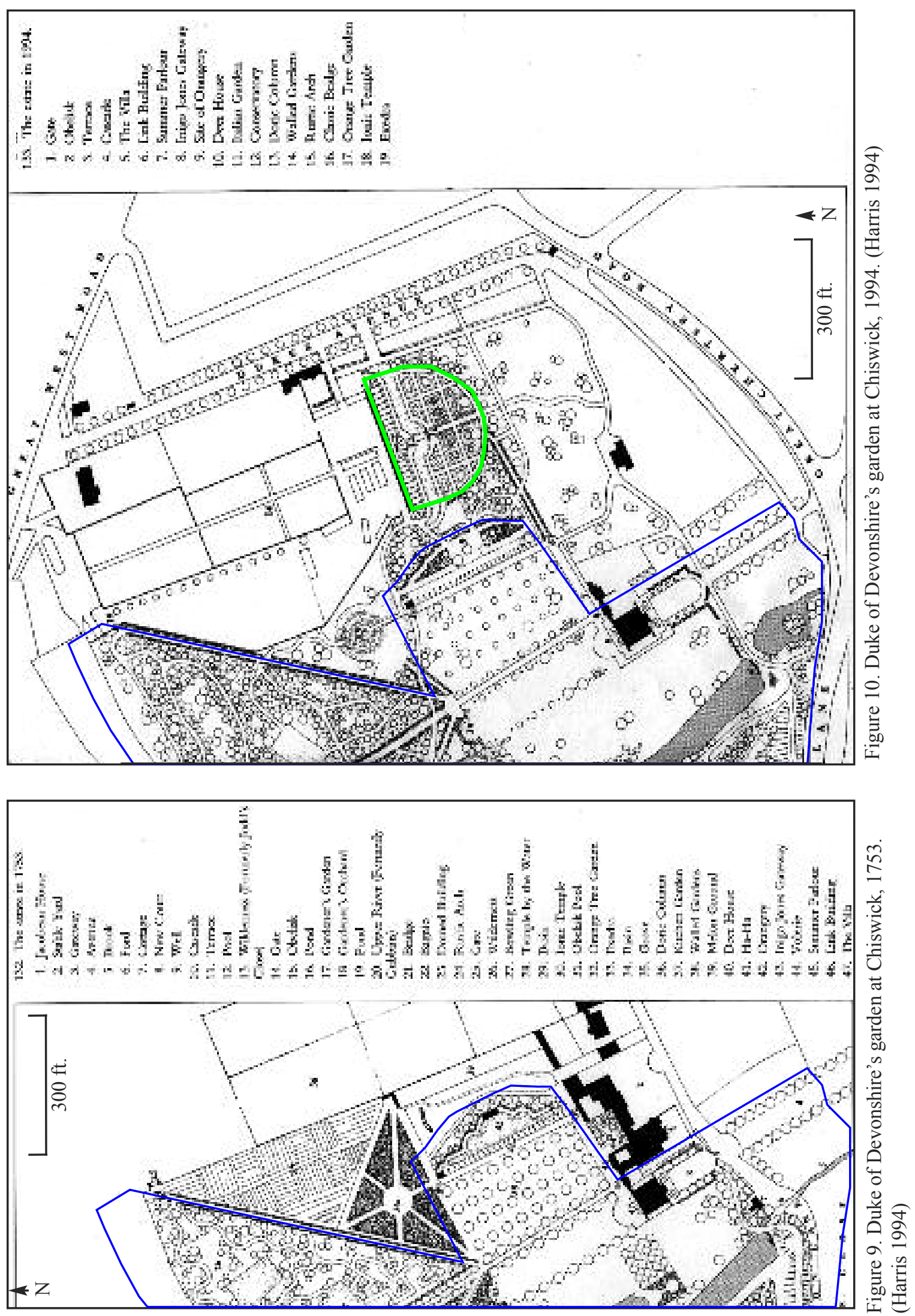


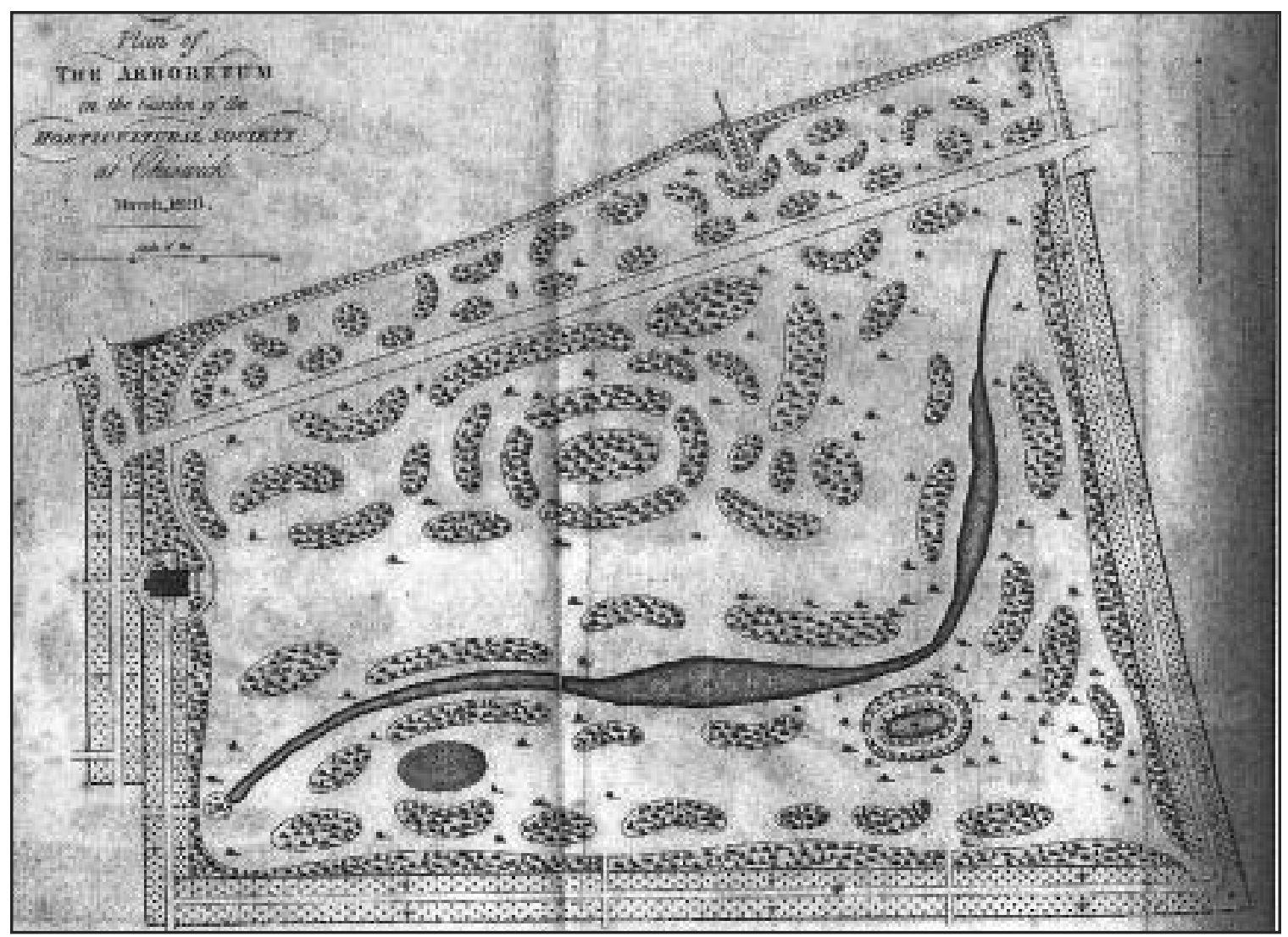

Figure 11. Horticultural Society of London arboretum at Chiswick (Elliot 2004:62).

in terms of educational focus and social position) it would have been for Bruce to visit the latter. The Fort Vancouver Line of Fire map (Peers 1844) indicates a geometric layout, as in the Duke of Devonshire's Italianate Garden, rather than the more natural-appearing landscape of the Horticultural Society's garden. With this in mind, project research focused on information pertaining to the style of the Duke of Devonshire's estate garden at Chiswick.

\section{Horticulture}

It appears that in the early years at Fort Vancouver, Dr. McLoughlin was involved with the Garden on a day-to-day basis. Eloisa McLoughlin, his daughter, commented in an oral interview that at some point (she is not specific about the date), "They got a good gardener and we did not need an Indian after that" (Harvey 1878). Although recent scholarship has shown that the American Indians in the Pacific Northwest practiced a certain 
amount of horticulture (Deur and Turner 2005), the creation and maintenance of a formal, European-style garden was not an easily translatable skill. As such, Dr. McLoughlin would have had to provide a considerable amount of supervision. The Dr. had shown himself to be interested in horticulture early in his career, often bringing samples of produce he had grown at his posts to regularly-held meetings of the North West Company (Morrison 1999). He also received an award from the Horticultural Society of London for "assisting in the promotion of botany" (Erigero 1992:26). This award most likely arrived with a packet of seeds, requested by botanist David Douglas, who had been using Fort Vancouver as a base for botanical research in the 1820s (Erigero 1992).

Erigero (1992) cites sources that indicate that seeds were provided to Fort Vancouver by the HBC, both overland from York Factory and by ship directly from England. As mentioned above, the Horticultural Society of London sent seeds, and individuals also brought them to the site, notably Captain Simpson who probably brought the first apple seeds in the late 1820s (Erigero 1992:25). William Tolmie brought dahlia and acacia seeds from Hawaii (Erigero 1992:132), and researched the possibility of shipping grafts of "Peach, Apricot, Plum and Cherry trees," although it is not known whether this occurred (Erigero 1992:133). George Roberts, in his 1838 Thermometrical Register, commented that gooseberry had been brought from England two years before (Erigero 1992:133).

The plants that Billy Bruce brought with him from Chiswick arrived "under glass" (Erigero 1992:133). This comment probably refers to Wardian cases, developed in England specifically for transporting live plants on board ships (Hershey 1996). The use of these glass boxes allowed for $90 \%$ survival of plants, rather than the $90 \%$ loss that had been experienced on board ship without them. Wardian cases were instrumental in the development of horticultural science during the colonial period, and it is possible that other plants were shipped to Fort Vancouver in this manner.

Many sources name the different fruits, vegetables, herbs and flowers growing in 
the Garden, some of them requiring a controlled environment: cold frames for dahlias, melons and cucumbers; greenhouses for citrons, lemons, oranges and pomegranates (although there is no direct evidence for greenhouses at Fort Vancouver), and root houses for storing turnips, potatoes and parsnips. Erigero (1992) provides a good overview of these sources. Fort Vancouver was particularly noted for its apples, with observers likening them to ropes of onions bunched for sale, and indicating that branches had to be propped up to keep them from breaking (Erigero 1992:134). This abundance and variety of fresh fruits and vegetables would have contributed greatly to the health of those employees attempting to subsist on Company rations.

Numerous plants that are now considered just "flowers" were grown in the past for medicinal uses. It is possible that nearly all of the flowers in the HBC Garden had practical uses. If that is the case, an emphasis on aesthetic and status as represented by the presence of certain plants, due to the labor and material resources required for their care, may be incorrect. The simple presence of these plants is not enough. Research needs to be conducted to determine the probability that these ornamental plants were being processed for medicinal use. Documentary sources are very sketchy on the subject of flowers. The only specific species mentioned are roses and dahlias). There are, however, comments indicating that there were "ornamental plants and flowers" and "many other pretty flowers" (Taylor 1992:Appendix D).

Many of the plants that documents indicate were growing in the HBC Garden would have benefitted from soil enhancement practices. Research on these practices, and other technologies that may have been used, would provide direction for reconstruction and maintenance of the HBC Garden. Loudon's An Encyclopedia of Agriculture: Comprising the Theory and Practice of the Valuation, Transfer, Laying Out, Improvement, and Management of Landed Property; and the Cultivation and Economy of the Animal and Vegetable Productions of Agriculture is known to have been in the Dr. McLoughlin's library 
(Hussey [197?]:156), and should be reviewed for pertinent information. A few statements were made in documents about soil enhancement relative to the cultivated fields at Fort Vancouver. It is logical to assume that these methods, as appropriate, would have been employed in the Garden. James Douglas, as an example, commented on the importance of "keeping the soil in good heart, by fallowing and manures" (Erigero 1992:68), so it is highly likely that manure was used in the Garden.

In reference to technology, there is an $1844 \mathrm{HBC}$ inventory of Farm Utensils being used at Fort Vancouver noting some specific garden tools: 25 Garden Hoes, and 1 English Seed Drill (Hussey ([197?]:180). The inventory from 1848 has a specific category for “Gardners [sic] Tools," which includes an axe, 2 dung forks, 3 garden hoes, 2 rakes, 2 tenon saws, a shovel and 5 spades ([197?]:180). McKie (1981:70), notes that Fort Langley manufactured and shipped 4 garden hoses (presumably rubber as such hoses were being manufactured elsewhere at the time) to New Caledonia, and 30 garden hoses to Fort Colville. It seems unlikely that these facilities would have had garden hoses, and Fort Vancouver would not. Perhaps the 1844 reference to 25 Garden Hoes should read 25 Garden Hose, considering the phonetical spelling prevalent at the time. It seems illogical to have 25 garden hoes and only 1 or 2 of other tools, while 25 garden hoses may have been needed to transport water in such a large space.

Historical documents, however, do not indicate how the paths in the Garden were surfaced, or with what material. For many centuries in the western world gravel walkways have been preferred, but nut shells, seashells, marl, crushed brick, and general debris (e.g. tobacco pipe fragments, glass, lead shot and pottery sherds), pressed into the natural sediments were also used (Hume 1974:22-23). According to Loudon (1824), garden paths in general were kept level and pressed by the use of a heavy roller. It was undoubtedly prohibitive, due to the weight, to have rollers shipped to Fort Vancouver, but the blacksmith shop possibly could have produced them. There is no known record at this time of rollers 
being used in the Garden at Fort Vancouver. On September 28, 1844, during the forest fire, Thomas Lowe, HBC clerk at the Fort, noted in his diary, "Most of the men engaged in cutting the grass in the garden, and watching the fires" (Erigero 1992:137). It is possible that the Garden paths were planted with grass, however, Loudon considers grass paths an inferior method, allowing one's feet to get damp (Elliott, 2004:62). It should be noted that the Historical Society of London's Chiswick garden had grass paths, at least within the arboretum (Elliott, 2004:62).

Labor

Determining who provided labor in the Garden, such as men cutting grass, is another research goal for this project. There are a few contemporary comments in reference to workers in the Garden. Hussey ([197?]:38) states that, "general laborers and Indian employees undoubtedly were assigned to the garden as other duties permitted." He also states that the school boys, sons of HBC employees and orphans, were employed as Garden labor, “earning their keep" according to Dr. McLoughlin (Hussey [197?]:38). A letter written to Governor Simpson in 1833 indicated that there was only one man in the Garden (Hussey [197?]:156). This probably means one man assigned full time (most likely Bruce). Loudon (1824:722) indicates that, as a general rule, one full-time man per acre is required to properly maintain a garden space. The HBC Garden, which was approximately eight acres at its maximum, then, would have required eight full-time workers. However, the Daily Journal of Occurrences from Fort Nisqually, a HBC fort near what is now Tacoma, Washington, indicates that agricultural labor fluctuated greatly in its application, with resources being utilized as demand required (Dickey 1989). This was most likely the practice at Fort Vancouver also. In that event, there would have been periods when considerably more than eight workers would have been required in the Garden, such as at harvest time, and times when less than eight workers would have been in the garden as agricultural priorities shifted. 
Of course, there were other sources of labor. The articles of agreement for British men during the 1830 s indicated that wives and children, "being found in provisions by the said Company, if required to do so... render their services at hay-making, sheep-sheering, weeding, and such other light work as they may be equal to." (Hussey, c.1977:60). It is most likely that all families of Company employees, not just those of British employees, were required to "render services." All the wives of the HBC employees were either full, or some portion American Indian from the local area, with traditional resources to provide for their families. Changes had to occur to cause these women to choose to work in the Company Garden.

European contact did not initially change indigenous economic systems that were already in place. Aspects that did change at the outset included an intensification of quantity and diversification of products traded due to the introduction of pack animals. It was now cost-effective to send higher quantities and heavy and bulky items longer distances (Teit 1928:121). Also, the demands of new trading partners (Europeans and Americans) for subsistence items required a change in work organization and valuation. The collective activities of the house group decreased while personal wealth (and therefore status) increased (Oberg 1973:60). The demand for subsistence items specifically produced a shift in the status of women. Wright (1981) and Peterson del Mar (1995) discuss the possibility that native women's status increased during the contact period due to the demand for their subsistence goods. Later, as traders developed their own methods of subsistence (the HBC became extensively involved in agriculture and salmon processing at Fort Vancouver and other posts), the demand for these women's products lessened even as their dependence on imported trade goods grew. As a result, women turned to working for wages to obtain these goods (Wright 1981:533) and the previous subsistence system became secondary. Foraging in the immediate area of the Fort would have become difficult due to cultivated fields, pastures and logging operations. Certainly disease also played a role in this 
subsistence change. Some of the earliest explorers, arriving in the late 1700s, noted evidence of smallpox having already arrived in the area (Boyd 1999:17). An intermittent fever (assumed to be either malaria or influenza) in the 1830s dealt a final blow to much of the native population, with conservative estimates of an $80 \%$ decrease from pre-contact population numbers (Boyd 1999:3; Taylor and Hoaglin 1962:169). These two factors, European contact and disease, seriously disrupted trade networks and foraging activities.

With indigenous trade networks collapsed and foraging activities difficult, the native wives and mixed ethnicity children of the $\mathrm{HBC}$ employees were dependent on the company for provisions, and may have had no choice but to work for what they received. However, Dr. Tolmie, an officer of the HBC stationed at Fort Vancouver, and at times in charge of agricultural activities, notes his efforts in teaching the local natives to cultivate potatoes (Erigero 1992). Also, research has shown that indigenous and mixed ethnicity people from Fort Vancouver had worked as farmers, and were not familiar with traditional foodways when they arrived at the White Salmon reservation in 1857 (Deur 2011:168).

According to Hussey ([197?]:57), the majority of what are now considered domestic activities (cooking, serving, baking, etc.), were considered "honourable" occupations and therefore held by men in the early-to-mid 19th century. It is likely that the women were limited to those jobs specifically stated in the articles of agreement "hay-making, sheep-sheering [sic], weeding, and such other light work as they may be equal to" (Hussey c. 1977:60).

The archival research shows that the HBC Garden is consistently referred to as being on the north side of the Fort stockade, and sometimes referred to as "Orchard," probably due to the presence of fruit trees in this space as well as in an orchard to the west. The placement and dimensions of the Garden are symmetric to the early, square stockade except for the western boundary which has different locations on the various maps. There was one definite structure in the Garden, the Summer house, and possibly another in the 
southwest corner near the stockade. Seeds for many imported plants were purchased by the HBC and sent from London to Fort Vancouver, and visitors commented on additional plants seen in the Garden, not included in the seed lists. These plants consisted of primarily vegetables with many fruits and some herbs and flowers. The lists of specific vegetables and fruits are extensive, while only a few herbs and even fewer flowers are noted, giving a sense of what items were important to visitors, and possibly the Dr. who would have been walking the Garden paths with his guests.

The Line of Fire map is the only document showing a layout of these paths, which, according to the map, were quite wide and may have been surfaced with grass. The map also shows a path running from the stockade to the north, in a location that would have required a previously unknown gate in the stockade, The layout represented on the Line of Fire map is similar to that of the Italianate Garden at the Duke of Devonshire's estate at Chiswick. The principal gardener, Billy Bruce, is known to have visited this garden and to have stated his desire to emulate it. Bruce started as a laborer with the $\mathrm{HBC}$, and is consistently listed as the principal gardener approximately eight years after arriving at Fort Vancouver. His initial job as laborer indicates a low level of education, which may have effected certain characteristics of the Garden. The individuals that provided labor in the Garden may have also effected some of its characteristics, as documents indicate they were likely local American Indian wives and widows of Company employees and their children.

Even so, it is clear from the types of plants being grown that the Garden, along with providing nutrition for the elites of the Company, was a scientific laboratory, with plants being grown in cold frames, and probably greenhouses. It is also clear from documents that it is a limited access, invitation only space, with Dr. McLoughlin being the master. 


\section{CHAPTER 3. Summary of Research, Article and Publication Review Relating to Garden Archaeology Projects and Methods}

Research was conducted to determine the existence of garden archaeology projects in the Pacific Northwest and worldwide. While there is room for further research, it appears that very little garden archaeology has been conducted in the Pacific Northwest, and possibly Western North America. Therefore, to be as informed as possible, background information on garden archaeology outside of the Pacific Northwest was also surveyed. The review of these projects provides insight into methods that worked in given situations, and methods that were unsuccessful. For this project, this helped in determining methods to expend resources on, and methods to be employed comparatively, to determine the efficiency of one to another. For future projects, it is hoped that this research will provide a framework to aid in the development of research designs. A summary of the results of this research follows. More extensive discussion of each article and publication reviewed can be found in Appendix A.

Garden Archaeology in the Pacific Northwest

The first step was researching for projects in the Pacific Northwest. This was, initially, conducted at the Oregon and Washington State Historic Preservation Offices (SHPO), including speaking with several employees who indicated they had no memory of archaeological projects focusing on gardens. Computer searches also produced no projects of these types. Further research could be conducted at the Oregon SHPO, as their records of Cultural Resource Surveys are not completely digitized.

Publications and articles were then focused on, including library catalogs, journal databases and academic search engines. This research turned up a report by Roderick Sprague (1983), discussing a project at English Camp on San Juan Island. Attempts were made to find evidence of the "Royal" garden at the site (Figure 12). Remote sensing was 


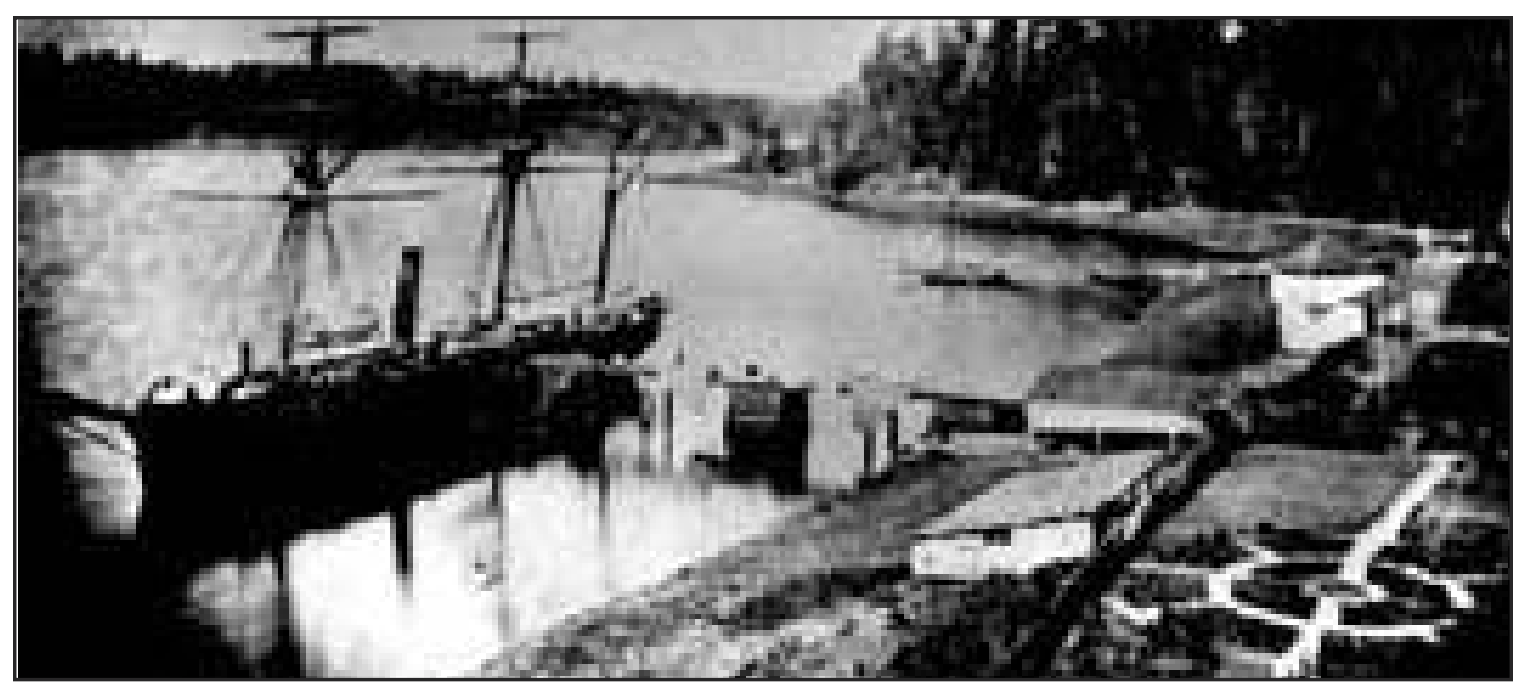

Figure 12. A ca. 1870 image of English Camp, with the formal garden in lower right corner. Photo courtesy of National Park Service.

employed followed by surface stripping, with negative results. It was speculated that the garden sediments had been removed during later activities.

Another aspect of the regional research included contacting several archaeologists, both professional and academic, in both the U.S. and Canada, and also requesting information through the HistArch website. The archaeologists did not know of any such projects, and no response was received from the website inquiry.

Based on the above research, there has been only one archaeological project focusing on a garden in the Pacific Northwest, that at English Camp, where the garden sediments appeared to have been removed. The efficacy of the methods employed in this case cannot be determined.

\section{Garden Archaeology Worldwide}

This research was conducted through library and journal database searches and academic search engines, and limited to reports written in English. Nine articles are reviewed in this thesis (Appendix A), discussing sites in Asia, Africa, the Middle East, Continental Europe and Britain. Time periods discussed range from $100 \mathrm{BC}$ to $1900 \mathrm{AD}$. 
A few of the projects reviewed were experimental in terms of employing various methods on one project to determine their effectiveness in this type of investigation.

The results of the article review suggest that, in terms of plant remains, it is possible, even in sediments known to have characteristics that would be detrimental to pollen preservation, for pollen to be well preserved and that analysis of these microartifacts can be very informative (Hume 1974; Jashemski 1979; Currie and Locock 1991; Moynihan 2000). The locations of insect-pollinated plants, which generally drop their relatively heavy pollen in the location that the plant is growing, can also be determined, through the identification of pollen in sediments (Moynihan 2000). It is also possible to identify, by noting differences in soil characteristics caused by the decay of roots, the locations of trees, and, given certain circumstances, tree taxon from evidence of the configuration of roots in the sediment (Jashemski 1995).

These sediments can also be dated by several methods, including the presence of artifacts, as refuse was often used to loosen the soil, and analyzed for the presence of additives used to enhance fertility (Hume 1974; Jashemski 1979, 1995; Currie and Locock 1991). The types of additives can also help to determine what was being planted.

Remote sensing (including aerial photography) can detect subtle differences between such things as paths and beds, intricate bedding patterns, and hard landscaping (Aston 1974; Jashemski 1979; Currie and Locock 1991; Aspinall 1997; Miller and Gleason 1999; Bedal 2001), although Currie and Locock noted that small garden beds could be entirely missed with one meter transects. The ideal situation for this type of testing is sediments that have not experienced alteration over time, as overlying features make it difficult to discern the less-defined characteristics generally found in a garden (Currie and Locock 1991; Miller and Gleason 1999).

Finally, it is indicated that less disturbing methods of sub-surface testing be initially utilized due to the size of garden spaces, followed by mechanical scraping of later deposits 
not related to the garden, then trenching, with close vertical controls (Miller and Gleason 1994; Jashemski 1995). Two types of excavation trench methods were reviewed; small trenches, attempting to conserve as much of the site as possible (Currie and Locock 1991); and large trenches, which increase the potential for understanding the geometric characteristics of what were, relatively speaking, spaces of expansive use and concept (Miller and Gleason 1994). Familiarity with proportions utilized in garden style layouts for various time periods can help to determine areas of a possible garden site to focus on for testing (Miller and Gleason 1994).

Several key points from this review can be employed in developing a research design for, and implementing a garden archaeology project:

- Analysis of microbotanical artifacts within garden sediments can not only provide identification of plants to (generally) genus, but also indicate where plants were being grown;

- Slight differences in sediments, such as those found in a garden and related to paths, irrigation, and even ornately patterned planting beds, can be seen with remote sensing equipment, provided a garden site is relatively undisturbed;

- Root casts, changes in sediment reflecting the location of a tree, are discernible during excavation and can provide information related to taxon;

- There are two approaches to excavation trench size advocated: small trenches in order to preserve the archaeological record (although small is not defined); and large trenches, as a response to the size of identifiable aspects of a garden, and in order to understand vertical variation within a garden

Several of these key points were used to develop the research design for this project (Chapter 5). However, familiarity with stratigraphic sequences at the site based on previous archaeology made the employment of some of these techniques redundant. And, it was necessary to fit the project to the goals of the field school research design. 


\section{CHAPTER 4. Previous Archaeology at the Site of the Hudson's Bay Company Garden at Fort Vancouver}

Several archaeological testing projects have been conducted within, or on the margins of, the early- to mid-19th century HBC Garden as represented on Peers' 1844 Line of Fire map (Figure 2). A review of these projects follows. Figure 13 maps all of the projects discussed below.

Louis Caywood (1955) conducted the first archaeological investigations at the site of the HBC Fort Vancouver (Figure 13). These investigations began in 1947 and were completed in 1952. Although no testing was done in the Garden proper, Caywood did test along the north stockade wall and in the area of the bastion (Figure 14). These elements of the stockade formed the southern boundary of the Garden. Caywood's reports are very sketchy, not unexpected for investigations conducted during this phase in the development of historical archaeological research. Caywood $(1955: 38,39,51)$ indicates that a few of the artifacts found could be related to gardening activities including metal fragments of two hoes, two mattocks, a brass spigot and three brass spigot handles. There is little information in the report indicating where these tool fragments were found, although the artifact database at Fort Vancouver indicates that one of the garden hoe blades was found in the area of the Harness Shop (just east of the Chief Factor's House in the northeastern corner of the stockade) and the other was found during Fur Store excavations (along the south central portion of the stockade). Neither location is very near the Garden. Caywood (1955) does note, however, that the spigots and spigot handles (which he attributes to water and liquor casks) were found in the area of the bastion. As the bastion is on the southern margin of the Garden it is possible that they were used on barrels employed to transport water to the Garden. It is also possible that barrels with unknown contents were stored in the lower level of the bastion. 


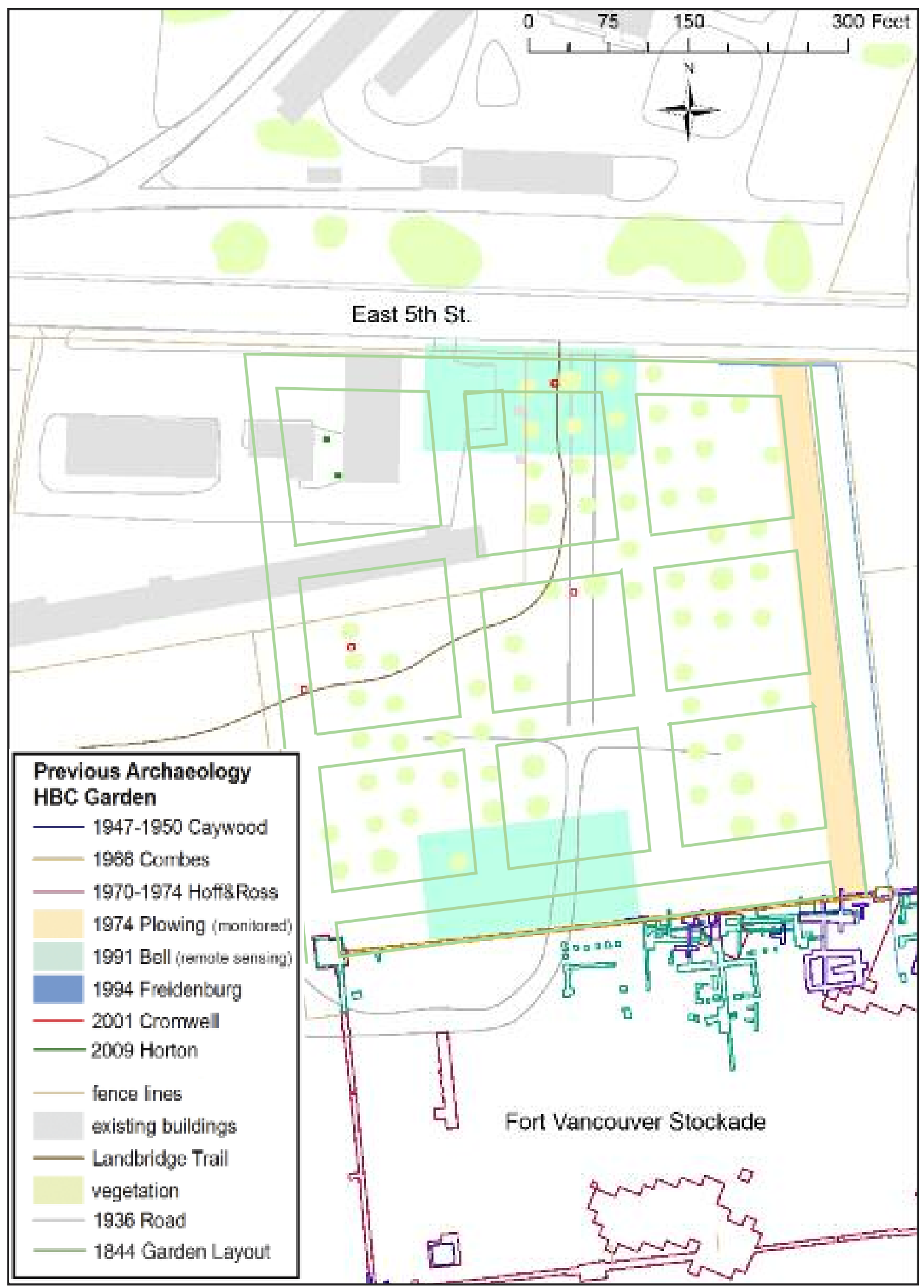

Figure 13. Map of previous archaeology projects conducted within, and on the margins of, the HBC Garden. The 1844 Garden Layout layer is based on HBC clerk Henry Peers' Line of Fire map (Figure 8). 


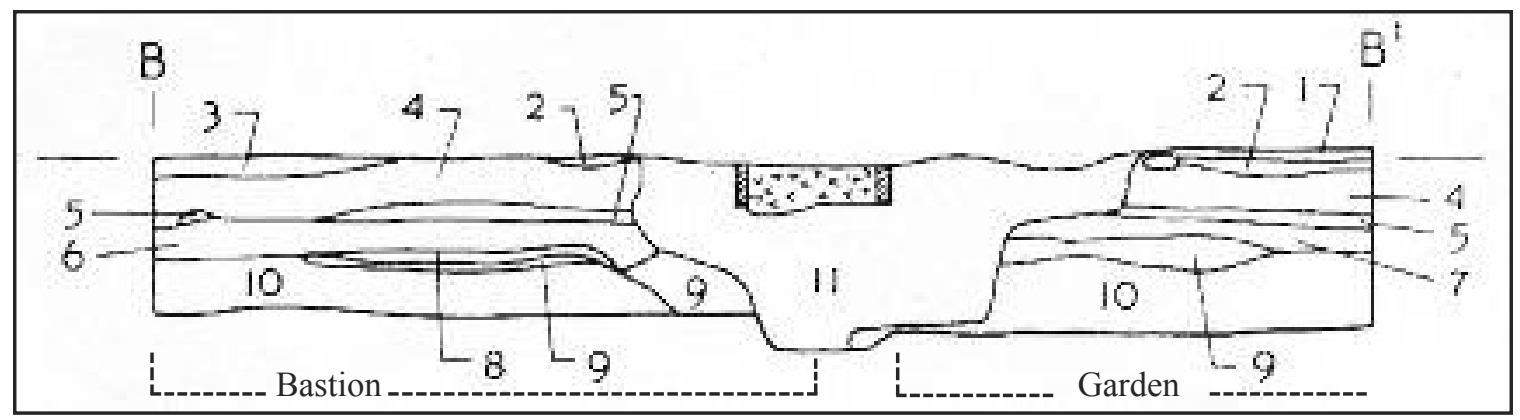

Figure 14. This Caywood (1955:6, 9) profile (illustration faces north) shows the interior of the HBC bastion on the left (west), a modern concrete sill marking the location of the original bastion wall (11), and the HBC Garden on the right (east). Strata 3 and 4 represent WWI deposits, Stratum 5 is the 1894 flood silt, Stratum 6 (inside the bastion) is debris from the bastion burning, Stratum 7 (outside the bastion) is mixed clay and ash, also from the bastion burning. Strata 8 and 9 consist of backfill from the construction of the bastion. Stratum 10 is moist, loose silty clay with occasional bits of wood, charcoal and HBC artifacts in the upper portions. This stratum (10) was not identified as either "disturbed" or "intact" in the report. Stratum 11 is fill from 1947 excavations.

In 1966, John Combes conducted investigations on the entire north stockade wall, also the southern boundary of the HBC Garden (Figure 13). These investigations were conducted in preparation for the creation of concrete footings for the reconstructed stockade wall. A $3 \mathrm{ft}$. $(0.91 \mathrm{~m})$ wide by $4 \mathrm{ft} .(1.22 \mathrm{~m})$ deep trench was excavated with shovels. No screening of sediments for artifacts was performed. The excavation trench was divided into 10, 1 ft. (0.30 m) long “units," but no vertical control was employed. A total of 2,083 artifacts was cataloged, $51 \%$ of them were some form of ceramic fragment (Combes 1966:6). Artifact concentrations in the trench corresponded with "trash pits" (actually privy pits) excavated by Caywood. Combes' report is singularly valuable in that it provides a highly-detailed map of each stockade post butt that was encountered. The implications of this map for the current excavations of the HBC Garden are reviewed below, in the Discussion, Chapter 8.

Hoffman and Ross (1974a) also report on further excavations of the bastion, at the northwest corner of the stockade, along the southern boundary of the Garden (Figure 13). Areas excavated that were within the Garden produced no features or artifacts definitively identified as being representative of garden activities.

In 1987, 51 machine-dug auger holes, $1 \mathrm{ft} .(30 \mathrm{~cm})$ in diameter, were dug at 
approximate $50 \mathrm{ft}$. $(15.24 \mathrm{~m})$ intervals between the "existing rows of orchard trees" in the HBC Garden in preparation for the installation of an irrigation system (Thomas 1987). Unfortunately, no map of the project is available. The report summary indicated that no significant cultural deposits would be effected by the irrigation project. This report is interesting in that it notes a previous archaeological project on the site of the HBC Garden for which there does not appear to be any documentation: "monitoring and artifact recovery during NPS plowing of the historical scene interpretive garden" (Thomas 1987:1). Photographs indicate that the "interpretive garden," and also plowed areas for the planting of cereal crops, were originally located on both the east and west sides of the path into the north gate of the reconstructed stockade (Figure 15). So the above-mentioned monitoring (and historical scene plowing and gardening activities) would have partially taken place on the site of the HBC Garden, disturbing the intact deposits on the eastern boundary.

Another project, focusing on remote sensing, specifically soil electrical conductivity metering and ground penetrating radar (GPR), was used to test the Summer house location

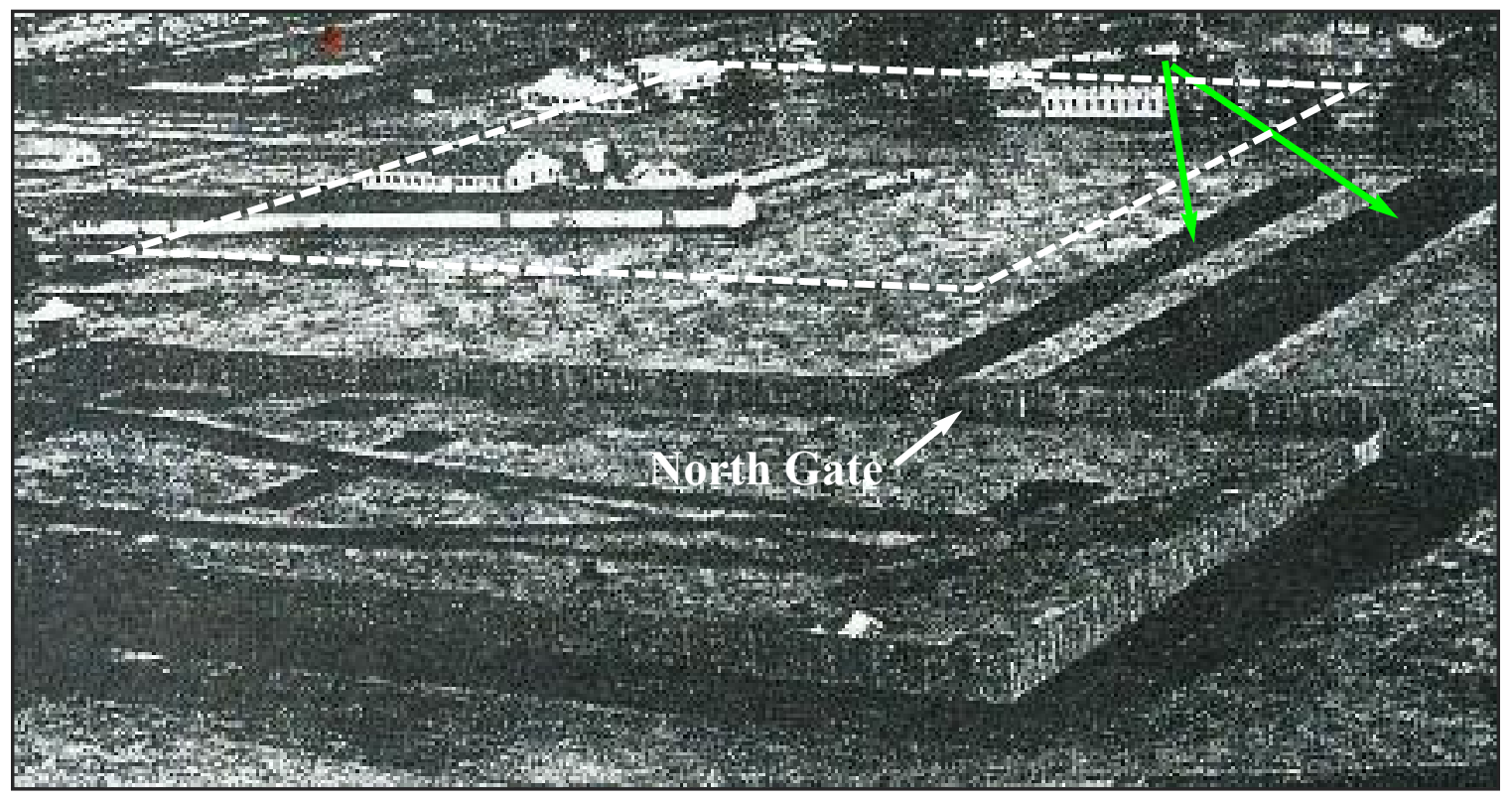

Figure 15. Aerial photo (facing northwest) from The Columbian newspaper in 1974 showing the reconstructed HBC stockade and the two dark plowed strips (green arrows) on either side of the north gate. The plowed strip on the west (left) side is in the HBC Garden site. The dotted line represents the boundaries of the Garden as shown on the Line of Fire map (Peers 1844). 
and a possible well location in the Garden (Bell 1991). The location of the Northern test area (Figure 13), the probable location of the Summer house, was determined through analysis of the Line of Fire map (Peers 1844) and contemporary illustrations (Figures 3, 4, 5 and 6). More than 10 transects, each about $100 \mathrm{ft}$. $(30.48 \mathrm{~m})$ in length, were run utilizing each remote sensing method. Transects were generally $25 \mathrm{ft} .(7.62 \mathrm{~m})$ apart, however, trees, fences and structures were avoided. The conductivity testing was performed on park property only, as the U.S. Army portion of the site is covered in asphalt. Three subsurface anomalies were found on park property, all of which were attributed to 20th century ground-disturbing activities. The GPR testing, however, was extended to U.S. Army property. Two of the anomalies located, SSA-6 and SSA-7, were interpreted to be possible foundation remains (Figure 16). Applying a schematic of the Garden layout, based on the 1844 Line of Fire map, to these remote sensing maps places the east wall of the Summer house approximately in the location of anomalies SSA-6 and SSA-7 (Figure 17).

The Southern test area, (Figure 13) the possible location of an HBC-period well, was also tested with both sensors. A survey area $100 \mathrm{ft}$. $(30.48 \mathrm{~m})$ north-south and $220 \mathrm{ft}$. $(67.06 \mathrm{~m})$ east-west was laid out with the southwest corner, $1 \mathrm{ft} .(0.30 \mathrm{~m})$ north of the north stockade wall and $300 \mathrm{ft} .(91.44 \mathrm{~m})$ east of the stockade/bastion intersection. Five transects, $25 \mathrm{ft} .(7.62 \mathrm{~m})$ apart and $200 \mathrm{ft} .(60.96 \mathrm{~m})$ in length were completed. What was interpreted to be a well, between 5 and $9 \mathrm{ft}$. (1.52 $\mathrm{m}$ and $2.74 \mathrm{~m})$ in diameter, was located in a surface depression by both sensors. In this area the distance between transects was decreased to $3 \mathrm{ft}$. $(0.91 \mathrm{~m})$. The anomaly was interpreted to be a back-filled, masonry-lined shaft feature, consistent with an HBC well.

Monitoring was conducted in 1994 during the digging of a trench along the south side of East 5th Street (Figure 13) for a telephone upgrade (Freidenberg and Thomas 1994). A maximum $1.5 \mathrm{ft}$. $(0.46 \mathrm{~m})$ wide by $3.5 \mathrm{ft}$. $(1.07 \mathrm{~m})$ deep trench was machine-excavated. The northern edge of this trench was $3 \mathrm{ft}$. $(0.91 \mathrm{~m})$ south of the NPS rail fence, within the HBC Garden site, extending "eastward from the telephone pole for approximately $110 \mathrm{ft}$. 


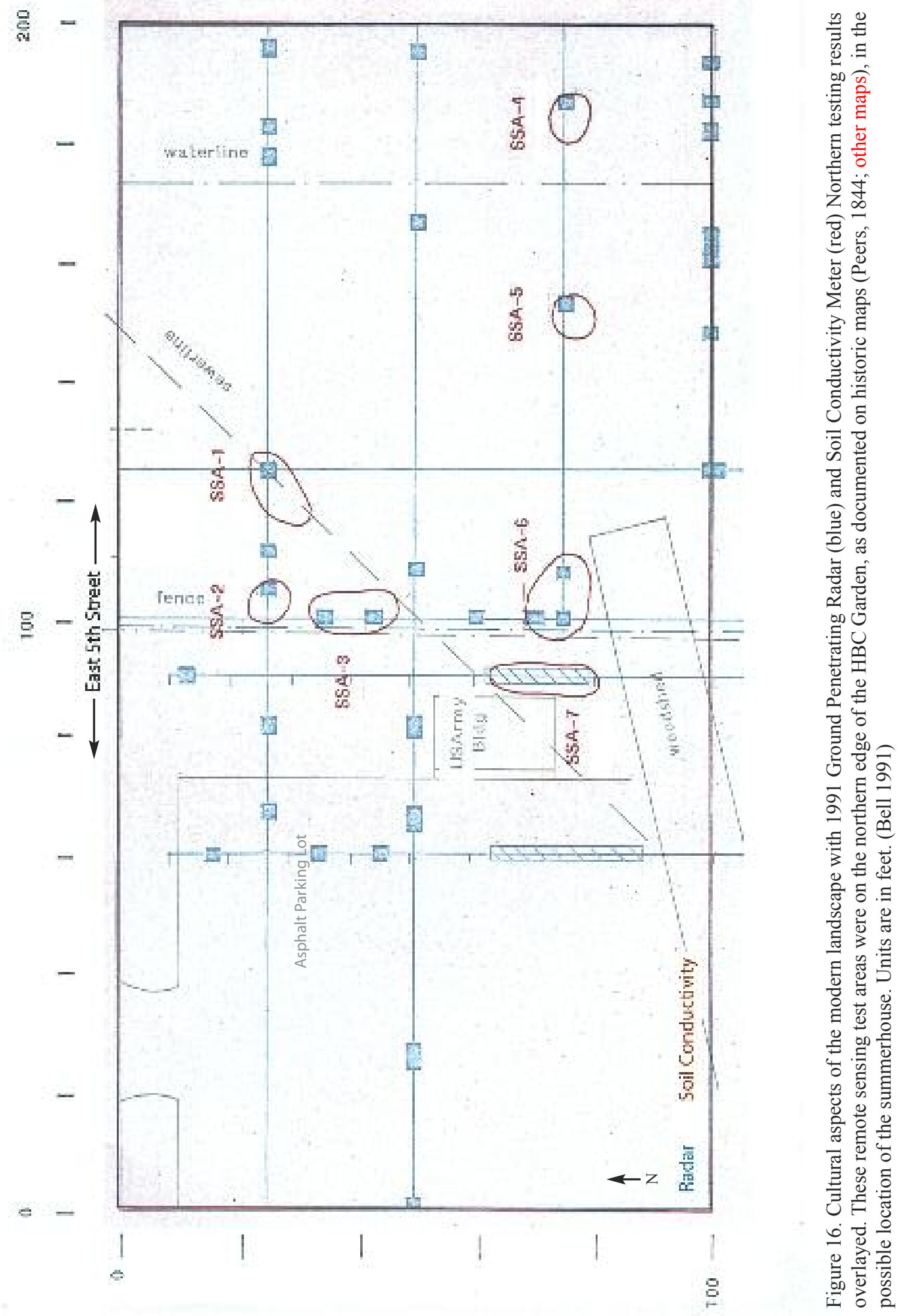




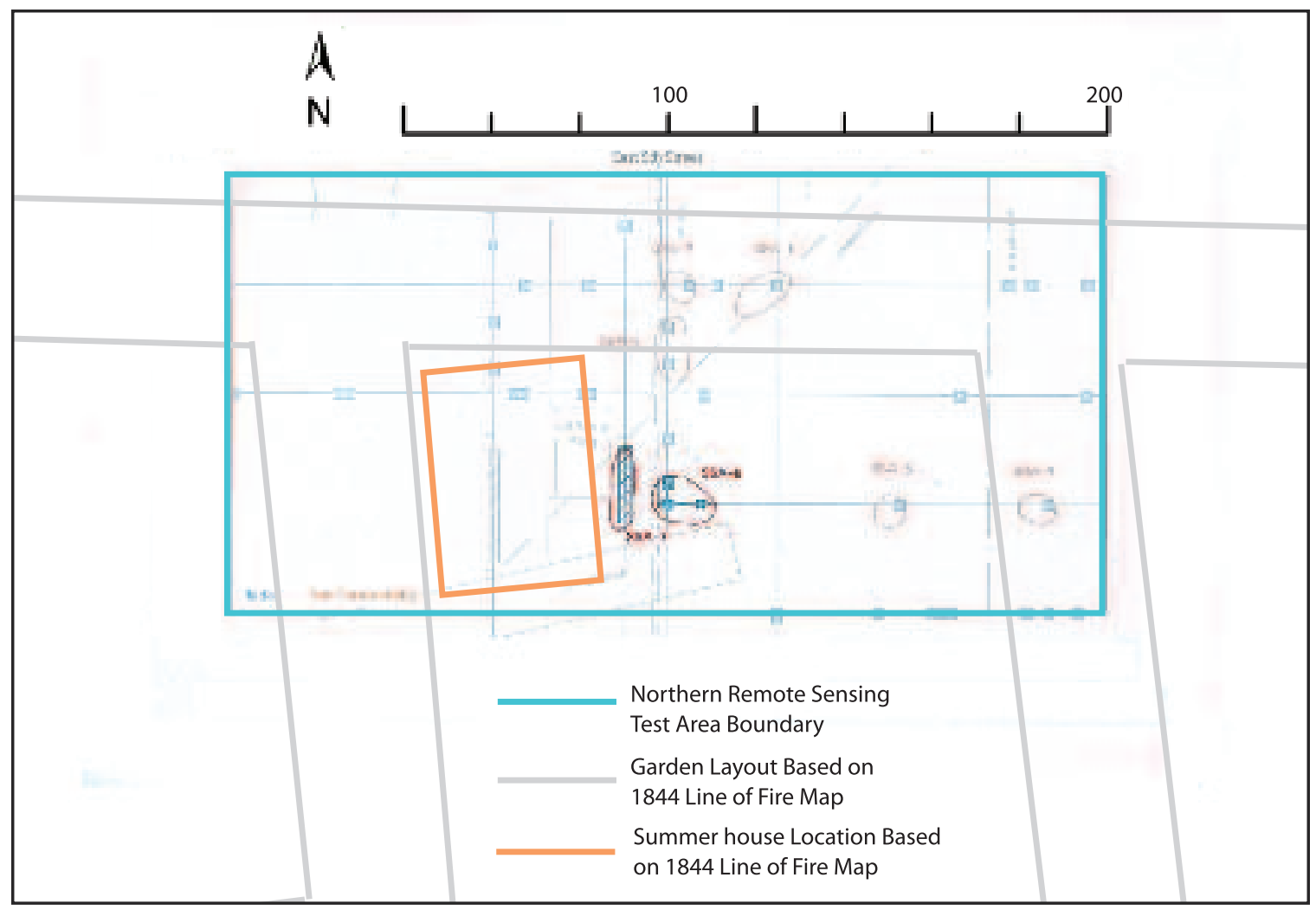

Figure 17. The relationship of anomalies (SSA-6 and SSA-7) found during remote sensing and identified as possible building foundations (Bell 1991), and the Garden layout, including the Summer house, based on the Line of Fire map (Peers 1844).

$(33.52 \mathrm{~m})$. At this point the trench turned south and ran along the western edge of the current Garden Exhibit. This north-south running portion of the trench is outside of the HBC Garden site. No HBC-period artifacts were noted in the east-west running portion of the trench, which was within the HBC Garden site. The report does not note whether the deposits exposed during the trenching project were intact or disturbed, so it is impossible to determine if the lack of artifacts found in the portion of the trench dug on the Garden site has any significance to HBC Garden activities.

Another project was conducted in 2001 in the area of the Garden. Four shovel tests were dug along the proposed route (Figure 13) of the Discovery Loop Trail (Cromwell, 2001). Although the report states that "[a]rtifacts from every historic period associated with the Vancouver National Historic Reserve (VNHR) were recovered in every excavated shovel 
test" (Cromwell 2001:3), the tables of Recovered Artifacts for Shovel Tests ST1 through ST4 (those in the Garden) do not attribute any artifacts to the HBC period (Cromwell 2001:7-8). The report does state, however, that intact sediments were found below $30 \mathrm{~cm}$ in STs 1 through 3, providing impetus for further testing in that area of the Garden. The sediment characteristics of ST 4 are not noted, but the recovered artifacts table (Cromwell 2001:Table 4) shows that 20th century artifacts were found throughout, and in Level 5, 40

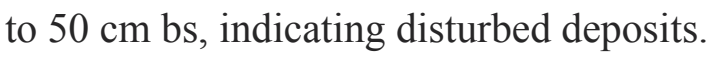

Another project in the area of the bastion, a mechanically-dug, narrow trench on the north side of the reconstructed north stockade wall, was archaeologically monitored in 2002. The trenching was completed within deposits disturbed during the reconstruction of the north stockade wall. No features were found and artifacts, a mix of HBC and U.S. Army items, were not collected (Cromwell 2002).

Two shovel tests were dug in 2009 (Figure 13), after the fieldwork reported in this thesis was completed, in deposits which would be impacted during the demolition of U.S. Army building P-408, which sat on the western edge of the HBC Garden, on the south side of East 5th Street (Horton 2009). Shovel Test 01 was excavated to $80 \mathrm{~cm}$, and Shovel Test 02 was to $100 \mathrm{~cm}$. Intact 19th century deposits were found, however the artifacts were of low diagnostic value and none were identified to the HBC occupation.

Previous archaeology conducted on the Garden was essentially limited to the margins of the site. While intact sediments were found in shovel tests dug near the eastern boundary (Cromwell 2001) and the northern boundary (Horton 2009), and units near the bastion (Caywood 1955), artifacts were few and non-diagnostic to gardening activities. Investigations of the north stockade wall provided valuable information towards interpreting features found during the 2005 field season of this project. Remote sensing (Bell 1991) provided evocative anomalies in the possible location of an $\mathrm{HBC}$ well, near the north wall of the stockade, and in the possible location of the HBC Summer house, on the northern edge of the Garden. 


\section{CHAPTER 5. Archaeological Research Design and Methods for the Fort Vancouver Garden Project}

The primary goals for the archaeological research portion of this project were to determine:

- the layout, dimensions and characteristics of the beds and paths

- the location and characteristics of the historically documented garden well (Well \#4)

- the identification of plants cultivated in the garden

- the identification of artifacts from which inferences can be drawn relating to the use of the Garden and perhaps the gender, age and ethnicity of the gardeners

- to confirm historical documents that the garden was a limited-use space

- the identification of hard landscaping (irrigation, path borders, structures, etc.)

- the identification of soil enhancement techniques

- any changes to the layout, dimensions and characteristics of the garden over time

- testing of two different methods of garden excavations: large trenches (utilized extensively in the eastern United States on colonial sites (Miller and Gleason 1994), and small trenches, the preferred method in England (Currie and Locock 1991).

As noted above, several occupations post-dating the HBC were located in the same horizontal space as the Garden. Some of these occupations have been agricultural, some industrial. All occupations have created some degree of sediment disturbance. With that in mind, an excavation strategy (detailed below) involving Fort Vancouver historic map, illustration and photo research, information obtained through garden archaeology research (Chapter 3), and previous archaeology at the site (Chapter 4) was developed. The results of this research guided the positioning of excavation units in areas that historically have had the least disturbance. Beyond that consideration, units were positioned to address specific research questions, and the results of Bell's (1991) remote sensing project. 
To achieve the goals noted above, research of archaeological documents focused on methods to apply that could result in information on the following expectations:

- there would be some disturbance of HBC deposits,

- remote sensing would not be effective due to overlaying occupations and activities,

- a path would be distinct from a bed, allowing for extrapolation of the Garden layout.

- tree root casts would be found,

- aspects of hard landscaping would be found,

- changes to the size of the Garden would be discernible as changes in layout,

- artifact quantities would be low relative to other areas of Fort Vancouver,

- artifacts may have been used to "loosen up" clay sediments,

- pollen and phytoliths would be well-preserved and provide information on what plants were grown in the Garden, where they were grown, and whether the paths were surfaced with grass.

These expected conditions can be determined archaeologically through the identification of differences in sediment texture and structure, the type and quantities of artifacts found, and analysis of sediments for microbotanical artifacts.

\section{EXCAVATION STRATEGY}

The 2005 strategy employed the eastern United States "colonial sites" method of larger trenches (see Chapter 3). Figure 18 shows two "Test Areas," TA1 and TA2, excavated during that season. The 1844 Line of Fire map (Figure 2), which delineates a Garden layout, drove trench placement decisions. Erigero (1992:128) estimates that the paths represented on this map were 20 feet wide. When developing the schematic drawing used for trench placement the proportions shown on the Line of Fire map (relative to the length of the north stockade wall from the western gate post to the northwest corner) suggest paths approximately 30 


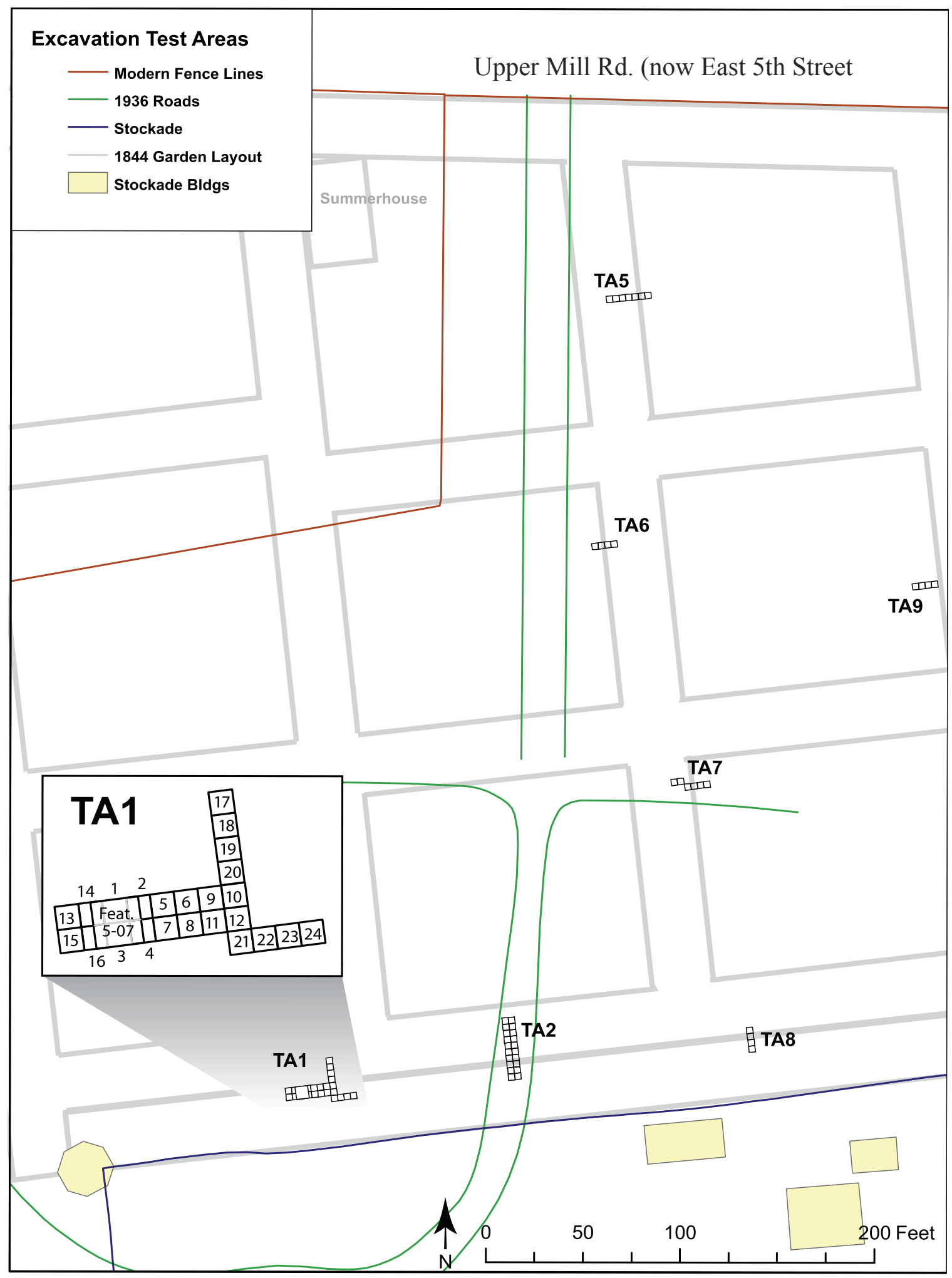

Figure 18. Archaeological excavation Test Areas. $1 \mathrm{~m}$ x1 m excavation units were numbered consecutively left to right and/or north to south, with the exception of TA1 (see inset). The gray lines are the schematic map created to represent the Garden layout as shown on the 1844 Line of Fire map, and assumes that the paths were $30 \mathrm{ft}$. wide. 
feet in width. This dimension is also viable as it coincides with 5 toise.*

Test Area 1 (TA1): As the results of remote sensing (ground penetrating radar and soil conductivity) conducted in two locations on the inferred Garden site (Bell 1991) had not been sub-surface tested, it was decided to excavate in the location of the inferred "well" in the southwest corner of the site. GPR was run over this location again in 2005 as a demonstration for Field School students, using an antenna for deeper investigation (as compared to 1991), with similar results. Also, a distinct depression, possibly the well, was located in this area. GIS maps indicate that the depression is located directly under the south wall of a WWI Spruce Mill building. Further, Bell (1991) interpreted the results of the GPR testing to indicate the presence of a "back-filled, masonry-lined, well." A $2 \mathrm{~m}$ x $8 \mathrm{~m}$ trench consisting of $161 \mathrm{x} 1$ $m$ units was excavated in this location, placed to cross this depression. The trench was begun during a PSU Field Methods class practicum, and continued during the field school. The trench was divided into $1 \mathrm{~m} \mathrm{x} 1 \mathrm{~m}$ units (Figure 18), which were excavated concurrently. Unit TA1-16 was excavated independently as a control unit, to determine the expected stratification at the site.

Test Area 2 (TA2): East of TA1, was $2 \mathrm{~m}$ x 10 m, consisting of $201 \mathrm{~m} \times 1 \mathrm{~m}$ units, which were also excavated concurrently, other than TA2-20, a control unit which was excavated individually to determine stratification in this area.

TA2 was located to potentially cross the edge of the southern east-west Garden path as shown on the Line of Fire map (Peers 1844), from the bed against the north stockade wall. The intent was to determine if distinct stratification changes related to the path were present. This trench potentially crossed a path edge into planting beds south of the path. The Line of Fire map also suggests a feature centered east to west in the garden, near the

\footnotetext{
*toise: a French unit of measurement equaling 1.949 meters utilized in colonial Quebec and often employed in fur-trade architecture. (http://www.sizes.com/units/toise.htm, accessed 3/6/11). It appears that this unit of measure was used in the HBC Village (Mulalley 2011:44), but results of archaeological research on remains of buildings inside the stockade indicate that English Feet was the measurement method utilized in this location (Brauner 1995; Hoffman \& Ross 1973, 1974, 1976, Thomas 1991).
} 
stockade wall, possibly a path. This trench was placed to determine the nature and characteristics of that possible path feature. However, possible disturbance was high in this area. GIS maps confirm the presence of a 1930s road in this location.

\section{EXCAVATION STRATEGY}

The test excavation strategy for the 2006 field school was based on the results of the 2005 excavations and additional review of extant historical maps, drawings, other illustrations, and historical and aerial photographs. The testing research design was altered based on the findings from the 2005 excavations, and to address the relative value of large versus small trenches (as utilized in England). Specifically, shorter and narrower test trenches attempted to follow out some of the probable garden paths based on the Line of Fire map (Peers 1844). Further, one trench tested the location of the root houses northeast of the garden, to determine if this area contained intact remains of the structures and their contents (Figure 18). The results of the trench to locate the root houses is not included in this document.

Test Area 1 (TA1): Based on the results of 2005 excavations (see Feature 507, Appendix C), work here was continued, employing shoring to test if the feature was a well dating to the $\mathrm{HBC}$ period. In addition, two $1 \mathrm{~m} \mathrm{x} 4 \mathrm{~m}$ test trenches (units 17-24) were excavated north and east of the 2005 excavation block to follow out a compacted surface identified as a possible garden path (see Feature 509 below).

Test Areas 5, 6, 7 and 8 (TA5, TA6, TA7, TA8): These $1 \mathrm{~m} \mathrm{x} 4 \mathrm{~m}$ trenches were placed to explore the location of the boundary between Garden paths and Garden beds, based on the Line of Fire map (Peers 1844), in order to extrapolate the remaining geometric layout of the Garden. It was also hoped to find distinctive strata, features, and artifacts associated with other garden hard landscaping.

Test Area 9 (TA9): After information was obtained at Colonial Williamsburg relating to the methods employed in creating hot beds in the 19th century, an additional $1 \mathrm{~m} \mathrm{x} 4 \mathrm{~m}$ 
trench was excavated in the proposed location of these structures in the HBC Garden (Erigero 1992:128). According to Loudon (1824:766), hot beds consisted of an approximate $2 \mathrm{ft} .(.61 \mathrm{~m})$ wide and $3 \mathrm{ft} .(.91 \mathrm{~m})$ deep hand-dug trench which was then filled within $1 \mathrm{ft}$. $(30 \mathrm{~cm})$ of the surface with fresh manure. The remaining area was filled with dirt. Seeds and young plants generally native to warmer environments were then planted in the hot bed, which was often covered with a cold frame (glass and wood, essentially a flatish, portable greenhouse). The rotting manure would heat the dirt, allowing the seeds to germinate, or the plant to grow. TA9 was placed along what is inferred to be the eastern edge of the eastern-most Garden bed, in an area that appears to have had little disturbance by later occupations (Figure 18).

The sampling strategy for pollen, phytolith and macrofloral analysis implemented in 2006 was identical to that employed in 2005, minus the column sample.

\section{SPECIAL SAMPLING}

A sampling procedure was developed to collect sediment samples for the extraction of pollen grains and phytoliths. Sediment was collected for each testing method from deposits determined (by artifact identification and sediment characteristics) to be intact HBC period. Trowels were cleaned prior to collecting the sediment sample by wiping them on a paper towel. Sediment samples were consistently taken from the northwest $50 \mathrm{~cm} \mathrm{x}$ $50 \mathrm{~cm}$ quadrant of a given $1 \mathrm{~m} \times 1 \mathrm{~m}$ unit. The surface of the intact deposit was first scraped so that the sediments collected would be freshly exposed and therefore not contaminated with modern pollen. Sediments for pollen analysis were collected first, with sediments for

phytolith analysis taken immediately afterward from the same location. Sediments for the two forms of analysis were bagged separately and labelled.

Sediment samples from a non-Garden provenience were taken for comparison to those samples taken from the Garden (as inferred from the 1844 Line of Fire map) 
(Appendix G). This non-Garden provenience was located approximately $516 \mathrm{~m}$ from the northeast corner of the Garden site, and approximately $632 \mathrm{~m}$ from the location of the sediment samples taken during the HBC Garden project, just north of the Fort Vancouver National Historic Site Visitor Center. From the 1820 s to the present, the area was first an HBC agricultural field (Hussey [197?]:108), then U.S. Army Parade Ground, and finally NPS property. The samples were taken from the north wall of a shovel test excavated during testing related to a remodeling project at the Visitor Center (Cheung et al 2010).

Sediment samples for this project were sent to Paleo Research Institute, Golden, Colorado, for phytolith analysis (Appendices D and E). Samples for pollen analysis were sent to both Paleo Research Institute (Appendix E) and the Andrew Fiske Memorial Center for Archaeological Research at The University of Massachusetts Boston, Boston, MA (Appendices F and G). Samples for macrobotanical analysis were also sent to the Andrew Fiske Center (Appendix H).

\section{EXCAVATION METHODS}

Sediments were excavated during both field seasons in stratigraphic levels, or no more than $10 \mathrm{~cm}$ arbitrary levels for strata that were more than $10 \mathrm{~cm}$ thick. Intact $\mathrm{HBC}$ deposits were excavated in stratigraphic levels, or $5 \mathrm{~cm}$-thick arbitrary levels. It was assumed, based on previous excavations at the site, that the stratification of sediments within the HBC Garden would be distinctive and include deposits related to NPS activities, the fill from the WWI spruce mill, and the HBC period.

Deposits up to and including the WWI spruce mill fill were excavated using skim shoveling and breaker bar, while intact HBC deposits were excavated by trowel. Excavated sediments were sieved through nested $1 / 4$ in. $(0.64 \mathrm{~cm})$ and $1 / 8$ in. $(0.32 \mathrm{~cm})$ wire mesh hardware cloth.

A Total Station was used to confirm baselines, set to the orientation of the Garden 
and stockade. Excavation units were set off of these baselines. Vertical provenience was maintained using a vertical datum tied into the unit through the use of a unit datum, line levels, and string, or in some cases, an optical level.

Matrix recovered from the excavations was sieved through nested $1 / 4-$ and $1 / 8$-inch (6 and $3 \mathrm{~mm}$ ) mesh hardware cloth. Collected artifacts from each unit were separated by material and bagged by excavation level or feature. A bag catalog for each unit was maintained in the field to track the collection. Information from each level was recorded on an NPS level record form, including the site name and number, the unit provenience, feature designator, level, strata, excavator, date of excavation, excavation technique, a plan sketch (if appropriate), a detailed sediment description, inventory of samples, and descriptive section. At least two walls of each block excavation were profiled and photographed (using a digital camera and black and white print film). The profiles were drawn to scale, showing stratigraphic breaks, strata designations, soil constituents, feature boundaries, and evidence for disturbance.

Features were given a unique number and documented photographically, on feature forms, and with a scaled plan and profile sketch. As deemed appropriate, wood and sediment samples were collected. Artifacts found within features were collected by stratigraphic unit and these strata were measured vertically and horizontally.

Artifacts were prepared, processed, analyzed, and curated to the Secretary of the Interior's standards at the Fur Store curation facility at Fort Vancouver National Historic Site. All recovered artifacts were cleaned by either wet washing or dry brushing. Artifacts from each unit of provenience were assigned a unique field lot number. Bags of ceramics, glass, ferrous metal, other metal, faunal remains, stone artifacts, and diagnostic artifacts from each lot were assigned a unique field specimen number. Lab activities were conducted by NPS volunteers under the coordination and supervision of the author, and with the assistance of Doug Wilson, Bob Cromwell, Tessa Langford, Danielle Gembala, Heidi Pierson, Leslie 
O'Rourke and Beth Horton. A computer-based database for all recovered materials was maintained to track the materials through the various analysis steps. After cleaning, artifacts were analyzed by material type, manufacturing and technological characteristics, and formation process traces. Previously constructed typologies for Fort Vancouver were employed to identify the collected artifacts. The artifacts from this project were cataloged with the NPS' Interior Collections Management System (ICMS) software, and are stored under accession numbers 3047 and 3062.

Field work was conducted from May 20, 2005 to August 5, 2005; June 13, 2006 to August 4, 2006 and August 13, 2007 to August 24, 2007. The field crew for 2005 consisted of: Doug Wilson, Principal Investigator; Field Supervisors Elaine Dorset and William Gardner O'Kearney, PSU Anthropology Dept. graduate students; Beth Horton and Amitava Chowdhury, WSU PhD. candidates, and 24 university students. Lab Director was Danielle Gembala, University of Washington PhD candidate. The field crew for 2006 consisted of: Doug Wilson, Principal Investigator; Field Supervisors Elaine Dorset and Meris Mullaley, PSU Anthropology Dept. graduate students; Beth Horton and Amitava Chowdhury, WSU PhD. candidates, and 17 university students. Lab Director was Heidi Pierson, Chico State University graduate student. 


\section{CHAPTER 6. Archaeological Testing Results}

The archaeological excavations resulted in little macroscopically visible information, such as distinctive sediments related to paths and planting beds, hard landscaping (border materials, irrigation features, water features), and root casts, related to the existence and characteristics of the Garden. Several of the units were determined definitively to consist of disturbed deposits, while others were questionable. Figure 18 indicates the locations of the Garden site excavation units and Appendix B provides a summary of the results of each unit. Specific information is noted in this chapter relating to several $\mathrm{HBC}$ features. The characteristics of these features infer that they represent activities on this landscape during the HBC occupation. Discussion of two features from later occupations at the Garden site (Features 505 and 507) can be found in Appendix C. The remainder of the features from later occupations are not discussed in this document. Finally, a summary of artifact quantities and distribution is provided, and several distinctive artifacts are described.

A summary of results in this chapter:

- all trenchs contained disturbed sediments, several of the small trenches had no intact deposits;

- the large trenches had localized disturbances with surrounding intact deposits;

- a stratigraphic sequence for the Garden site was established. The presence of Stratum IV, the 1894 flood silts, in the strata was used as a marker indicating intact deposits below;

- the anomaly noted during GPR testing at TA1 inferred to be an HBC well, was determined to be a WWI dry well;

- a compacted surface within the HBC deposits was found at TA1, expanding beyond the unit walls of the trench

- two other features, strips of ultra-compacted sediments and a probable hearth were also found in TA1;

- remains of a small post were found in TA8, most likely from the HBC period. 
As noted above, both large trench excavations (TA1 and TA2) and several small trenches (TAs 5 through 9) were dug during this project. Both sizes of trenches had areas of disturbance. However, the larger amount of excavation done within a contiguous area resulted in finding intact deposits adjacent to the localized disturbed areas.

The results of excavations in TA1, the "well" location that was GPR tested in 1991, and again in 2005 with similar results, indicate that what initially appeared to be anomalies consistent with those found related to a known well inside the fort palisade (Bell 1991), was actually a later occupation (mid-twentieth century) trash pile, approximately $4 \mathrm{~m}$ in diameter, which had been used to fill a dry well, probably dating to WWI when many temporary housing buildings, including bath houses, were located on the Garden site (see Feature 507, Appendix C).

\section{STRATIGRAPHY}

A consistent stratigraphic sequence was developed for undisturbed deposits at the Garden site (Figure 19). This sequence is as follows:

Stratum I: Sod, NPS Fill

Stratum II: Modern U.S. Army (1920-1948)

Stratum III: U.S. Army WWI Spruce Mill (1917-1918)

Stratum IV: Flood Silt Deposit (1894)

Stratum V: Early U.S. Army and HBC occupation (1829-1894)

Stratum VI: Culturally Sterile (pre-1829) B Horizon

Stratum VII: C Horizon Gravels

The presence of Stratum IV (1894 flood silt) was used as a marker indicating that Hudson's Bay Company deposits below (representing the inferred Garden), were intact. Appendix B indicates excavation units containing Stratum IV flood silts.

TA5 (Figure 18) contained probable disturbed sediments, with wire nails and other 


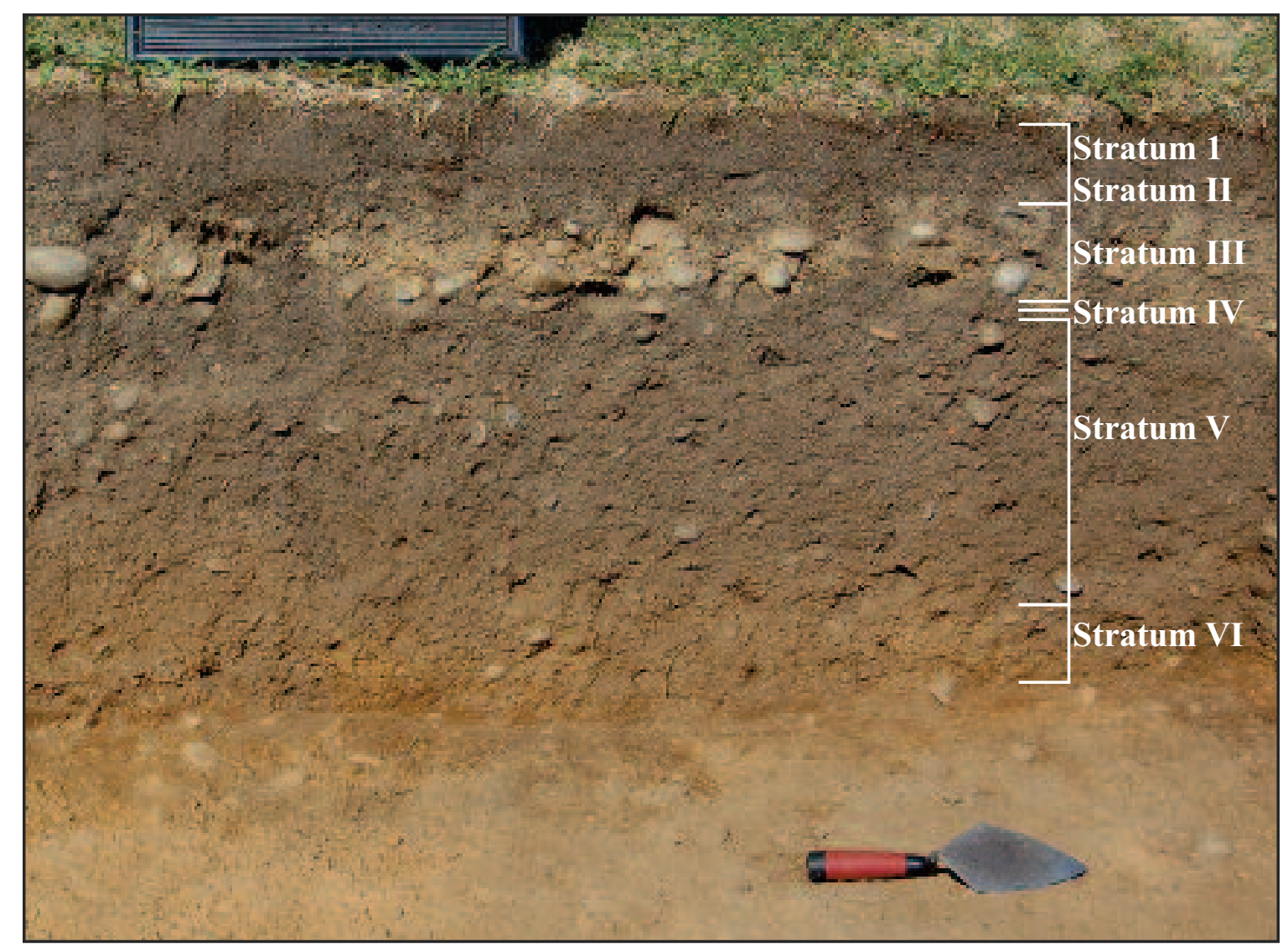

Figure 19. A typical profile of sediments at the HBC Garden site, found in the west wall of excavation units TA1-13 and TA1-15. Photo courtesy of the National Park Service.

20th c. artifacts through out the deposits and a gravel stratum (Feature 614) probably associated with a 20th C. road. Only units 1, 5, 6, and 7 were excavated in this trench. TAs 6 and 9 were also determined to be disturbed, containing probable WWII fill. TA7 contained two features (616 - horizontal linear wood and 619 - compacted sediment), that were initially thought to be related to $\mathrm{HBC}$ activities, but the presence of wire nails and plastic defined the features as 20 th century.

\section{HUDSON'S BAY COMPANY PERIOD FEATURES}

Four features were found during this project that could definitively be attributed to the HBC period (Table 1). Three of the features: Feature 509, a compacted surface; 509A, a 
possible hearth; and 509B, ultra-compacted

Table 1. HBC Features

sediments within Feature 509, were found in

\begin{tabular}{lll}
\hline Feature & Location & Character \\
\hline 509 & TA1 & Compacted surface \\
\hline 509A & TA1 & Hearth \\
\hline 509B & TA1 & Ultra-compacted surface \\
\hline 621 & TA8 & Wooden post \\
\hline
\end{tabular}

Feature 509, 509A, 509B in TA1

Feature 509 (Figure 20) is a highly compacted HBC surface (as determined by artifact types). Artifact counts within this feature were 364 artifacts per $\mathrm{m}^{3}$, a $30 \%$ increase over that of the HBC deposits (excluding the sheet trash in TA2) in the remainder of the Garden site units, and comparable to the TA2 sheet trash (369 artifacts per $\left.\mathrm{m}^{3}\right)$. The compacted sediments (and relatively higher artifact counts) may indicate that this surface was exposed and/or did not experience sedimentary deposition for a long period, or that activity in this area was greatly increased over the remainder of the Garden. Gravel percentages, the fine fraction (silt loam) and color (10 YR 3/3) were consistent with surrounding non-feature HBC deposits. The thickness of Feature 509 ranges from $2 \mathrm{~cm}$ to $10 \mathrm{~cm}$. The northern portion of the feature exhibited several thin lenses of alternating soft and hard deposits. This may have occurred due to yearly weather patterns, or some other unknown process. The overall compacted sediments appeared to diminish in thickness and coverage in the eastern units. However, on the north and south boundaries of TA1, the compacted surface extends beyond the walls of all units. On the west the feature is truncated by Feature 507, the WWI dry well, and did not continue in units to the east of that feature. Feature 509 is clearly of significantly larger size than was exposed during excavations, continuing to the north and south. Based on the Line of Fire map (Peers 1844), Feature 509 is located both in a Garden bed, and in the path directly to the north of the Garden bed. It is interesting that this map doesn't indicate anything significant in this area, but the map also doesn't show any sheds 


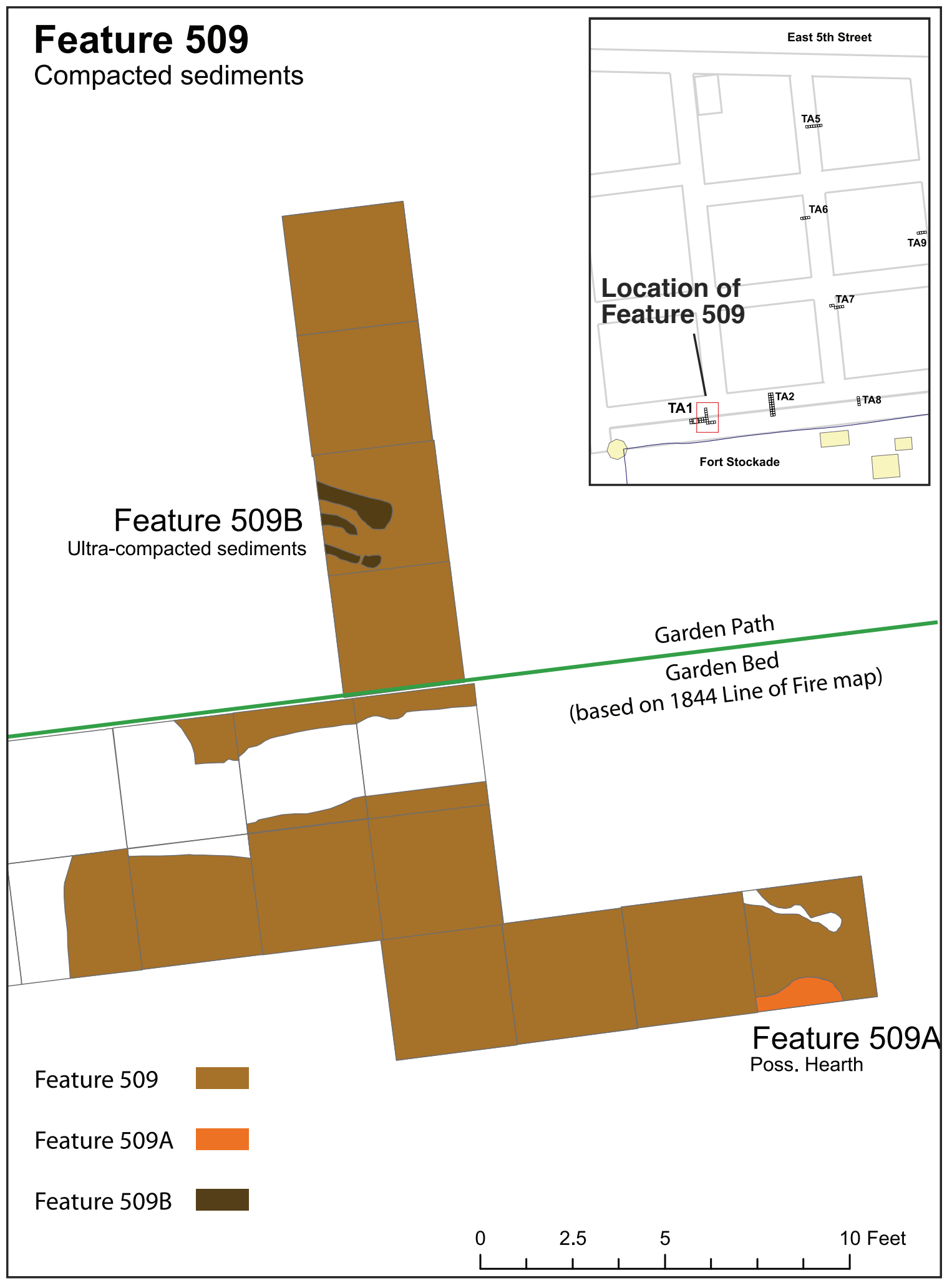

Figure 20. Features 509, 509A and 509B in TA1. 
or other support-type facilities on the local landscape.

Feature 509A (Figure 20) was a possible hearth located in the southeastern portion of the TA1, at the bottom of Feature 509. The feature was approximately $8 \mathrm{~cm}$ thick, $73 \mathrm{~cm}$ wide, and continued into the south wall of unit TA1-24. The total shape could not be determined, but the exposed portion had curved edges, implying a circular shape. The gravel percentage in the sediments increased by $100 \%$, with a significant amount of charcoal in very poor condition, preventing collection of more than a small sample $(\mathrm{n}=18)$.

Feature 509B (Figure 20) was a total $1 \mathrm{~m}$-wide by $5 \mathrm{~cm}$-thick set of "strips" of extremely compacted sediments in the north central portion of Feature 509. These compacted strips may have been created when an object of great weight was placed in this area. An example would be the support structure for water barrels.

\section{Feature 621}

Feature 621 was a wooden post located in the west wall of TA8, in the south central area of the Garden (Figure 21) probably from the HBC period. There was no discernable post hole, probably indicating that the post was simply driven into the ground. Stratum IV, 1894 flood silt, was found at this location, near the top of the post. The post was either still present at the time of the flood, or placed into the ground after it, as the flood silts surround the remains of the post rather than flowing over it. These remains are about $4 \mathrm{~cm}$ thick by $6 \mathrm{~cm}$ wide and $13 \mathrm{~cm}$ in length. The wood was quite degraded, and it is unknown if it was a milled piece or unworked. One fragment of free-blown, light olive vessel glass was found in Feature Level 2 (10-20 cm from the top of the post, Stratum V HBC). Two flat glass fragments found within a $10 \mathrm{~cm}$ level of sediment underneath the post date to $1830-1845$, based on a thickness of 1.24 mm (.048 in.) (Roenke 1978). A pollen sample taken immediately below the post contained crocus and horehound, both introduced plants.

A review of available historical maps for this location indicates uses such as 


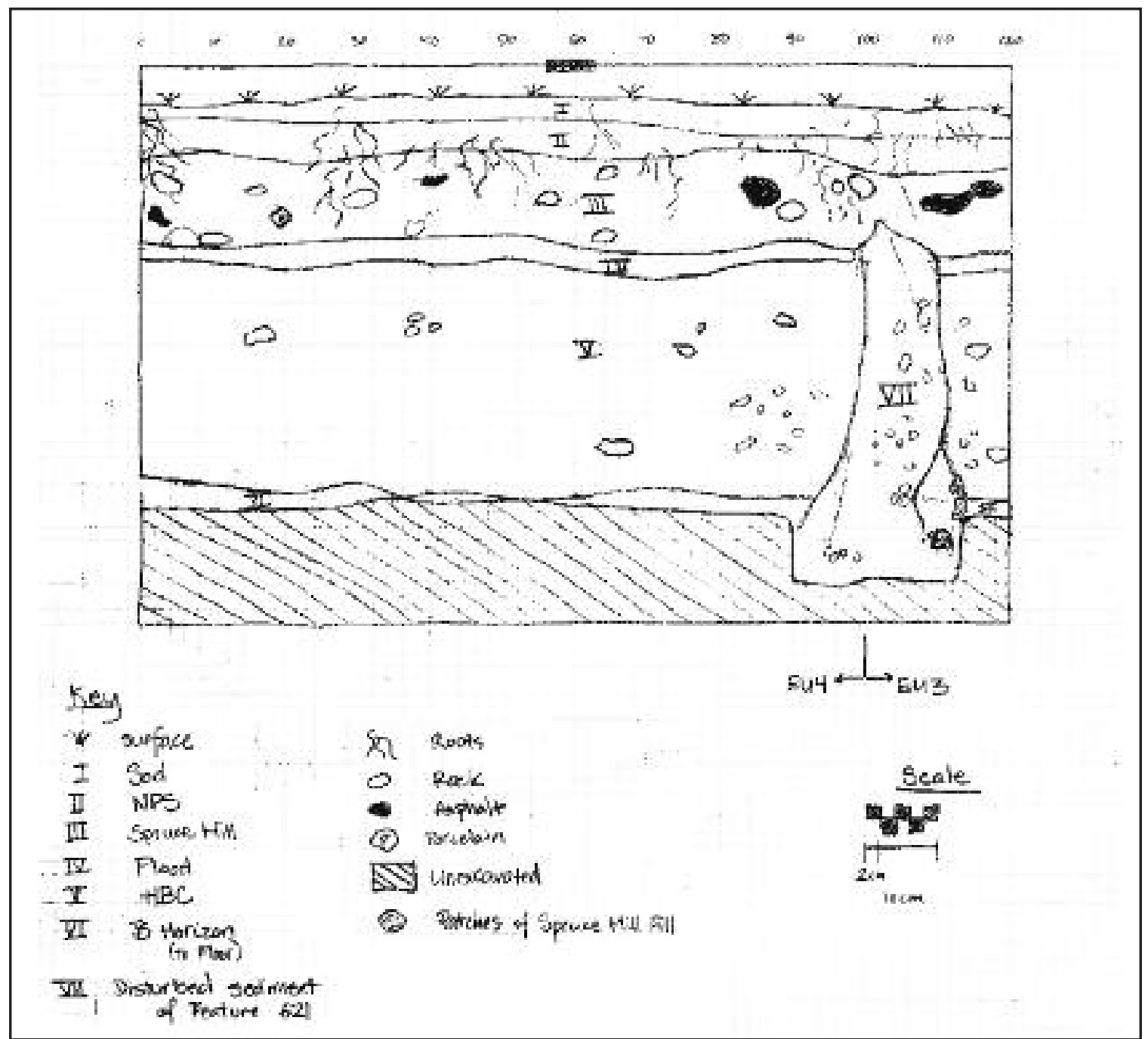

Figure 21. Profile of west wall of TA8, showing Feature 621 post on right (VII). Image courtesy of the National Park Service.

“meadows" (unknown cartographer 1870), "pasture," (Wood 1879), "Company gardens," (Lydecker 1889), and "skirmish range" (McCrea 1892) after the HBC occupation and up to WWI. These activities are not compatible with having posts on the landscape. The soldiers most likely grew relatively labor-free root vegetables in their garden, and would not have required support posts for trellises. As the post was truncated some time previous to the WWI sand and gravel fill event to prepare the landscape for the spruce mill, it is likely that this post feature is an aspect of the HBC occupation.

In summary, several of the small trenches contained disturbed deposits. The two 
large trenches, TA1 and TA2, also contained localized disturbed deposits surrounded by intact sediments. A stratigraphic sequence was developed for the site. Four HBC-period features were found. A highly-compacted surface in the area of TA1, with relatively high density of artifacts. The boundaries of this feature appear to be at the east end of TA1, in the area of Feature 507 (dry well) on the west, while the north and south boundaries could not be determined as they extend past the excavations in TA1. Associated with this feature are a highly-compacted area (Feature 509B, and a hearth (Feature 509A). Feature 621 (TA8), the remains of a post, is likely from the HBC period.

The possible location of an HBC well, in TA1, was determined to be a dry well from the early 20th century WWI spruce mill, which had been later (post 1935) filled with primarily architectural trash. No changes in sediment that could have represented garden paths was found. 


\section{CHAPTER 7. Artifacts and Archaeobotanical Remains}

This chapter discusses artifacts found within HBC deposits. None of the artifacts were clearly representative of gardening activities, however, the fact that they were deposited during the HBC period, in a known Garden (based on historial documents and results of this project), implies that they represent some type of activity in the Garden. A spatial distribution analysis of total artifacts is reviewed, artifact types and quantities are briefly discussed, and classified by function. Microartifact (pollen and phytolith) analysis of sediment samples obtained from HBC deposits is also reviewed. A discussion of the results generated from this data can be found in Chapter 8 .

A summary of results in this chapter:

- the artifact distribution shows relatively higher quantities of artifacts associated with the compacted surface (Feature 509) in TA1, and in the west central portion of TA2;

- overall, artifact quantities found at the site are significantly lower than those found in other locations at Fort Vancouver;

- artifact types were dominated by architectural items (41\%) no artifacts specific to gardening activities were found, a very few artifacts relating to gender and/or class were recovered, the majority from the TA2 sheet trash, in terms of domestic artifacts, vessel glass dominated at TA1 and ceramics at TA2.

- phytolith analysis indicates that the site was a meadow with native grasses, and that this signature does not change over time

- pollen analysis identified many plants already known from documents to have been grown in the Garden, plus several previously unknown plants.

- spatial distribution analysis of absence/presence of pollen indicates where certain plants were growing in the Garden

\section{ARTIFACT DISTRIBUTION}

Excavation trenches were placed in locations (Figure 22) that were hoped to show a transition in sediment characteristics from a Garden bed to a Garden path, based on a GIS 
map created from the Garden layout as represented in the Line of Fire map (Peers 1844). It was hypothesized during development of the project that it was possible for there to be either more artifacts in the Garden beds, as it had been common practice for many centuries to loosen sediments by adding trash, or for there to be more artifacts in the path areas, representing items dropped by gardeners and visitors. Either case would have been represented in the archaeological record as significant differences in the spatial distribution of artifacts. Figure 22 indicates the spatial distribution, based on artifact counts per $\mathrm{m}^{3}$, of all artifacts recovered from the HBC strata during these excavations. TAs 5, 6 and 9, in the northern portion of the site, consisted of disturbed sediments and did not contain intact HBC deposits. When looking at only the trenches that contained intact HBC sediments (TAs 1, 2, 7 and 8), as shown in the figure, there is no consistent pattern of artifact distribution that

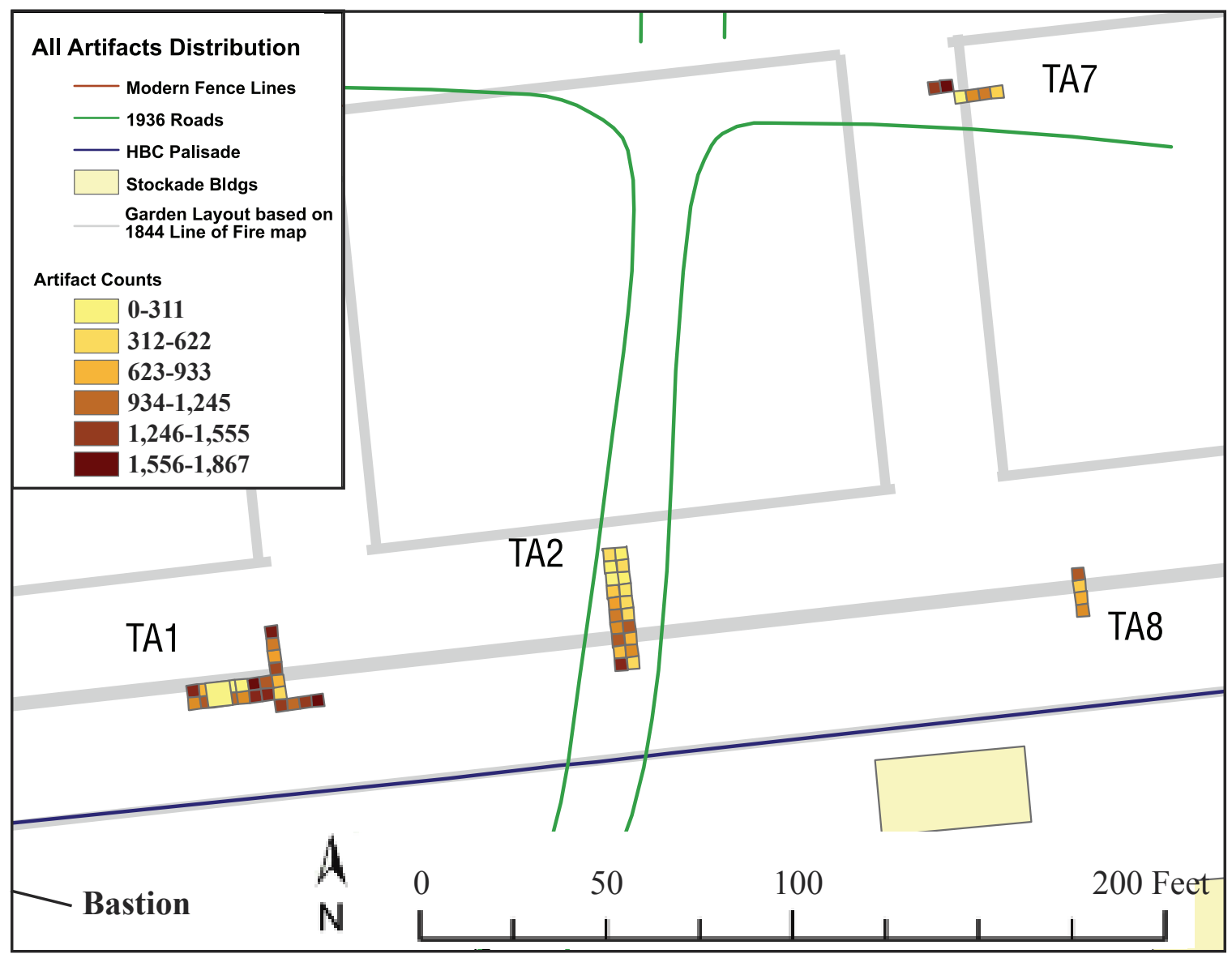

Figure 22. Spatial distribution of all artifacts. 
illustrates a boundary or transition between Garden path and Garden bed. TA7 and TA8 had higher artifact counts in the "path." TA2's distribution is anomalous on the south end due to an inferred sheet trash deposit (see Discussion below), however, artifact counts were low in the "path" area of the trench as compared to TA7 and TA8. TA1 exhibits an overall anomalous distribution, with the western portion of the trench disturbed by later WWI activities, and the remainder of the trench (which contains Feature 509, compacted surface) having a variable artifact distribution.

The 2004 Powder Magazine excavation inside the Fort stockade (Pierson et al. 2009:Table 8), and 2011 HBC Village excavations (Wilson, report pending) provide data for an intersite artifact count density comparison (Figure 23). This comparison provides supporting evidence for statements in historical documents that access to the Garden was limited. The Village, like the Garden, was also adjacent to the fort stockade, but was a living space for the Company's employees, while use of the Garden was restricted based on the hierarchical structure of fur-trade society. Narcissa Whitman, among others, indicated that

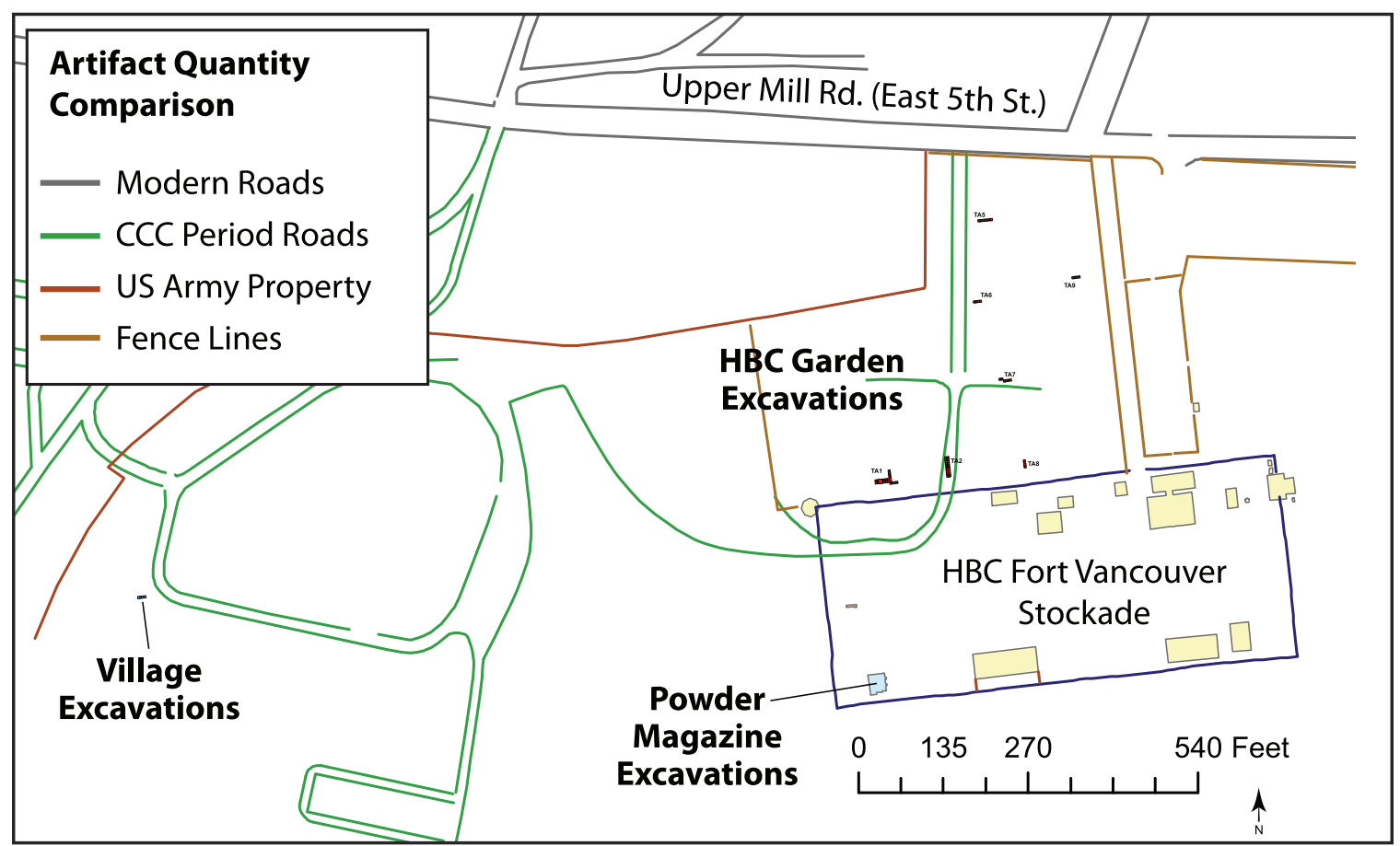

Figure 23. Locations of excavation units (Village, Powder Magazine) used for artifact quantity comparison to the HBC Garden site. 
Dr. McLoughlin invited her to enjoy the Garden (Whitman 1982). The Powder Magazine was a brick and stone structure in the southwest corner of the Fort stockade (Pierson et al. 2009). While this may not be the best comparison to a Garden site, essentially all of the excavations conducted inside the stockade have focused on structures, so any comparisons from this area would yield similar results.

Table 2 compares artifact counts per $\mathrm{m}^{3}$ from specific areas of the HBC Garden site to a trench excavated in the HBC Village in 2011 (Block A, 1x1 m units 5 through 8), that are inferred to be outside of houses (based on evidence of house floors in nearby units [Kardas 1969]), and the Powder Magazine excavations inside the Fort stockade. The artifacts counts from these two comparatives are significantly higher than those in the Garden.

Table 2. HBC Garden and Village Artifact Count Comparison (artifacts per $\mathrm{m}^{3}$ )

\begin{tabular}{lccc}
\hline Location & $\begin{array}{c}\text { Artifact } \\
\text { Count }\end{array}$ & $\begin{array}{c}\text { Volume } \\
\text { Excavated }\left(\mathrm{m}^{3}\right)\end{array}$ & $\begin{array}{c}\text { Artifacts } \\
\text { per }^{3}\end{array}$ \\
\hline HBC Garden Project & & & \\
TA1 (exclusive of Feature 509) & 1,171 & 3.04 & 385 \\
TA2 & 1,175 & 3.52 & 334 \\
Feature 509 (TA1) & 223 & 0.63 & 354 \\
\hline 2011 HBC Village Excavations & & & \\
A05 through 08 & 3,166 & 1.21 & 2,617 \\
\hline 2004 HBC Powder Magazine Excavations & 24,053 & 7.00 & 3,436 \\
\hline
\end{tabular}

The artifact distribution indicates higher relative quantities of artifacts in portions of TA1 and TA2, and overall significantly lower quantities of artifacts in the Garden site as compared to other locations at Fort Vancouver. 


\section{ARTIFACTS}

A total of 3,990 artifacts were found in $10.65 \mathrm{~m}^{3}$ of $\mathrm{HBC}$ deposits excavated during these investigations. These artifacts, along with all documents generated during this project, are stored in the curation facility at Fort Vancouver National Historic Site, cataloged under accession numbers 3047 and 3062.

A brief overview of artifact types and their functional classifications (Sprague 1981), follows. While the artifacts themselves may not, in a literal sense, reflect activities in a Garden, they were found in HBC deposits, within a Garden known both from historical documents and the results of microbotanical analysis of sediments (see below). Therefore, whatever their use or reason for being in that place, they are relevant to activities in the HBC Garden.

\section{Personal Functional Classification}

Beads

A total of 58 beads was found in HBC deposits at the garden site (Figure 24). The majority $(n=42)$ were found in TA2. A total of $27(47 \%)$ was identified as hot tumbled, and $24(41 \%)$ were wire wound. Twenty of the beads (34\%) were identified as FOVA type \#1003, a white, wire wound, seed bead. Only one bead, found in TA2, was faceted. One possible stone bead was found in Feature 509, the compacted

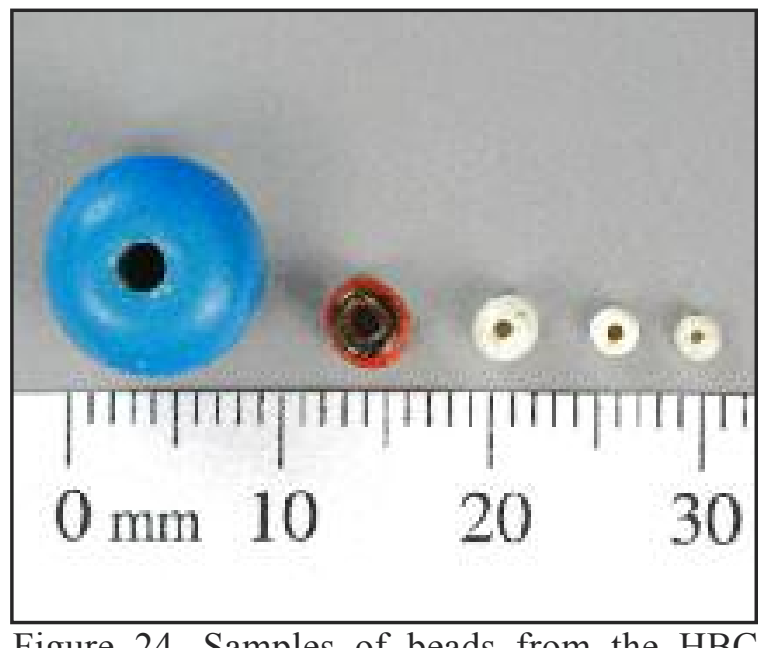

Figure 24. Samples of beads from the HBC Garden excavations. Photo courtesy of the National Park Service.

surface at TA1. It was only partially drilled, $9.2 \mathrm{~mm}$ length, $10.4 \mathrm{~mm}$ diameter, a semi-translucent, tan orange quartz. 
Buttons

Two buttons were found in HBC deposits. One, found in TA2, was a U.S. military, General Service, brass button, dating to 1854-1902, two-piece with an eye or loop back (Figure 25). On the front there is an eagle with spread wings and a lined shield on its chest. The eagle has an olive branch in its left talons, and 13 arrows in the right. The only letters discernible on the back of the button are "PHIL," possibly

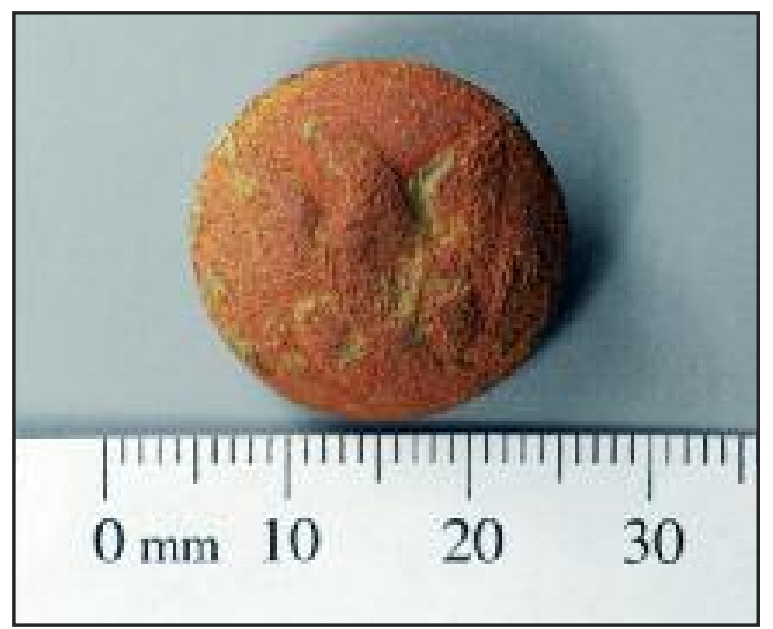

Figure 25. Brass button illustrating effect of dezincification process. Photo courtesy of the National Park Service.

indicating the manufacturer "W.G. Mintzer Phild," dating the button more tightly to 1858-1870, definitively the 19th century U.S. Army occupation of the site. The button is an orange color with spongy texture, possibly due to dezincification, a process that leaches the zinc out of the alloy, leaving the copper. This process occurs due to exposure to water (Rodgers 2004:110). The other button, found in TA1, was a 4-hole, Prosser-molded white porcelain. This button dates to post-1840 (Sprague 2002).

Trade Ring Glass Inset (Figure 26)

Trade rings, and other jewelry items, were imported by the HBC to trade with the American Indians and employees of the Company. Fragments and intact items of jewelry have been found sporadically during excavation projects across the site. Only one item of jewelry

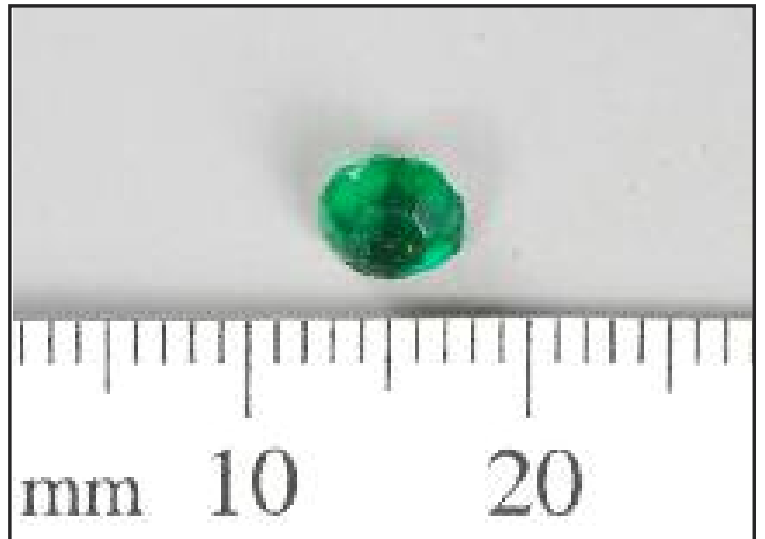

Figure 26. Emerald-colored glass trade ring inset. Photo courtesy of the National Park Service. 
was found during the Garden excavations, a green glass "gem" inset from a trade ring, found in TA2.

\section{Tobacco Pipe}

Tobacco pipe fragments are ubiquitous in archaeological excavations at Fort Vancouver, often in concentrations at what are inferred to be social spaces, such as near doorways and at the sides and backs of buildings. A total of 251 tobacco pipe fragments was found during Garden excavations, $75 \%$ of them in the TA2 sheet trash deposit. None of the fragments were identifiable to type, so dates could not be obtained.

\section{Domestic Functional Classification}

Bone

A total of 124 bone fragments, 39\% of them from the TA2 sheet trash deposit, were found. Generally very small fragments, 9 were identified to mammal, including 1 (large mammal) that exhibited cut marks and 2 that were calcined.

\section{Ceramic}

Ceramic fragments (along with other trash) have been used in gardens for centuries to loosen up sediments that are heavy with clay (Currey and Locock 1991, Hume 1974, Loudon 1824). It is not indicated in contemporary documents whether this technique was employed at Fort Vancouver. A total of 311 ceramic fragments, or 29 fragments per $\mathrm{m}^{3}$, of several types were found. A total of 143 fragments (46\%) were found in the sheet trash deposit in TA2.

9 fragments of terra cotta were found in TA2-5, Levels 6 and 7, north of the sheet trash deposit. Terra cotta has been used for potting plants (among other uses) for thousands of years. A review of Ross (1976) found no other fragments of terra cotta found at the site, 
nor any mention of terra cotta pots being imported by the HBC. It is most likely that any pots utilized were "country made," perhaps fashioned of wood.

Two fragments of salt-glazed stoneware were found. These fragments are from utilitarian vessels, kiln-fired at a temperature that makes the ceramic impervious to liquids, so the vessels do not require a glaze. Salt added to the kiln during firing creates a soda-glass coating on the outside of the vessel.

The majority of the earthenware found was undecorated whiteware $(68 \%), 25 \%$ of the earthenware was transferprint, a significant majority of it (92\%) blue (Figure 27). Very few of the fragments were large enough to allow the identification of pattern. Those patterns identified - willow, dating from the 1780 s to the 20 th century and lily, ca. 1827 to the 20th century (Sussman 1979:138, 235), were available within the 1825-1860 HBC occupation period at the site.

A total of 31 fragments of porcelain

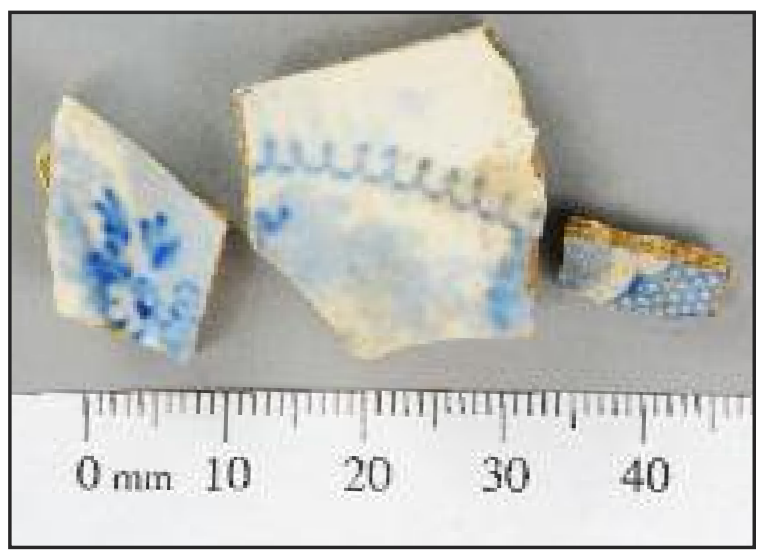

Figure 27. Blue transferprint fragments. Photo courtesy of the National Park Service.

was found, $87 \%$ of them were white undecorated fragments. Three of the fragments were Chinese handpainted porcelain. One of the Chinese fragments (Figure 28) appears to be the rim of a flower pot (Lot 482, Spec 5). Another of the Chinese porcelain fragments has an orange handpainted scalloped pattern on the rim. This pattern was evident on a bowl found by Louis Caywood at Fort Vancouver,

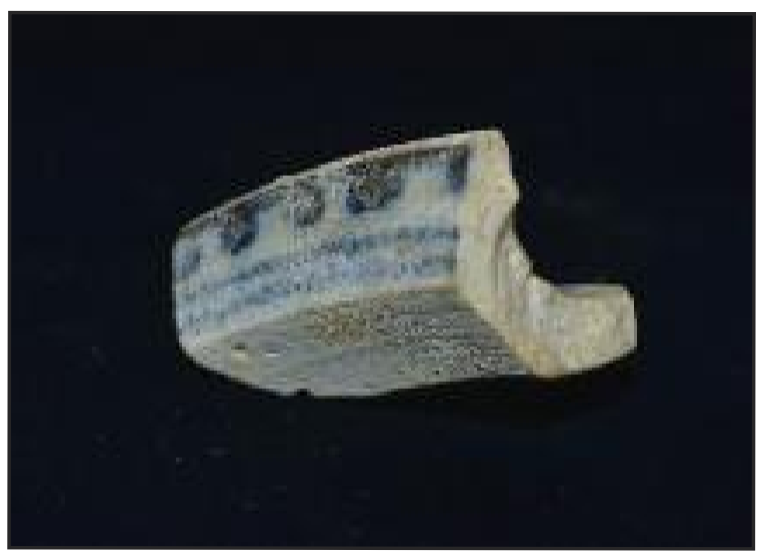

Figure 28. Chinese handpainted porcelain fragment, possibly the rim of a flower pot, Nanking pattern. Photo courtesy of the National Park Service. 
although the provenience within the site is unknown. This particular pattern comprised 11\% of the ceramic assemblage at Fort Spokane, near now Spokane, Washington, a North West Company/HBC post in the Columbia Department (Cromwell 2006:11). Cromwell hypothesizes that these ceramics were initially imported by the North West Company, a Canadian fur-trade company, as the British Oriental trade was monopolized by the British East India Company, precluding the Hudson's Bay Company from trading with the Orient.

Vessel Glass

A total of 348 fragments of vessel glass were found. 54\% of the total was found in TA2, $55 \%$ of those, or $25 \%$ of the total, were found in the sheet trash deposit. $41 \%$ of the total $(n=401)$ was found in TA1. $95 \%$ of the total was found in these two excavation trenches, on the southern edge of the Garden, indicating little activity in the remainder of the Garden.

\section{Architecture Functional Classification}

\section{Brick}

Thirty percent of the total of 74 brick fragments found were in TA1-13, on the western end of the trench, in the hypothesized location of a Garden structure. Ten fragments $(7.4 \%)$ of the total found were identified as English brick, while $41 \%(n=30)$ were identified as American in origin.

Coal, Coke, Clinker, Slag

A total of 893 fragments of coal, coke, clinker and slag were found, $40 \%$ of them in the TA2 sheet trash deposit. These are included in the architectural functional classification, (as fixed heating), but may represent blacksmithing activities. 
Flat Glass

Flat glass thickness was analyzed after

Table 3. Primary modes of flat glass thickness and corresponding thickness Roenke (1978), who observed that window (Roenke 1978)

glass increased in thickness over time. This method is often used to date cultural deposits, and/or to determine relative dating of events. Flat glass was also used in mirrors, lamps and lanterns, however, only 4 fragments of flat glass were identifiable as mirror glass, while the remainder is assumed to be window glass.

\begin{tabular}{|c|c|}
\hline Primary Modes (in.) & Dates (ca.) \\
\hline 0.045 & $1830-1840$ \\
\hline 0.055 & $1835-1845$ \\
\hline 0.065 & $1845-1855$ \\
\hline 0.075 & $1850-1865$ \\
\hline 0.085 & $1855-1885$ \\
\hline 0.095 & $1870-1900$ \\
\hline 0.105 & $1900-1915$ \\
\hline
\end{tabular}

Table 3 shows the primary modes of glass thickness and their corresponding dates.

Analysis of the thickness of flat glass fragments from Strat V (HBC deposits) in TA1 and TA2 resulted in a thickness mode of 0.054 inches, dating to roughly 1835-1845. Flat glass from Strata VI through VIII dated to 1830-1840. These two thickness modes are consistent with the HBC period. Flat glass quantities were insignificant in $\mathrm{HBC}$ deposits in TA7 $(n=6)$ and TA8 $(n=21)$ and were not included in this analysis.

A total of 504 flat glass fragments were found. A total of 193 fragments, or 38\% was found in TA1, the possible location of a structure, while 219 fragments, or $43 \%$ were found in TA2, 101 fragments, or $20 \%$ of the total, in the sheet trash deposit.

Nails

A total of 127 wire nails was found within the HBC deposits at the Garden site. Twenty of these $(16 \%)$ were found in TA1, and $65 \%(n=82)$ were found in TA2. It is possible that the presence of an early 20th century gravel road over portions of TA2 caused objects from later occupations to be mixed with the HBC deposits.

A total of 147 square nails was found. Units at TA2 contained 64 square nails, or 
$44 \%$ of the total found. Units at TA1 contained 40 square nails, or $27 \%$ of the total found. Very few of the nails were identifiable to type. A total of 27 of the nails was machine-cut.

\section{Wood/Charcoal}

A total of 1,142 fragments of wood/charcoal were found, 505 fragments or $44 \%$ in units in TA1. A significant portion of the fragments from TA1 were related to early 20th century features (french drains, Features 505, 512; and the early 20th century dry well, Feature 507), which intruded into HBC deposits.

\section{Commerce and Industry Functional Classification}

This class of artifacts includes agricultural items: horseshoe nails $(\mathrm{n}=11)$, barb wire $(n=3)$, muleshoe $(n=1)$, crushed rock $(n=41)$, a fragment of garden hose (see below) macrobotanicals (see Archaeobotanical Remains below); Hunting items: lead shot (n=3), clay pigeon fragment $(n=1)$; Medical items: glass syringe head $(n=1)$, and a glass rod $(n=1)$. All of these items were found in such low quantities that supported inferences are not possible, although see Glass Syringe Head below.

\section{Garden Hose}

A rubber hose fragment, $16.7 \mathrm{~cm}$ in length, was found within HBC deposits in TA2-18 (Figure 29). The fragment is very heavy $(118 \mathrm{~g})$ and may have sunk down into earlier deposits from a later occupation, perhaps due to trampling during the wet season. There is a pattern of reinforcing (or waterproofing) material underneath the

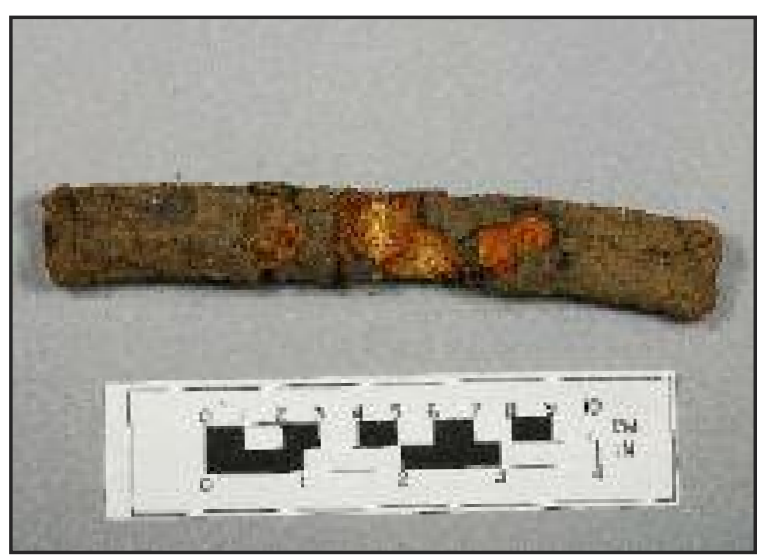

Figure 29. Rubber hose fragment. Photo courtesy of the National Park Service. 
rubber. As the rubber vulcanization process was not patented until 1844 (Bellis 2012), it is not likely that this hose, with it's vulcanized rubber and machine-manufactured lining material, is from the HBC period.

Glass Syringe Head

This end-fitting from a glass medical syringe was found in TA2 (Figure 30). A dispensary is hypothesized to have been located on the east wall of the 1829-1834 stockade (Erigero 1992:Map 2). A later dispensary was located in the southeast corner of that stockade, and after the stockade had doubled in size (to the

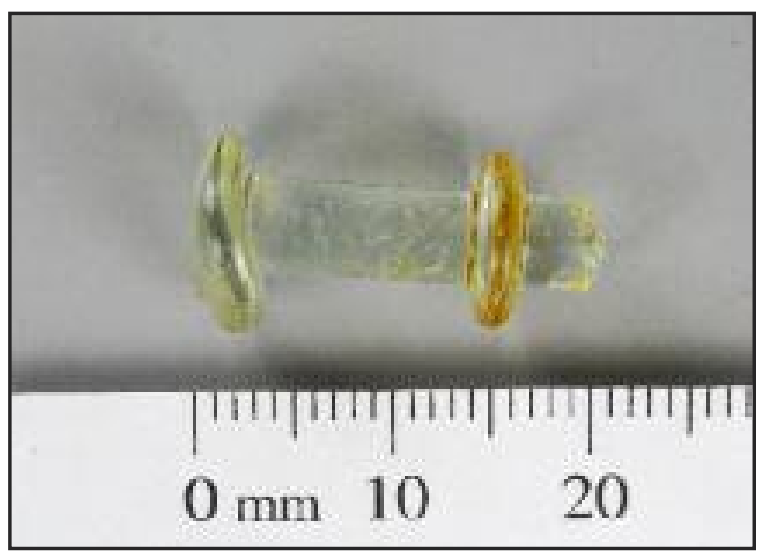

Figure 30. End fitting from a glass medical syringe. Photo courtesy of the National Park Service. east), the dispensary was located on the south wall, near the east corner (Erigero 1992:Map 3). No other identifiable fragments of medical equipment were found during the Garden excavations.

A total of 5 metal fasteners, (washers, screws, nuts and bolts), representing Industry, were found, the majority manufactured by machine. The low quantities of this type indicate that these artifacts likely fell from the wall of the deposits above, or were displaced by bioturbation.

\section{Group Services Functional Classification}

This class of artifacts includes Transportation items: asphalt $(\mathrm{n}=8)$, railroad spikes $(n=3)$; and Education: graphite $(n=1)$. These artifact quantities are so low that supported inferences are not possible. 


\section{Pre-Contact Functional Classification}

Lithics

Evidence of lithic tools and tool-making is found regularly at Fort Vancouver National Historic Site, although not in great quantities. One projectile point fragment was found within the HBC deposits, in unit TA2-17. The point is made from black chert, and measures $7.93 \mathrm{~mm}$ long, $9.3 \mathrm{~mm}$ wide, and $2.68 \mathrm{~mm}$ thick. It is broken at the tip, base and shoulder and has not been identified to type. There is no evidence of heat-treating.

One rusty-brown chert, edge-modified flake (26.54 mm long, $11.18 \mathrm{~mm}$ wide, 6.65 mm thick) was found in TA2-13, in HBC deposits. Also, three fragments of chert debitage were found, one each in TA1, TA2 and TA8, also in HBC deposits. These fragments were small, with a maximum platform thickness of $1.77 \mathrm{~mm}$. There is no heat treating or cortex evident on any of the flakes.

Artifacts by Functional Classification

Table 4 provides a comparison of artifacts by functional classification (Sprague 1981). The figures in the table are raw counts, showing relative artifact distribution comparisons within a test area, not comparing one test area to another. TA1 is dominated by architectural artifacts, primarily coal, coke, clinker, slag (Fixed Heating), and window glass, with some brick fragments. Domestic artifact quantities, largely vessel glass, are also significant. TA2 also contained significant quantities of architectural artifacts window glass and square nails. Domestic artifact quantities were high, however the dominant type was ceramics rather than vessel glass as in TA1. Nearly all of the personal artifacts were found in TA2. These primarily consisted of beads, alcohol bottle fragments and tobacco pipe fragments. Both TA7 and TA8 had relatively high quantities of architectural artifacts, with TA8 also having relatively high quantities of domestic artifacts (ceramics and vessel glass). 
Table 4. HBC Artifacts by Functional Classification

\begin{tabular}{lcccccc}
\hline Functional Class & TA1 & TA2 & TA7 & TA8 & Total & $\%$ \\
\hline Personal & 26 & 299 & 1 & 7 & 333 & 10 \\
\hline Domestic & 285 & 315 & 13 & 34 & 647 & 19 \\
\hline Architecture $^{1}$ & 503 & 815 & 28 & 35 & 1381 & 41 \\
\hline Commerce and Industry $_{\text {Manufacturing }}$ & 68 & 8 & 4 & 2 & 82 & 2 \\
\hline Commercial Services & 1 & 0 & 0 & 0 & 1 & $<1$ \\
\hline Group Services & 0 & 1 & 0 & 0 & 1 & $<1$ \\
\hline Education & 3 & 7 & 0 & 0 & 10 & $<1$ \\
\hline Manuport & 1 & 0 & 0 & 0 & 1 & $<1$ \\
\hline Pre-Contact $^{\text {Mnknown }}{ }^{2}$ & 0 & 1 & 0 & 1 & 2 & $<1$ \\
\hline Untal $_{\text {To }}$ & 1 & 2 & 0 & 1 & 4 & $<1$ \\
\hline
\end{tabular}

1 includes coal, coke, clinker and slag as "Fixed Heating." However, the presence of a blacksmith shop on-site during the HBC period may have affected these results.

2 the high counts in the "Unknown" class represent wood and charcoal fragments. The majority of the wood and charcoal fragments from TA1 and TA7 are most likely from later-period features which intruded into the Strat V deposits, therefore the inclusion of wood and charcoal in statistics relating to HBC activities is not valid.

\section{ARCHAEOBOTANICAL REMAINS}

The importance of paleobotanical analysis in landscape archaeology cannot be overly stressed. Deborah Pearsall, in Paleoethnobotany, states that, "[P]Pollen and phytolith data [are] central for (but not restricted to) investigating human-landscape interrelationships (2000: 352). In garden archaeology, these analyses can provide information pertaining to: (a) the configuration of a garden (e.g., shapes and orientation of paths or planting beds), (b) the location of a garden surface within sediments, (c) the types of plants grown in the garden, (d) soil enhancement methods, and (e) changes to the above mentioned aspects over time.

The field sampling procedures developed for this investigation were adapted from Pearsall's Paleoethnobotany (2000). Excavators took sediment samples during both 2005 and 2006. 


\section{PHYTOLITH ANALYSIS}

The phytolith record was dominated by cool season native grasses (Appendices B and C). Only minimal amounts of Cerealia (wheat, rye, oats, barley) were found. Quantities of Cerealia remained constant throughout the samples, including the culturally sterile sample. This culturally sterile sample was included in a column of samples, representing a time span from prehistoric deposits to the modern surface. The presence of Cerealia in the culturally sterile sample may indicate contamination, or bioturbation. The analysis of the column sample shows evidence of fires (microscopic charcoal fragments) at the site during the culturally sterile (prehistoric) period. Charcoal decreased in samples from the HBC period and later, while phytolith levels are similar to the culturally sterile sample. The conclusion is that the phytolith levels at the site, over time, are typical of a meadow of native grasses, with little change from the prehistoric period to today.

\section{POLLEN ANALYSIS}

While pollen studies are often conducted to understand environmental changes over time (Miller and Gleason 1994; Pearsall 2000; Weber 1996), the short duration of the HBC occupation precludes using these studies in this manner, at least in terms of introduced garden plants. This study focuses on the presence or absence of introduced (non-native) plant pollens; the identification of plants, both introduced and native; and the spatial distribution of various species, which can be determined when focusing on insect-pollinated plants. Therefore all samples tested were included in the results, rather than limiting the study to those samples that contained enough pollen grains for environmental reconstruction.

Analysis of pollen grains found in HBC sediment samples collected during Garden excavations confirmed the presence of many plants previously noted in historical documents (Taylor 1992:Appendices B, D, E). The cultural sterile sediments from the column sample 
(Lots 545 and 546) contained only one introduced plant, Cerealia (Appendices E and F), which the analyst attributed to contamination. Lot 546, from the same provenience as Lot 545, but sent to a different analyst (Appendix D), did not contain Cerealia, possibly confirming the contamination conclusion. The lack of introduced plants in the cultural sterile level confirms that these plants are associated with the HBC occupation.

Table 5 lists garden plants for which pollen grains were found that were NOT previously known to have been grown at Fort Vancouver. The newly-discovered plants are a mix of ornamentals and herbal remedies, with several also providing fruit, nuts, vegetables and spices. There are also two arboreal species (elm and hickory) whose primary uses were as ornamentals and to provide firewood and/or hardwoods. The pollen analysis also indicates several native plants either growing in the garden, or nearby as background vegetation. Several

Table 5. Introduced plants not previously known to have been grown at Fort Vancouver from historical documents, based on pollen analysis of Garden excavation sediments

$\begin{array}{lll}\text { Common Name } \quad \text { Family Name } & \text { Non-Food Uses } & \begin{array}{l}\text { Plant Element } \\ \text { for Food Use }\end{array}\end{array}$

\begin{tabular}{llll}
\hline Aster* & Asteraceae & Ornamental & \\
\hline Barberry & Berberidaceae & Ornamental & Berry \\
\hline Chamomile & Asteraceae & Herbal & Pollen \\
\hline Crocus & Iridaceae & Ornamental & \\
\hline Daphne & Thymelaeaceae & Ornamental & Nut \\
\hline Elm & Ulmaceae & Ornamental, Wood & Leaves \\
\hline Hickory & Juglandaceae & Wood & Flower \\
\hline Horehound & Lamiaceae & Herbal & Leaves \\
\hline Marigold & Asteraceae & Ornamental & \\
\hline Pinks** & Caryophyllaceae & Ornamental & Flowers, Leaves \\
\hline Tansy & Asteraceae & Insecticide & \\
\hline Tobacco & Solanaceae & Recreation, Insecticide & \\
\hline Viola & Violaceae & Ornamental, Herbal & \\
\hline Zinnia & Asteraceae & Ornamental & \\
$*$ Aster is native to western North America, however no aster pollen was found in the culturally sterile sample \\
$*$ Carnation, Dianthus, Sweet William & &
\end{tabular}


of these plants have known uses as ornamentals, herbals, or provide nutrition (Table 6).

The pollen analysis, similar to the phytolith analysis, further indicates that there was an abundance of weedy taxa growing on the site throughout time (Appendix F:47). It is also interesting that pollen from the family Rosaceae, which includes many of the fruit trees mentioned in historical documents as being grown at Fort Vancouver (Hussey [197?]), almonds, roses, and several other ornamental plants, is only very minimally found in the samples in terms of quantity, but is found in $38 \%$ of the HBC-period samples.

Table 6. Native plants with economic uses growing in the garden, or nearby

\begin{tabular}{llll}
\hline Common Name & Genus Name & Non-Food Uses & $\begin{array}{l}\text { Plant Element } \\
\text { for Food Use }\end{array}$ \\
\hline Poplar & Populus & Ornamental, Wood & \\
\hline Blueberry, Cranberry & Vaccinium & & Berries \\
\hline Yarrow & Achillea & Ornamental, Herbal & Leaves \\
\hline Hops & Humulus & & Flowers \\
\hline Currants & Ribes & Herbal & Berries \\
\hline Sunflower or & Helianthus & Ornamental & Nuts, Roots \\
Jerusalem Artichoke & & & \\
\hline Ragwort & Senecio & Herbal & \\
\hline Goldenrod & Solidago & Herbal & \\
\hline
\end{tabular}

Because garden plants are generally insect-pollinated (having relatively heavy pollen grains), rather than wind-pollinated (such as grasses and cereal crops), it is possible to develop inferences on the general vicinity within which a plant was growing through a spatial distribution analysis of the presence, or absence, of pollen grains (Moynihan 2000; Jacobucci 2007). Figures 31 through 34 show the spatial distribution of the pollen found during Garden excavations from several garden plants (as an example of this analysis). Gray shaded areas indicate that a sediment sample for pollen analysis was taken at that location, but that pollen from that particular plant was not found in the sample. Only results from TA1, TA2 and TA 8 were included in this analysis as the remainder of the Test Areas were 


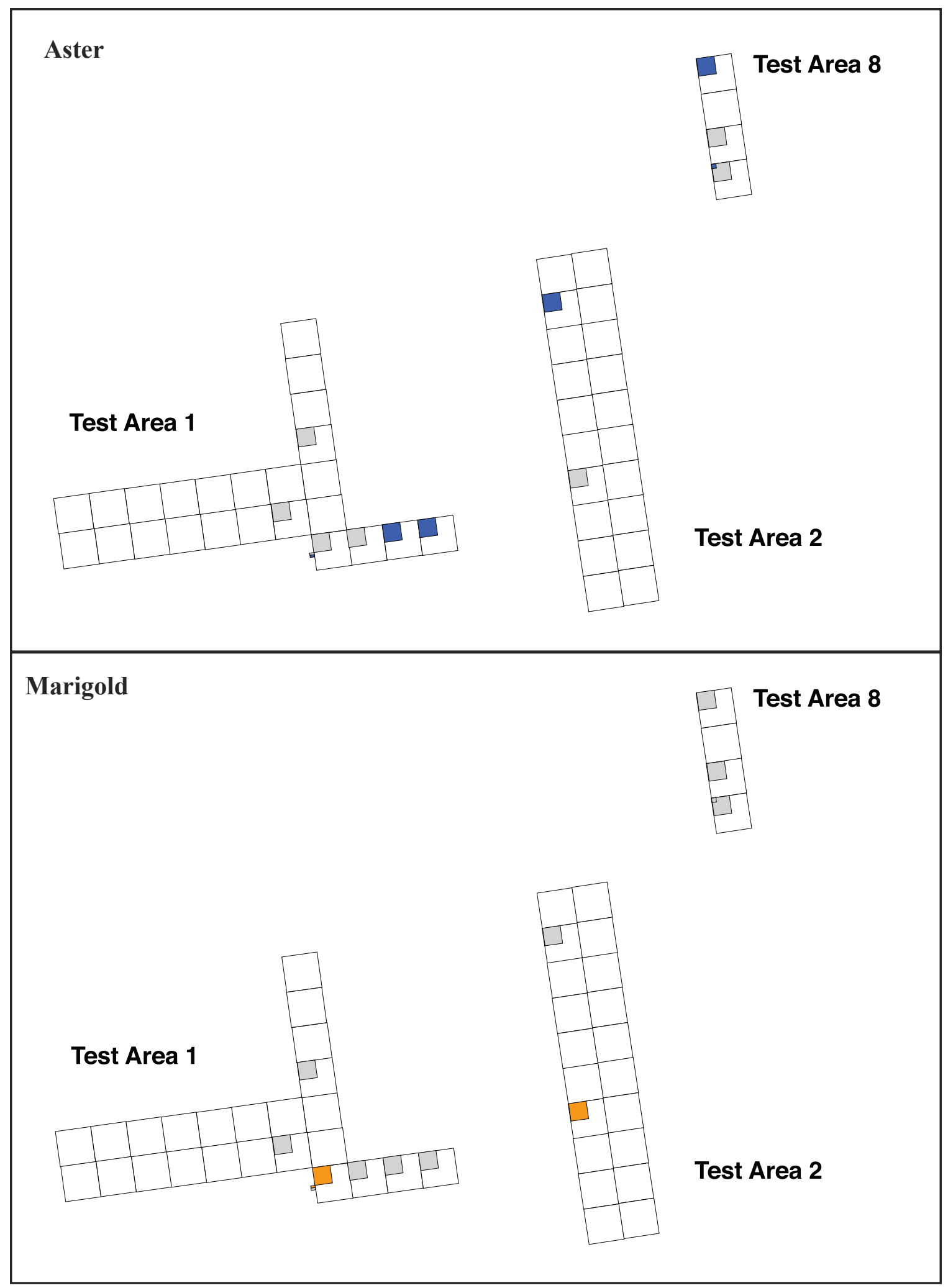

Figure 31. Spatial distribution of aster and marigold pollen found in HBC deposits. Test Areas are not in true spatial relationship to each other. 


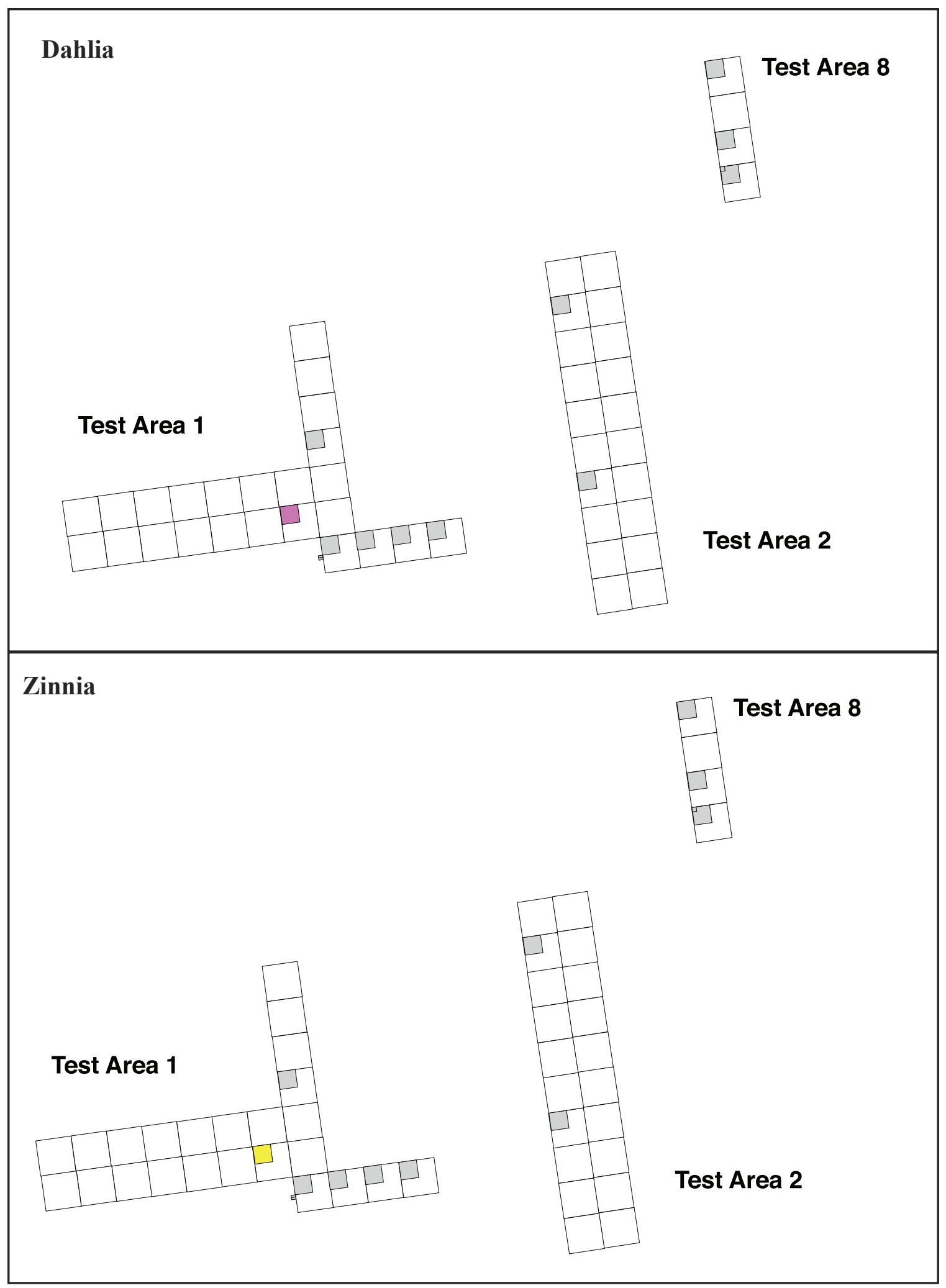

Figure 32. Spatial distribution of dahlia and zinnia pollen found in HBC deposits. Test Areas are not in true spatial relationship to each other. 


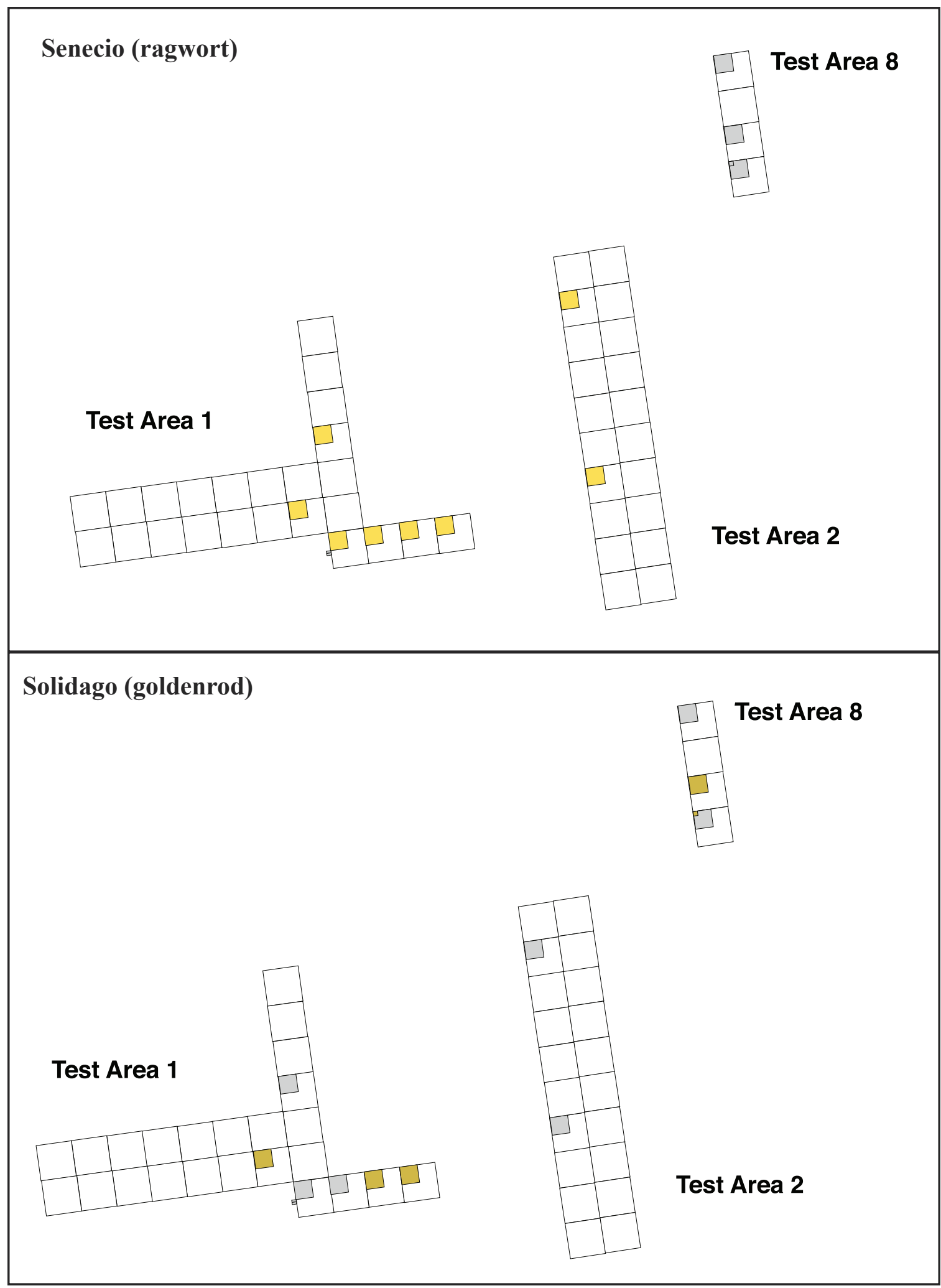

Figure 33. Spatial distribution of senecio and solidago pollen found in HBC deposits. Test Areas are not in true spatial relationship to each other. 


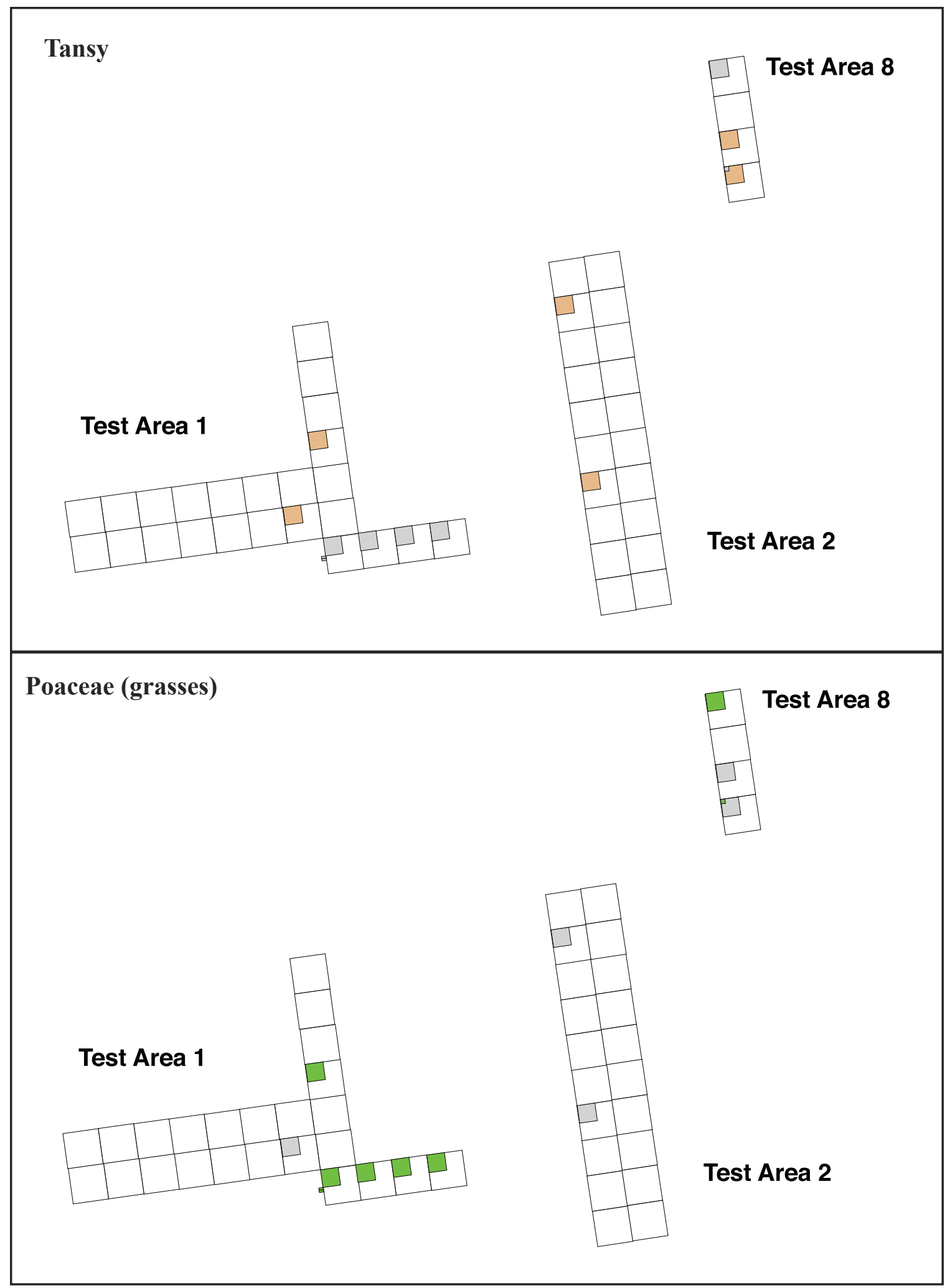

Figure 34. Spatial distribution of tansy and poaceae pollen found in HBC deposits. Test Areas are not in true spatial relationship to each other. 
disturbed or questionable. The sediment sample taken from Feature 607 in TA 4-1, which was questionable for a HBC feature, contained no definitively introduced plants.

The spatial distribution analysis of these selected plants indicates several locations where the plants would have been growing. Of note: dahlia pollen was found in only one provenience, unit TA1-11 (see Figure 18 for unit designations), but comprised a significant portion $(6.30 \%)$ of the pollen in the sample, second only in quantity to a likely native Ligulaflorae (possibly dandelion); zinnia, although also found in TA8, comprised 5\% of the same sample as dahlia from TA1-11; Senecio and Solidago, possibly weedy taxa but with economic uses, are heavily present in TA1, but were also flowering near introduced plants; Poaceae (grasses) are nearly non-existent (less than $4 \%$ of the total counted pollen) other than in TA1. Further, in reference to the pollen found in the samples from TA1, (Figures 31 through 34), all of the above taxa are present in that location. Actually, of the introduced plant pollens found during this project $(n=26), 96 \%$ percent of them were found to be present at TA1. Crocus was the only introduced plant not present at TA1. When the pollen from native plants with economic uses $(n=8)$ is added to the total, the percentage of plants that were likely intentionally planted in the Garden that have left evidence of their presence at TA1 is $97 \%$.

\section{Inconsistencies of Results}

Sediment samples from the column sample (Lots 533 through 546) were sent to two different independent labs for pollen analysis. Sidement from the column sample were initially sent for analysis in 2006 (Appendix E). The report that was generated from the pollen analysis of these samples was inadequate in its content, so sediments from the column sample were included in those sent for pollen analysis later in 2006, to a second independent lab (Appendix F). The results from the two analyses on the column sample sediments are inconsistent. The only introduced plants identified within the sediment samples from the 
HBC proveniences (Lots 541 and 543) by the first lab were Cerealia and red clover. The second lab identified, in sediments from the same proveniences (Lots 542 and 544) both Cerealia and red clover, plus citrus, mulberry, Rosaceae (fruit trees, roses, many herbs and shrubs - this pollen could represent native plants rather than introduced), aster (not present in the culturally sterile samples, so assumed to be introduced), marigold, daphne, horehound, maize, zinnia, and several additional plant families and genus' that represent either introduced plants that are noted in historical documents, or native plants.

A review of the sample preparation process for each lab shows similarities in the chemicals used to separate the pollen grains from the sediments, but the technique descriptions are so significantly summarized that comparison is difficult for a non-analyst. The first lab provided no information on percentages of unidentified pollen in the samples, and the second lab used a much wider range of comparative collection resources. Therefore, inferences in this thesis related to pollen are limited to the data generated from the analysis conducted by the second lab. The identification of crocus in Feature 621, the post found in TA8, was provided by the first lab, the second lab did not receive this provenience for analysis.

Non-Garden Pollen Analysis

Sediment samples from several proveniences that were likely to be non-garden were collected and sent for pollen analysis (Appendix E) to provide comparison to samples taken from the HBC Garden site. These proveniences are located north of the Fort Vancouver National Historic Site Visitor's Center, on the north side of the driveway in front of the building, approximately 516m from the HBC Garden. Historical documents indicate this was a cultivated field during the HBC period (Hussey [197?]:108), and the U.S. Army Parade Ground from 1849 to 1948, when the National Park Service took over management of the historic site. All samples provided $(n=6)$ contained enough pollen to be used for 
environmental reconstruction (Appendix G:244). The results from pollen analysis of the $\mathrm{HBC}$ deposits indicate a period of intense land use defined by a decrease in arboreal pollen and increase of pollen from invader species. A minor amount of Cerealia and Trifolium (red clover) pollen was recovered, supporting contemporary statements of an agricultural field in the vicinity. However, these samples were inconsistent with samples tested from the Garden excavations in that only minute evidence of other introduced plants were found within the sediments, and arboreal pollen counts were much higher, indicating trees within close proximity and growing densely. Introduced plants found within what are inferred to be the HBC-period sediments (Samples 2 through 4) were Fabaceae (acacia), Moraceae (mulberry, fig), Calendula (marigold), Daphne, and possibly Lysimachia (loosestrife).

\section{MACROBOTANICAL ANALYSIS}

A total of 34 samples of macrobotanical remains picked from wet-screened matrix were sent to an independent lab for analysis. The samples contained the following economical plants: cf.* Ficus carica (fig), Rubus sp. (blackberry/raspberry), and Sambucus sp. (elderberry), as noted in Appendix H. The remains were uncarbonized, possibly indicating that they are of modern origin. However, as the HBC period is fairly recent (early-to-mid-19th century), it is possible that the remains have not yet decomposed. The charcoal within the samples was too small for definitive identification. It is stated in the report that plant preservation at the site appears to be poor.

In summary, the spatial distribution of artifacts found during this project indicates a high-activity area in TA1, and a sheet trash deposit in TA2. However, no consistent distribution of artifacts as related to differential use of paths and beds was present. Very few artifacts were found that could be applied to questions of gender, ethnicity, age, number of garden laborers, or specific garden activities. Still, artifacts found within HBC deposits,

* In this document, this abbreviation represents a less than definitive identification. 
in the known Garden, do represent some form of activity on that landscape. Sprague's artifact classification system was applied, which indicated concentrations of architectural artifacts in both TA1 and TA2. Nearly all of the personal artifacts were found in TA2, reinforcing the inference of a trash deposit in this location.

The analysis of microartifacts (pollen, phytolith and macrobotanical) provided the only archaeological evidence that there had been a Garden in this space during the HBC period. These analyses also provided valuable information on both introduced and native plants grown in the Garden, and the locations of those plants. Phytolith analysis provided evidence for inferences made relating to the Garden paths being surfaced with grass, most likely native meadow grasses. 


\section{CHAPTER 8. Discussion}

This chapter summarizes the results of these historical, and archaeological investigations at the HBC Garden site.

\section{THEORETICAL CONCEPTS: A GARDEN AS POWER}

The HBC Garden at Fort Vancouver represented a piece of the homeland. Narcissa Whitman has left us the most detailed historical description. Upon being invited by Dr. McLoughlin for a walk in the garden, she commented on the many varieties of fruit, "apples, peaches, grapes, and pear, plum and fig trees. Cucumbers, melons, beans, peas, beats, cabbage, taumatoes and every kind of vegitable" (Whitman 1836:50). She noted that the beds and walks were "tastefully arranged" and "lined with strawberry vines" and "a good Summer house covered with grape vines" (Whitman 1836:50).

Based on the results of the archival research (Chapter 2), it seems clear that Dr. McLoughlin, who is noted to be on possession of the Garden in several historical documents (Erigero 1992), intended the Garden to be as close a representation of the British aesthetic as possible, with the implied imperialistic symbolism that would accompany its presence. Wide paths would imply that the HBC had plenty of real estate at its disposal and found value in visually-pleasing creations. The Italianate layout of the garden connects the imperialistic dominator to the classical civilization of Rome, a common theme in European hierarchical culture. Imported cultivars would indicate a significant level of control over the environment, worldwide connections, and again, value in the aesthetic. The well-maintained Garden also provided a contrast between it and the rugged natural terrain, civilizing the environment. The produce from the Garden was, on the one hand, limited to the gentlemen's table (Hussey, [197?]:40), therefore the presence of the Garden reinforced the hierarchical system, both within the company, and in relationship to the "others." On 
the other hand, the Garden had its practical purposes.

The HBC Garden at Fort Vancouver represented much more than home-grown victuals and sublime strolls on a summer evening. The Garden's style was representative of emerging European fashion. The Garden was also used experimentally, in keeping with colonial focus, gathering information on the suitability of various plants to a particular environment and testing methods with which to manipulate that environment. The fruit trees grown in the Garden and Orchard represent the first successful foray into this industry in the Pacific Northwest, literally providing the seeds for what has become a significant segment of the current economy in the region. It is probable that many of the plants grown were used for medicinal purposes, contributing to the wellness of the inhabitants. The Garden also provided employment to indigenous peoples whose economic lifeways had been disrupted by the European presence, both by disease and through a desire for trade goods.

With the rise of the middle class at the turn of the nineteenth century, and the accompanying domestic modes and cultural aesthetics as aspects of British nationhood, (and therefore British imperialism), formal gardens contained a myriad of symbolic meanings, both to the dominating society and the "other." The Hudson's Bay Company, while primarily a for-profit institution, was charged with the responsibility of holding millions of acres of land in North America for the British crown, and repeatedly employed imperialistic and colonial ideology to do so. The HBC Garden was, among many other things, a tool brought into play to serve the United Kingdom in its quest to alter the world to its own image.

Concepts such as these were used to understand the purpose of characteristics of colonial-period gardens in Annapolis, Maryland, primarily focusing on William Paca's Garden. Batty Langley, in the publication New Principles of Gardening, written in 1726 and cited by Leone (2005), states that cities were usually designed "according to baroque principles..." using "avenues, facades, focal points, and lines of sight," employing 
perspective and optical illusion. These principles applied to gardens also. At Fort Vancouver, it seems that perhaps the wide paths as "avenues" and the "focal point" of the Summer house in the distance from the southern end of the garden, near the stockade, would adhere to these concepts, but optical illusion does not seem to have been a factor as much as simply delineating the transition from civilized to wild with the Summer house as the boundary. Leone (2005) also states that formal landscapes "were intended to illustrate the principles of optics, hydrology, the engineering of slopes, the heat and light supplies needed by plants, and, of course, the variety of plant life." However, these aspects noted by Leone as indicative of representations of power in a garden are notably absent in the HBC Garden. There is no hard landscaping (bed borders, water features, irrigation, etc.), no surfaced paths, no terracing with which to create illusion that would cause visitors to pause and wonder just how far away the Summer house was (Leone 2005:64). Leone (2005:67) also argues that these gardens (William Paca's garden in Annapolis in particular) were "about power, not plants," after Althusser, who hypothesized that "ideology hid the origin of exploitative relationships, and that it was material." Leone (2005:67) applies this concept by stating that the Paca Garden layout (which employed hard landscaping and terraces to achieve the optical illusion of a larger garden than was actually there), "was built to naturalize the conflict between slaveholding, [and] diminishing power. Paca was moderately wealthy and apparently quite concerned about protecting what he had. The illusion of the size of his garden provided visitors with a sense of greater importance than Paca knew to be true.

While it has been said by many scholars of the HBC that it exploited both its employees and the indigenous people, it does not appear that the Garden at Fort Vancouver was used as a representation of power perceived in the way that Paca and other colonials in the eastern United States did. For centuries the HBC had a clear concept of the power they held over these people. It is true, however, that by the mid-19th century the company's power over individuals, particularly in the Pacific Northwest as it became inundated with 
independent Americans, was beginning to wane (Merk 1968). It may be that the oversized Garden of 1844, about 8 acres (Peers 1844), is related to hanging onto, or reinforcing, a perception of power that was actually slipping out of the Company's hands.

More convincing though, is the contrast between the long-standing policies of the $\mathrm{HBC}$ relating to the unequal access to food at the various hierarchical levels of the Company (Hamilton 2000), and the difficulty of maintaining a level of control in this regard in a region where food was abundant and easily obtained by means other than through the Company. Loudon (1824) indicates that vegetables appropriate for the lower class are "cabbages... hardy borecoles... early potatoes... [and] parsneps [sic]." The Garden was a persistent reminder that exotic foods from around the world were still not available to certain classes of employees, nor to the local inhabitants. As time passed and Fort Vancouver became a significant point of import and export, there were also other reasons, much more pragmatic, for the size of the Garden.

George Simpson made it quite clear that not just officers of the Company, their families, visitors of sufficient status, and ship's officers were realizing the bounty of the Garden. He states that ordinary seamen had "the run of the gardens," also commenting that a group of boys training on one of the ships had access to the Garden's produce (Merk 1968:310). These statements illustrate the particular circumstances at Fort Vancouver as compared to other HBC posts. Ships were constantly coming and going at this very busy hub of regional activity. The cargoes they carried were the lifeblood of the Company. The greater success the Company had at getting these ships to and from their destinations, the greater the profit.

Medical science at this time was beginning to understand, particularly in the case of living on board ship for long periods of time, that access to fresh fruits and vegetables greatly enhanced the physical condition of the crew. The citrus trees grown at Fort Vancouver were not just for afternoon lemonade. It had been known for over two centuries 
that citrus fruit was a treatment for scurvy (Bown 2003b:89), a degenerative disease that was common on board ship, but it had only been lazily applied to the problem. By the 19th century the connection had become quite clear, if not the exact cause - a deficiency of Vitamin C (Bown 2003a).

While the size and Italianate layout of the Garden undoubtedly represented home, inequality, a focus on the domestic, and a separation from the "other," it is also valid that, typical of Dr. McLoughlin's streamlined style of business and life (Erigero, 1992; Morrison 1999), that the Garden had its practical connotations. Loudon (1824) states that a 1 acre kitchen garden will feed 16 people. The 40 or so elites living inside the fort would require two and a half acres of kitchen garden. The remaining 5+ acres were likely to supply the ships' crews, and for ostentatious display. In other words, the Garden landscape was about profit and status.

\section{ARCHIVAL DOCUMENT RESEARCH}

As there is no documentation relating to the size and layout of the Garden previous to 1844 , overlaying the location of the 1829 to $1834-36$ stockade onto the Line of Fire map (Peers 1844) provides some validity to speculation (Figure 18). As it was common for the HBC to employ a symmetrical, hierarchical arrangement of buildings within a stockade (Hamilton 2000; Monks 1992), which is based on medieval hierarchical concepts, just as with a geometric Italianate-style garden, locations of elements that are not in evidence can be extrapolated. Based on these concepts, it has been hypothesized that the original Chief Factor's House, in the early, square stockade, was located across the stockade from the main (south) entrance to the Fort, in the location representing governance and power. As is shown in Figure 8, this places the hypothesized northwest gate (see Excavation discussion below) in the center of the north stockade wall, behind the Chief Factor's House, while the garden is symmetrically placed behind the stockade. However, Henry Spalding noted the Garden 
was about 5 acres in size in 1838 (Erigero 1992:127). As Narcissa Whitman saw the Summer house, on the northern end of the Garden in 1836, if the Garden was only 5 acres about that time, the portions of the Garden that extend to the east and west past the dimensions of the stockade may not have existed at the time of the original stockade.

Although there are illustrations from a later period (1840s and 1850s) that indicate structures such as cold (glass) frames, and possibly greenhouses and a garden shed within the areas of the Garden that were tested during this project (Figures 3 through 6), no definitive evidence of these structures was found. This can probably be attributed to disturbance from U.S. Army activities, post-HBC, encountered during this project, and/or the need for more excavated units in those areas.

The presence of certain plants in the Garden would confirm the presence of protective structures. Historical documents provide information on what seeds were delivered to Fort Vancouver, and observations of visitors on what was growing in the Garden. Several of the plants (such as citrus) would have required protection in this environment. These archival sources also show that the primary focus was food plants vegetables and fruits, and a few herbs. There is little archival evidence of specific flowers, but several comments stating that many flowers of different types were growing in the Garden. The composition of different types of plants know from the archival sources enforces the notion that the Garden's purpose was first to provide nutrition, although the fact that the food plants were not native to this region, and their compatibility with this environment was unknown, speaks to the scientific.

\section{FINDING A HIDDEN GARDEN}

The lack of garden archaeology projects in the Pacific Northwest prompted a wide-ranging search for information on any similar garden projects, even as far away as India. The one project from the Pacific Northwest, English Camp, San Juan Island National 
Historical Park, involved several types of remote sensing and surface stripping, similar to that done on colonial sites in the eastern U. S., but unfortunately there was no garden to be found. Remote sensing (GPR) was also used at the Petra, Jordan water gardens. The success of this technique at this site was attributed to the structural features and a lack of later disturbance and alteration. Resistivity and magnetometry were successfully used at the sites in Britain that were reviewed, even identifying the remains of serpentine-shaped flower beds hidden under later landscaping. Bell's 2005 GPR testing at the HBC Garden was also somewhat successful. The testing done at the "well" did indeed reflect the basic characteristics of the feature that was ultimately excavated, and, although it has not been excavated yet, the GPR anomalies found in the location of the Summer house appear to also be representative of that type and size of structure. Aerial survey was also valuable at several sites due to the size of landscape features. The global projects reviewed, and the results of testing in the $\mathrm{HBC}$ Garden, indicate that remote sensing techniques have value when investigating gardens. This is especially vital when considering the significant amount of landscape that often needs to be tested.

Miller and Gleason's technique of finding a garden's boundaries, axes and determining access was tested during this project, without success. That is not to say the technique is flawed, it is quite logical. But it would need to be a site where the garden surface was relatively undisturbed, and that had distinct sediment differences at the boundaries, (or trash used to surface paths), which does not appear to be the case in the HBC Garden. It is highly likely that most gardens will not contain high counts of artifacts, making it difficult to use spatial distribution patterns to define boundaries.

Currie and Locock (1991) advocates small trenches (as a standard technique in Britain), opposing the destruction of the archaeological record and the many difficulties of large-scale excavations. Miller and Gleason (1994) suggest large excavations after remote sensing to determine likely places, and using heavy machinery to scrape the surface, 
exposing garden features. Both of these trench methods were employed during the HBC Garden project, including scraping the 20th century surface off TA2 with a backhoe. It would not have been possible to completely excavate that $2 \mathrm{~m} \times 10 \mathrm{~m}$ trench with the available crew during one field season had that not been done, primarily due to extremely compacted sediments from a 1930s gravel road overlying the Garden sediments. Unfortunately, it is difficult to compare the relative success of the two trench size techniques as the majority of the small $(1 \mathrm{~m} \mathrm{x} 4 \mathrm{~m})$ trenches dug contained disturbed sediments. However, a certain amount of the ambiguous information obtained from the small trenches was due to their size. Stratum changes were much more visible in the larger trenches (TA1 and TA2). The extent of the compacted sediment (Feature 509) in TA1 was, in fact, determined by finding it in the long profiles, as it was excavated out in several units by students before it was realized what it was. Based on this project, it is not possible to definitively determine which technique has more value, but the inclination is to find more value in the larger trenches, as the disturbances were generally localized and intact sediments were found surrounding them.

It is hoped that the documentary research on other garden archaeology projects, along with the application on this project of some of the techniques advocated will provide archaeologists in the Pacific Northwest with a framework of options to apply to future garden sites.

\section{DISCUSSION OF PREVIOUS ARCHAEOLOGY RESULTS}

The majority of the previous archaeology conducted on the HBC formal garden site was performed on what is presumed to be the margins of the garden (Peers 1844). The actual boundaries of the HBC formal garden were not determined by these projects. All of the previous projects, whether within the garden or on the margin, are consistent in that they indicate a mix of disturbed and intact deposits, and very few HBC period artifacts. 


\section{East 5th Street}

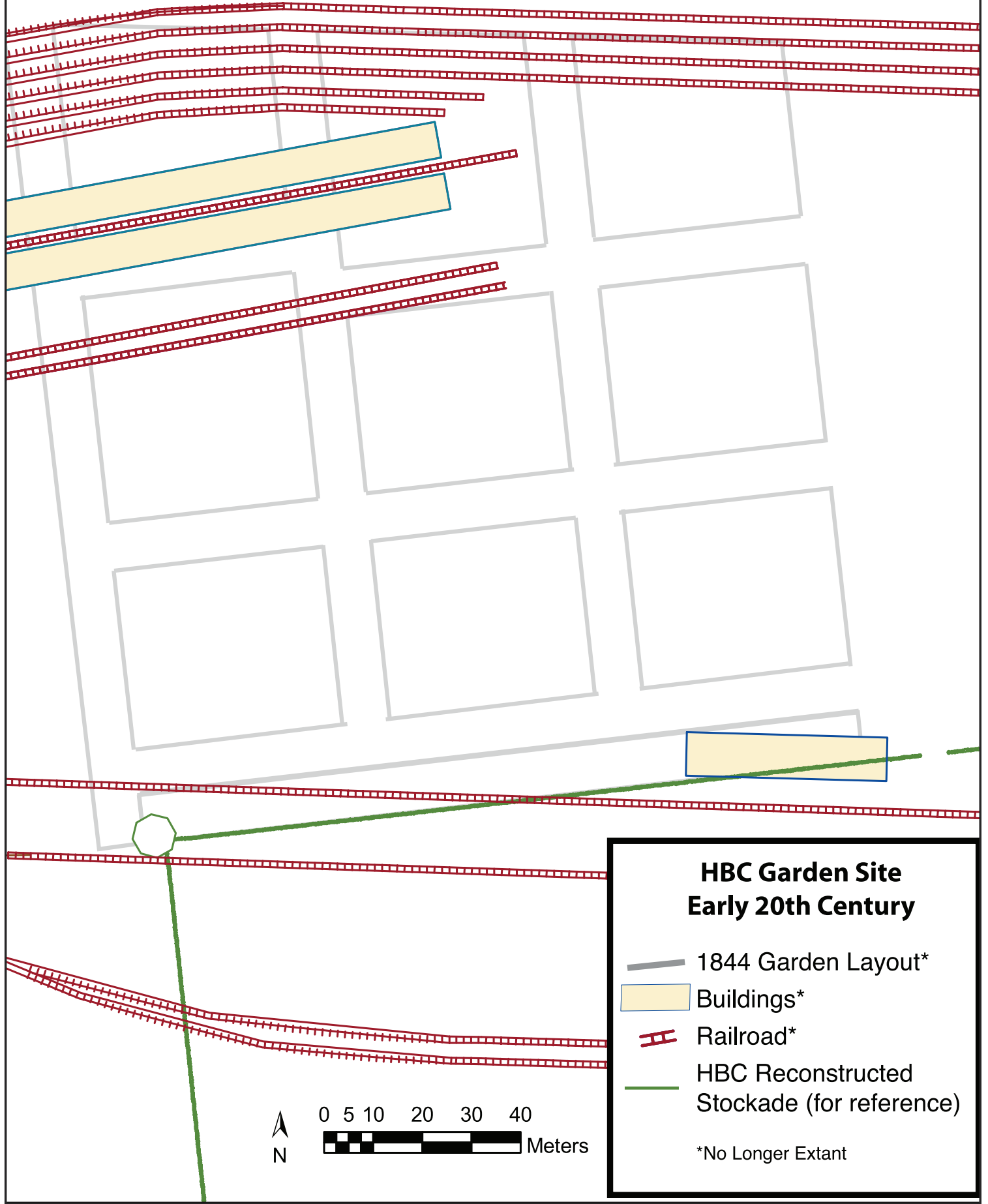

Figure 35. Early-20th century activities on the site of the HBC Garden. 


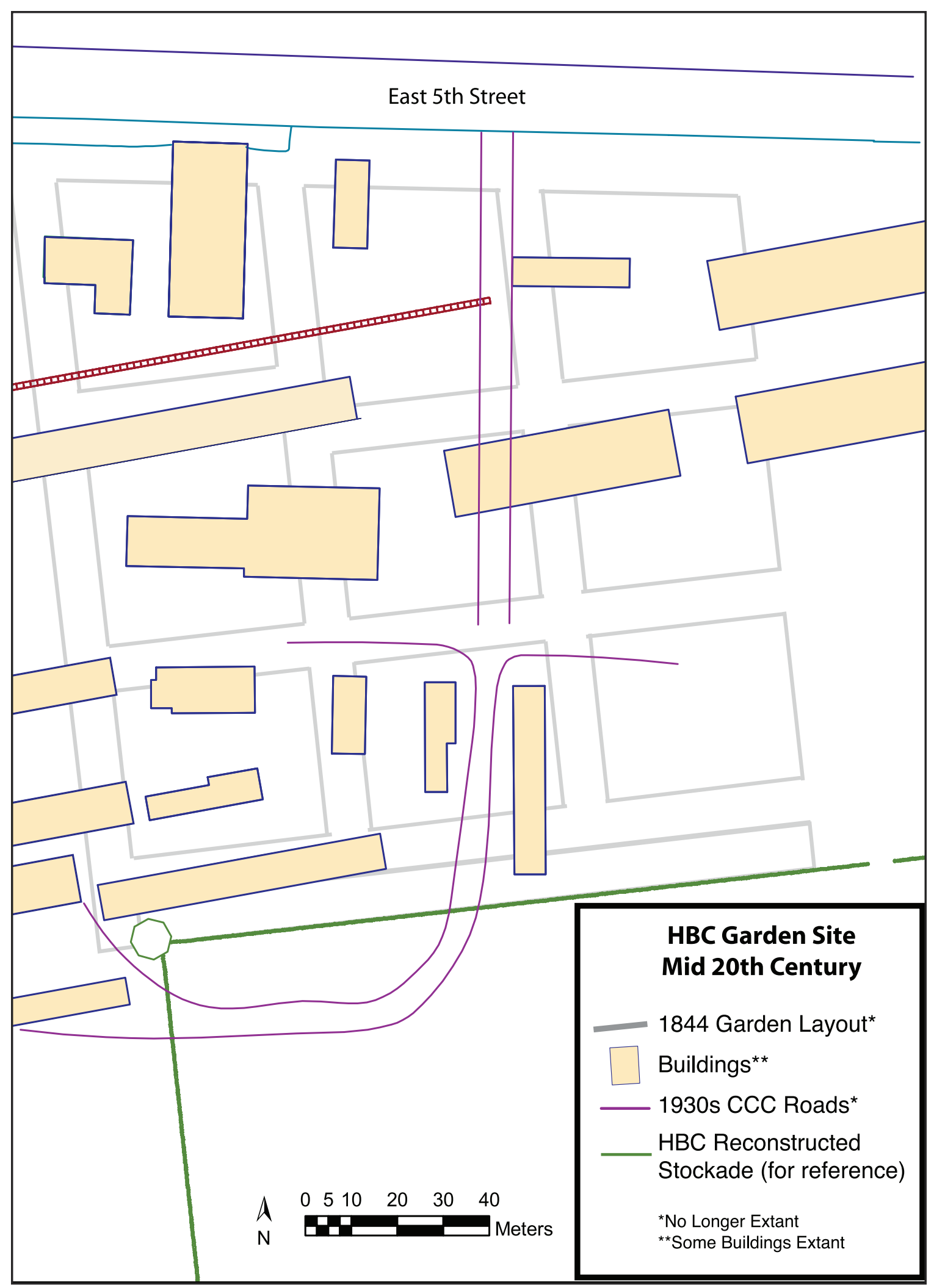

Figure 36. Mid-20th century activities on the site of the HBC Garden. 
As can be seen in Figures 35 and 36, the HBC Garden site has most likely experienced significant disturbance from the subsequent activities of the U. S. Army, although it is known that the majority of the buildings were temporary and most likely did not disturb archaeological deposits.

Bell's 1991 remote sensing results in the area of the Summer house provide information on possible remaining intact features from the only Garden structure known from historical documents. Bell refers to two anomalies in the southern portion of the test area (SSA-6 and SSA-7) as appearing to be building foundation remains. When the Garden layout based on the Line of Fire map (Peers 1844) is applied to the plan view of the remote sensing test area, it appears that the GPR in the U.S. Army asphalt parking area was not as successful at reading the deposits as Bell had indicated, as anomalies SSA-6 and SSA-7 would represent the east wall of the building, with the remains of the rest of the building underneath the asphalt parking lot, where GPR testing was done, but Bell noted no anomalies.

The GPR results for the well area (TA1) were somewhat accurate in that a purposely dug hole was found. However it was not back-filled and masonry-lined, but rather filled with trash, primarily galvanized metal and concrete. Still, it should be considered that the GPR results were successful in that the overall character of the feature was accurate.

\section{5-2007 ARCHAEOLOGICAL EXCAVATIONS}

The stratification of sediments in the Garden was as expected, and consistent with sequences found inside the Fort stockade, just to the south of the Garden. There was a considerable amount of sediment disturbance from U.S. Army activities, dating from the 1850 s to the 1940 s. Several test areas in the Garden were either only partially excavated (TA5, TA7, TA9) or the disturbance evident was sufficient to result in ambiguous conclusions. 1894 flood silts, used as a marker to indicate that intact HBC/Early U.S. Army 
deposits are present below, were found sporadically, and occasionally definitively, particularly in TA1, TA2, and TA8. The quantity of gravels found was not sufficient to indicate that the Garden paths were surfaced with gravel, and no differences in sediment characteristics that could be attributed to paths as compared to beds were found.

\section{Archaeological Features}

A few features were found that were related to the HBC occupation. Features 509, 509A and 509B were all located in TA1. Feature 509, the $4 \mathrm{~cm}$ to $10 \mathrm{~cm}$ thick compacted sediments, may indicate an area of long-term, heavy use. It is clear that the sediments in this area were not tilled or planted during the HBC period. In certain portions of this feature the sediments formed thin lenses, possibly due to seasonal weather changes, or some other unknown actions. Feature 509A, several strips of ultra-compacted sediment in the northern units of TA1, are inferred to have been compressed by some item of heavy weight sitting in the same place for an extended period of time. A support stand for a water barrel has been proposed. Feature 509B, a possible hearth in the southeast portion of TA1, was found just underneath the compacted sediments of Feature 509. This may represent a temporary campsite, perhaps at the time of the construction of the Fort stockade.

Feature 621, a small post found in TA8, had artifacts (pollen and flat glass) dating to the HBC period directly below the post, and cartographic research provides no explanation for a post in this area during the early U.S. Army period. It is likely an HBC feature, a trellis or decorative fence post.

\section{Artifact Distribution Analysis}

When comparing the artifact counts from the HBC Garden project to counts from projects conducted inside the stockade and in the Village, it is clear that the Garden space was used very differently. The low occurrence of artifacts in the Garden indicates that very few 
people were in the space, that trash (other than in TA2) was not dumped in the Garden, and/or that the Garden in its entirety was kept relatively clean of trash. The presence of the sheet trash in TA2 most likely does not reflect any Garden activities, and may be from a period early in the history of the Fort, before the Garden was created, or perhaps the Garden in its early phases did not continue up to the stockade wall as it clearly did by 1844 . Another possibility is that the path coming out of the gate in the stockade near TA2 (see below), was extensively and consistently used (not surprising since it would have been the only way out of the back of the 1829 to 1834-36 Fort) and trash was deposited in that area due to its proximity to the gate. This would be consistent with other archaeological findings at Fort Vancouver (Caywood 1955; Hoffman and Ross 1974b; Ross et al. 1975;). The presence of trash deposits, generally behind fort buildings, is also stated to infer nearby access to buildings, such as doors (Hoffman and Ross 1974b:57, 228, 238). This method of trash disposal (within close proximity of buildings) was common into the early 20th century, previous to municipal garbage removal programs (Groover 2001; King and Miller 1987; Orser 2004). Artifact counts were also relatively high at TA1, which provides further indication that this was a concentrated-activity area, unlike the rest of the Garden, or that the surface in this location was exposed for a long period of time.

Hypothesized Gate in North Stockade Wall

It was hypothesized during excavations that the quantity and richness of artifacts in TA2 represented sheet trash. As 19th century trash disposal practice generally involved throwing trash out the door, creating deposits in close proximity to the access, this led to researching the possibility of there being a previously unknown gate in the north stockade wall. TA2 was originally placed in order to investigate the enigmatic symbols on the Line of Fire map in that location, which had been hypothesized to represent a "P" for path, and a dotted line representing the path itself. If this symbol did represent a path, logic would 
dictate that there was a gate in the stockade wall at the south end of the path.

Illustrations of the north palisade wall archaeological investigations conducted by John Combes in 1966, in preparation for the reconstruction of the wall, were analyzed. These illustrations represent the post "butts" which remained in the ground after the fort burned in the 1860s. The reconstructed stockade wall has larger "king" posts at regular intervals, however, this doesn't appear to be consistent with the original design, as Combes illustrations of the original post butts does not reflect regular intervals of king posts. This

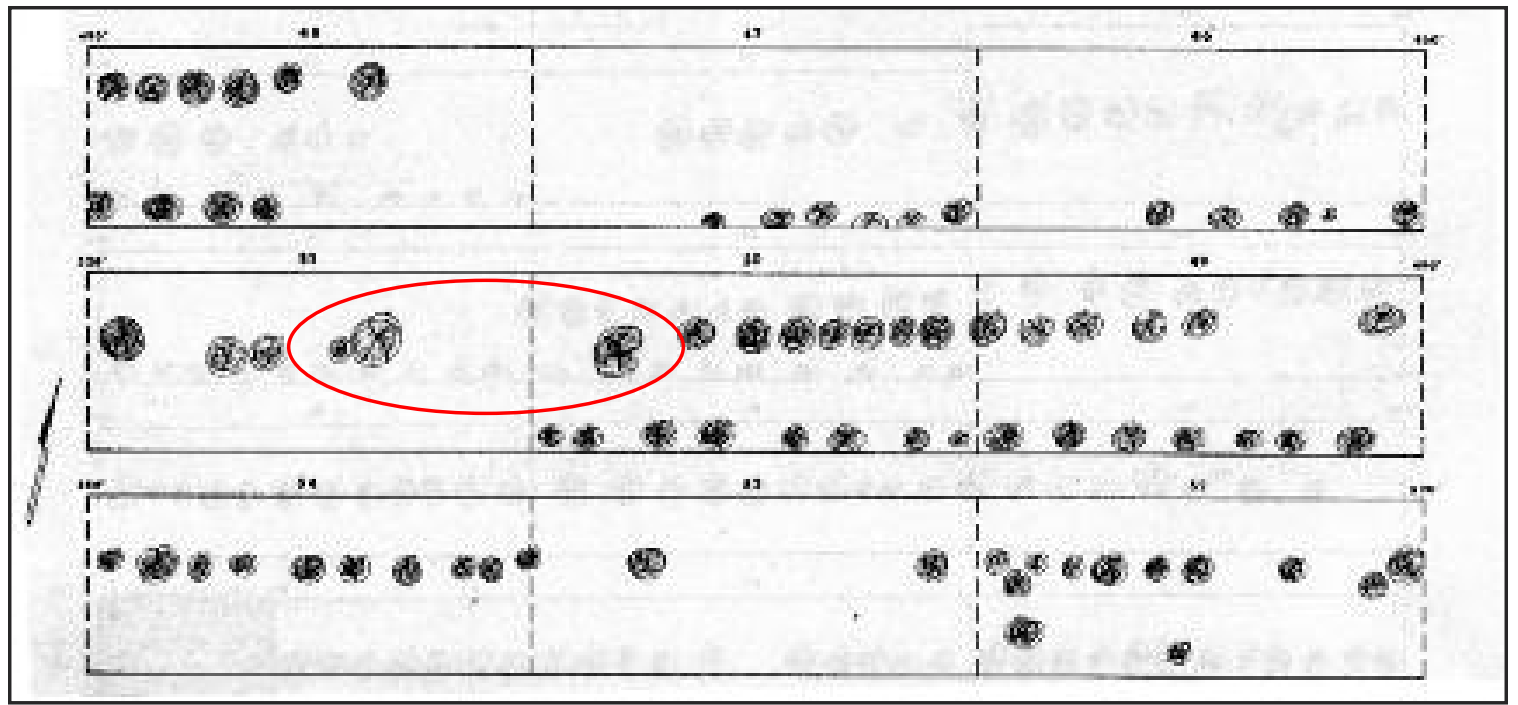

Figure 37. Combes' illustration of the linear trench dug during 1966 investigations to expose the north stockade wall post butts remaining in the ground. Section numbers, above each rectangle, increase to the west. The red circled king posts correspond to the two dots on the stockade wall in Figure 38.

made it easy to recognize an anomaly in Sections 54 and 55 (Figure 37), an open space with two large posts, possibly king posts, on either side. The space between these large posts is approximately 6 feet, or 1 toise. In Combes' illustrations, each section (delineated by vertical dotted lines) is 10 feet. GIS maps were created to place this anomaly on the reconstructed wall (Figure 38). The dark blue line in the figure represents the original (and reconstructed) north stockade wall. The "king posts" noted in Combes' illustration align very closely to TA2. Figure 38 also shows the relative frequency of artifacts in TA2, with darker colors representing higher quantities. The area of darker colors in TA2 is the "sheet trash" noted 


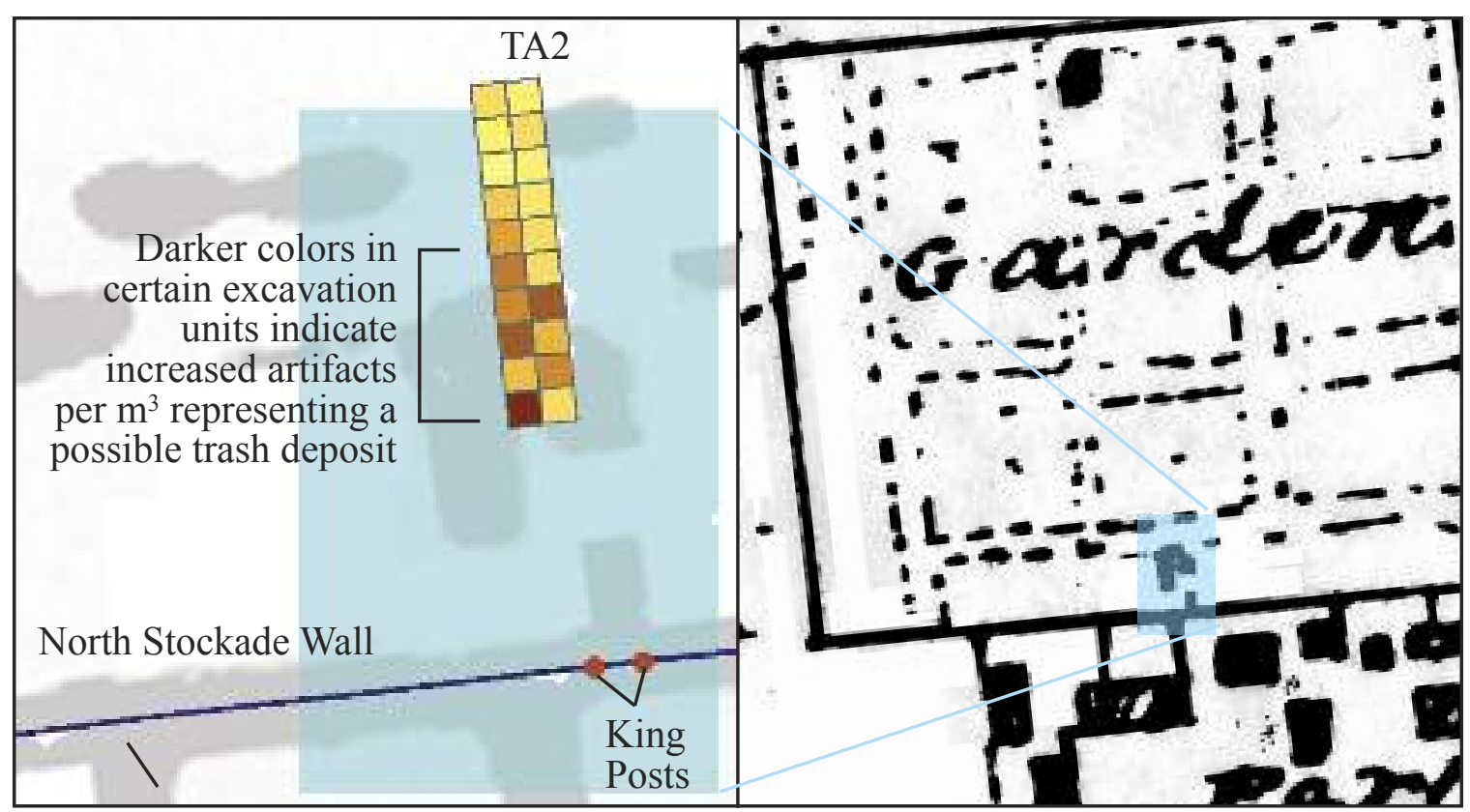

Figure 38. This figure shows the location of the king post butts indicated in Figure 44, and their relationship to the TA2 sheet trash deposit. The detail of the 1844 Line of Fire map shows that its enigmatic symbols along the southern boundary of the Garden also line up with the king posts.

during 2005 excavations. This gate, which would have been located in the center of the north wall of the early, square stockade (Figure 8), behind the hypothesized location of the Chief Factor's house, would have limited formal access to those that Dr. McLoughlin invited through the gate at the back of his house and into the Garden.

\section{Artifact Functional Classification}

The functional classification of artifacts (Sprague 1981) is distinctive in that TA2 has a significantly higher number of personal artifacts. This contributes to the inference that TA2 contained a sheet trash deposit from inside the Fort, also supporting the hypothesis of a previously undocumented gate in the north stockade wall. It is unlikely that trash would have been carried out the front (south) gate and around to the back of the stockade, or, carried from the northeast gate to that location.

There was a significantly higher count of Commerce and Industry-classed artifacts in TA1. These artifacts were primarily a concentration of crushed rock found within Feature 
509 in TA1-18 that were classified as Agricultural. It is not know if this concentration was unique, or if the crushed rock was not collected from other units.

Architecture-classed artifacts dominated both TA1 and TA2. In TA2 this is most likely related to the sheet trash. However, in TA1 it raises the possibility of a structure having been in the nearby area. In Domestics, it is interesting that TA1 is dominated by vessel glass, while TA2 is dominated by ceramics. The reason for this is unclear.

Artifacts

Flat glass thickness modes showed a fairly distinct date separation between Stratum V (1835-1845) and Strata VI through VIII (1830-1840) in both TA1 and TA2. This may indicate that no tilling or turning of the soil occurred in either location. The compacted surface (Feature 509) in TA1 is consistent with this finding, and the possibility of a path coming out of a gate in the Fort near the location of TA2 would also have precluded this area as a garden bed. Based on other archaeological testing projects related to buildings at Fort Vancouver (Pierson 2009:37), the density of flat glass at TA1 (53 fragments $/ \mathrm{m}^{3}$, is not sufficient to indicate windows in a building in the immediate vicinity. Of course, it is possible that there was a building, but without windows. However, also based on testing related to buildings within the stockade, the density of nails at TA1 (11 nails $/ \mathrm{m}^{3)}$, is not sufficient to indicate the presence of a structure in the immediate vicinity.

Only one artifact was found that may indicate gender. A green glass trade ring inset was found in TA2. It was found in the area of the sheet trash, so it is possible that it actually came from within the stockade. It has been stated (personal communication, Mike Twist) that the male laborers often wore significant amounts of jewelry, so the ring may not represent the presence of women in the Garden. However, an HBC account from York Factory states that a shipment of rings were being returned to Britain because "Rings is too wide, the generality of the female sex having small fingers" (Carlos 2001:20) Clearly there 
was no market in rings large enough for men.

A fragment of garden hose was found in TA2. The vulcanization process (which made rubber consistency constant at any temperature) was discovered in 1839. But rubber products, including hoses, were being made before that. As stated above, it is known from primary documents that rubber hose was being manufactured at Fort Langley (east of Vancouver, British Columbia). This hose, however, is likely from a later date. The pattern of a layer of reinforcing material (or waterproofing material) is exposed where the rubber has torn away. This technique of reinforcing or waterproofing was prevalent in the later 1900 s, but further research should be conducted to more accurately date the fragment.

A few pre-contact lithic artifacts were found. A projectile point fragment was found in TA2, and 4 flakes, (TA1, TA2, TA8). The flakes are probably from retouch or repair. This would represent opportunistic activities such as, hunting, and butchering, rather than a location of lithic manufacture.

The overall lack of artifacts in the Garden indicates that trash was not being used to either provide firmness to the paths, or break up the soils in the beds. The spatial distribution does indicate, however, that a trash dump was located in the area of TA2. As people threw trash out of buildings onto the landscape during this period, the presence of sheet trash in this location is a supporting line of evidence for a gate in the stockade wall, just to the south. Coal, coke, clinker and slag, generally associated with blacksmithing activities at this site, are significant in the sheet trash deposit, also indicating that the artifacts in this deposit came from inside the stockade, where the blacksmithing facilities were located (Erigero 1992). Similarly, the relative abundance of tobacco pipe fragments in the sheet trash deposit (75\%) argues for the sheet trash coming from inside the stockade, as the quantities of tobacco pipe fragments in the remaining Garden deposits are very low. The low quantities of tobacco pipe fragments in the remainder of the deposits could argue for the Garden being a limited access space, and/or that smoking was not allowed. 


\section{ARCHAEOBOTANICAL REMAINS}

Phytolith Analysis

The conclusion of the phytolith analyst was that the Garden site was a meadow of native grasses, changing little over time. This may indicate that the grass that the men were cutting in the Garden during the 1844 fire were native grasses. Very few imported grass pollens or phytoliths were found. It is hypothesized, therefore, that the paths in the Garden were simply the native grasses, cropped short to create paths. These grasses would have required minimal care, being perfect for the xeric moisture regime (wet winters, dry summers) that is prevalent in this area of the region. Quantities of Cerealia were constant through time, indicating that these crops were not actually grown in the Garden, which would have exhibited as a sharp increase in phytolith counts. The presence of Cerealia in the culturally sterile sample, taken $8 \mathrm{~cm}$ to $18 \mathrm{~cm}$ below Feature 509, the compacted surface, may indicate contamination or bioturbation, or an early use of the Garden site as an agricultural field. As the charcoal evidence of fires decreased in the historic period, it is possible that Fort Plain was subjected to regular burning by native people to cultivate a more hospitable hunting environment, or to chase fauna to controlled locations (Ames and Maschner 1999:142).

\section{Pollen Analysis}

Pollen from several previously unknown plants was found within the HBC deposits. Also, sediment samples from deposits inferred to be pre-European occupation, based on a lack of artifacts, did not contain introduced plants. Some of the identified plants in the HBC deposits were arboreal, confirming the presence of trees in the Garden, some of them of quite large (elm, hickory). Of the 14 plants species that are newly discovered, 8 of them are primarily known as ornamentals, showing that aesthetics were an aspect of the Garden. 
It appears that most, if not all, of the fruits and vegetables grown in the Garden were recorded in documents, as no new plants of these types were identified in the pollen results. Rosaceae, which includes fruit trees, was found in $38 \%$ of the samples, but in small quantities. This would indicate that a few fruit trees, roses, raspberries, were growing throughout the areas of the Garden that had intact HBC deposits.

The pollen results are consistent with the phytolith results in that an abundance of weedy taxa were found, possibly indicating, again, that the paths remained as native meadow grasses. The amount of pollen from grasses "do not refute the historical record, but cannot corroborate," that the paths were surfaced with grass (Appendix F:226). Minimally, there was grass in the vicinity.

Pollen from several useful native plants was also found. It is difficult to determine if they were intentionally planted, or if they simply represent a portion of the weedy population. As it was common in colonial Canada to utilize native plants (Von Baeyer 1997), it is likely that at least some of these native plants were intentionally placed in the Garden, particularly those that would ordinarily grow in different climates and environments from that of Fort Vancouver. However, at this time, there is no information available indicating how the HBC at Fort Vancouver utilized native plants.

The spatial analysis suggests the presence (and absence) of several of the newly discovered plants. This will aid in reconstructing the Garden. One of the most interesting aspects of this analysis is that $97 \%$ of the species found (previously known species included) left pollen at TA1. It is not possible for all of these plants to have been growing in this location, particularly as a significant portion of the area is a highly-compacted surface and definitely not garden bed. These data support the hypothesis that the southwest corner of the Garden was some sort of administrative area with access to the inside of the stockade, possibly the location of a garden shed. The many types of pollen were transported to this area either on plants that were brought there to be processed and/or taken into the stockade, 
or on the garden worker's feet.

Two species of plants, dahlia and zinnia, are both from warmer climates. It is known from historical documents that the dahlias were grown in cold frames. Significant amounts of pollen from these two plants were found at TA1. It's possible that in the 1829 to $1834-36$ period, when the stockade was essentially half of its final size and the Chief Factor's House was on the northwest corner rather than the northeast corner, these valuable plants were grown very close to the gate, just at the back of the Chief Factor's House, or the plants were processed there.

The presence of plants imported from other lands makes it clear that the HBC Garden, while largely meant to provide healthy food to the Company's employees, was also focused on the science of botany, attempting to understand the needs of plants, and researching the methods required to grow them in environments that presented distinct challenges. As stated above, the presence of flowers in the Garden speaks to a desire to create a sense of home, Britain being known during this period for its beautiful gardens (Loudon 1824). It also speaks to the HBCs access to resources and power, flowers being thought to be purely aesthetic, although research needs to be done related to the possible medicinal properties of the ornamental plants found by pollen analysis. Interestingly, pollen analysis conducted on samples taken from the Village landscape in 2010 possibly indicate, by the presence of imported plants (acacia, mimosa, hibiscus, daphne), that the hierarchy at Fort Vancouver was not as strident as historical documents indicate, or was collapsing as proposed in this document, or that the working class was engaging in blatant rebellion against the Company. The fact that three of the introduced plants could easily have come from or through Hawaii, in that respect it may simply be a case of, as in the HBC Garden, people bringing a bit of home to this new land.

The analysis of pollen from a non-garden provenience provided a comparison that confirmed that the HBC deposits within the historically-documented Garden site are, in fact, a garden that contained fruit, vegetables, herbs and flowers. 


\section{Macrobotanical Analysis}

This analysis method was minimally utilized due to a lack of diagnostic specimens. A few economical plants were found, but the analyst presented the possibility that they were modern as it was not likely that they would have remained in the soil without being carbonized. The analyst then stated that plant preservation at the site appeared to be poor, but did not state the criteria for that conclusion. 


\section{CHAPTER 9. Conclusions and Recommendations}

This thesis project, which represents the most extensive archaeological investigation conducted on a garden in the Pacific Northwest, has shown that the Garden at Fort Vancouver fulfilled many diverse roles for the Hudson's Bay Company. Documentary research and archaeological results showed that it is highly likely that, at least initially, the Garden was used to maintain the social hierarchy of the Company, providing foodstuffs and a landscape that only the gentlemen, their families, and select visitors were allowed to access. The extent and scope of this space may have been intentionally formed to address the hypothesis that food was abundant in this locality, making it difficult for the Company to maintain its usual control over this resource. Ironically, as the Company's activities grew in the region, the Garden came to represent a transition in this practice, as ship's crews, considered to be of the labor class and therefore not having access to fresh produce, required these foods to maintain their health on long voyages, which translated to greater profit for the Company.

Further research, related to the lack of garden archaeology in the western United States, and a review of previous archaeology at the site, resulted in an opportunity to provide a background framework for archaeologists to apply to future projects, not only from worldwide documentary sources, but also from these archaeological investigations, which employed several techniques noted in the reviewed projects. The previous archaeological projects at the site provided no information related to the HBC Garden.

The 2005, 2006 and 2007 archaeological investigation results suggested a Garden that was largely utilitarian, a jardin de potager, or kitchen garden, that also contained exotic plants that grew naturally in environments very unlike the Pacific Northwest. These plants would have required technology, expertise and experimentation that illustrates that the HBC Garden was a state-of-the-art botanical experiment. This evidence indicates the power of 
the $\mathrm{HBC}$, however, this Garden was dissimilar to colonial Gardens in Annapolis, as researched by Mark Leone, which employ tricks of visual perspective achieved through extensive hard landscaping in order to give the impression of a much larger space. This Garden had no hard landscaping, and it appears that the "wide paths" noted in historical documents were simply the native meadow grasses, kept manicured and orderly, lending validity to the argument that the Garden was, at its root, a functional space.

The features found also contributed to this argument: a highly-compacted surface at TA1, containing pollen from nearly $100 \%$ of the species found in the remainder of the excavations, indicating a high-activity, and/or highly-specialized, use of that space; and a possible trellis post near the stockade wall, a protected area that would have been ideal for tender (and experimental) plants. The artifact distribution also confirms high-activity at TA1, with a significantly increased quantity of artifacts, and the possibility of a structure as indicated by a relative increase in structural artifacts. There is also a possibility of a previously undocumented gate in the north stockade wall, as represented by sheet trash in TA2. Further documentary research of archaeological investigations on this wall, which mapped an open space bounded by king posts directly south of TA2, and the functional classification of the artifacts found at TA2, which includes domestic artifacts and a few items that clearly represent trash from other locations within the stockade, strengthen this hypothesis, as well as research relating to the hierarchical arrangement of structures generally employed by the HBC, and Garden layout techniques that Billy Bruce would have seen at the Duke of Devonshire's garden at Chiswick. This research showed a consistency with these known techniques in the shape and layout of the early, square Fort Vancouver stockade, the size and orientation of the Garden, which was symmetrical to the stockade, and the location of the Summer house.

Few artifacts were found that represented Garden activities, or provided information about who worked in the Garden. One glass inset from a trade ring suggests that labor-class 
women were in the Garden, which would confirm historical documents, but is very slim evidence to provide additional support. The only information about the existence of the Garden, that fact that it was in this location on the north side of the stockade, and confirmation that fruits, vegetables, herbs and flowers, including exotic plants, was provided by the identification of microbotanical remains.

It is hypothesized that the phytolith analysis findings, which stated that the natural meadow plants did not change over time, indicate that the wide paths in the Garden were surfaced with native grasses. The pollen analysis provided confirmation of many plants previously known from historical documents. This analysis also found remains of several plants not previously known to have been grown at Fort Vancouver, and remains of native plants that may have been purposefully grown in the Garden. Spatial distribution analysis of the pollen results will guide decisions when reconstructing the Garden, as pollen grains from insect-pollinated plants are heavy and tend to drop close to the location of the plant. Analysis of pollen from a non-Garden provenience confirms that the plants grown in the space north of the Fort stockade were of different species, and relatively higher richness of species, than those that were growing in a historically-documented agricultural field, confirming the presence of a Garden north of the stockade.

While the results could not address many of the research questions that were asked in the beginning of this project, those results that were obtained have provided a significantly enhanced understanding of how the HBC used this space, and the reasons for the Garden's scope and content. The archaeological results are an additional line of evidence for the information found in documentary sources, providing data that speaks for, or against, written comment that may have been biased or incomplete. The results of this project provides the Fort Vancouver National Historic Site with validated research to employ in reconstructing the Garden, as required by the National Park Service Technical Preservation Services (NPS 2012), informing the public on 19th century foodways, and specifically life at the Hudson's 
Bay Company Fort Vancouver. As it is becoming increasingly accepted that a return to agricultural practice of the past is our hope for a healthy future, the HBC Garden at Fort Vancouver has the potential to once again become a timely, informative, botanical experiment, providing health and nutrition for the local population.

\section{Recommendations}

There are several research topics for which additional research would enhance our understanding of the HBC's representations and uses of this garden landscape at Fort Vancouver:

1. Research on the possible medicinal uses of plants that are now considered to be ornamental, for which we have evidence of their presence in the Garden;

2. Research on native plants to determine those that naturally grow in a different environment, to determine if they were intentionally planted or are simply weeds, and their possible cultural uses;

3. Loudon's The Encyclopedia of Agriculture (1825) should be reviewed for information relevant to garden practice as this publication is known to have been in Dr. McLoughlin's library;

4. Additional research should be conducted on Billy Bruce's visit to Chiswick, and on the gardens at Chiswick at the time of his visit. These records are at Chatsworth House, the country seat of the Duke of Devonshire (personal conversation, Dr. Nigel Barker, English Heritage);

5. Additional archaeological investigations focusing on:

a) the boundaries of the compacted surface at TA1, and the possibility of a structure at that location; 
b) the eastern edge of the Garden for evidence of hot beds, cold frames, and/or greenhouses;

c) the Summer house (which likely doubled as a greenhouse);

d) finding fence lines (boundaries of the Garden), especially on the western edge as historical maps are inconsistent;

e) the possibility of lines of posts near TA8 (if Feature 621 represents a trellis, the posts would have been fairly close together;

f) additional $1 \mathrm{~m} \mathrm{x} 4 \mathrm{~m}$ trenches to obtain more information on the effectiveness of this size of trench versus larger trenches when investigating a garden. 


\section{SOURCES CITED}

Map of Fort Vancouver, Washington Territory from Circular \#4, Report on Barracks and Hospitals and Description of Military Posts, Surgeon General's Office.

1870 Map on file at Fort Vancouver National Historic Site.

Ames, Kenneth M. and Herbert D. G. Maschener

1999 Peoples of the Northwest Coast: Their Archaeology and Prehistory. New York: Thames and Hudson.

Aspinall, A., J. A. Pocock, R. J. Westwood

1997 The Terrace Garden at Shibden Hall, West Yorkshire: An Integrated Study in Garden History, Vol. 25, No. 2, pp.. 219-229. London: The Garden History Society.

Aston, Michael and Trevor Rowley

1974 Landscape Archaeology: An Introduction to Fieldwork Techniques on Post-Roman Landscapes. London: David \& Charles.

Author Unknown

1997 The Archaeology of the Fur Trade in The Midden, Vol. 29, No. 1. Archaeological Society of British Columbia.

Bedal, Leigh-Ann

2001 Petra Garden Feasibility Study 2001. Washington: Dumbarton Oaks. http://www.doaks.org/PetraNew/petraHOME.html

Bell, James W.

1991 Report of the Remote Sensing Survey at Fort Vancouver National Historic Site. Department of the Interior, National Park Service. Report on file at Fort Vancouver National Historic Site.

Bellis, Mary

http://inventors.about.com/od/gstartinventors/a/CharlesGoodyear.htm, accessed $3 / 10 / 2012$

Bown, Stephen R.

2003a The Age of Scurvy: How a Surgeon, a Mariner and a Gentleman helped Britain win the Battle of Trafalgar. Chichester, UK: Summersdale.

2003b SCURVY: How a Surgeon, a Mariner and a Gentleman Solved the Greatest Medical Mystery of the Age of Sail. New York: St. Martins Griffin.

Boyd, Robert T.

1999 The Coming of the Spirit of Pestilence. Seattle: University of Washington Press. 
Carlos, Ann M. and Frank D. Lewis

2001 Agents of Their Own Desires: Indian Consumers and the Hudson's Bay Company 1700-1770. Department of Economics, University of Colorado.

Carlson, Roy L. and Martin P.R. Magne (editors)

2008 Projectile Point Sequences in Northwestern North America. Publication No. 35. Burnaby, B.C., Canada: Simon Fraser University Archaeology Press.

Caywood, Louis R.

1955 Final Report, Fort Vancouver Excavations. Department of the Interior, National Park Service. Report on file at Fort Vancouver National Historic Site.

\section{Columbian}

1974 Fort Stockade Takes Form. Vol. No. 113, Monday, Feb. 18.

1990 Roots: Fort Vancouver Historic Garden Preserves Taste of Bygone Era. Sunday, September 16: Section C. Vancouver, WA.

Colquhoun, Kate

2003 "The Busiest Man in England” A Life of Joseph Paxton, Gardener, Architect \& Victorian Visionary. Boston: David R. Godine.

Combes, John D.

1966 Archaeological Excavations of the North Wall. Department of the Interior, National Park Service. Manuscript on file at Fort Vancouver National Historic Site.

Covington, Richard

1846 Plan of Fort Vancouver. Copy on file at Fort Vancouver National Historic Site.

Cromwell, Robert J.

2001 Archaeological Subsurface Survey of the Discovery Loop Trail Route on NPS Property. Department of the Interior, National Park Service. Letter report on file at Fort Vancouver National Historic Site.

2006 The Ceramic Wares of the Ca. 1810-1826 North West Company/Hudson's Bay Company Fort Spokane, 45SP5. Department of the Interior, National Park Service. Manuscript on file at Fort Vancouver National Historic Site.

2002 Archaeological Monitoring of a Utility Trench Excavation for Electrical Lines to the Fort Vancouver Bastion. Department of the Interior, National Park Service. Letter report on file at Fort Vancouver National Historic Site.

Currie, C. K., and M. Locock

1991 An Evaluation of Archaeological Techniques Used at Castle Bromwich Hall, 1989-90 in Garden History, Vol. 19, No. 1, pp. 77-99. London: The Garden History Society. 
De Cunzo, Lu Ann, Therese O’Malley, Michael J Lewis, George E. Thomas, and Christa Wilmanns-Wells

1996 Father Rapp's Garden at Economy: Harmony Society Culture in Microcosm. Landscape Archaeology, edited by Rebecca Yamin and Karen Bescherer Metheny. Knoxville: The University of Tennessee Press.

Deur, Douglas

2011 An Ethnohistorical Overview of Groups with Ties to Fort Vancouver National Historic Site. Pacific West Region: Social Science Series Number 2011-02. Department of the Interior, National Park Service. Manuscript on file at Fort Vancouver National Historic Site.

Deur, Douglas and Nancy J. Turner, eds.

2005 Keeping it living: traditions of plant use and cultivation on the Northwest Coast of North America. Seattle: University of Washington Press.

Dickey, George, ed.

1989 Journal of Occurrences at Fort Nisqually. Tacoma, Washington, Mort Nisqually Historic Site, Metropolitan Park District. Manuscript on file at Fort Vancouver National Historic Site.

Drower, George

2001 Garden of Invention: The Stories of Garden Inventors \& Their Innovations. Guilford, CT: First Lyons Press.

Elliott, Brent

2004 The Royal Horticultural Society: a history 1804-2004. Chichester, UK: Phillimore.

Erickson, Clark L.

1994 Methodological Considerations in the Study of Ancient Andean Field Systems. The Archaeology of Garden and Field edited by Naomi F. Miller and Kathryn L. Gleason. Philadelphia: University of Pennsylvania Press.

Erigero, Patricia C.

1992 Cultural Landscape Report, Vol. II. Seattle, WA. National Park Service, Department of the Interior, Cultural Resources Division, Pacific Northwest Region, Denver Service Center. Manuscript on file at Fort Vancouver National Historic Site.

Falade, J. B.

1990 Yoruba Palace Gardens in Garden History, Vol. 19, No. 1, pp. 47-56. London: The Garden History Society. 
Franklin, Maria

2004 An Archaeological Study of the Rich Neck Slave Quarter and Enslaved Domestic Life. Colonial Williamsburg Research Publications. Colonial Williamsburg Foundation.

Freidenberg, Linda and Bryn Thomas

1994 Results of Archaeological Monitoring of an Underground Telephone Line at Fort Vancouver National Historic Site, Vancouver, Washington. Department of the Interior, National Park Service. Manuscript on file at Fort Vancouver National Historic Site.

Groover, Mark D.

2001 Linking Artifact Assemblages to Household Cycles: An Example from the Gibbs Site in Historical Archaeology, Vol. 35, No. 4, pp. 38-57.

Hall, Martin

1993 The Archaeology of Colonial Settlement in Southern Africa in Annual Review of Anthropology, Vol. 22, pp. 177-200. Palo Alto, CA: Annual Reviews.

Hamilton, Scott

2000 Dynamics of Social Complexity in Early Nineteenth-Century British Fur-Trade Posts in International Journal of Historical Archaeology, Vol. 4, No. 3, pp. 217 273. New York: Plenum Publishing.

Harris, John

1994 The Palladian Revival: Lord Burlington, his villa and garden at Chiswick. New Haven, CT: Yale University Press.

Harvey, Eloisa

1878 Life of John McLoughlin, Governor of the Hudson's Bay Company's Possessions on the Pacific Slope at Fort Vancouver. Fort Vancouver Records.

HBCA

1838 Hudson's Bay Company Archives housed at Archives of Manitoba, Canada.

Heath, Barbara J., Randy Lichtenfeld, Keith Adams, Lori Lee and Elizabeth Paull 2004 Poplar Forest Archaeology: Studies in African American Life. Excavations and Analysis of Site A, Southeast Terrace and Site B, Southeast Curtilage, June 2003June 2004. Report to the Public Welfare Foundation.

David Hershey

1996 Doctor Ward's Accidental Terrarium. The American Biology Teacher 58:276-281. 
Hoffman, J. J. and Lester A. Ross

1974a Fort Vancouver Excavations - VII: Northwest Bastion and Stockade System. Department of the Interior, National Park Service. Manuscript on file at Fort Vancouver National Historic Site.

1974b Fort Vancouver Excavations - VI: Sales Shop and Powder Magazine. Department of the Interior, National Park Service. Manuscript on file at Fort Vancouver National Historic Site.

1976 Fort Vancouver Excavations 1829-1860: FOVA XIII Structural Inventory. U.S. Department of the Interior. National Park Service. Manuscript on file at Fort Vancouver National Historic Site.

Horton, Beth

2009 Results Of Archaeological Sub-Surface Testing for Demolition of U.S. Army Building P-408, Vancouver Barracks, Vancouver National Historic Reserve, Vancouver, Washington. Department of the Interior, National Park Service. Report on file at Fort Vancouver National Historic Site.

Hume, Audrey Noel

1974 Archaeology and the Colonial Gardener. Williamsburg, VA: The Colonial Williamsburg Foundation.

Hussey, John

[197?] Fort Vancouver Farm. Department of Interior, National Park Service. Manuscript on file at Fort Vancouver National Historic Site.

1976 Fort Vancouver: Historic Structures Report. Historical Data, Volume II. U.S. Department of the Interior, National Park Service. Manuscript on file at Fort Vancouver National Historic Site.

c.1977 Women of Ft. Vancouver. Department of the Interior, National Park Service. Manuscript on file at Fort Vancouver National Historic Site.

Jacobucci, Susan A.

2007 An Analysis of Pollen From Fort Vancouver Washington. Report prepared for Fort Vancouver National Historic Site, Department of Interior, National Park Service. Manuscript on file at Fort Vancouver National Historic Site.

Jacobucci, Susan A. and Heather B. Trigg

2010 A Pollen Analysis of a Hudson's Bay Company Non-Garden Provenience, Fort Vancouver, Washington. Report prepared for Fort Vancouver National Historic Site, Department of Interior, National Park Service. Manuscript on file at Fort Vancouver National Historic Site. 
Jashemski, Wilhelmina F.

1979 "The Garden of Hercules at Pompeii" (II.viii.6): The Discovery of a Commercial Flower Garden in American Journal of Archaeology, Vol. 83, No. 4, pp. 403-411. Boston: Archaeological Institute of America.

Jashemski, Wilhelmina F., J. E. Ross, R. J. Lewis, M. E. Timpson, S. Y. Lee

1995 Roman Gardens in Tunisia: Preliminary Excavations in the House of Bacchus and Ariadne and in the East Temple at Thuburbo Maius in American Journal of Archaeology, Vol. 99, No. 4, pp. 559-576. Boston: Archaeological Institute of America.

Jessett, Thomas E., ed.

1959 Reports and Letters of Herbert Beaver, 1836-1838. Portland, OR: Champoeg Press.

Kelso, Gerald K.

1994 Palynology in Historical Rural-Landscape Studies: Great Meadows, Pennsylvania. American Antiquity, Vol. 59, No. 2, pp. 359-372.

King, Julia A., and Henry M. Miller

1987 The View from the Midden: An Analysis of Midden Distribution and Composition at the van Sweringen Site, St. Mary’s City, Maryland. Historical Archaeology, Vol. 21., pp. 37-59.

Lal, Vinay

2005 Manas: India and its Neighbors. Los Angeles: University of California at Los Angeles. http://www.sscnet.ucla.edu/southasia/History/Mughals/ mughals.html

Larrabee, Edward McM. and S. Kardas

1969 Exploratory Excavations for the Kanaka Village, Fort Vancouver National Historic Site. Department of the Interior, National Park Service. Manuscript on file at Fort Vancouver National Historic Site.

Leone, Mark P.

2005 The Archaeology of Liberty in an American Capital: Excavations in Annapolis. Berkeley: University of California Press.

Loudon, John Claudius

1824 An Encyclopaedia of Gardening: comprising the theory and practice of horticulture, floriculture, arboriculture, and landscape-gardening, including all the latest improvements; a general history of gardening in all countries; and a statistical view of its present state; with suggestions for its future progress in the British Isles, Vol. 1. London: Longman, Hurst, Rees, Orme, Brown and Green. 
Lydecker, G. J.

1889 Plan of Vancouver Barracks and Military Reservation - prepared under the

direction of Major G.J. Lydecker. Map on file at Fort Vancouver National Historic Site.

Matson, R.G. and Gary Coupland

1995 The Prehistory of the Northwest Coast. San Diego, CA: Academic Press

McConnell, Brvt. Captain J. R.

1854 Map of the Government Reserve at Fort Vancouver, W. T. Copy on file at Fort Vancouver National Historic Site.

McCrea, Tully

1892 Plan of Vancouver Barracks and Military Reservation - prepared under the direction of Major Tully McCrea. Map on file at Fort Vancouver National Historic Site.

McKie, James Melvin

1981 Selected Structures of the Hudson's Bay Co.: A Functional Assessment. Master's thesis, University of Idaho, Moscow.

Merk, Frederick

1968 Fur Trade and Empire: George Simpson's Journal. Cambridge, MA: The Belknap Press of Harvard University Press.

Miller, Naomi F. and Kathryn L. Gleason

1994 The Archaeology of Garden and Field. Philadelphia: University of Pennsylvania Press.

Mithen, Steven and Emily Black, editors

2011 Water, Life and Civilisation: Climate, Environment and Society in the Jordan Valley. Cambridge: Cambridge University Press.

Monks, Gregory

1992 Architectural Symbolism and Non-verbal Communication at Upper Fort Garry in Historical Archaeology Vol. 26(2), pp. 37-57.

Morrison, Dorothy Nafus

1999 Outpost: John McLoughlin and the Far Northwest. Portland, OR: Oregon Historical Society Press.

Moynihan, Elizabeth B. (editor)

2000 The Moonlight Garden: New Discoveries at the Taj Mahal. Washington: Smithsonian Institution. 
Mulalley, Meredith J.

2011 Rebuilding the Architectural History of the Fort Vancouver Village. Master's Thesis, Portland State University, Oregon

National Park Service

2012 Technical Preservation Services: Reconstruction. http://www.nps.gov/tps/standards/four-treatments/treatment-reconstruction.htm. Accessed 6/10/12.

Nelson, Peter

2007 Power and Place: The Dynamics of Non-Verbal Communication in the HumanLandscape Interrelationship at Fort Vancouver. University of Washington Research Paper. Manuscript on file at Fort Vancouver National Historic Site.

Nicholson, Edward

1912 Men and Measures, A History of Weights and Measures, Ancient and Modern, London: Smith, Elder \& Co.

Oberg, Kalvervo

1973 The Social Economy of the Tlingit Indians. Seattle: University of Washington Press.

Orser, Charles E., Jr. (editor)

2002 Encyclopedia of Historical Archaeology. New York: Routledge.

2004 Historical Archaeology, 2nd Edition. Upper Saddle River, NJ: Pearson Prentice Hall.

Pearsall, Deborah M.

2000. Paleoethnobotany: A Handbook of Procedures, second edition. San Diego: Academic Press.

Peers, Henry

1844 Sketch of Fort Vancouver and Plain, Representing the Line of Fire in September 1844... Prepared by the Hudson's Bay Company. Copy on file at Fort Vancouver National Historic Site.

Peterson del Mar, David

1995 Intermarriage and Agency: A Chinookan Case Study in Ethnohistory, Vol. 42, No. 1, pp. 1-30.

Pettigrew, Richard M.

1981 A Prehistoric Culture Sequence in the Portland Basin of the Lower Columbia Valley. University of Oregon Anthropological Papers No. 22. 
Quartermaster Map

1879 Map of Fort Vancouver, Washington from Quartermaster General's Consolidated and Reservation File. Map on file at Fort Vancouver National Historic Site.

Roberts, George B.

1838 Thermometrical Register. Manuscript on file at Fort Vancouver National Historic Site.

Rodgers, Bradley A.

2004 The Archaeologist's Manual for Conservation. New York: Kluwer Academic Publishers.

Roenke, Karl G.

1978. Flat Glass: Its use as a Dating Tool for Nineteenth Century Archaeological Sites in the Pacific Northwest and Elsewhere. Memoir Number Four, Northwest Anthropological Research Notes 12: No. 2, Part 2.

Ross, Lester A.

1976 Fort Vancouver 1829-1860: A Historical Archeological Investigation of the Goods Imported and Manufactured by the Hudson's Bay Company. Washington, D.C. National Park Service, Department of the Interior, Cultural Resources Management Division, Manuscript on file at Fort Vancouver National Historic Site.

Ross, Lester A. and Bryn H. Thomas, Charles H. Hibbs, Caroline D. Carley. 1975 Fort Vancouver Excavations - X: Southeastern Fort Area. Department of the Interior. National Park Service. Manuscript on file at Fort Vancouver National Historic Site.

Samford, Patricia M., Gregory J. Brown and Ann Morgan Smart

1986 Archaeological Excavations on the Tazewell Hall Property. Department of Archaeology, Colonial Williamsburg Foundation.

1999 Archaeological Investigations at the Brush-Everard Site, Williamsburg, Virginia. Colonial Williamsburg Research Publications, Colonial Williamsburg Foundation.

Schiffer, Michael B.

1988 The Structure of Archaeological Theory. American Antiquity, Vol. 53, No. 3, pp. 461-485.

Sjoberg, Alf

1976 Phosphate Analysis of Anthropic Soils in Journal of Field Archaeology, Vol. 3, pp. 447-454. 
Stilson, Lee, Dan Meatte and Robert G. Whitlam

2003 A Field Guide to Washington State Archaeology. Sponsored by Washington State Department of Transportation, Washington State Parks and Recreation Commission and Office of Archaeology and Historic Preservation.

Sprague, Roderick

1981 A Functional Classification for Artifacts from 19th and 20th Century Historical Sites in North American Archaeologist, Vol. 2, No. 3, pp. 251-261.

1983 San Jaun Archaeology, Vol. 1. Moscow, Idaho: University of Idaho Laboratory of Anthropology.

2002 China or Prosser Button Identification and Dating in Historical Archaeology, Vol. 36, No. 2, pp. 11-127.

U.S. Army Signal Corps

1918 Spruce Mill Division Map. Copy on file at Fort Vancouver National Historic Site.

Sunday Oregonian

1974 Pioneer Gardening Attempted. 28 July:36. Portland, OR.

Sussman, Lynne

1979 Spode/Copeland Transfer-print Patterns in Canadian Historic Sites: Occasional Papers in Archaeology and History. Ottawa, Ontario: National Historic Parks and Sites Branch, Parks Canada.

Taylor, Herbert C. and Lester L. Hoaglin, Jr.

1962 The "Intermittent Fever" Epidemic of the 1830s on the Lower Columbia River in Ethnohistory, Vol. 9, No. 2, pp. 160-178. Duke University Press.

Taylor, Terri A.

1992 Cultural Landscape Report: Fort Vancouver National Historic Site, Vol. 2. Seattle, WA. National Park Service, Department of the Interior, Cultural Resources Division, Pacific Northwest Region, Denver Service Center. Manuscript on file at Fort Vancouver National Historic Site.

Teit, James H.

1928 The Middle Columbia Salish in University of Washington Publications in Anthropology, Vol. 2, No. 4, ed. Franz Boas, pp. 83-128. Seattle: University of Washington Press. 
Thomas, Bryn

1987 Untitled letter report. Department of the Interior, National Park Service. Letter report on file at Fort Vancouver National Historic Site.

Todd, Edgeley W., editor

1961 The Adventures of Captain Bonneville, U.S.A., in the Rocky Mountains and the Far West. Norman: University of Oklahoma Press.

Turner, Tom

1986 English Garden Design: History and Styles Since 1650. Woodbridge, UK: Antique Collectors' Club.

Vavasour, Mervyn

1845 Sketch of Fort Vancouver and Adjacent Plains. Map on file at Fort Vancouver National Historic Site.

Von Baeyer, Edwinna

1997 Garden Voices: Two Centuries of Canadian Garden Writing. Toronto: Random House of Canada.

Weber, Carmen

1996 Landscape Archaeology. Rebecca Yamin and Karen Bescherer, editors. Knoxville, TN: The University of Tennessee Press.

Whitman, Narcissa

1982 My Journal, 1836. Fairfield, WA: Ye Galleon Press.

Wright, Mary C.

1981 Economic Development and Native American Women in the Early Nineteenth Century in American Quarterly, Vol. 33, No. 5, pp. 525-536. 
A Historical and Archaeological Study of the Nineteenth Century Hudson's Bay Company Garden at Fort Vancouver

Focusing on Archaeological Field Methods and Microbotanical Analysis

APPENDICES 


\section{APPENDIX A}

A Review of Research, Articles and Publications Relating

to Garden Archaeology Projects and Methods 


\section{APPENDIX A \\ A Review of Research, Articles and Publications Relating to Garden Archaeology Projects and Methods}

This appendix includes detailed information related to research that was conducted to learn and understand methods utilized in garden archaeology projects in the Pacific Northwest region. Results of this research indicated that very few of these projects had been don in the region, so the research was expanded to a worldwide scope, but focusing on reports written in English. A summary of this information can be found within the above thesis, Chapter 3.

\section{GARDEN ARCHAEOLOGY IN THE PACIFIC NORTHWEST}

Oregon State Historic Preservation Office, visited April 2005

After consultation with several employees, including Dennis Griffin, state archaeologist, Cultural Resource Surveys (as classified at this office) were focused on, attempting to identify historic period sites that may or may not have been archaeologically excavated. This, however, was a daunting task, and only a portion of them were reviewed. Discussions with employees at the office resulted in a consensus that none of them were aware of any garden archaeology projects in the surveys. Gary Curtis, database specialist, conducted a computer search using various keywords and provided a short list of historical sites, some of which had experienced some form of excavation. While all of these documents were not viewed, Mr. Curtis was fairly confident that none of the projects involved gardens.

Washington Department of Archaeology and Historic Preservation, visited May 2005

The database at this office (WISAARD) is not set up for keyword search. It is possible 
to search for words in titles of each project, but that research must be conducted by quad. There are many quads in the state. Also, site numbers for historical sites are no longer designated with an $\mathrm{H}$ (representing "historical"), so it is not possible to use the GIS system to find historical sites. The office does have several publications and reports relating to the Hudson's Bay Company, some of which are not available at the Ft. Vancouver library. These were reviewed and they provided information pertaining to the presence of gardens at $\mathrm{HBC}$ posts.

\section{Review of Literature}

Internet searches of several library catalogs, journal databases and academic search engines, such as Google Scholar, have turned up nothing definitive. A downloadable publication, "Field Guide to Washington Archaeology," mentions several sites (a trading post, several missions and U.S. Army forts, a few towns) that have been archaeologically tested (Stilson, Meatte, Whitlam 2003). A publication of the Archaeological Society of British Columbia, "The Midden," contains an article relating to archaeological investigations at Fort Langley, an HBC post supplied by Fort Vancouver and located east of what is now the city of Vancouver in British Columbia. While a garden is not mentioned, the article notes that European red elderberry seeds were found in a cellar. It is commented that, "The presence of a [sic] 'exotic' plant species early in the history of the fort is very interesting. (author unknown 1997:7). It is not clear from the article how it was determined that these cellars were "early" structures. Certainly the seeds (or plants) to grow these elderberries must have come from Fort Vancouver, particularly if the cellars are from Fort Langley's early history, previous to the HBC moving the majority of the Columbia Department's import and export operations to Fort Victoria on Vancouver Island in 1845 (Erigero 1992:56).

The one example found of an attempt to excavate a garden (Figure 1) is English Camp, a circa 1860s British military site on San Juan Island, between the Straits of Georgia and Juan de Fuca. The area known from photographs to be the formal ("Royal") garden was tested with one,

*This may refer to a nuclear density gauge. 


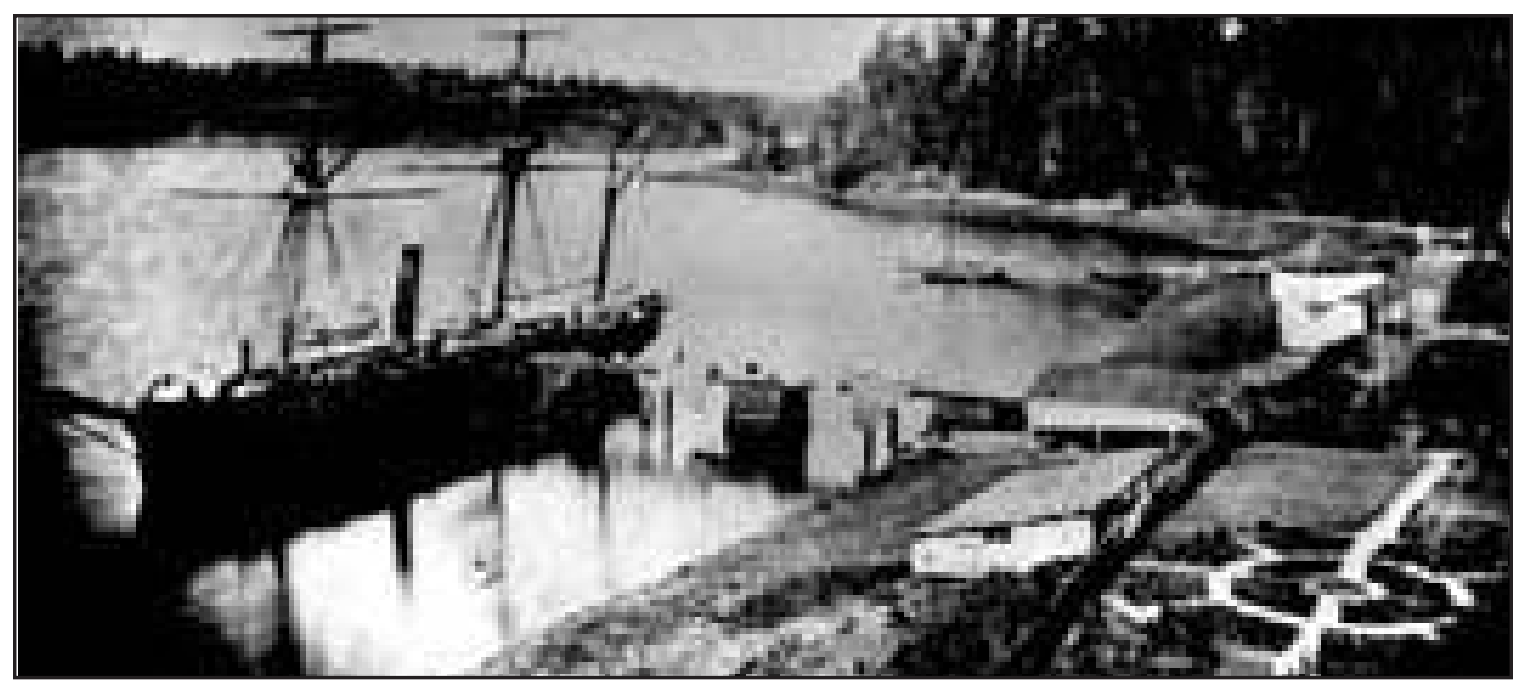

Figure 1. A ca. 1870 photo of English Camp, with the formal garden in lower right corner. Photo courtesy of National Park Service.

two and four probe resistivity, magnetometry, an "atomic source moisture and density gauge,"* and surface stripping (Sprague 1983:10). Evidence of the garden was not found and it was speculated in the report that the garden sediments had been stripped away during the 20th century for use elsewhere at the site.

\section{Contacts Made}

The following archaeologists and anthropologists were contacted via email:

- Dr. David Brauner, Oregon State University: No information.

- Robert Melnick, University of Oregon (UO): No response.

- Dr. Nancy Turner, University of Victoria: No information.

- Madonna Moss, UO: No information.

- Jim McDonald, University of Northern British Columbia: No information from him or his associates.

- Lou Ann Speulda, Fish and Wildlife: Noted Spanish Mission archaeology in California (see Global Archaeology below).

- Brad Bowden, Historical Research Associates: No information. 
- A review of the HistArch website provided a lead to Thomas A. Brown, who presented a paper to the Society for California Archaeology titled, “"Plants are Cultural Artifacts, Too!" in 1997. He may be associated with the Luther Burbank Home and Gardens in Santa Rosa, CA. They were contacted: No response.

- An email was sent via HistArch asking for information: No responses. 


\section{GARDEN ARCHAEOLOGY WORLDWIDE}

This section discusses a variety of forms of garden archaeology. The archaeological investigations discussed below are grouped by continent or region, beginning far afield in both time and geography, and moving towards sites with increased significance to Fort Vancouver. The goal of this research was to examine how other archaeologists have approached garden excavations in order to conduct an informed investigation at Fort Vancouver. It was certainly possible that features such as remains of irrigation trenches, garden bed borders, path surfaces and tree root casts would be found during this investigation. It was also hoped that this information would provide a framework for future archaeologists investigating garden sites in the Pacific Northwest.

Asia

There are several reports on garden excavations conducted in India, generally related to the Islamic Mughal (Mongol) empire. The Mughal territory, growing from north central India in the early 16 th century, encompassed all of India and Afghanistan by the early 18th century. The empire lasted until 1857, although after 1803 the Mughal emperors were "pensioners of the East India Co" (Lal 2005). These emperors were extremely wealthy, creating a "courtly culture" which employed a garden aesthetic, a characteristic of their homelands in central Asia (Lal 2005, Moynihan 2000:6).

The Mughal emperor Babur first built gardens across the Yamuna River from the Taj Mahal, at Agra, in the 16th century. Soon, both sides of the river were filled with the walled enclosures and formal gardens of the wealthy. These gardens were filled with "elaborate renditions of cut-stone architecture, water chutes, standing pools, flowing fountains, and plantings intended to stimulate all the senses" (Moynihan 2000:43). The Mahtab Bagh (Moonlight Garden), was located directly across the Yamuna River from the Taj Mahal. The alignment and width of this garden exactly matches the dimensions of the Taj, 
indicating its significance (Moynihan 2000:6).

The U.S. NPS conducted a 7-year study of Agra (the Agra Heritage Project), concluded in 1995, in reference to Agra's designation as a World Heritage Site. Archaeological investigations of the Mahtab Bagh began in 1996 (Moynihan 2000:6). The investigations consisted of historical document research, a thorough mapping of the surface of the site, an attempt at aerial survey (the remote control plane crashed), the removal of two to three meters of flood silts (which unfortunately were deposited at the edge of the river, covering up any archaeological remains of access to the garden from that location), excavation of architectural remains and paleoethnobotanical analysis, the first conducted at a Mughal site (Moynihan 2000).

The report reviewed does not discuss excavation methodology, simply what was found and where. The focus is largely on architectural features, which included water features (both aesthetic and functional), constructed terraces, tiled surfaces and foundation remains. Botanical analysis began with analyzing the plants that were at the location today. There were three reasons for this: the modern vegetation was documented, the inventory of modern plants could be used as a reference collection for the excavations, and the inventory "helped provide indirect insights into the kind of plants growing there in the past" (Moynihan 2000:44). The majority of the modern plants were weeds, indicating the state of the site today. The edge of the river in this area is cultivated, so there were many annual cultigens. Several species of trees were located on the site, some of them possibly descendents of those planted by the Mughals. The identification of specific modern plants, obtained through pollen analysis, was encouraging for the possibility of identification of plants from the HBC Garden at Fort Vancouver.

Obtaining samples from Mughal proveniences at Agra was more daunting. Coring devices were used to reach through the flood silts to these sediments. Three dozen soil samples were taken for pollen testing, however, analysis showed that the pollen preservation 
was not optimal. It was decided not to waste more time and effort on this form of testing. Flotation and fine screens were employed in areas of minimal disturbance to obtain macrofloral remains. These samples were taken from plaster walkways and terraces at various locations, and activity surfaces related to the square pool in the center of the garden. It is not known how the identifications of surface types was arrived at, as this publication only relates results. The materials obtained were analyzed with light and electron microscopy. Charred remains of cypress, red cedar, cashew, jujube and magnolia trees were found along with charred cockscomb seeds. All but one of these plants (cypress) have a "long history of use" in the area (Moynihan 2000:54). All of the plants are historically documented as being desirable in Mughal gardens, and the cedar and magnolia have night-blooming flowers, appropriate for a Moonlight Garden. It is assumed in the "interpretation of the evidence" that the proveniences in which the various pollen remains were found is the location of the original plant (Moynihan, 2000:54). The majority of garden plants are insect-pollinated. The pollen from these plants is relatively heavy, and generally drops to the ground in the general location of the growing plant (Jacobucci 2007).

\section{Africa}

The Yoruba culture began in Nigeria circa eighth century A.D. The Yoruba people "attached great importance to garden design as art [and] were preoccupied with building elaborate gardens for their deities, kings and chiefs" (Falade 1990:47). Investigating these gardens is difficult as there are no historical documents or plans. Oral traditions are not discussed in the article. The only evidence is that which can be obtained through archaeology. Most Yoruba palace gardens have been altered, with only fragments of the original gardens remaining (Falade 1990).

Archaeological investigations indicate that Yoruba palace gardens were walled-in areas surrounding the palace buildings, consisting of "farm gardens, kitchen gardens, sacred 
gardens with temples, herb gardens, graveyards and wilderness landscaping" (Falade 1990:53). Hard landscaping included paths, temples, monuments and statues. The only provisions for water were areas (impluvium) to catch the rain. Although the article indicates that this evidence was obtained archaeologically, other than aerial survey, the article does not specify what forms of testing were done.

The gardens of a 4th century Romano-African house in Tunisia were excavated by Wilhelmina Jashemski in 1990. The house had a peristyle garden (an open area in the center of the house), and a courtyard garden.

Preliminary soil cores were taken in order to "identify the buried Roman surface" (Jashemski 1995:563). The top 25-30 cm were then removed from the trenches in the gardens. The soil descriptions of the gardens were compared to those of the outlying areas. Several root casts were found in the last occupation layer. The "soil formed when the root decayed was of an entirely different texture and color from that of the surrounding soil" (Jashemski 1995:563). As seen in Figure 2, root casts, even though of a different color and texture, may be difficult to discern during excavation. Figure 3 shows several root casts in which the sediments that replaced the decomposed roots have been removed and cement or plaster has been poured in. The surrounding sediments are then removed, leaving a cast of the root cavity. Three rectangular "cavities," interpreted to be decayed wooden bases for benches or tables were also found. The appearance of the soil

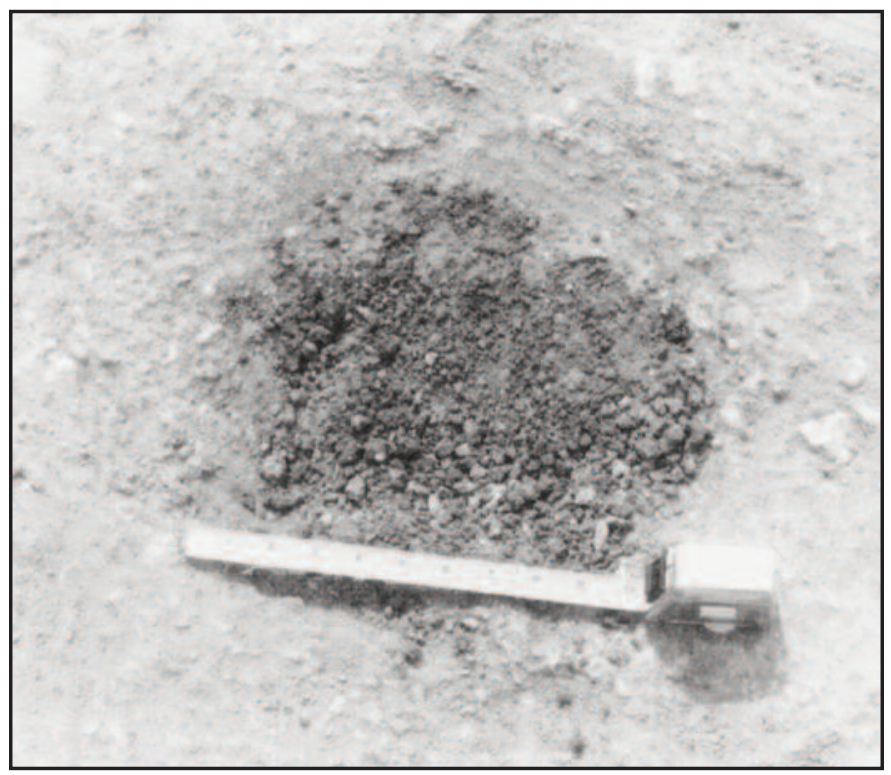

Figure 2. Decayed tree root $23 \mathrm{~cm}$ in diameter (Jashemski 1995:565). 
in these cavities was consistent with the soil in the root casts (Jashemski 1995).

Burned olive pits and bones in the garden provide evidence, similar to other Roman house sites which contain no internal kitchen, of cooking in the courtyard garden, just outside the triclinium, or dining room.

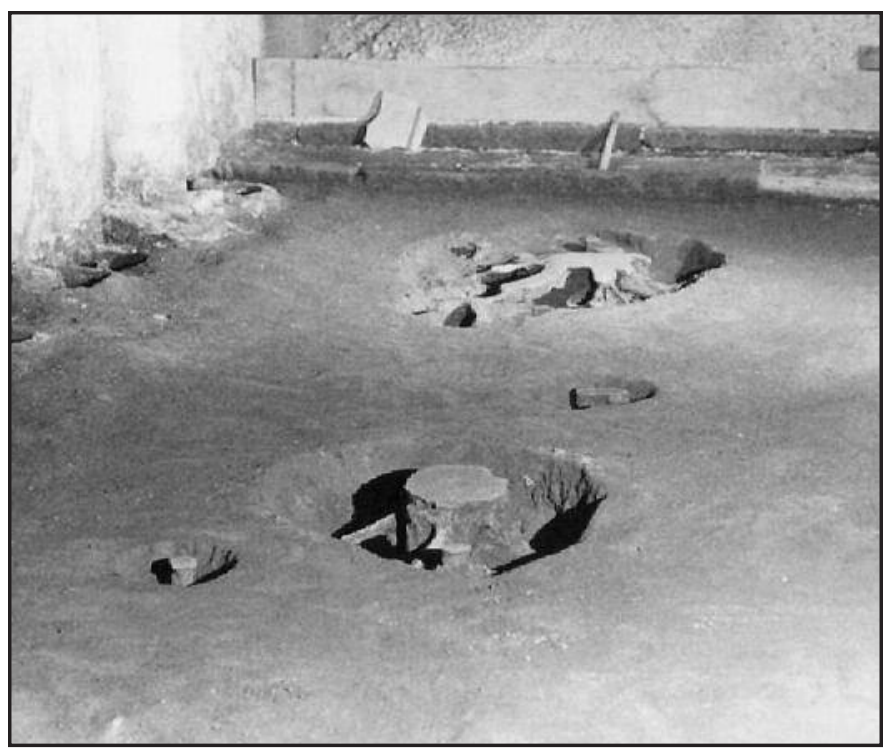

Figure 3. Casts of root cavities (Jashemski 1995:568). The garbage from meal preparation and consumption was burned and then buried (Jashemski 1995).

There is evidence in the peristyle garden, which is located in the family area of the house, of a row of root casts. Jashemski indicates that this represents a produce garden, although she provides no supporting evidence for this statement (Jashemski 1995).

Both of the gardens contain a high frequency of root casts, indicating that they were planted informally and densely. Jashemski states that, based on her experience at several Roman house excavations, that this is not unusual, that not all gardens were formally planted. The shape and size of the root casts were used to infer the identity of the trees planted in the garden: olive, fig and apricot (Jashemski 1995).

Soil testing indicated that the sediment in the gardens was quite different from the sediment from the outlying areas. Specifically it contained several heavy metal components of unknown origin (Jashemski 1995).

The Middle East

Archaeological investigations in 1998 at Petra, Jordan, indicated that what had been 
previously thought to be a marketplace was actually a water garden complex, dated circa 100 BC-AD 100. A "feasibility study" was conducted during the summer of 2001 consisting of ground penetrating radar, soil cores and "strategically placed excavations" (Bedal 2001). Goals of the study related to whether or not an earthen terrace had been a garden and its state of preservation, whether or not certain testing methodologies would apply to garden archaeology, to identify major components, and to obtain as much information as possible with limited expense (Bedal 2001).

A total of 103 transects was run using GPR, with readings every $50 \mathrm{~cm}$ (Bedal 2001). A $400 \mathrm{MHz}$ antenna was used, collecting data to a depth of about 3.5 meters. Horizontal slice maps of the data were created with an amplitude analysis program (Bedal 2001). Several stone structures were identified at an approximate depth of $75 \mathrm{~cm}$ (Bedal 2001). The most well-defined (northern) structure was retested at $25 \mathrm{~cm}$ increments at which point early occupation components were discerned underneath the "garden" terrace (Bedal 2001). A three dimensional representation of the northern structure was created by combining horizontal and vertical slices. The resulting reconstruction indicates that the building had columns on three sides and a solid wall on the fourth (Bedal 2001).

Excavation trenches were placed at three of the major structures indicated by the GPR data, and one trench in an area untested by the GPR as it contained a post-classical raised field. In the case of the northern structure, the GPR unit was dragged over the site, and red flags were placed in the exact locations of the walls of the structure. This allowed for exact placement of the trenches. Excavations in these trenches indicate that the building is post-Nabataean, possibly Byzantine. Its alignment with other, early components of the water garden indicate a continued use of the garden by later peoples. A stone pit was found underneath the building foundations which had not been picked up by the GPR, an indication of possible issues with this type of testing (Bedal 2001).

The GPR also indicated areas with no features, which assisted in the soil testing design. 
Sixteen auger tests were conducted in order to view the stratigraphic sequence on the garden terrace (Bedal 2001). Excavations were planned to be large horizontal units. The author indicated that this would allow for the identification of subtle features such as "tree pits, root cavities and earthen irrigation channels" (Bedal 2001). The soil samples were floated to obtain macrofloral remains. The results of these investigations on the garden terrace are not indicated in the available publication (Bedal 2001). The success of the GPR investigations is undoubtedly related to the structural components of the various occupations, and the fact that the site has been relatively unaltered over the centuries. A summary of more recent work in Water, Life and Civilisation: Climate, Environment and Society in the Jordan Valley (Mithen and Black 2011:213) relates conclusions that the area was, in fact, a water garden, with "ostentatious display," as a representation of the power of rulers in a very arid environment. The central pool was surrounded by gardens that reached to the edge of the city streets, $50 \mathrm{~m}$ away. Excavation methods employed from 2001 to today are not discussed, and reports relating to the project during the last decade are not readily available.

\section{Continental Europe}

Pompeii is a well-published archaeological site. A garden was discovered and partially excavated in 1953-1954. Further excavations in 1972-1974 showed that the site was a commercial flower garden based on the "soil contours, planting pattern, provisions for watering, ancient pollen and perfume bottles" (Jashemski 1979:403). Written documentation indicates that the business of growing flowers for perfumed oils, garlands

and general use was very important in the area. The garden had been badly damaged by modern trees and shrubs that had grown up since the 1952-1954 excavations. This slowed the work down considerably, but several ancient root casts and post holes were found. The soil contours (as confirmed by aerial photography) were wide beds bordered by water 
channels. It was in these channels that the root casts were found. These water channels were fed with water from the roof of the building or poured in from the street. The beds at one end of the garden are higher than at the other, allowing the water to flow naturally throughout the garden (Jashemski 1979).

The soil in the beds had been enhanced with very small fragments of pumice, which would have retained moisture. Soil samples for pollen testing were taken in an area still covered with lapilli (small volcanic rocks). The results of the pollen analysis were qualified by the researcher (Dimbleby), indicating that although he felt that the pollen had been deposited just previous to the eruption, it could have been blown in, brought in with compost or in the water. That said, pollen from olive trees and polypody fern was found. Neither of these plants grow in Pompeii today. There were low frequencies of pine, walnut and hazel, which are wind pollinated plants, indicating that these pollens had blown in (Pearsall 2000). The high frequency of olive, which is an insect-pollinated plant, is quite definitive for olive trees being cultivated in the garden. The frequencies for weeds and grasses were very low, implying that the garden was highly maintained (Jashemski 1979).

The discovery of root casts within terra cotta pots buried in the ground could indicate, based on historical writings, that citron (perhaps lemon) trees were being cultivated in this garden. These pots were found along a wall, which would have been a protected place to grow delicate plants. The remainder of the garden is the wide beds with associated water channels. Although no pollen was found in these beds, it is assumed that they contained flowers.

\section{Britain}

Landscape archaeology in Britain is largely conducted by pedestrian survey ("fieldwork") and aerial reconnaissance. As indicated in Figure 4, an aerial view of the remains of 16th century terraced gardens, this methodology can help immensely in identifying landforms that are distinctly indicative of human intervention on the landscape. 


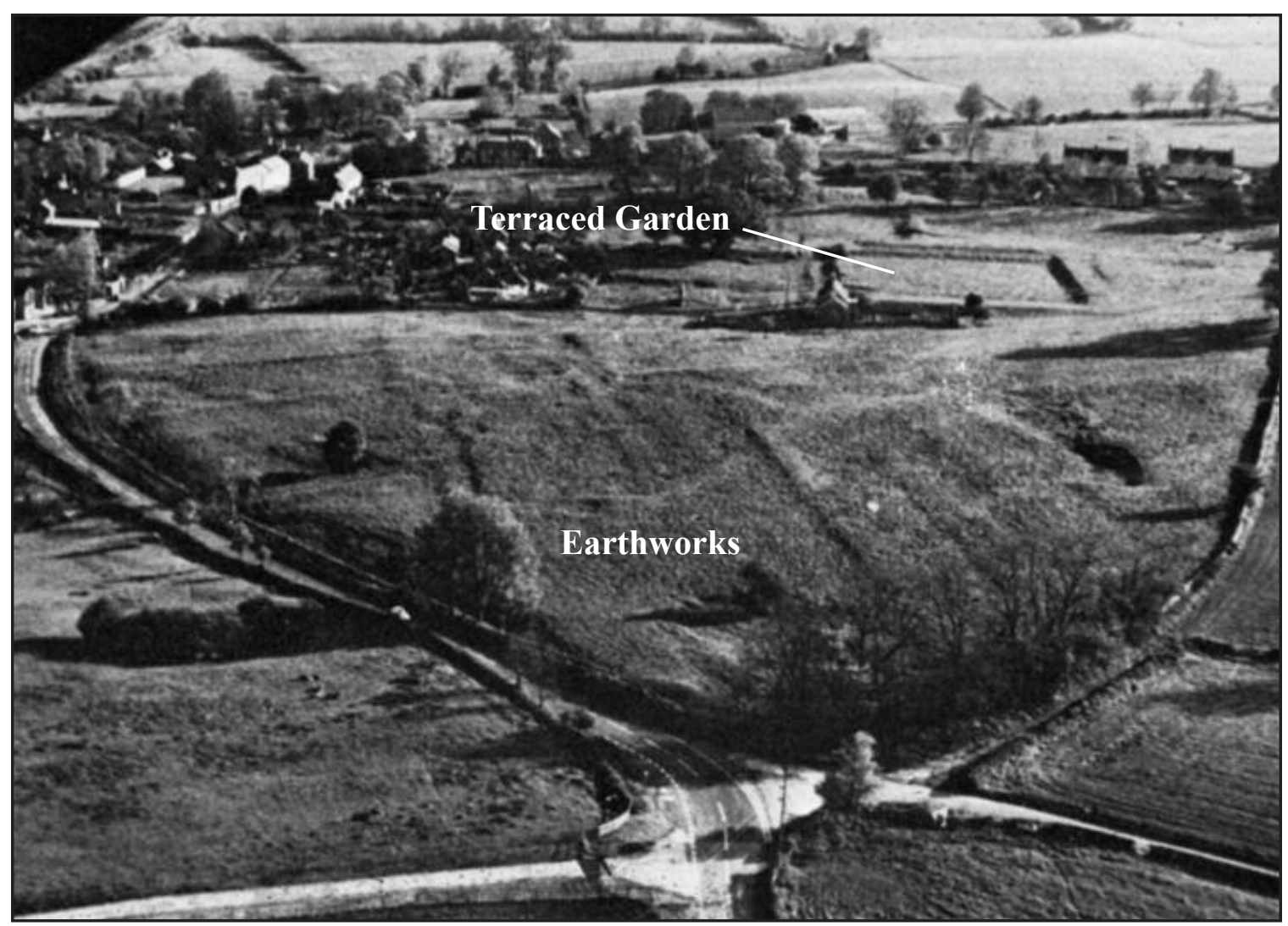

Figure 4. Aerial photo of Medieval "earthworks" and 16th century terraced gardens, evident just below the ground surface (annotations by author) (Aston 1974:171).

Archaeological investigations at Castle Bromwich Hall in 1989-91 were seen as an opportunity to test several techniques in an historical-period garden setting. The remains of gardens at this location were primarily 19th century, the same time frame as the HBC occupation at Fort Vancouver. Surface survey recorded existing buildings and landforms (Currie:1991:81). Geophysical techniques employed were resistivity and magnetometry. Two areas were tested, the Best Garden, which was a lawn at the time of testing, and the Middle Terrace, which contained a mix of trees, shrubs and grass. Transects were spaced at one meter within a $20 \mathrm{~m}$ x $20 \mathrm{~m}$ square. The survey provided valuable information on large, well-defined features, but could not sort changes to the garden over time, the readings becoming confused when features overlapped each other and often not recording features that were found in later excavations. It is also stated that these techniques could not map 
near-surface features, probably due to root disturbance, and surface features confused the readings of features below them. Also, at one meter width transects, many garden beds could be missed entirely. Currie (1991:82) concluded that geophysical survey is of questionable value for investigating historical gardens.

In reference to excavation technique, Currie $(1991: 90,93)$ advocates small test trenches, based on an opposition to the destruction of the archaeological record, and the impossibility, in terms of time and money, of doing large-scale excavations on a landscape. Narrow trenches were dug stratigraphically, and documented with maps, photography and field notes. The results of the excavations included finding hard landscaping: drains, filled-in ponds, gravel paths, planting beds and terraces, and a "complex sequence of activities over the last 400 years" (Currie 1991:93). Figure 5 illustrates a geometrically shaped planting bed, possibly used for carpet bedding (color-coordinated schemes of flowering plants placed close together to create a carpet of flowers), a style that was extremely popular in Britain in the mid-19th century. Meter sticks in the photo indicate that this trench is approximately $2 \mathrm{~m} \times 6 \mathrm{~m}$. It is unclear if this is considered a "small" trench. No description of how the various aspects of this landscaping was discerned in the sediments is provided. As a conclusion on the value of excavation, the author states that it disclosed many garden attributes that would not have been known otherwise (Currie 1991:79).

Soil analysis was also

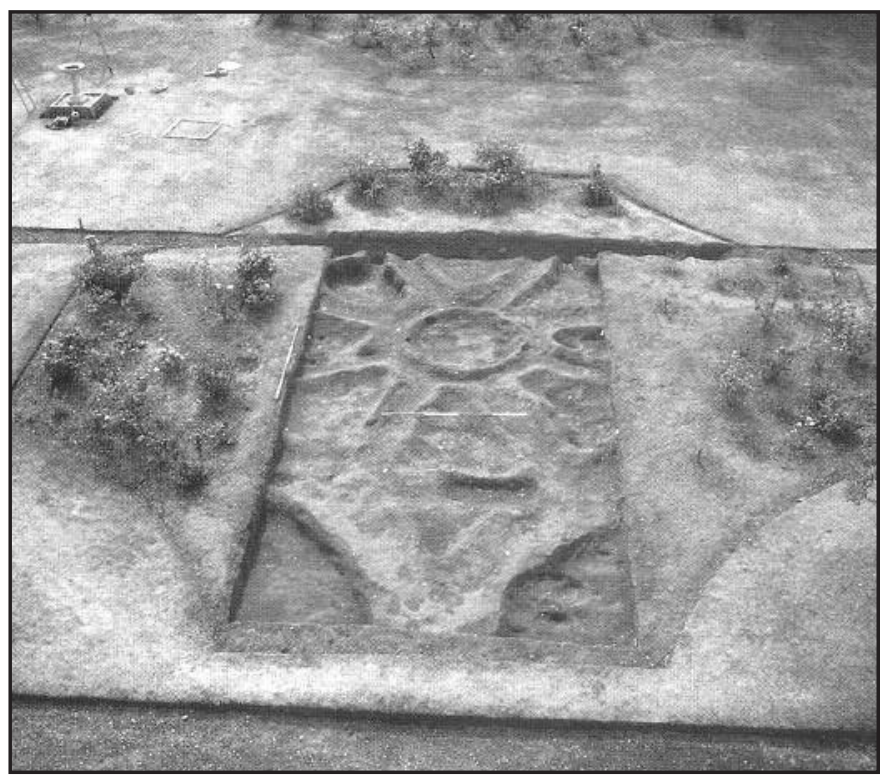

Figure 5. Excavations exposed 1860s skeleton plan of a parterre. (Currie 1991:80) 
conducted at this site. Particle size analysis, which can identify the sources of soils, was of limited use and provided no valuable information. Phosphate percolation* (used to date artificial soil constructions, such as banks and terraces), produced incoherent results. The inference is that mixed soils were used to create the features in the first place. Testing for $\mathrm{pH}$ levels indicated that the natural soils were very low in $\mathrm{pH}$. This would make it extremely difficult to grow healthy plants. The $\mathrm{pH}$ levels in the garden soils were much higher, indicating that considerable enhancement had taken place (Currie 1991:84). High phosphate levels (and excavation) indicated that ash and charcoal had been added to the soils. The level was also sufficiently high to infer that manures and composts had been added. Calcium levels suggest that the soil was limed to lower the acidity. High levels of magnesium would also be produced by the addition of charcoal. Gridded sampling strategies for soil analysis could help to indicate planting beds that have been unrecognizably altered, and the locations of wooden bed edges that had decomposed (Currie 1991:87).

The soils were tested for both bone and botanical remains. It was considered that the acidity of the soil would not be conducive to good preservation, but testing indicated that bone and macrofloral remains were well-preserved. Results of these analyses were pending at publication (Currie 1991:88). Pollen preservation and contamination were also concerns, but again, it was concluded that the pollen was surprisingly well-preserved, and frequencies of various types of pollen were more than adequate to determine those that were "background contamination" (such as grasses). It was concluded that the site had been predominantly pasture, with more trees during the medieval period than later. The frequency of cereal pollen was determined to be too high to be blown in, and it was inferred that it was brought in on straw, possible contained in the manure. Other pollens identified were

\footnotetext{
*A review of articles relating to using phosphate analysis to interpret anthropic sediments did not provide any information on how phosphate percolation could be used to date such sediments. Sjoberg (1976:448) states that phosophorus analysis was being employed in an attempt to provide relative and absolute dates. The science behind this method of dating was not provided, nor were any articles found that derived from these experiments (other than the article above).
} 
holly, hazel, walnut, celery and parsley. Plant identifications were limited to genus. The authors stated that pollen sampling was very valuable to the analysis of historic garden spaces, particularly considering the limited sampling strategy employed on this project (Currie 1991:90).

The soils were also dated with optical luminescence. When mineral grains are exposed to the sun, electrons are trapped in the "lattice" (Currie 1991:91). These electrons are released when the minerals are heated. The rate of release is measured to determine the last date of exposure to sunlight, indicating the date of deposition. Samples were taken from pond and sluice silts. It is not explained why these particular proveniences were appropriate. Although dates of 10,000 BP were obtained from the samples, indicating that the deposits had been contaminated by introduced soils, the author indicated that this testing method has been employed successfully at other sites (Currie 1991:92).

It is indicated that artifact analysis is paticularly valuable in gardens for determining refuse disposal practices. Areas of this garden were identified as "key" disposal areas, possibly to enhance the soil (Currie 1991:92). The focus for this analysis on this project was to provide a chronology for site development, utilizing artifacts such as ceramics. The results of this analysis are documented elsewhere (Currie 1991:92).

Resistivity and magnetometry testing were also conducted at the gardens at Shibden Hall, (also a 400-year-old site), in 1995 (Aspinall 1997). Readings were taken at .5 m intervals across the lawn at the front of the Hall. Anomalies were seen that were inferred to be metal pipes and stone drains. Possible remains of an orchid house were identified, and individual areas of high resistance were interpreted to have been tree plantings. The magnetic survey (Figure 6) picked up the remains of the serpent-shaped flower beds (Figure 7) located at the front of the Hall. 


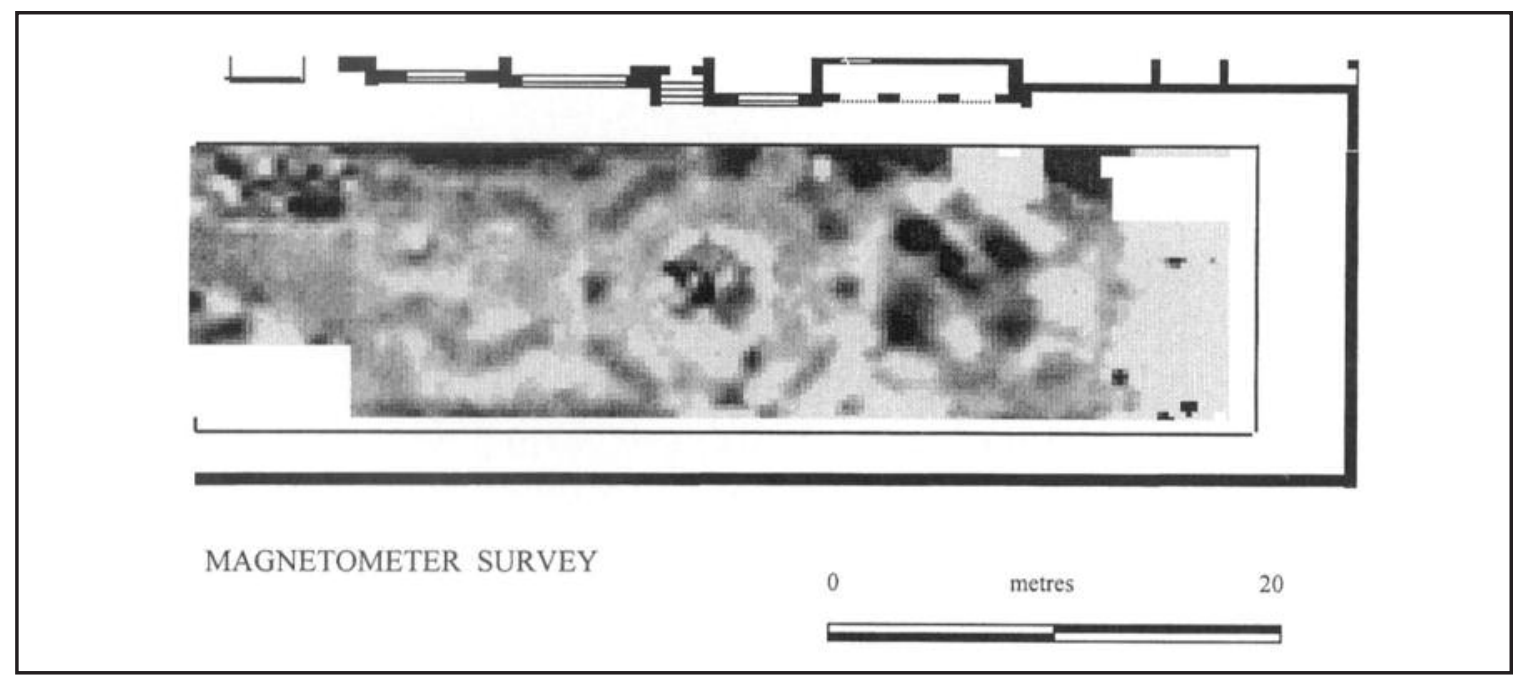

Figure 6. Magnetometer survey showing serpent- and circular-shaped garden beds (Aspinall 1997:226).

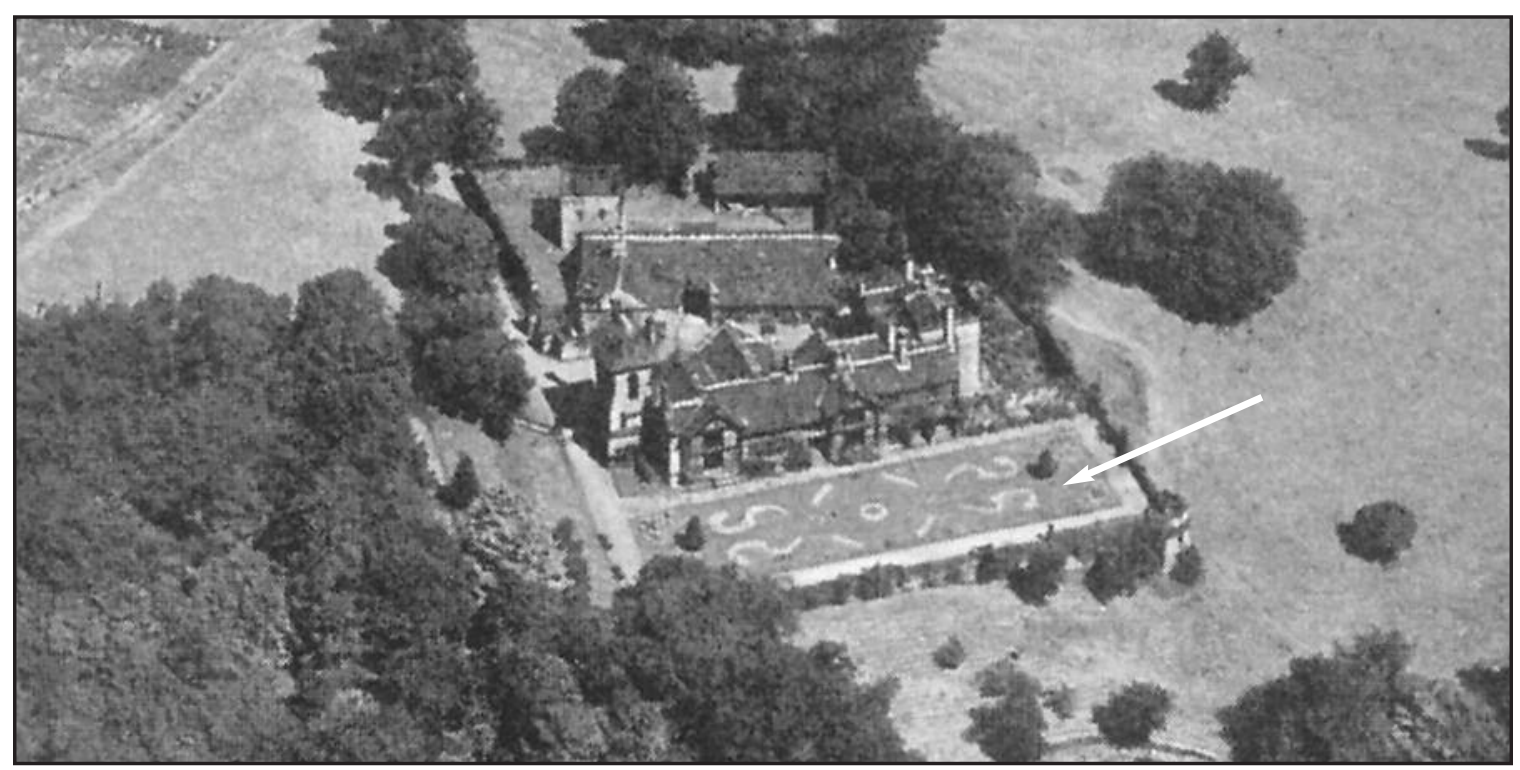

Figure 7. 1930s aerial photo showing serpentine-shaped garden beds at front of Shibden Hall (Aspinall 1997:224).

As previously stated, there is an abundance of information relating to garden archaeology in Britain. The investigations at Castle Bromwich Hall provide a very good overview of the possibilities of various forms of testing, while the project at Shibden Hall shows the value of geophysical testing (in a relatively undisturbed context) to determine excavation strategies. 


\section{Eastern United States}

Miller and Gleason (1994), in The Archaeology of Garden and Field, provide an overview of archaeological techniques that have been applied to finding gardens in primarily colonial sites in the Eastern United States. They state that in the area of the Chesapeake, archaeologists often use heavy machinery to scrape the surface, exposing post holes, walks, and planting beds. This technique is not used in the mid-Atlantic, where gardens are fragmentary aspects of later urban occupations (Miller and Gleason 1994:169). Gardens that have remained intact, largely due to their proximity to estate homes, were continuously replanted, often in the new "revival" styles, creating a palimpsest of original and reused styles. Miller and Gleason note that most archaeological techniques developed for landscape archaeology by archaeologists such as Kelso at Carter's Grove and Noel Hume at Williamsburg cross over into relevance in a garden site (Miller and Gleason 1994:170). However, in gardens, expectations based on the planter's world view, his opinions on the place of nature, and his competitiveness with his neighbors must be included in archaeological research design (Miller and Gleason 1994: 170).

As in the section related to England above, Miller and Gleason advocate remote sensing as invaluable in determining excavation locations that will generate relatively higher quantity and quality of data, vital considerations when an often immense area is being considered for research. Several sites are discussed where the remote sensing results were disappointing, similarly to Castle Bromwich Hall. Even with these difficulties, Miller and Gleason advocate this technique as essential, performing better when finding "tree lines, planting beds and access areas" (Miller and Gleason 1994: 173).

Sub-surface testing methods discussed include (in order of disturbance level): geologists's split spoon auger; steel T-probes (which can indicate buried brick paths and trace building walls); soil cores, post-hole diggers and probes; checkerboard excavation 
strategy; and trenching (Miller and Gleason 1994:174). The less-disturbing methods would be followed up with more extensive excavation.

Key to understanding the spatial use of a garden are the determination of the boundaries, finding the major axes, and determining access (Miller and Gleason 1994:181). When digging trenches over a large area, it is difficult to determine the vertical relationship between the strata. Very close controls of vertical distance must be maintained in order to comment on possible terraces, beds with different uses, and the relationships of features (Miller and Gleason 1994:186).

Generally, the measurements of formal gardens in the 18th century mirror the proportions of the house. For example, the width of a rectangular bed may be consistent with the height of a house. In William Paca's garden, a 3:4:5 rectangle proportion (based on the perch, a measurement equaling 16.5 feet) was used. This proportion stems from pre-13th century and is the basis for the later "rod" length (Nicholson 1912). Geometric dimensions ordered height, depth and width. Applying this measurement methodology to archaeological research design will indicate likely areas of emphasis in a garden (Miller and Gleason 1994:195).

Audrey Noel Hume (1974) discusses colonial garden technology employed at Williamsburg relating to paths and plants. Archaeological testing has indicated that paths were often paved with a mix of tobacco pipe, glass and ceramic, undoubtedly acting similarily to adding gravel to the sediments. Heavy rollers of stone or iron were used to compact, level and smooth surfaces. An 18th century writer, Philip Miller, advocates the rolling of paths when "it rains so very fast that the walks swim with water" (Noel Hume 1974:25). Figure 8 illustrates a horse drawn roller and water tank, with the path being watered after rolling. The exact purpose of this technique is not clear, other than perhaps "melting" the sediments to make them more cohesive with the added elements (gravel, ceramic, etc.). This technology should be identifiable in archaeological contexts, which would contain increased frequencies of artifacts, specifically pipe, ceramic and glass, 
and compacted surfaces.

The well in John Custis' 18th century garden in Williamsburg was a good source for identifiable pollen and macrofloral remains. The waterlogged contents of the well

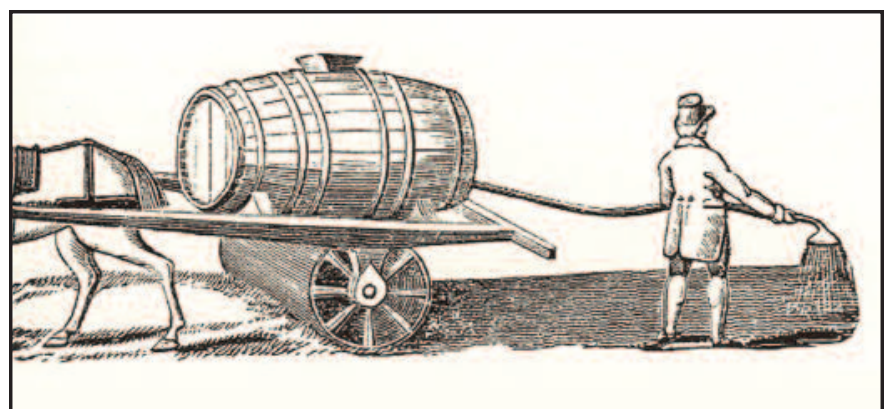

Figure 8. Combination roller, watering equipment (Drower 2001:69).

provided excellent preservation of pollen, twigs, seeds, fruit and even leaves (Noel Hume 1974:31). Dutch boxwood, planted by Custis according to his correspondence, was trimmed some forty years after Custis' death and the clippings thrown into the well. These clippings were still green when brought to the surface during the excavation of the well (Noel Hume 1974:31). The analysis of these materials confirmed written documentation that the garden had contained both native and introduced species, and specifically identified sixteen plants that Custis had indicated in correspondence were growing in his garden (Noel Hume 1974:31). 


\section{APPENDIX B}

Results of 2005 and 2006 Excavations by Unit 
APPENDIX B

Results of 2005 and 2006 Excavations by Unit

\begin{tabular}{|c|c|c|c|c|c|c|c|c|c|c|c|c|c|c|c|c|c|c|c|c|c|c|c|c|c|c|c|c|}
\hline $\begin{array}{l}\tilde{y} \\
\text { ț } \\
2\end{array}$ & & & & 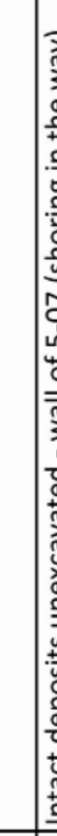 & 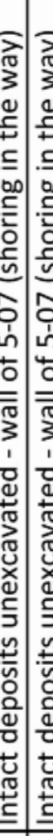 & 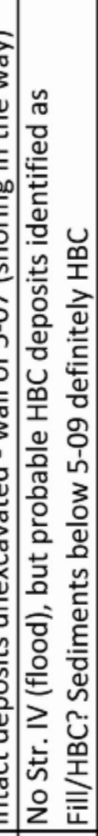 & 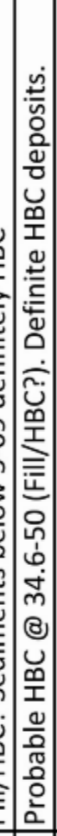 & 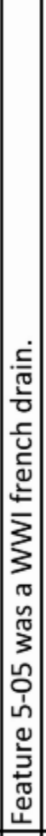 & 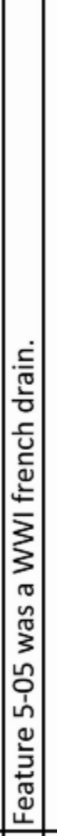 & & & 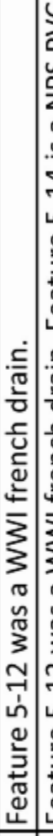 & 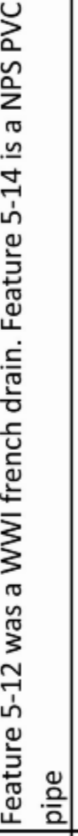 & & 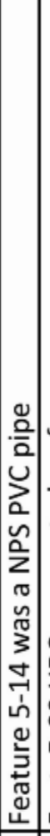 & 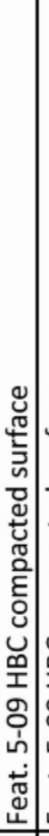 & 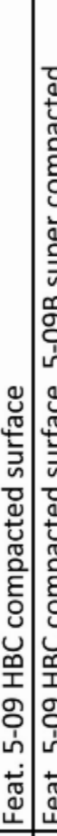 & 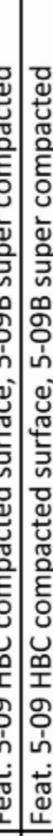 & 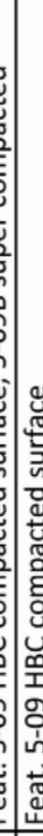 & 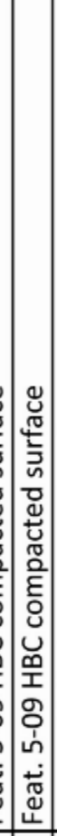 & 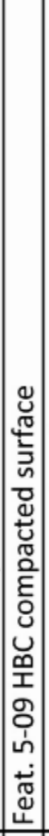 & 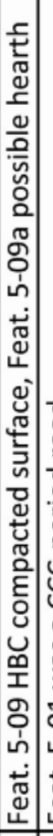 & 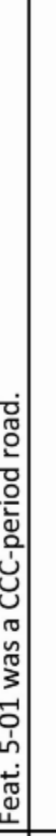 & 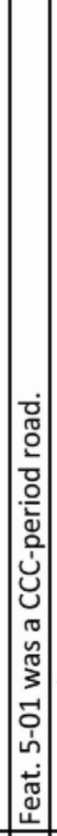 & 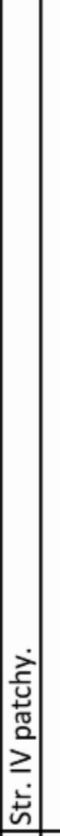 & & & 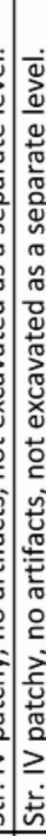 \\
\hline 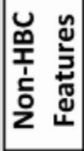 & & 命 & 它 & 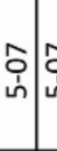 & 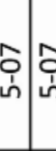 & 今ે & $z$ & $\mid \begin{array}{l}n \\
\text { ஸे } \\
\text { ஸे }\end{array}$ & |r & $z$ & $z$ & ㄱ. & 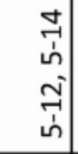 & $z$ & जे & $z$ & $z$ & $z z$ & 2 & $z$ & $z$ & $z$ & $>z$ & $>$ & $z=$ & $z z$ & $z$ & $z$ \\
\hline 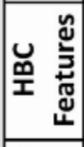 & $z$ & $z$ & $z=$ & $z$ & 羲 & 옴 & 官 & 务 & 是| & 是| & 曷 & $z$ & $z$ & $z$ & $z$ & $>$ & $>>$ & $>>$ & $>$ & $>$ & $>$ & $>$ & $z=$ & $z$ & $z$ & $z z$ & 2 & 2 \\
\hline 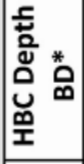 & . & 0 & 0.0 & 00 & 0 & 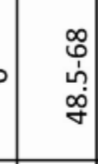 & 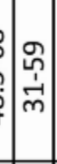 & $\mid \begin{array}{l}0 \\
\\
\\
m\end{array}$ & $\left|\begin{array}{l}0 \\
0 \\
0 \\
1 \\
\end{array}\right|$ & $\mid$ & $\mid \begin{array}{l}n \\
$\cline { 1 - 1 } \\
$\left.\dot{y} \\
\infty \\
m\end{array}\right]$ & & 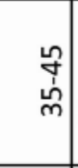 & 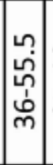 & $\begin{array}{l}\varphi \\
y \\
\vdots \\
n \\
m\end{array}$ & 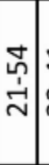 & 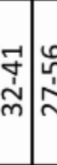 & 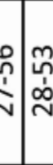 & 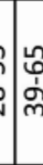 & $\begin{array}{l}0 \\
0 \\
\vdots \\
\vdots\end{array}$ & $\begin{array}{l}\text { 우 } \\
\stackrel{1}{\gamma} \\
\forall\end{array}$ & $\begin{array}{l}-1 \\
0 \\
\dot{m} \\
\dot{\gamma}\end{array}$ & & 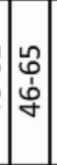 & $\mid \begin{array}{c}1 \\
⿱ \\
⿱ \\
\dot{f} \\
\forall\end{array}$ & 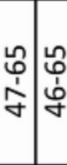 & & 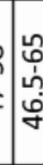 \\
\hline 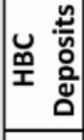 & $z$ & $z$ & $z$ & $z$ & 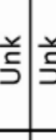 & $>$ & $>$ & $>$ & $>1$ & $>$ & $>>$ & $>$ & $>$ & $>$ & $>$ & $>$ & $>>$ & $>>$ & $1>$ & $>$ & $>$ & $>$ & $>>$ & $>$ & $>$ & $>>$ & $>$ & $->$ \\
\hline 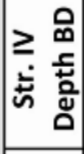 & 0 & 0 & $\circ$ & $\circ c$ & 00 & $\circ$ & $\mid \begin{array}{c}n \\
m \\
m \\
\dot{m} \\
m\end{array}$ & $\begin{array}{l}\vec{p} \\
\dot{\rho} \\
\dot{m}\end{array}$ & 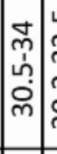 & 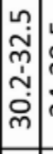 & $\begin{array}{l}n \\
\infty \\
m \\
m \\
\dot{p} \\
m\end{array}$ & $\begin{array}{l}\hat{m} \\
\dot{\omega} \\
\grave{m}\end{array}$ & $\begin{array}{l}\stackrel{\sim}{\tilde{p}} \\
\dot{m} \\
\dot{m}\end{array}$ & $\mid \begin{array}{l}0 \\
\tilde{m} \\
\dot{m} \\
\tilde{m}\end{array}$ & $\sim$ & : & 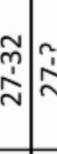 & : & 辛 & $\begin{array}{l}0 \\
⿱ 亠 乂 \\
\grave{m}\end{array}$ & $\left|\begin{array}{c}q \\
\stackrel{\gamma}{\gamma} \\
\dot{\gamma}\end{array}\right|$ & $\begin{array}{l}\text { ₹ } \\
⿱ \\
\text { fे }\end{array}$ & 00 & 0 & \%. & ه & $\mid \begin{array}{l}f \\
f \\
b\end{array}$ & $\hat{n}$ \\
\hline $\begin{array}{l}\geq \\
\dot{\hbar}\end{array}$ & $z$ & $z$ & $z$ & $z$ & 恙 & $z$ & $>$ & - & $>$ & . & & $>$ & & & 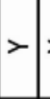 & ح & $>$ & & & $>$ & $>$ & $>$ & $z \mid z$ & $z$ & $>=$ & $z=$ & $>$ & $>$ \\
\hline : & & $\sim$ & $m=$ & $\sigma \Delta$ & C & 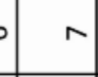 & $\infty$ & $\sigma$ & 의: & $\exists$ & & $\stackrel{m}{-}$ & $\exists$ & 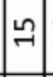 & 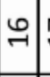 & $\Rightarrow$ & \begin{tabular}{l|l}
$\stackrel{9}{\rightarrow}$ & 9
\end{tabular} & తa & $\bar{\tau}$ & $\approx$ & $\tilde{\sim}$ & $\Delta$ & $\Rightarrow 1 \sim$ & $m$ & $\nabla$ & o & $r$ & $\infty$ \\
\hline 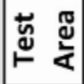 & $\overrightarrow{\mathbb{E}}$ & $\overrightarrow{\mid}$ & $\vec{t}$ & $\vec{s}$ & $\overrightarrow{\mid} \mid \vec{F}$ & $\overrightarrow{\mathbb{5}}$ & 亲 & $\overrightarrow{\mathbb{E}}$ & $\overrightarrow{\mathbb{E}}$ & $\overrightarrow{\mathbb{E}}$ & 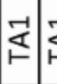 & 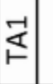 & $\overrightarrow{5}$ & $\overrightarrow{\mathbb{E}}$ & $\overrightarrow{\mathbb{C}}$ & 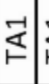 & 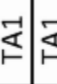 & $\begin{array}{l}1 \\
\mathbb{1}\end{array}$ & $\stackrel{\square}{1}$ & $\overrightarrow{\mid r}$ & 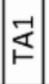 & 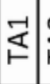 & $\mathbb{\leftarrow} \mathbb{\lessgtr}$ & $\stackrel{\mathbb{\digamma}}{\vDash}$ & $\tilde{\leftarrow} \mid$ & $\underset{1}{\mathfrak{s}}$ & $\stackrel{\mathbb{\alpha}}{\leftarrow}$ & \\
\hline
\end{tabular}




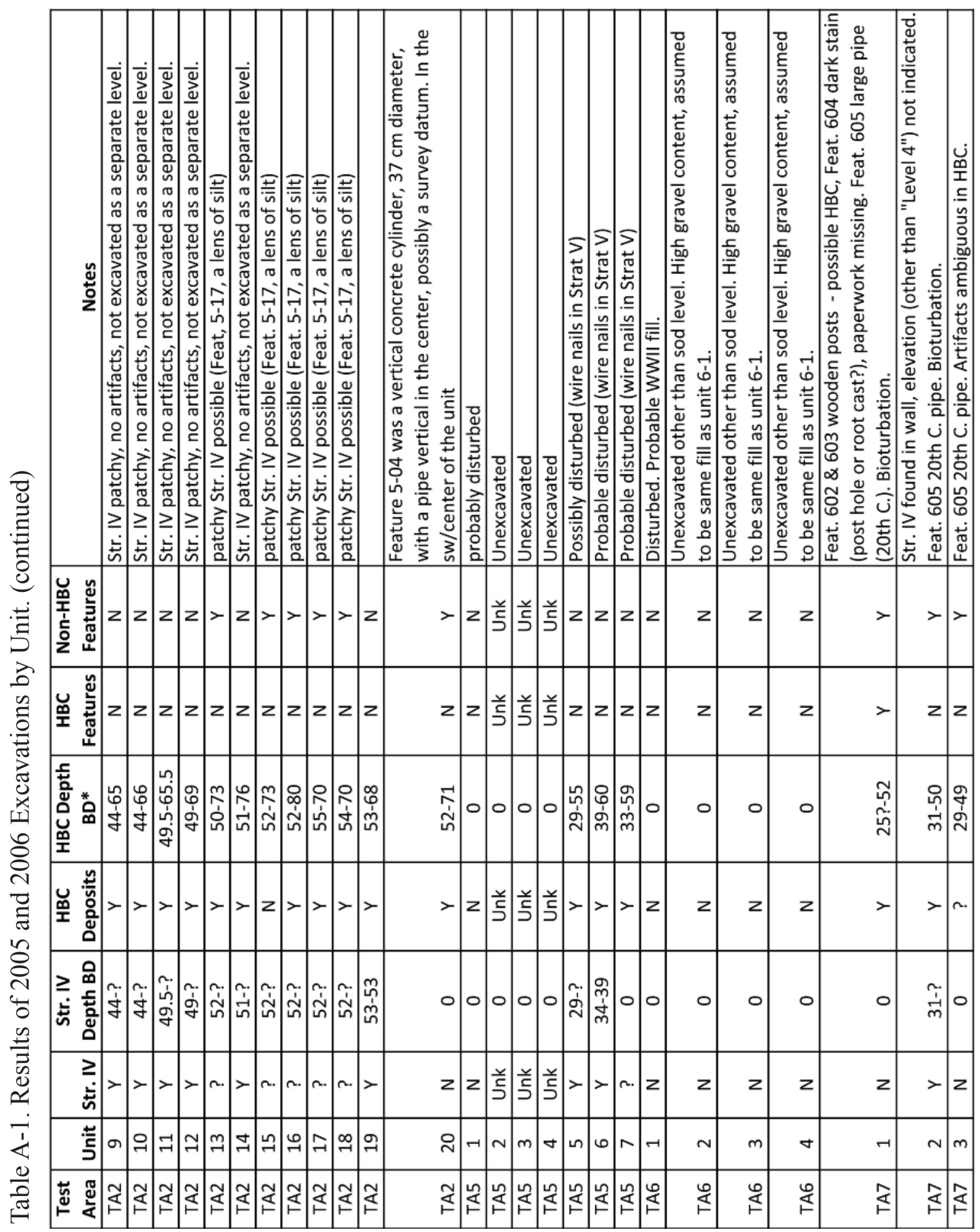




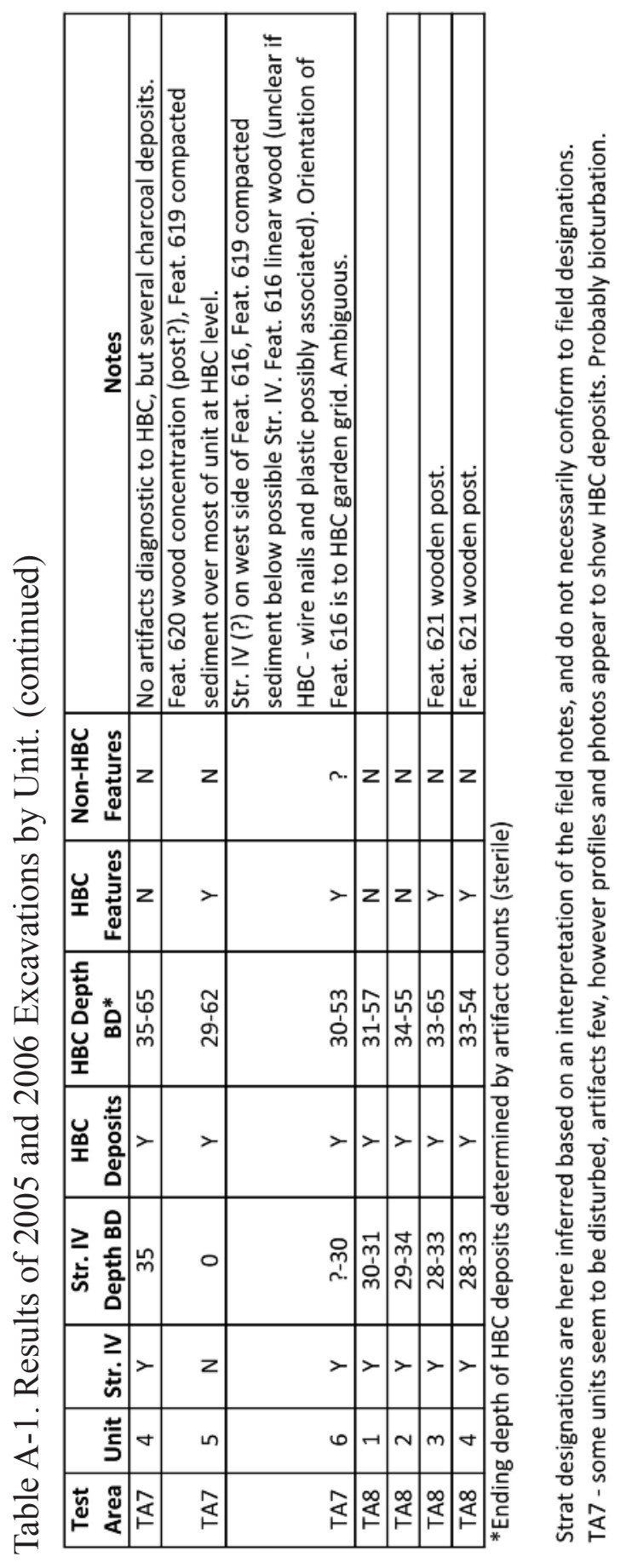




\section{APPENDIX C}

Archaeological Features Inferred to be Related to the Hudson's Bay Company Occupation by Previous Archaeological Testing and Determined to be 20th Century Occupation by Sub-surface Testing During the HBC Garden Project 


\section{APPENDIX C \\ Archaeological Features Inferred to be Related to the Hudson's Bay Company Occupation by Previous Archaeological Testing and Determined to be 20th Century Occupation by Sub-surface Testing During the HBC Garden Project}

These features (Feature 505 and Feature 507) have not been included in the text of this document as they are not related to its focus, the HBC Garden, but rather date to the 20th Century Army occupation. The two features were found in TA1, which had been inferred to be an HBC-period well based on anomalies found during ground penetrating radar testing (Bell 1991). They are included as an Appendix due to the focus that was placed, and resources that were expended on this location during the planning and execution of this project.

Feature 507, discovered in 2005 and continued with safety-shoring in 2006, was the southern half of an extensive trash deposit containing corrugated roofing metal, concrete tiles with red, yellow, and blue paint stains on their surfaces, white porcelain wall tiles, a largely intact toilet, manufactured by The T.P. Co., Trenton, N.J. patent date 1890, concrete sewer pipe (not used at this site until the 1930s or 1940s), metal machinery parts, and many other industrial artifacts. Below the trash deposit were the remains of several large, milled wooden timbers (cribbing) laid at right angles, creating a square shape (the northern side of the square continued into the north wall of the trench and the cribbing on the west side had been displaced) with associated wire nails (Figure B-1). The two visible wooden timbers were $96 \mathrm{~cm}$ and $115 \mathrm{~cm}$ long, and $30 \mathrm{~cm}$ in depth. At a depth of $144 \mathrm{cmbd}$, just below the bottom of the wooden cribbing, a complete alcohol bottle was found, embossed with the text, "Federal Law Forbids Sale or Reuse of This Bottle." This statement was embossed on alcohol bottles from 1935 to 1964 . This date provides a TPQ for the Feature 507 trash of 1935. The wooden cribbing is likely from a WWI dry well, due to the association of a french drain (Feature 505) sloping into the area of the cribbing from the east (Figure B-2), with another possible French drain sloping in from the west (Feature 512). French drains were employed 
to dispose of waste water at this site during WWI. A shovel test was dug into sediments below the cribbing (from $199 \mathrm{cmbd}$ to $260 \mathrm{cmbd}$ ), showing a 9-10 cm layer of silt and natural C horizon sediments below the silt, indicating that the feature is not an HBC-period water well.

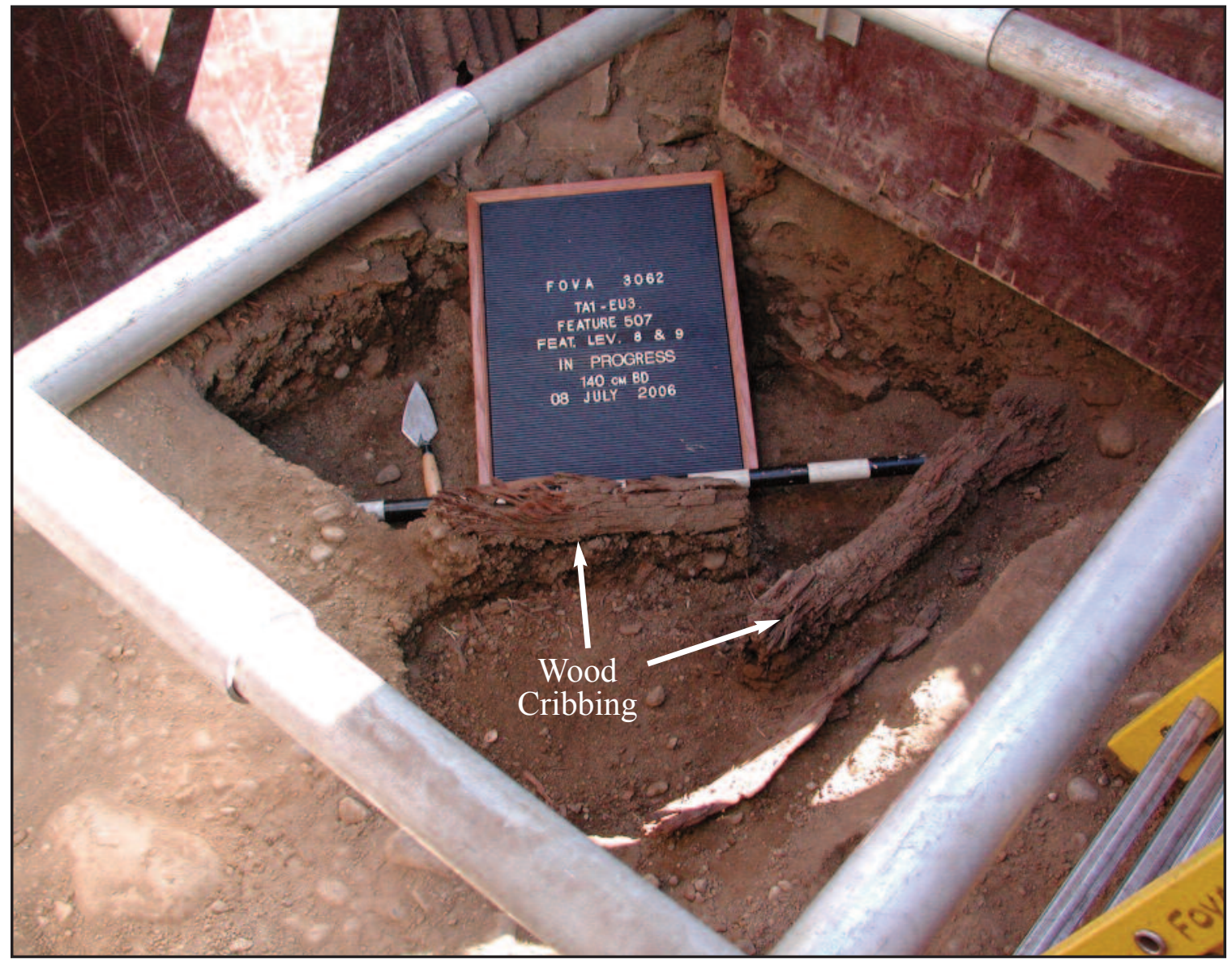

Figure B-1. Facing north, Feature 507 wooden cribbing. The metal tubes are shoring for the deep excavation. Photo courtesy of the National Park Service. 


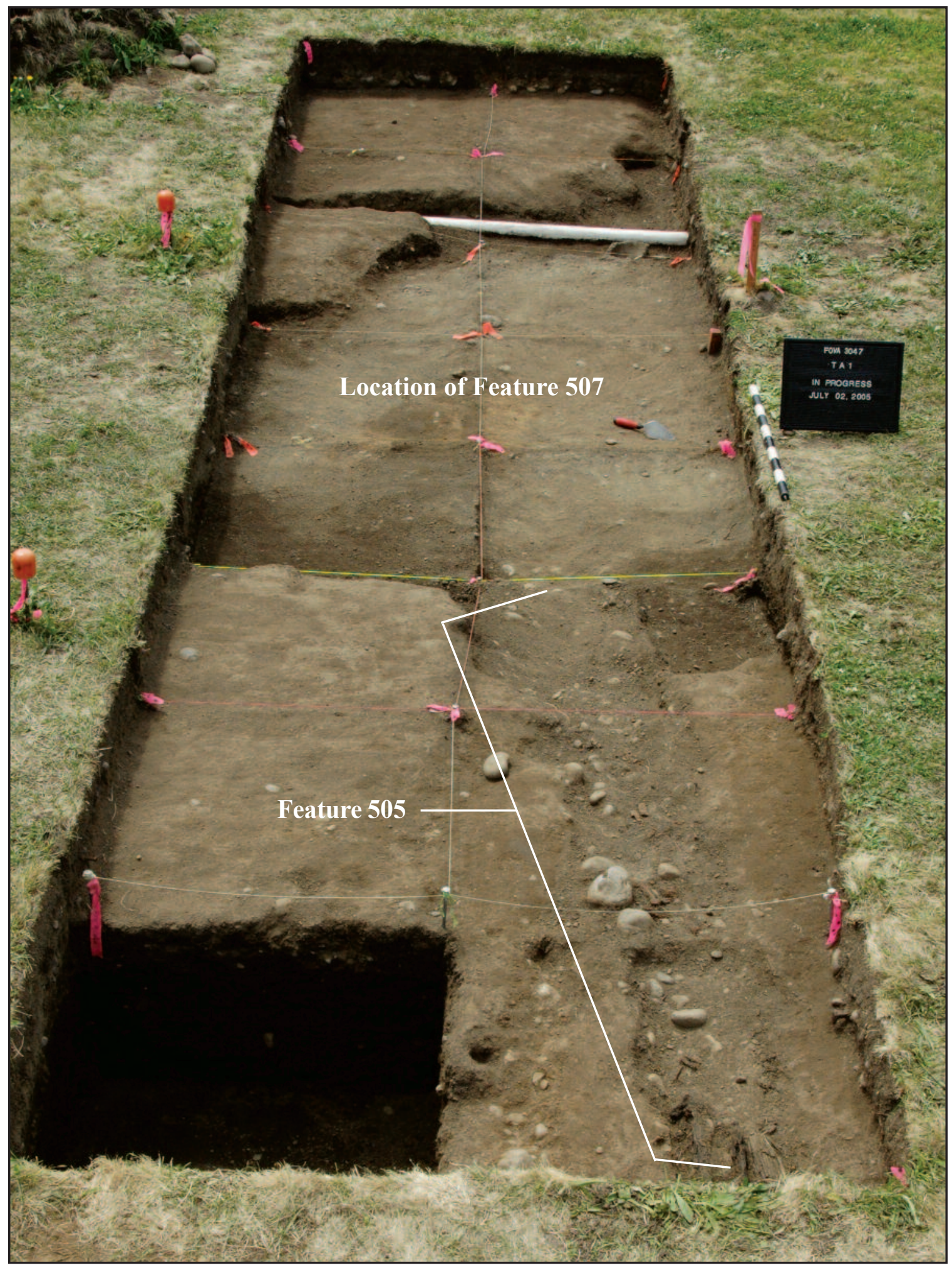

Figure B-2. Facing west, Feature 505 French drain trench, with associated rocks and wood fragments. Feature 507 (post-1935 trash deposit and WWI dry well) was found in the excavation units at the center of the trench. Photo courtesy of the National Park Service. 


\section{APPENDIX D}

Phytolith Analysis of Samples from Ft. Vancouver National Historic Site, Washington 
PHYTOLITH ANALYSIS OF SAMPLES FROM

FT. VANCOUVER NATIONAL HISTORIC SITE, WASHINGTON

By

Linda Scott Cummings

Paleo Research Institute Golden, Colorado

Paleo Research Institute Technical Report 06-51

\section{Prepared For}

Vancouver National Historic Reserve Vancouver, Washington

August 2006 


\section{INTRODUCTION}

Four samples from Ft. Vancouver National Historic Site, Washington, were submitted for phytolith analysis. This historic site is a nineteenth century fur-trade post located along the Columbia River. Samples were recovered from a compacted surface possibly associated with a well and two stratigraphic units within a possible historic garden area maintained by the Hudson's Bay Company, as well as from the modern surface.

\section{METHODS}

Extraction of phytoliths from these sediments was based on heavy liquid floatation. Sodium hypochlorite (bleach) was first used to destroy the organic fraction from $50 \mathrm{ml}$ of sediment. Once this reaction was complete, the samples were rinsed to remove the bleach. If the samples contained calcium carbonates, they were reacted with hydrochloric acid, then the samples were rinsed until neutral. A small quantity of sodium hexametaphosphate was added to each sample once it reached neutrality, then the samples were allowed to settle according to Stoke's Law in settling columns. This process was repeated with EDTA. These steps remove clay prior to heavy liquid separation. Next the samples were freeze dried. The dried silts and sands were then mixed with sodium polytungstate (density 2.3) and centrifuged to separate the phytoliths, which will float, from the other silica, which will not. Phytoliths, in the broader sense, may include opal phytoliths and calcium oxalate crystals. Calcium oxalate crystals are formed by Opuntia (prickly pear cactus) and other plants including Yucca, and are separated, rather than destroyed, using this extraction technique, if these forms have survived in the sediments. Any remaining clay is floated with the phytoliths, and is further removed by mixing with sodium hexametaphosphate and distilled water. The samples are then rinsed with distilled water, then alcohols to remove the water. After several alcohol rinses, the samples are mounted in cinnamaldehyde for counting with a light microscope at a magnification of 500x. Phytolith diagrams are produced using Tilia, which was developed by Dr. Eric Grimm of the Illinois State Museum for diagraming pollen.

\section{PHYTOLITH REVIEW}

Phytoliths are silica bodies produced by plants when soluble silica in the ground water is absorbed by the roots and carried up to the plant via the vascular system. Evaporation and metabolism of this water result in precipitation of the silica in and around the cellular walls. Opal phytoliths, which are distinct and decay-resistant plant remains, are deposited in the soil as the plant or plant parts die and break down. They are, however, subject to mechanical breakage and erosion and deterioration in high $\mathrm{pH}$ soils. Phytoliths are usually introduced directly into the soils in which the plants decay. Transportation of phytoliths occurs primarily by animal consumption, man's gathering of plants, or by erosion or transportation of the soil by wind, water, or ice.

The three major types of grass short-cell phytoliths include festucoid, chloridoid, and panicoid. Smooth elongate phytoliths are of no aid in interpreting either paleoenvironmental conditions or the subsistence record because they are produced by all grasses. Phytoliths 
tabulated to represent "total phytoliths" include the grass short-cells, buliform, trichome, elongate, and dicot forms. Frequencies for all other bodies recovered are calculated by dividing the number of each type recovered by the "total phytoliths".

The festucoid class of phytoliths is ascribed primarily to the Subfamily Pooideae and occur most abundantly in cool, moist climates. However, Brown (1984) notes that festucoid phytoliths are produced in small quantity by nearly all grasses. Therefore, while they are typical phytoliths produced by the Subfamily Pooideae, they are not exclusive to this subfamily. Chloridoid phytoliths are found primarily in the Subfamily Chloridoideae, a warm-season grass that grows in arid to semi-arid areas and require less available soil moisture. Chloridoid grasses are the most abundant in the American Southwest (Gould and Shaw 1983:120). Bilobates and polylobates are produced mainly by panicoid grasses, although a few of the festucoid grasses also produce these forms. Panicoid phytoliths occur in warm-season or tall grasses that frequently thrive in humid conditions. Twiss (1987:181) also notes that some members of the Subfamily Chloridoideae produce both bilobate (Panicoid) and Festucoid phytoliths. "According to (Gould and Shaw 1983:110) more than $97 \%$ of the native US grass species $(1,026$ or 1,053$)$ are divided equally among three subfamilies Pooideae, Chloridoideae, and Panicoideae" (Twiss 1987:181).

Buliform phytoliths are produced by grasses in response to wet conditions and are to be expected in wet habitats of floodplains and other places. Trichomes represent silicified hairs, which may occur on the stems, leaves, and the glumes or bran surrounding grass seeds.

Diatoms and sponge spicules also were noted. Long diatoms are cosmopolitan, occurring in many sediments. They indicate at least some soil moisture. Sponge spicules represent fresh water sponges. Their presence in these samples probably indicates wind transport of lacustrine deposits. For instance, in Illinois their recovery in upland soils is noted to accompany loess deposits derived from floodplains (Jones and Beavers 1963).

\section{DISCUSSION}

Ft. Vancouver is a $19^{\text {th }}$ century fur-trade post located on the Columbia River in Washington and exhibits minimal evidence of pre-contact Native American use. Historic components later than the fur-trade post include early US Army Occupation (from 1849 until today), WWI Spruce Mill and Air Base, CCC Headquarters, and National Park Service from the 1950 s until present. Local vegetation is typical of an urban area and includes planted grassy fields, open areas, and mixed grass and tree areas. During the historic area, an 8-acre formal garden was created and maintained by the Hudson's Bay Company between approximately 1829 and 1855 . Both kitchen and decorative plants were grown mixed together. Fruit trees, including citrus trees, were planted within the formal garden, as well as to the west. A summerhouse or greenhouse was present on the property, as were root cellars. Phytolith samples were collected from the "garden testing area".

Phytolith analysis is particularly suited to identifying grasses. Cultivated cereals also are grasses, so this analysis has the potential to identify the presence or probable presence of cultivated cereals. Most fruit trees, as well as many kitchen plants and decorative plants, do not 
produce unique phytoliths (or any phytoliths at all) in their leaves or stems. Some of the fruits do produce phytoliths. The vast majority of the phytoliths recovered from the samples examined represent grasses.

Sample 434-1 represents the modern surface (Table 1). This sample was dominated by festucoid grass short cells (Figure 1), among which circular and crenate forms are the most abundant. These represent the grasses planted in the area. In addition, a few grass short cells typical of those produced by chloridoid and panicoid grasses were observed. As noted by Twiss (1987:181), festucoid grasses produce small quantities of short cells that are typical of those produced by chloridoid and panicoid grasses. Therefore, it is most likely that all of the grass short cells represent festucoid or cool season grasses planted in this area. Buliforms are surprisingly absent in this sample. These large forms represent cells that control leaf rolling as a response to dry conditions. Buliforms will silicify when the grasses have received sufficient water and do not exercise this function (leaf rolling) regularly. Given the site location, it is surprising that buliforms are absent from the modern record and rare in the historic record. Trichomes represent acicular hair cells on grasses, and as such, represent part of the grass assemblage. Elongates also are produced in grasses and represent grasses in general. Long diatoms are ubiquitous in sediments, so their recovery here is no surprise. A small quantity of sponge spicules were present. These forms are found in moist sediments. It is rare to recover sponge spicules from sediments that exhibit no buliforms.

The historic record is represented by samples 421-1, 423-1, and 424-1, collected from a compacted surface that might have been associated with a well in an historic garden maintained by the Hudson's Bay Company, and two more samples from the historic garden area. These samples are quite similar to one another and also similar to the modern surface sample. Again, festucoid grass short cells dominate the record, with circular and crenate forms the most abundant of these cells. Forms typical of chloridoid and panicoid grasses also were observed but were not abundant. Once again, it is likely that they were produced by the cool season (festucoid) grasses growing in this area. Elongate forms are typical of all grasses. The elongate dendritic cells might have been produced by either brome grasses or cereals. If they represent brome grasses, then they are part of the record of local vegetation growing in the area. If they represent cereals, then they might be present as a result of horses walking through the area and leaving dung, provided that the horses had been allowed to eat stalks of cereals or cereal grains. Alternatively, they might be present through the use of kitchen scraps as part of a compost mix for the gardens. When these cells are broken apart rather than retained as sheet elements, as they often are in sediment samples, identification separating brome grasses and cereals is very difficult. A single epidermal tissue fragment with wavy cell margins was observed in sample 421-1. This epidermal fragment represents leaf tissue from a plant that cannot be identified to genus or family, since epidermal fragments with wavy or angular edges are common in many plants. Recovery of a single spiny spheroid in sample 4231 suggests the presence of a weedy spurge. It is possible that another plant is represented, but this form is well known from Euphorbia. Long diatoms are present in all of the samples in small quantities, while round diatoms are present only in sample 424-1, which yielded a single sponge spicule. Recovery of the round diatoms and a sponge spicule in this sample is consistent with moist sediments. 


\section{SUMMARY AND CONCLUSIONS}

Phytolith analysis of three samples from the historic garden area maintained by the Hudson's Bay Company and a single modern surface sample substantiate growth of grasses in all areas sampled. An abundance of grass long and short cells was recovered from each of the samples. Non-grass phytoliths were extremely rare in these records. Examination of these samples for pollen would likely yield more evidence of plants grown in the area, since the strength of phytolith analysis at this latitude is in identifying grasses. Recovery of dendritic elongate forms might reflect either growing brome grasses or the presence of cereals. Pollen analysis might weil help clarify this issue. 
TABLE 1

PROVENIENCE DATA FOR SAMPLES FROM SITE FOVA 3047

\begin{tabular}{|c|c|c|c|l|l|}
\hline $\begin{array}{c}\text { Sample } \\
\text { No. }\end{array}$ & $\begin{array}{c}\text { Feature } \\
\text { No. }\end{array}$ & Level & $\begin{array}{c}\text { Depth } \\
\text { (cmbd) }\end{array}$ & $\begin{array}{l}\text { Provenience/ } \\
\text { Description }\end{array}$ & Analysis \\
\hline $434-1$ & & & & Modern surface control & Phytolith \\
\hline $421-1$ & $5-09$ & 6 & 605 & $\begin{array}{l}\text { Soil sample from a compacted surface, } \\
\text { possibly associated with a well, in an historic } \\
\text { garden maintained by Hudson's Bay } \\
\text { Company }\end{array}$ & Phytolith \\
\hline $423-1$ & 6 & 62 & $\begin{array}{l}\text { Soil sample from an historic garden } \\
\text { maintained by Hudson's Bay Company }\end{array}$ & Phytolith \\
\hline $424-1$ & 8 & 55.5 & $\begin{array}{l}\text { Soil sample from an historic garden } \\
\text { maintained by Hudson's Bay Company }\end{array}$ & Phytolith \\
\hline
\end{tabular}




\section{REFERENCES CITED}

Brown, Dwight A. 1984 Prospects and Limits of Phytolith Key for Grasses in the Central United States. Journal of Archeological Science 11:345-368.

Gould, F. N. and R. B. Shaw 1983 Grass Systematics. Texas A\&M University Press, College Station.

Jones, Robert L. and A.H. Beavers 1963 Sponge Spicules in Illinois Soils. Soil Science Proceedings:438-440.

Twiss, Page C.

1987 Grass-Opal Phytoliths as Climatic Indicators of the Great Plains Pleistocene. In Quaternary Environments of Kansas, edited by W. C. Johnson, pp. 179-188. 5 ed. Kansas Geological Survey Guidebook Series. 


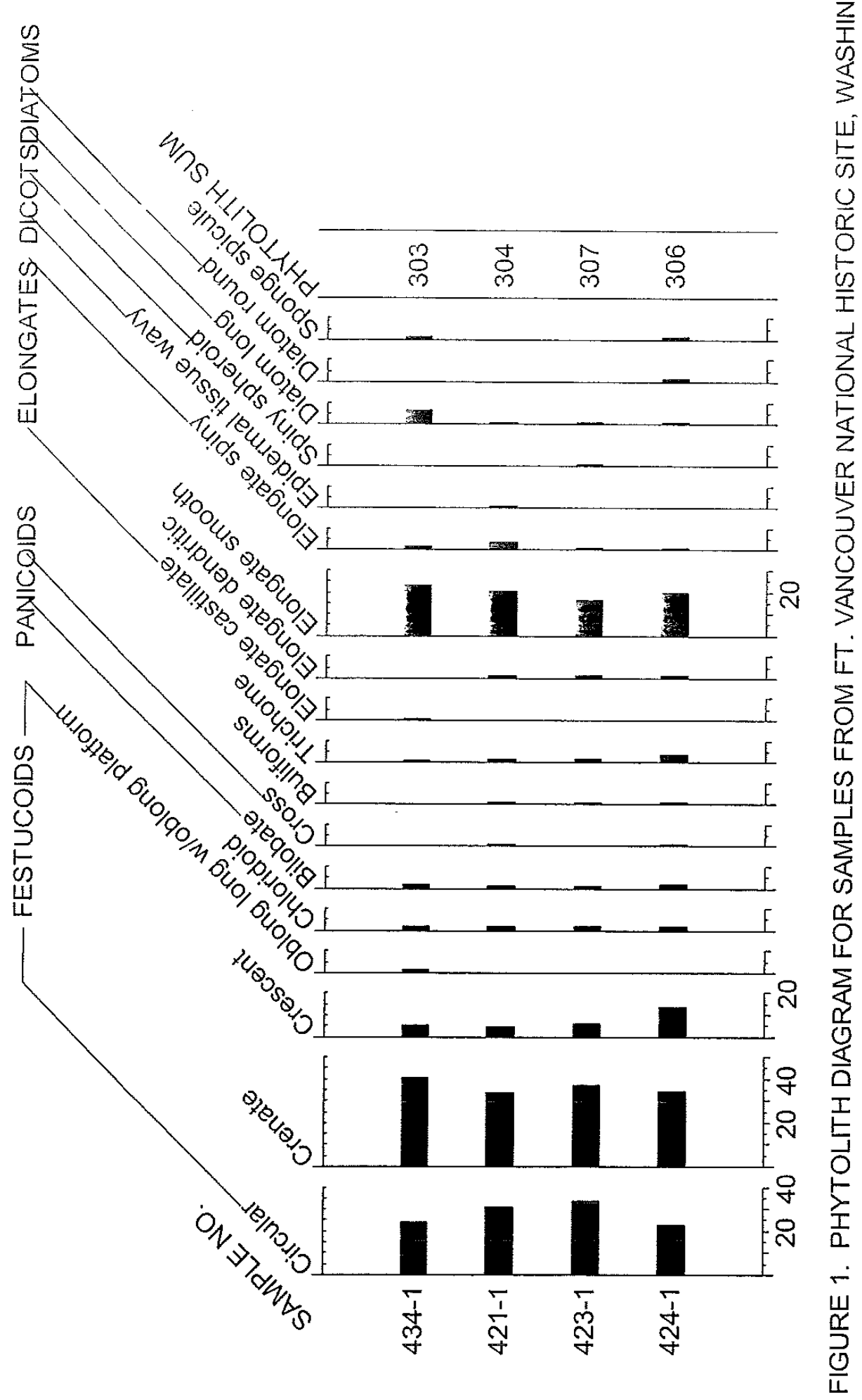




\section{APPENDIX E}

Pollen and Phytolith Analysis of a Historic Garden at Fort Vancouver National Historic Site, Vancouver, Washington 


\title{
POLLEN AND PHYTOLITH ANALYSIS OF A HISTORIC GARDEN AT FORT VANCOUVER NATIONAL HISTORIC SITE, VANCOUVER, WASHINGTON
}

\author{
By \\ Linda Scott Cummings \\ Paleo Research Institute, Inc. \\ Golden, Colorado
}

Paleo Research Institute Technical Report 06-91

\author{
Prepared For
}

Fort Vancouver National Historic Site

National Park Service

Vancouver, Washington

March 2007 
Pollen and phytolith samples were examined from locations thought to belong to a historic garden area that was part of Fort Vancouver. Samples were examined from seven different excavation units, some of which were associated with features. This analysis focused on identifying any plants that might have been planted in the gardens and describing local vegetation.

\section{METHODS}

\section{Pollen}

A chemical extraction technique based on flotation is the standard preparation technique used in this laboratory for the removal of the pollen from the large volume of sand, silt, and clay with which they are mixed. This particular process was developed for extraction of pollen from soils where preservation has been less than ideal and pollen density is lower than in peat.

Hydrochloric acid (10\%) is used to remove calcium carbonates present in the soil, after which the samples are screened through 150 micron mesh. The samples are rinsed until neutral by adding water, letting the samples stand for 2 hours, then pouring off the supernatant. A small quantity of sodium hexametaphosphate is added to each sample once it reaches neutrality, then the samples are allowed to settle according to Stoke's Law in settling columns. This process is repeated with ethylenediaminetetraacetic acid (EDTA). These steps remove clay prior to heavy liquid separation. The samples are then freeze dried. Sodium polytungstate (SPT), with a density 1.8 , is used for the flotation process. The samples are mixed with SPT and centrifuged at $1500 \mathrm{rpm}$ for 10 minutes to separate organic from inorganic remains. The supernatant containing pollen and organic remains is decanted. Sodium polytungstate is again added to the inorganic fraction to repeat the separation process. The supernatant is decanted into the same tube as the supernatant from the first separation. This supernatant is then centrifuged at 1500 $\mathrm{rpm}$ for 10 minutes to allow any silica remaining to be separated from the organics. Following this, the supernatant is decanted into a $50 \mathrm{ml}$ conical tube and diluted with distilled water. These samples are centrifuged at $3000 \mathrm{rpm}$ to concentrate the organic fraction in the bottom of the tube. After rinsing the pollen-rich organic fraction obtained by this separation, all samples receive a short (20-30 minute) treatment in hot hydrofluoric acid to remove any remaining inorganic particles. The samples are then acetolated for 3-5 minutes to remove any extraneous organic matter.

A light microscope is used to count the pollen to a total of approximately 100 to 200 pollen grains at a magnification of $500 x$. Pollen preservation in these samples varied from good to poor. Comparative reference material collected at the Intermountain Herbarium at Utah State University and the University of Colorado Herbarium was used to identify the pollen to the family, genus, and species level, where possible.

Pollen aggregates were recorded during identification of the pollen. Aggregates are clumps of a single type of pollen, and may be interpreted to represent pollen dispersal over short distances, or the introduction of portions of the plant represented into an archaeological setting. Aggregates were included in the pollen counts as single grains, as is customary. The presence of aggregates is noted by an " $\mathrm{A}$ " next to the pollen frequency on the pollen diagram. Pollen diagrams are produced using Tilia, which was developed by Dr. Eric Grimm of the Illinois State 
Museum. Total pollen concentrations are calculated in Tilia using the quantity of sample processed in cubic centimeters (cc), the quantity of exotics (spores) added to the sample, the quantity of exotics counted, and the total pollen counted and expressed as pollen per cc of sediment.

Indeterminate pollen includes pollen grains that are folded, mutilated, and otherwise distorted beyond recognition. These grains are included in the total pollen count, as they are part of the pollen record. The charcoal frequency registers the relationship between pollen and charcoal. The total number of microscopic charcoal fragments was divided by the pollen sum, resulting in a charcoal frequency that reflects the quantity of charcoal observed, normalized per 100 pollen grains.

Pollen analysis also includes examination for and identification of starch granules to general categories, if they are present. Starch granules are a plant's mechanism for storing carbohydrates. Starches are found in numerous seeds, as well as in starchy roots and tubers. The primary categories of starches include the following: with or without visible hila, hilum centric or eccentric, hila patterns (dot, cracked, elongated), and shape of starch (angular, ellipse, circular, eccentric). Some of these starch categories are typical of specific plants, while others are more common and tend to occur in many different types of plants.

\section{Phytoliths}

Extraction of phytoliths from these sediments also was based on heavy liquid floatation. Sodium hypochlorite (bleach) was first used to destroy the organic fraction from $50 \mathrm{ml}$ of sediment. Once this reaction was complete, the samples were rinsed to remove the bleach. If the samples contained calcium carbonates, they were reacted with hydrochloric acid, then the samples were rinsed until neutral. A small quantity of sodium hexametaphosphate was added to each sample once it reached neutrality, then the samples were allowed to settle according to Stoke's Law in settling columns. This process was repeated with EDTA. These steps remove clay prior to heavy liquid separation. Next the samples were freeze dried. The dried silts and sands were then mixed with sodium polytungstate (density 2.3) and centrifuged to separate the phytoliths, which will float, from the other silica, which will not. Phytoliths, in the broader sense, may include opal phytoliths and calcium oxalate crystals. Calcium oxalate crystals are formed by Opuntia (prickly pear cactus) and other plants including Yucca, and are separated, rather than destroyed, using this extraction technique, if these forms have survived in the sediments. Any remaining clay is floated with the phytoliths, and is further removed by mixing with sodium hexametaphosphate and distilled water. The samples are then rinsed with distilled water, then alcohols to remove the water. After several alcohol rinses, the samples are mounted in cinnamaldehyde for counting with a light microscope at a magnification of 500x. Phytolith diagrams are produced using Tilia, which was developed by Dr. Eric Grimm of the Illinois State Museum for diagraming pollen. 


\section{PHYTOLITH REVIEW}

Phytoliths are silica bodies produced by plants when soluble silica in the ground water is absorbed by the roots and carried up to the plant via the vascular system. Evaporation and metabolism of this water result in precipitation of the silica in and around the cellular walls. Opal phytoliths, which are distinct and decay-resistant plant remains, are deposited in the soil as the plant or plant parts die and break down. They are, however, subject to mechanical breakage and erosion and deterioration in high $\mathrm{pH}$ soils. Phytoliths are usually introduced directly into the soils in which the plants decay. Transportation of phytoliths occurs primarily by animal consumption, gathering of plants by humans, or by erosion or transportation of the soil by wind, water, or ice.

The three major types of grass short-cell phytoliths include festucoid, chloridoid, and panicoid. Smooth elongate phytoliths are of no aid in interpreting either paleoenvironmental conditions or the subsistence record because they are produced by all grasses. Phytoliths tabulated to represent "total phytoliths" include the grass short-cells, buliform, trichome, elongate, and dicot forms. Frequencies for all other bodies recovered are calculated by dividing the number of each type recovered by the "total phytoliths".

The festucoid class of phytoliths is ascribed primarily to the Subfamily Pooideae and occur most abundantly in cool, moist climates. However, Brown (1984) notes that festucoid phytoliths are produced in small quantity by nearly all grasses. Therefore, while they are typical phytoliths produced by the Subfamily Pooideae, they are not exclusive to this subfamily. Chloridoid phytoliths are found primarily in the Subfamily Chloridoideae, a warm-season grass that grows in arid to semi-arid areas and require less available soil moisture. Chloridoid grasses are the most abundant in the American Southwest (Gould and Shaw 1983:120). Bilobates and polylobates are produced mainly by panicoid grasses, although a few of the festucoid grasses also produce these forms. Panicoid phytoliths occur in warm-season or tall grasses that frequently thrive in humid conditions. Twiss (1987:181) also notes that some members of the Subfamily Chloridoideae produce both bilobate (Panicoid) and Festucoid phytoliths. "According to (Gould and Shaw $1983: 110$ ) more than $97 \%$ of the native US grass species $(1,026$ or 1,053 ) are divided equally among three subfamilies Pooideae, Chloridoideae, and Panicoideae" (Twiss 1987:181).

Buliform phytoliths are produced by grasses in response to wet conditions and are to be expected in wet habitats of floodplains and other places. Trichomes represent silicified hairs, which may occur on the stems, leaves, and the glumes or bran surrounding grass seeds.

Diatoms and sponge spicules also were noted. Long diatoms are cosmopolitan, occurring in many sediments. They indicate at least some soil moisture. Sponge spicules represent fresh water sponges that grow in a variety of locations, including puddled water. 


\section{ETHNOBOTANIC REVIEW}

It is a commonly accepted practice in archaeological studies to reference ethnographically documented plant uses as indicators of possible or even probable plant uses in prehistoric times. The ethnobotanic literature provides evidence for the exploitation of numerous plants in historic times, both by broad categories and by specific example. Evidence for exploitation from numerous sources can suggest a widespread utilization and strengthens the possibility that the same or similar resources were used in prehistoric times. Ethnographic sources outside the study area have been consulted to permit a more exhaustive review of potential uses for each plant. Ethnographic sources document that with some plants, the historic use was developed and carried from the past. A plant with medicinal qualities very likely was discovered in prehistoric times and the usage persisted into historic times. There is, however, likely to have been a loss of knowledge concerning the utilization of plant resources as cultures moved from subsistence to agricultural economies and/or were introduced to European foods during the historic period. The ethnobotanic literature serves only as a guide indicating that the potential for utilization existed in prehistoric times--not as conclusive evidence that the resources were used. Pollen and macrofloral remains, when compared with the material culture (artifacts and features) recovered by the archaeologists, can become indicators of use. Plants represented by pollen will be discussed in the following paragraphs in order to provide an ethnobotanic background for discussing the remains.

\section{Cerealia}

The Cerealia group consists of the economic members of the grass family including Triticum (wheat), Avena sativa (oat), Hordeum vulgare (barley), and Secale cereale (rye). These plants are part of the cereal grains that were named for Ceres, the Roman goddess of agriculture. These seeds are noted to "have played a crucial role in human nutrition and cultural evolution" (McGee 1984:226). These grains are used to make beer and bread, which have been staples in the human diet since at least 3000 B.C. The cereal grains are concentrated sources of protein and carbohydrates and continue to provide the majority of the caloric intake for much of the world's population. Wheat, barley, and oats have been the most important grain in the Middle East and Europe (Hickey and King 1981:436; McGee 1984:227-229).

\section{(Camas)}

Camassia quamash

Camassia quamash (camas) bulbs have a high sugar content and are noted to have been exploited throughout the Great Basin wherever they occur. Often, they are part of a complex of roots, tubers, and bulbs that were utilized. They can occur with other members of the Liliaceae (lily family) and various members of the Apiaceae (umbel family). On the southern Columbia Plateau, the modern Sahaptin people harvest camas between April and June depending on elevation. In this area, sunny south-facing slopes produce the first crops, while on shady north-facing slopes root crops are harvested slightly later. Roots and bulbs can be processed immediately upon collection or stored in the ground for later use. Camas bulbs most often were cooked for several days in stone-lined pits. Bulbs also were sometimes boiled down to form a syrup. Turney-High (1941:33-34) reports that the Kutenai and Flathead cooked camas with black moss and wild onion, and that camas porridge made in this manner can be kept for up to two years without a change in flavor. Camas grows on moist open meadows in the western 
United States from Montana to British Columbia and California (Fowler 1986:69; Harrington 1967:161-163; Prouty 1994:582-587; Yanovsky and Kinsbury 1938).

\section{DISCUSSION}

Ft. Vancouver National Historic Site is located on the north side of the Columbia River in Vancouver, Washington. The fort is situated just outside the floodplain and slightly upstream from the mouth of the Willamette River on the opposite side. This location was chosen, at least in part, with an eye towards its agricultural potential, since locally grown produce would enhance the self-sufficiency of the post and reduce the cost of importing food. The local prairie sloped upward to dense fir forests.

Seven pollen and phytolith samples were examined from six strata in Excavation Unit (EU) 21 (Table 1), representing the culturally sterile horizon, overlain by deposits associated with Hudson's Bay Company and US Army use and other deposits until the present. In addition, pollen or pollen and phytolith samples were examined from seven additional locations representing time periods from pre-1894 until World War $\mathrm{l}$.

The pollen record (Figure 1) from the stratigraphic samples begins at the base with sample 545 , which is heavily dominated by microscopic fragments of charcoal. This culturally sterile horizon appears to represent an interval that included fires, whether it predates building of the fort by a long period of time, or represents clearing of the area using fire immediately prior to construction of the fort. Some of the charred fragments represent either members of the Asteraceae or sunflower family or grasses (Poaceae), based on their morphology (Table 2). The pollen content of this sample was co-dominated by High-spine Asteraceae and Poaceae pollen, reflecting a relatively open setting or meadow that supported members of the sunflower family and grasses. In addition, pollen representing trees are rare and included Alnus, Betula, $P$ seudotsuga, and Quercus, representing alder and birch growing along the river, as well as Douglas fir and oak growing up slope of the site. Other pollen recorded in this sample includes Artemisia, Cirsium, Liguliflorae, Caryophyllaceae, Cheno-am, Corylus, Plantago, Eriogonum, Polygonum aviculare-type, Rosaceae, and Cerealia, indicating the presence of sagebrush, thistle, members of the chicory tribe of the sunflower family, members of the pink family, chenoams, hazel, plantain, wild buckwheat, knotweed, a member of the rose family, and probably contamination or mixing of sediments with cultural sediments to introduce pollen from cereal grains.

The phytolith record from this level was thoroughly dominated by festucoid grass short cells, indicating the abundance of cool season grasses in the local grass community. This is expected for this location, where the vast majority of grasses are expected to be part of the cool season grass population. A few chloridoid-type and panicoid-type grass short cells also were noted and probably represent production of these types of short cells within grasses of the cool season group. Buliforms are present, indicating that the cells that control leaf rolling were being silicified. Trichomes represent silicification of hair cells, often those that are part of the inflorescence or flowering structure. Elongate forms are typical of grasses in general and do not impart additional information.

Sample 543 represents the lower portion of Stratum V, which is associated with the Hudson's Bay Company occupation of the area. This level yielded a significantly smaller 
quantity of microscopic charcoal fragments. High-spine Asteraceae pollen begins a slow decline, while Liguliflorae and Plantago pollen begin an equally slow increase through the next several samples. Poaceae pollen remains stable, representing local grasses. Cerealia pollen is present and not abundant, being noted in a similar frequency to that in the sterile sample below. The most interesting occurrences of small quantities of pollen are the introduction of Apiaceae and Trifolium pratense-type, representing a member of the umbel family and red clover. Although red clover was introduced by Anglos, it is possible that this pollen type represents a clover that is native to the area. Sudden appearance of this pollen type in a moderate frequency suggests that it represents an introduced plant that got an immediate "foothold" in the area.

The phytolith record from this level is very similar to that in the lower level, registering increases in crenate forms of festucoid grass short cells and trichomes.

The pollen record for the upper portion of Stratum V (sample 541), representing the early US Army occupation, is a continuation of trends begun in sample 509. These trends continue through sample 535, representing the US Army occupation between 1920 and the 1940s, with the exception that the quantities of Plantago pollen do not continue to increase regularly. Cerealia pollen registers its largest frequency in sample 541, representing the early US Army occupation. Cerealia pollen then falls off in frequency, increasing again in sample 535 . In general, Cerealia pollen is noted in higher frequencies in these five samples than it was in the lower two samples. The uppermost pollen sample (533), representing the National Park Service occupation between the 1940 s and the 2000 s, is marked by declines in Liguliflorae and Cerealia pollen. Recovery of Sporormiella dung fungal spores in sample 535 from Stratum II, representing US Army occupation of the area, suggests the presence of horses or other grazing animals. The fungal spore, Sporormiella, represents a dung fungus that often becomes more abundant in Historic Period sediments following the historic introduction of grazing animals, such as horses. It increasing presence in historic samples has been noted in numerous palynological studies (Davis 1987). Sporormiella fungal spores are not confined to the dung of introduced grazers, since they also occur in dung from moose, wild sheep, deer, elk, caribou, and rabbits. The increase of Sporormiella spores in historic sediments may relate to changing land use patterns and increase in the length of time that herds of animals occupy any given area.

The phytolith record for these intervals remains fairly static. The record is heavily dominated by festucoid grass short cells, representing cool season grasses. The stratigraphic samples provide an idea concerning the general pollen rain and phytolith signature for this area against which the samples from specific locations may be compared.

The pollen record for the individual areas samples does not exhibit as smooth a transition between time periods as the stratigraphic record, suggesting that these locations are providing information concerning very local vegetation. For instance, samples 440 and 328 , representing a World War I dry well and the surface near the well, exhibit large to moderately large quantities of Poaceae and High-spine Asteraceae pollen, indicating that the local meadow was grassy and also supported members of the sunflower family. The quantities of Plantago pollen are moderately large in both samples, indicating that plantain was part of the meadow community. This is consistent with quantities of Plantago pollen observed in the stratigraphic samples. Sample 440 exhibits a small quantity of Trifolium pratense-type pollen, indicating local growth of red clover or a closely related plant, while sample 328 yielded only a Fabaceae or legume family identification of a single pollen. Other pollen types are similar to those recovered 
in samples from the stratigraphic record. A moderate quantity of Cerealia pollen was observed, indicating the presence of cereals. Recovery of Cerealia pollen might well be the result of discard of baked goods in various locations on the fort grounds. Even walking around with bread or crackers in one's hands is expected to leave a trail of not only crumbs, but also a contribution to the pollen record.

The phytolith record for sample 440 is very similar to that of the stratigraphic samples, with the exception that the total quantity of festucoid grass short cells was slightly depressed and the quantity of elongate smooth cells slightly elevated. This is insignificant in the interpretation of the record, as the elongate cells represent grasses in general and the information from the grass short cell portion of the record is very much like that expressed in the stratigraphic record. A small quantity of Sporormiella dung fungal spores was recovered in this sample, suggesting the possibility that horses walked through the area.

The pollen record for samples 255 and 336 , relating to the Hudson's Bay Company occupation, exhibit signatures slightly different from one another. Sample 255 was collected from the surface near the dry well in an area that yielded HBC artifacts. Sample 336 was collected from a root cellar. Sample 255 is very similar in pollen content to sample 328 , also collected from the surface near the dry well. Exceptions include the smaller quantity of High-spine Asteraceae and larger quantity of Liguliflorae pollen observed in sample 255 . In addition, sample 255 yielded a small quantity of Sporormiella dung fungal spores, indicating the probability that horses walked through this area. Sample 336 exhibits the largest quantity of High-spine Asteraceae pollen observed in the record from this site, with the single exception of sample 545 , reflecting a culturally sterile deposit. In addition, this sample exhibits very little Plantago pollen, reflecting plantain growing in the meadow. This sample exhibits the only evidence of Camassia pollen for this project, indicating that camas bulbs were stored in the root cellar. Camas was an important root crop for Native Americans living in the area. Many of the Hudson's Bay Company men are reported to have taken native women for wives, so recovery of evidence of the storage of camas bulbs is not surprising from a cultural standpoint. What is surprising is the recovery of Camassia pollen at all, since this pollen is rarely recovered in the archaeological record. Camas bulbs are collected in the spring, usually when the plants are in flower. Even so, very little pollen appears to be transported with the crop. Recovery of Camassia pollen in this sample is the only concrete evidence arguing for storage of plant remains in the root cellar.

Sample 336, representing the root cellar, also was examined for phytoliths. The phytolith record is very similar to that from other samples, with the exception that the quantity of crescent forms of festucoid grass short cells were elevated. This merely suggests the presence of a cool season grass that produced these forms in abundance. No evidence for storage of food items was observed.

Samples 406 and 409 were collected east and west of a wooden board that marked the boundary between the garden and a path. These two samples were similar in the pollen record in that both contained a type of Brassicaceae pollen that looks very much like that produced by radishes and several weedy members of the mustard family. Unfortunately, this pollen could not be identified to genus because of the similarity between pollen from some of the weedy members of the mustard family and radish. In addition, these two samples exhibited elevated Cerealia pollen frequencies, suggesting a number of possibilities. Compost containing kitchen debris might have been used in this area, baked goods might have been spilled or discarded in 
this area. Most other elements of the pollen record from this sample are similar to those from other samples in this record. Sample 409 also yielded a single Rosa-type polien, suggesting the presence of roses growing near this area. Sporormiella dung fungal spores were observed in sample 406, suggesting the presence of grazing animal manure, such as that from horses. The manure might reflect walking horses around the property or perhaps use of manure to fertilize the gardens.

Sample 550 represents a post and post-hole from a pre-1894 deposit. This sample was examined for both pollen and phytoliths. The pollen record is very similar to that observed in other samples. The quantity of Cerealia pollen was small. Interestingly, this is the only sample that yielded a fragment of a Crocus pollen. Crocus flowers might have been planted near this area:

\section{SUMMARY AND CONCLUSIONS}

Examination of pollen and phytolith samples from Ft. Vancouver National Historic Site documents local vegetation as typical of a meadow. This is consistent with written records. The pollen record indicates that various members of the sunflower family were abundant locally, with plants that produce High-spine Asteraceae pollen most abundant early in the record and plants of the chicory tribe more abundant later. Plantain became more abundant with time and would have been part of the grassy, meadow-type vegetation. Evidence of the presence of cereal grains was present throughout the pollen record, even in a very small quantity in the culturally sterile sample collected at the base of the stratigraphic record. This suggests at least some bioturbation of the sediments. The phytolith record indicates that the grasses that grew in this area were primarily, or perhaps all, cool season grasses, as is expected for this area. The pollen record produced evidence of storing camas in the root cellar associated with the Hudson's Bay Company occupation. Storage and use of camas is expected if members of the Hudson's Bay Company took Native Americans as wives or if Native Americans worked for HBC. Other than cereals and camas, there is no specific evidence of foods. Recovery of Crocus-type pollen recovered from the pre-1894 post-hole indicates local growth of crocus in this area. 
TABLE 1

PROVENIENCE DATA FOR SAMPLES FROM FT. VANCOUVER NATIONAL HISTORIC SITE

\begin{tabular}{|c|c|c|c|c|c|c|}
\hline $\begin{array}{c}\text { Sample } \\
\text { No. }\end{array}$ & $\begin{array}{l}\text { Unit } \\
\text { Ne. }\end{array}$ & $\begin{array}{l}\text { Depth } \\
\text { (cmbs) }\end{array}$ & Stratum & Feature & $\begin{array}{l}\text { Proveniencel } \\
\text { Descriotion }\end{array}$ & Analvsis \\
\hline $533 / 1$ & TA1 EU21 & $7-10$ & ST 1 & & $\begin{array}{l}\text { National Park Service, } \\
\text { 1940s - present }\end{array}$ & $\begin{array}{l}\text { Pollen } \\
\text { Phytolith }\end{array}$ \\
\hline $535 / 1$ & TA1 EU21 & $16-22$ & STII & & US Army, $1920-1940$ s & $\begin{array}{l}\text { Pollen } \\
\text { Phytolith }\end{array}$ \\
\hline $537 / 1$ & TA1 EU21 & $32-35$ & ST III & & $\begin{array}{l}\text { US Army, WWI Spruce } \\
\text { Mill, 1917-1918 }\end{array}$ & $\begin{array}{l}\text { Pollen } \\
\text { Phytolith }\end{array}$ \\
\hline $539 / 1$ & TA1 EU21 & $34-36$ & STIV & & 1894 Flood silts & $\begin{array}{l}\text { Pollen } \\
\text { Phytolith }\end{array}$ \\
\hline $541 / 1$ & TA1 EU21 & $36-41$ & ST V & & Early US Army (upper) & $\begin{array}{l}\text { Pollen } \\
\text { Phytolith }\end{array}$ \\
\hline $543 / 1$ & TA1 EU21 & $47-53$ & STV & & $\begin{array}{l}\text { Hudson's Bay Co (HBC) } \\
\text { (lower) }\end{array}$ & $\begin{array}{l}\text { Pollen } \\
\text { Phytolith }\end{array}$ \\
\hline $545 / 1$ & TA1 EU21 & $61-67$ & ST VI & & Culturally Sterile, B Horizon & $\begin{array}{l}\text { Pollen } \\
\text { Phytolith }\end{array}$ \\
\hline $440 / 1$ & TA1 EU3 & 261 & Shvl Tst & 507 & Probably WWI dry well & $\begin{array}{l}\text { Pollen } \\
\text { Phytolith }\end{array}$ \\
\hline $328 / 1$ & TA1 EU17 & 31 & ST V & 509 & $\begin{array}{l}\text { Surface near WWI dry well, } \\
\text { HBC artifacts }\end{array}$ & Pollen \\
\hline $255 / 1$ & TA1 EU20 & 36 & ST V & 509 & $\begin{array}{l}\text { Surface near WWI dry well, } \\
\text { HBC artifacts }\end{array}$ & Pollen \\
\hline $336 / 1$ & TA4 EU1 & 147 & STV & 607 & $\begin{array}{l}\text { Hudson's Bay Co. Root } \\
\text { cellar floor }\end{array}$ & $\begin{array}{l}\text { Pollen } \\
\text { Phytolith }\end{array}$ \\
\hline $406 / 1$ & TA7 EU6 & 35 & ST V & $\begin{array}{l}E \text { of } F . \\
616\end{array}$ & $\begin{array}{l}\text { East of wooden board } \\
\text { (boundary between garden } \\
\text { and path) }\end{array}$ & Pollen \\
\hline $409 / 1$ & TA7 EU6 & 35 & STV & $\begin{array}{l}\text { W of } F \\
616\end{array}$ & $\begin{array}{l}\text { West of wooden board } \\
\text { (boundary between garden } \\
\text { and path) }\end{array}$ & Pollen \\
\hline $550 / 1$ & TA8 EU4 & 67 & STV & 621 & $\begin{array}{l}\text { Post and post-hole, pre- } \\
1894\end{array}$ & $\begin{array}{l}\text { Pollen } \\
\text { Phytolith }\end{array}$ \\
\hline
\end{tabular}


TABLE 2 (Continued)

TABLE 2

POLLEN TYPES OBSERVED IN SAMPLES FROM FT. VANCOUVER NATIONAL HISTORIC SITE

\begin{tabular}{|c|c|}
\hline Scientific Name & Common Name \\
\hline \multicolumn{2}{|c|}{ ARBOREAL POLLEN: } \\
\hline Alnus & Alder \\
\hline Betula & Birch \\
\hline Juglans & - \\
\hline Juniperus & Juniper \\
\hline Pinaceae: & Pine family \\
\hline Abies & Fir \\
\hline Picea & Spruce. \\
\hline Pinus & Pine \\
\hline Pseudotsuga & Douglas-fir \\
\hline Tsuga & Hemlock \\
\hline Quercus & Oak \\
\hline Salix & Willow \\
\hline \multicolumn{2}{|c|}{ NON-ARBOREAL POLLEN: } \\
\hline Apiaceae & Parsley/Carrot family \\
\hline Asteraceae: & Sunflower family \\
\hline Artemisia & Sagebrush \\
\hline Cirsium & Thistle \\
\hline Low-spine & Includes ragweed, cocklebur, sumpweed \\
\hline High-spine & $\begin{array}{l}\text { Includes aster, rabbitbrush, snakeweed, } \\
\text { sunflower, etc. }\end{array}$ \\
\hline Liguliflorae & Chicory tribe, includes dandelion and chicory \\
\hline Boraginaceae & Borage family \\
\hline Brassicaceae & Mustard family \\
\hline Caryophyllaceae & Pink family \\
\hline Cheno-am & Includes the goosefoot family and amaranth \\
\hline
\end{tabular}


TABLE 2 (Continued)

\begin{tabular}{|c|c|}
\hline Scientific Name & Common Name \\
\hline Sarcobatus & Greasewood \\
\hline Corylaceae & Hazel family \\
\hline Cyperaceae & Sedge family \\
\hline Erodium cicutarium-type & Red-stemmed filaree, introduced \\
\hline Fabaceae: & Bean or Legume family \\
\hline Trifolium pratense-type & Red clover \\
\hline Trifolium repens-type & White clover \\
\hline Liliaceae Calochortus-type & Lily family \\
\hline Myriophyllum & Watermilfoil \\
\hline Onagraceae & Evening primrose family \\
\hline Plantago & Plantain \\
\hline Poaceae & Grass family \\
\hline Polygonaceae: & Knotweed/Smartweed family \\
\hline Eriogonum & Wild buckwheat \\
\hline Polygonum aviculare-type & Smartweed \\
\hline Polygonum sawatchense-type & Sawatch knotweed \\
\hline Rumex & Dock \\
\hline Ranunculus & Buttercup \\
\hline Rosaceae: & Rose family \\
\hline $\begin{array}{l}\text { Rosaceae - striate (includes Purshia, Prunus, } \\
\text { Coleogyne, Crataegus, Malus, and Pyrus) }\end{array}$ & $\begin{array}{l}\text { Rose family - includes bitterbrush, chokecherry, } \\
\text { cherry, plum, peach/nectarine, apricot, almond, } \\
\text { blackbrush, hawthorn, apple, and pear }\end{array}$ \\
\hline Rosa & Wild rose \\
\hline Solanaceae & Potato/Tomato family \\
\hline Toxicodendron & Poison ivy \\
\hline Typha angustifolia-type & Cattail \\
\hline \multicolumn{2}{|l|}{ CULTIGENS: } \\
\hline Cerealia & $\begin{array}{l}\text { Economic members of the grass family including } \\
\text { Triticum (Wheat), Avena sativa (Oat), Hordeum }\end{array}$ \\
\hline
\end{tabular}


TABLE 2 (Continued)

\begin{tabular}{||l|l|}
\hline Scientific Name & Common Name \\
\hline Camassia & vulgare (Barley), and Secale cereale (Rye) \\
\hline Crocus-type & Camas \\
\hline Indeterminate & Crocus \\
\hline STARCHES: & Too badly deteriorated to identify \\
\hline Starch w/Hilum & \\
\hline SPORES: & Typical of starches produced by grass seeds \\
\hline Lycopodium & \\
\hline Monolete & Clubmoss \\
\hline Trilete & Fern \\
\hline FUNGAL SPORES: & Fern \\
\hline Sporormiella & \\
\hline OTHER: & Dung fungus \\
\hline Concentricyste & \\
\hline Scolecodont & Indicator of wet, oxidized conditions \\
\hline Plant hair & Worm jaw \\
\hline Charred Asteraceae tissue fragment & Plant hair \\
\hline Charred Poaceae tissue fragment & $\begin{array}{l}\text { Charred tissue fragment from a member of the } \\
\text { sunflower family }\end{array}$ \\
\hline \hline & $\begin{array}{l}\text { Charred tissue fragment from a member of the } \\
\text { grass family }\end{array}$ \\
\hline
\end{tabular}




\section{REFERENCES CITED}

Brown, Dwight A.

1984 Prospects and Limits of Phytolith Key for Grasses in the Central United States. Journal of Archeological Science 11:345-368.

Davis, Owen K.

1987 Spores of the Dung Fungus Sporormiella: Increased Abundance in Historic Sediments and Before Pleistocene Megafaunal Extinction. Quaternary Research 28:290294.

Fowler, Catherine S.

1986 Subsistence. In Great Basin, edited by W. L. d'Azevedo, pp. 64-97. Handbook of North American Indians. vol. 11, W. C. Sturtevant, general editor. Smithsonian Institute, Washington D.C.

Gould, F. N. and R. B. Shaw

1983 Grass Systematics. Texas A\&M University Press, College Station.

Harrington, H. D.

1967 Edible Native Plants of the Rocky Mountains. University of New Mexico Press, Albuquerque, New Mexico.

Prouty, Guy L.

1994 Root Crop Exploitation and the Development of Upland Habitation Sites: A Prospectus for Paleoethnobotanical and Archaeological Research into the Distribution and Use of Economic Plants in the Fort Rock Basin. In Archaeological Researches in the Northern Great Basin: Fort Rock Archaeology Since Cressman, edited by C. M. Aikens and D. L. Jenkins, pp. 573-598. University of Oregon Anthropological Papers 50. Department of Anthropology and State Museum of Anthropology, University of Oregon, Eugene, Oregon.

Turney-High, Harry Holbert

1941 Ethnography of the Kutenai. Memoirs of the American Anthropological Association Number 56. American Anthropological Association, Menasha, Wisconsin.

Twiss, Page C.

1987 Grass-Opal Phytoliths as Climatic Indicators of the Great Plains Pleistocene. In Quaternary Environments of Kansas, edited by W. C. Johnson, pp. 179-188. 5 ed. Kansas Geological Survey Guidebook Series.

Yanovsky, E. and R.M. Kinsbury 1938 Analyses of Some Indian Food Plants. Journal of the Association of Official Agricultural Chemists 21(4):648-655. 


\section{APPENDIX F}

An Analysis of Pollen from Fort Vancouver Washington 


\title{
An Analysis of Pollen From Fort Vancouver Washington
}

\author{
By: Susan A. Jacobucci \\ Andrew Fiske Memorial Center for Archaeological Research at \\ The University of Massachusetts Boston \\ 100 Morrissey Blvd \\ Boston, MA 02125
}

January, 2007 


\section{Introduction}

The Andrew Fiske Memorial Center for Archaeological Research at the

University of Massachusetts Boston conducted a palynological analysis of twenty-four soil samples that were collected from the Fort Vancouver site (see Table 1). The samples were recovered from various contexts associated with the "garden testing area," a

Table 1

Proveniences of the Fort Vancouver Washington Pollen Samples

\begin{tabular}{|c|c|c|c|c|}
\hline LOT/SPEC & UNIT & LEVEL & STRAT/FEATURE & $\begin{array}{l}\text { OTHER } \\
\text { PROVENIENCE }\end{array}$ \\
\hline $334 / 1$ & TA4 & N/A & ST. V, F. 6-07 & Root Cellar Floor \\
\hline $335 / 1$ & TA4-1 & 147 & ST. V, F. 6-07 & \\
\hline $389 / 1$ & TA1-24 & 6 & St. $V$ & $41-42 \mathrm{~cm} \mathrm{bd}$ \\
\hline $392 / 1$ & TA1-21 & 7 & ST. V & $44-46 \mathrm{~cm} \mathrm{bd}$ \\
\hline $401 / 1$ & TA1-22 & 8 & ST.V & $46 \mathrm{~cm} \mathrm{bd}$ \\
\hline $420 / 1$ & TA1 & N/A & ST. IIIC/F. 5-07 & $\begin{array}{l}\text { Point } \\
\text { Provenienced }\end{array}$ \\
\hline $4 \overline{419 / 1}$ & TAI & N/A & ST. IIIC/F. 5-07 & $\begin{array}{l}\text { Point } \\
\text { Provenienced }\end{array}$ \\
\hline $428 / 2$ & TA1-20 & 7 & St. V, F. 5-09B & $36-46 \mathrm{~cm} \mathrm{bd}$ \\
\hline $422 / 1$ & TA1-11 & 6 & ST:V/F. 5-09 & N/A, Garden Path \\
\hline $425 / 1$ & TA2-13 & 6 & ST.V & $\begin{array}{l}\text { SW Corner of } \\
\text { Unit }\end{array}$ \\
\hline $433 / 1$ & TA2-3 & 6 & ST. V & $\begin{array}{l}\text { Point } \\
\text { Provenienced }\end{array}$ \\
\hline $431 / 1$ & TA1-23 & 8 & ST:V & $49 \mathrm{~cm} \mathrm{bd}$ \\
\hline $441 / 1$ & TA1-3 & 261 & F. 5-07, Shovel Test & \\
\hline $464 / 1$ & TA8-1 & 6 & $\mathrm{ST} \cdot \mathrm{V}$ & $41-42 \mathrm{~cm} \mathrm{bd}$ \\
\hline $484 / 1$ & TA8-4 & 6 & ST. V & N/A \\
\hline $497 / 1$ & TA8-3 & 6 & ST: V & $43 \mathrm{~cm} \mathrm{bd}$ \\
\hline $551 / 1$ & TA8-4 & 67 & St. V/F. 6-21 & \\
\hline $534 / 1$ & $\begin{array}{l}\mathrm{TA} 1-21 \mathrm{~W} . \\
\text { Wall }\end{array}$ & $7-10$ & ST. I & $\begin{array}{l}\text { Column Sample. } \\
\text { Surface Scrape }\end{array}$ \\
\hline $536 / 1$ & $\begin{array}{l}\text { TA1-21 W. } \\
\text { Wall }\end{array}$ & $16-22$ & ST. II & Column Sample \\
\hline $538 / 1$ & $\begin{array}{l}\text { TA1-21 W. } \\
\text { Wall }\end{array}$ & $32-35$ & ST. III & $\begin{array}{l}\text { Column Sample, } \\
\text { WWI Spruce Mill }\end{array}$ \\
\hline $540 / 1$ & $\begin{array}{l}\text { TA1-21 W. } \\
\text { Wall }\end{array}$ & $34-36$ & ST. IV & Column Sample \\
\hline $542 / 1$ & TA1-21 W. & $36-41$ & ST. V & Column Sample, \\
\hline
\end{tabular}




\begin{tabular}{|l|l|l|l|l|}
\hline & Wall & & & $\begin{array}{l}\text { HBC-Early U.S. } \\
\text { Army }\end{array}$ \\
\hline $544 / 1$ & $\begin{array}{l}\text { TA1-21 W. } \\
\text { Wall }\end{array}$ & $47-53$ & ST, V F. 5-09 & $\begin{array}{l}\text { Column Sample. } \\
\text { HBC }\end{array}$ \\
\hline $546 / 1$ & $\begin{array}{l}\text { Ta1-21 W. } \\
\text { Wall }\end{array}$ & $61-67$ & $\begin{array}{l}\text { ST. VI Sterile B } \\
\text { Horizon }\end{array}$ & Column Sample \\
\hline
\end{tabular}

"historically documented 8-acre (maximum) formal garden created and maintained by the HBC [Hudson Bay Company] circa 1829-1855" (Personal Communication Elaine

Dorset). Records specify that kitchen, decorative plants, and fruit trees were planted inside the formal garden area (Personal Communication Elaine Dorset). A

"summerhouse (greenhouse or social space - exact use not known) and root cellars" were also located within this garden as well as "an extensive fruit garden" situated to the west of it (Personal Communication Elaine Dorset).

Archaeologists have considered several research questions, which the pollen analysis conducted on soil samples taken from the garden testing area could address. Historical documentation describes a formal garden that was comprised of many imported floral species from England; however, the archaeological record to date has found little evidence of this and the historical record is incomplete regarding "which seeds provided by English growers were planted at Fort Vancouver and which ones were shipped to other posts" (Personal Communication Elaine Dorset). Archaeologists are also trying to decipher whether or not documented twenty to thirty foot wide garden paths were surfaced with grass. The pollen analysis addresses these issues, but also supports and augments the archaeology of Fort Vancouver and historical record.

\section{Methods}

Location of Subject within the Natural Pollen Spectrum 
Fort Vancouver is situated in the southeastern section of Washington just north of the Columbia River between the Cascade Mountains located to its east and the Coast Mountain ranges to the west. The site is positioned in the Puget Sound vegetational area and is surrounded by the Tsuga heterophylla vegetation zone (Franklin and Dyrness 1969: 38). Many vegetation types common to both zones were identified in the pollen analysis of soil samples extracted from the garden testing area at Fort Vancouver. Arboreal vegetation prevalent to both vegetation zones consists predominantly of gymnosperms. Douglas fir (Pseudotsuga menziesii) dominates modern successional tree stands with western hemlock (Tsuga heterophylla), and western red cedar (Thuja plicata) present in fluctuating amounts (Heusser 1978: 297). Western white pine (Pinus monticola) is commonly present and prefers fairly open forest habitats; while Sitka spruce (Picea sitchensis) is negligibly present in flood plains and inhabits areas near the mouths of rivers (Heusser 1978: 298). Beach or lodgepole pine (Pinus contorta) is sometimes locally present in plentiful quantities and grand fir (Abies grandis) is scarce (Heusser 1978: 297-298). Hardwoods such as red alder (Alnus rubra), giant chinquapin (Castanopsis chrysophylla), and bigleaf maple (Acer macrophyllum) are rare in the region, but are better represented at newly disturbed sites (Franklin and Dyrness 1969: 56). Black cottonwood (Populus trichocarpa), Oregon ash (Fraxinus latifolia), and willow (Salix sp.) sporadically appear and are usually associated with major water courses, while Pacific madrone (Arbutus menziesii) and Oregon white oak (Quercus garryana) are situated at lower elevations (Franklin and Dyrness 1969: 56; Heusser 1978: 298). 
The understory vegetation community characteristic of lower slopes and stream terraces of the Tsuga heterophylla vegetation zone is composed of exceptionally "lush understory shrubs, dicotyledonous herbs, and ferns" (Franklin and Dyrness 1969: 60). Vegetation such as blueberry (Vaccinium spp.), western woodfern (Dryopteris linnaeana), spinulose woodfern (D. spinulosa var. dilatata), pioneer violet (Viola glabella), brackenfern (Pteridium), and mosses are present in these environments (Franklin and Dyrness 1969: 60; Gleason and Cronquist 1964: 357; Heusser 1978: 299). Franklin and Dyrness (1969: 61-63) discuss vegetation successional patterns that occur after episodes of environmental disturbance such as a devastating fires or logging. Right after such an event, the first growing season consists of sparse vegetation cover, which is usually comprised of survival species from the original stand, followed during the second year by annual herbaceous invader species such as woodland ragwort (Senecio sylvaticus), which generates vast quantities of small, windborne seeds (Franklin and Dyrness 1969: 61). After the second year, but before shrubs such as alder species and California blackberry (Rubus ursinus) among others take hold, further weedy species such as fireweed (Epilobium angustifolium), bull thistle (Cirsium vulgare) and western brackenfern (Pteridium aquilinium) flourish (Franklin and Dyrness 1969: 61).

\section{Contexts}

Field schools conducted by the Vancouver National Historic Reserve collected twenty-four soil samples for pollen analysis during the 2005 and 2006 seasons. The samples collected predominately represent the Hudson's Bay Company occupation period of the Fort Vancouver site and were taken mainly from $1 \times 4$ m trenches, a $2 \times 8 \mathrm{~m}$ trench, and a $2 \times 10 \mathrm{~m}$ trench with all excavation trenches situated in the garden testing 
area (Personal Communication Elaine Dorset). Using clean trowels samples were collected from $50 \times 50 \times .5 \mathrm{~cm}$ areas of $1 \times 1 \mathrm{~m}$ units (Personal Communication Elaine Dorset). The samples also comprised a number of surface pinch samples to test the modern pollen and from a soil column, "with samples taken from each occupation stratum in the wall of a unit, modern down to culturally sterile" (Personal Communication Elaine Dorset).

\section{Laboratory methods}

Approximately $30 \mathrm{~g}$ of sediment were processed for each sample. Soil samples were weighed before they were processed using standard pollen extraction techniques. That is the samples were treated with hydrochloric acid to remove carbonates, hydrofluoric acid, to remove silicates, and acetolysis to remove organics (see Moore and Webb 1978: 22-27; Pearsall 2000: 294-296). Because of the high organic concentration contained in the soil some of the samples were also treated with potasium hydroxide. An exotic Lycopodium sp. control spike tracer was added to the samples to verify pollen density, concentration, and preservation (Larsen and MacDonald 1998: 819).

Several microscope slides of pollen residue were mounted in glycerol and prepared for each sample. The slides were scanned at 400x magnification. Following direction provided by other studies (Bryant Jr. and Hall 1993: 281; Pearsall 2000: 303; Trigg et al. 2003: 35), an attempt was made to count 300 pollen grains for each sample, with pollen grains classified as "identifiable" and "unidentifiable" included in the pollen totals, but the added control spike not inclusive of this number. Pollen grains were identified by comparing them to online images appearing on the web (www.geo.arizona.edu/palynology/pid00024.html), to a type collection housed at the 
University of Massachusetts Boston, and to published sources (Erdtman 1943; Kapp 1969, Kapp et al. 2000; McAndrews et al. 1973; Moore and Webb 1978; Moore et al. 1991). Pollen grains too deteriorated, crumpled, torn, or distorted to identify were classified as "unidentifiable," while any pollen grains encountered that were in good physical condition, but could not be identified beyond an unknown category were classified as "identifiable."

Pollen densities above 1000 grains per gram of sediment are considered satisfactory for environmental reconstruction (Hall 1981). The pollen densities for all twenty-four samples were calculated (see Table 2). Densities registered over 1000 grains of pollen per gram of soil for fourteen samples, while the densities of ten samples were lower. Even though these low density samples are not sufficient for environmental reconstruction, they are instrumental for this study because they chronicle some of the vegetation types that were present in the area at the time of the Hudson Bay Company's occupation. It is possible that the low density for these samples was caused by rapidly "buried soil" events (Moore and Webb 1978: 15) or were due to poor preservation conditions as a result of pollen grains being subjected to "pedogenesis, mechanical destruction, chemical oxidation, and microbial activity" (Bryant and Hall 1993: 280). This examination considers the implications affecting geographical scale associated with the production methods and dispersal capabilities of recovered pollen species. Pollen grains recovered from Fort Vancouver represent a regional, local, and partial vegetation history due to preservation conditions, pollination strategies, and identification issues, which affect pollen grains at varying rates (Bryant Jr. and Hall 1993: 281; Dincauze 2000: 345-346; Faegri et al. 1989: 11-38; King et al. 1975:181; Pearsall 2000: 251-252). 
Table 2

Pollen Densities

\begin{tabular}{|c|c|}
\hline Sample Number & Pollen Density \\
\hline 334 & 2564 \\
\hline 335 & 316 \\
\hline 389 & 3770 \\
\hline 392 & 807 \\
\hline 401 & 739 \\
\hline 420 & 1863 \\
\hline 419 & 5551 \\
\hline 428 & 782 \\
\hline 422 & 3606 \\
\hline 425 & 739 \\
\hline 433 & 3212 \\
\hline 431 & 689 \\
\hline 441 & 404 \\
\hline 464 & 992 \\
\hline 484 & 850 \\
\hline 497 & 1675 \\
\hline 551 & 3131 \\
\hline 534 & 10617 \\
\hline 536 & 8549 \\
\hline 538 & 1997 \\
\hline 540 & 2090 \\
\hline 542 & 2109 \\
\hline 544 & 2725 \\
\hline 546 & 813 \\
\hline
\end{tabular}

For this study some pollen grains could only be identified to the family level. For example, species of the Rosaceae family were grouped together because "identification of the pollen beyond a nebulous "Rosaceae" is usually impossible..." (Adams and Morton, Part II, 1974: 18). However, the majority of pollen grains were identified to the genus level. Pollen grains identified to vegetation belonging to the Compositae family were identified visually as individual genus types whenever possible, and also grouped for discussion purposes based on their mode of pollen production and dispersal. Compositae pollen grains classified as Liguliflorae have a fenestrate surface sculpturing. For this 
study Compositae species grouped as such were further subdivided into categories based on grain size. Other vegetation genera were also discussed in groupings based on whether they were arboreal or non-arboreal species and their method of pollination, specifically if they were classified as wind or insect-pollinated species.

Numerous noteworthy crop plants and weedy taxa are essentially non-arboreal species and generally insect or self-pollinated (Faegri et al. 1989: 186). These species, as well as many Compositae taxa classified as Tubuliflorae, generate a smaller quantity of pollen with their appearance in the pollen spectrum "accidentally registered" (Faegri et al. 1989: 186). Insect-pollinated and self-pollinated species usually signify "local plant communities and edaphic conditions" (Kelso and Beaudry 1990: 65) because their pollen grains tend to be heavier (Faegri et al. 1989: 13), are dispersed near the ground surface where wind velocities are reduced (Kelso 1994a: 11; Moore and Webb 1978: 111), and are infrequently incorporated within the pollen rain (Pearsall 2000: 259). Many arboreal and several Compositae species such as ragweed (Ambrosia) and cocklebur or burweed (Xanthium) are wind-pollinated. They produce larger quantities of pollen, which are dispersed into the air from higher elevations, and thus are usually credited for reflecting more of a regional representation (Kelso and Beaudry 1990: 65; Moore and Webb 1978: 109-114; Pearsall 2000: 258-260).

Pollen grains identified to the clubmoss (Lycopodium) category measured much larger than the size of the Lycopodium sp. control spike tracer pollen grains that were added to the samples. Several members of the Lycopodium genus are common to the Washington area (Britton and Brown, Vol. 1 1896: 40-43). Grasses were split into three categories for this examination: wild, European-introduced cereals, and maize (Zea 
mays), based on pollen grain size. Grass pollen grain size $<45 \mu \mathrm{m}$ in size were considered to be of the wild variety as some wild species measure over $40 \mu \mathrm{m}$ (see Wodehouse 1965: 310-319). Grass pollen grain size $\geq 45 \mu \mathrm{m}$ and $\leq 70 \mu \mathrm{m}$ were grouped into the European-introduced cereals category with species such as oats (Avena), rye (Secale), wheat (Triticum), and barley (Hordeum) belonging to this grouping. Any grass pollen grains exceeding $70 \mu \mathrm{m}$ in size were considered to be maize. There was only one recovered grass pollen grain measuring greater than this size.

\section{Results}

Pollen analysis revealed a total of 102 distinct taxa, not inclusive of the "unidentifiable" and "identifiable" categories, which were represented in the twenty-four soil samples taken from the garden testing area at Fort Vancouver (see Table 3). After the pollen grains from the samples were tabulated, percentages for all identified taxa were calculated for each sample (see Table 4). A description of the recovered taxa follows. The pollen data for the seven samples taken from the soil column were entered into a computer database (Tilia 2.0). This database calculated percentages of the pollen grains and I generated a pollen sum diagram, included at the end of the report (see Figure 1). The column samples were represented in sequence based on depth. 
Table 3

\section{Pollen Taxa Identified in the Fort Vancouver Sediment Samples}

Arboreal Pollen Inclusive of Shrubs

Abies

Acacia

Alnus

Berberis

Carya

Castanopsis

Celtis

. Citrus Type

Ericales

Fraxinus

Juniperus

Larix

- Morus

Picea

Pinus

Populus

Pseudotsuga

Quercus

Rosaceae

Salix

Shepherdia

Taxus

Thuja

Tsuga

Ulmus

Vaccinium

Non-Arboreal Pollen

Achillea

Actaea

Ambrosia

Anthemis

Apiaceae

Apocynum

Aquilegia

Artemisia

Asarum

Aster.

Bidens

Borago

Brasenia

Brassicaceae
Fir

Acacia

Alder

Barberry

Hickory

Chinquapin

Hackberry

Citrus

Crowberry

Ash

Juniper

Larch

Mulberry

Spruce

Pine

Cottonwood

Douglas Fir

Oak

Rose Family

Willow

Buffaloberry, Soapberry

Yew

Cedar

Hemlock

Elm

Blueberry, Cranberry

Yarrow (Tubuliflorae)

Baneberry

Ragweed

Chamomile (Tubuliflorae)

Carrot or Parsley Family

Indianhemp

Columbine

Sagebrush

Ginger

Aster (Tubuliflorae)

Beggarticks (Tubuliflorae)

Borage

Water Shield

Mustard Family 
Calendula Type

Carex

Caryophyllaceae

Centaurea

Cerastium

Cereales

Cheno/Am

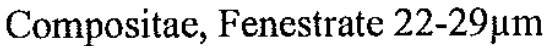

Compositae, Fenestrate $30-39 \mu \mathrm{m}$

Compositae, Fenestrate $40-45 \mu \mathrm{m}$

Cynara

Dahlia Type

Daphne

Eleocharis

Equisetum

Eriogonum

Euphorbia

Helianthus

Humulus

Iridaceae

Lamiaceae

Layia

'Liliaceae

Marrubium

Menyanthes

Nicotian.

Papaver

Phaseolus

Plantago

Poaceae

Polygonum

Portulaca

Ribes

Rumex

Sagittaria

Saxifraga

Senecio

Solanaceae

Solidago

Tanacetum Type

Thalictrum

Tribulus

Trifolium

Typha

Viola

Xanthium
Marigold (Tubuliflorae)

Sedge

Pink Family

r Coneflower (Tubuliflorae)

Chickweed

European-introduced cereals

Chenopodium/Amaranthus

Liguliflorae

Liguliflorae

Liguliflorae

Artichoke (Tubuliflorae)

Dahlia (Tubuliflorae)

Daphne

Spikerush

Scouring Rush, Field Horsetail

Buckwheat

Spurge

Sunflower (Tubuliflorae)

Common Hop

Iris Family

Mint Family

Tidytips (Tubuliflorae)

Lily Family

Horehound

Buckbean

Tobacco

Poppy

Bean

Plantain

Grass Family, Wild grasses

Knotweed

Purslane

Currant

Sheep Sorrel

Arrowhead

Saxifrage

Ragwort Type (Tubuliflorae)

Nightshade Family

Goldenrod (Tubuliflorae)

Tansy (Tubuliflorae)

Meadow Rue

Puncturevine

Clover

Cat-tail

Violet

Cocklebur 
Zea mays

Zinnia Type

Mosses and Ferns

Cryptogramma

Botrychium

Dicranum

Didymodon

Dryopteris

Hypnum

Lycopodium

Ophioglossum

Osmunda regalis

Polystichum

Pteridium

Selaginella

Sphagnum

Woodwardia
Maize, Corn

Zinnia (Tubuliflorae)

Rock-brake

Grape-fern

Moss

Moss

Wood-fern

Moss

Clubmoss

Adderstongue fern

Royal fern

Holly fern

Bracken fern

Spikemoss

Peat moss

Chain-fern 


\section{Table 4}

Pollen Counts and Percentages From Fort Vancouver

\begin{tabular}{|c|c|c|c|c|}
\hline & & mples, Lot $\mathrm{N}$ & nber & \\
\hline Taxa & 334 & 335 & 389 & 392 \\
\hline Abies & $7 /(2.33)$ & & & \\
\hline Alnus & $2 /(0.66)$ & & $18 /(5.54)$ & \\
\hline Juniperus & $4 /(1.33)$ & & $7 /(2.15)$ & \\
\hline Larix & $8 /(2.66)$ & & $5 /(1.54)$ & $2 /(1.74)$ \\
\hline Morus & & & & $2 /(1.74)$ \\
\hline Picea & $1 /(0.33)$ & & $6 /(1.85)$ & \\
\hline Pinus & $8 /(2.66)$ & & $7 /(2.15)$ & \\
\hline Populus & $1 /(0.33)$ & & & $2 /(1.74)$ \\
\hline Pseudotsuga & $7 /(2.33)$ & $3 /(5.36)$ & $4 /(1.23)$ & $2 /(1.74)$ \\
\hline Quercus & $2 /(0.66)$ & $2 /(3.57)$ & $7 /(2.15)$ & \\
\hline Rosaceae & $3 /(1.00)$ & $1 /(1.79)$ & & \\
\hline Salix & & & $3 /(0.92)$ & \\
\hline Shepherdia & $1 /(0.33)$ & & & \\
\hline Thuja & $9 /(3.00)$ & & & $2 /(1.74)$ \\
\hline Tsuga & $5 /(1.66)$ & & & \\
\hline Vaccinium & $8 /(2.67)$ & & & \\
\hline Achtllea & $3 /(1.00)$ & & & $5 /(4.35)$ \\
\hline Ambrosia & $3 /(1.00)$ & & $7 /(2.15)$ & \\
\hline Apiaceae & & & $6 /(1.85)$ & \\
\hline Apocynum & $1 /(0.33)$ & & & \\
\hline Aster & & & $8 /(2.46)$ & \\
\hline Brasenia & $2 /(0.66)$ & & & \\
\hline Brassicaceae & $6 /(1.99)$ & & $6 /(1.85)$ & $3 /(2.61)$ \\
\hline Calendula Type & $6 /(2.00)$ & & $6 /(1.85)$ & $3 /(2.61)$ \\
\hline Carex & $8 /(2.66)$ & & & $2 /(1.74)$ \\
\hline Cheno/Am & $3 /(1.00)$ & $2 /(3.57)$ & $11 /(3.38)$ & \\
\hline Fenestrate $22-29$ & $2 /(0.66)$ & $6 /(10.71)$ & $11 /(3.38)$ & $8 /(6.96)$ \\
\hline Fenestrate $30 \times 39$ & & & $30 /(9.23)$ & $9 /(7.83)$ \\
\hline Fenestrate $40-45$ & $2 /(0.66)$ & & $14 /(4.31)$ & \\
\hline Eleocharis & $5 /(1.66)$ & & & \\
\hline Equisetum & $60 /(20.00)$ & $10 /(17.86)$ & $17 /(5.23)$ & $20 /(17.39)$ \\
\hline Helianthus. & & & $7 /(2.15)$ & $1 /(1.74)$ \\
\hline Humulus & $3 /(1.00)$ & $1 /(1.79)$ & & \\
\hline Iridaceae & $2 /(0.66)$ & & $2 /(0.62)$ & $1 /(1.74)$ \\
\hline Liliaceae & $8 /(2.66)$ & $1 /(1.79)$ & $2 /(0.62)$ & \\
\hline Marrubium & & & $6 /(1.85)$ & \\
\hline Plantago & $6 /(2.00)$ & $3 /(5.36)$ & $17 /(5.23)$ & $3 /(2.61)$ \\
\hline Poaceae & & $2 /(3.57)$ & $5 /(1.54)$ & $4 /(3.48)$ \\
\hline Polygonum & & & $7 /(2.15)$ & \\
\hline Ribes & $2 /(0.66)$ & & $6 /(1.85)$ & $2 /(1.74)$ \\
\hline Rumex & & & $7 /(2.15)$ & \\
\hline Saxifraga & $1 /(0.33)$ & & $3 /(0.92)$ & \\
\hline
\end{tabular}




\begin{tabular}{|c|c|c|c|c|}
\hline Senecio & $32 /(10.66)$ & & $7 /(2.15)$ & $11 /(9.57)$ \\
\hline Solanaceae & $7 /(2.33)$ & & $6 /(1.85)$ & $2 /(1.74)$ \\
\hline Solidago & & & $5 /(1.54)$ & \\
\hline Thalictrum & & & $4 /(1.23)$ & \\
\hline Trifolium & & & $3 /(0.92)$ & \\
\hline Viola & $1 /(0.33)$ & & & \\
\hline Xanthitum & & & & $3 /(2,61)$ \\
\hline Cryptogramma & & $3 /(5.36)$ & & \\
\hline Dicranum & & $1 /(1.79)$ & & \\
\hline Didymodon & & $1 /(1.79)$ & $8 /(2.46)$ & \\
\hline Dryopteris & $5 /(1.66)$ & & & $8 /(6.96)$ \\
\hline Hypnum & $4 /(1.33)$ & $2 /(3.57)$ & & $3 /(2.61)$ \\
\hline Lycopodium & & $13 /(23.21)$ & $10 /(3.16)$ & \\
\hline Osmunda regalis & $5 /(1.66)$ & $1 /(1.79)$ & & \\
\hline Pteridium & $25 /(8.33)$ & & $12 /(3.69)$ & $6 /(5.22)$ \\
\hline Selaginella & $3 /(1.00)$ & & $4 /(1.23)$ & \\
\hline Sphagnum & $5 /(1.66)$ & & $8 /(2.46)$ & \\
\hline Unidentifiable & $20 /(6.66)$ & $4 /(7.14)$ & $17 /(5.23)$ & $11 /(9.57)$ \\
\hline Identifiable & $4 /(1.33)$ & & $6 /(1.85)$ & \\
\hline Totals & $300 /(100)$ & $56 /(100)$ & $325 /(100)$ & $115 /(100)$ \\
\hline
\end{tabular}


Table 4, Contd.

Pollen Counts and Percentages from Fort Vancouver

Taxa

Abies

Acacia

Alnus

Castanopsis

Celtis

Ericales

Juniperus

Larix

Morus

Picea

Pinus

Populus

Pseudotsuga

Quercus

Rosaceae

Salix

Taxus

Tsuga

Vaccinium

Achillea

Ambrosia

Anthemis

Apiaceae

Asarum

Borago

Brasenia

Brassicaceae

Calendula Type

Caryophyllaceae

'Cereales

Cheno/Am

Fenestrate 22-29

Fenestrate 30-39

Fenestrate 40-45

Cryptotaenia

Daphne

Eleocharis

Equisetum

Helianthus

Humulus

Iridaceae

Lamiaceae
Samples, Lot Numbers

$\begin{array}{llll}401 & 420 & 419 & 428\end{array}$

$3 /(0.85)$

$1 /(0.28) \quad 3 /(0.91)$

$6 /(1.69)$

$5 /(1.41)$

$1 /(0.91)$

$1 /(0.30)$

$2 /(0.56)$

$1 /(0.91) \quad 17 /(4.80) \quad 9 /(2.74)$

$1 /(0.91)$

$4 /(1.13)$

$2 /(1.72)$

$3 /(2.73) \quad 9 /(2.54) \quad 7 /(2.13) \quad 1 /(0.86)$

$3 /(0.85) \quad 6 /(1.83) \quad 1 /(0.86)$

$6 /(5.46) \quad 6 /(1.69) \quad 11 /(3.35) \quad 3 /(2.59)$

$3 /(0.85) \quad 2 /(1.72)$

$1 /(0.85) \quad 10 /(3.05) \quad 1 /(0.86)$

$5 /(1.41)$

$3 /(2.73)$

$2 /(1.82)$

$5 /(1.44)$

$6 /(1.83)$

$1 /(0.30)$

$1 /(0.86)$

$1 /(0.86)$

$1 /(0.91) \quad 4 /(1.13)$

$1 /(0.86)$

$1 /(0.28)$

$1 /(0.86)$

$5 /(1.41)$

$3 /(0.91)$

$1 /(0.28)$

$4 /(1.13)$

$2 /(1.82)$

$4 /(1.22) \quad 2 /(1.72)$

$3 /(0.85)$

$7 /(1.98)$

$3 /(2.59)$

$2 /(1.82)$

$24 /(6.78)$

$4 /(3.45)$

$6 /(5.50)$

$7 /(1.98)$

13/ (3.96)

$7 /(6.03)$

$7 /(6.36)$

$35 /(10.67)$

$28 /(8.54)$

$10 /(3.05)$

$1 /(0.91)$

$1 /(0.91)$

$27 /(24.55)$

$36 /(10.17)$

$14 /(4.27)$

$7 /(2.13)$

$1 /(0.91) \quad 3 /(0.85)$

$1 /(0.91)$

4/ (1.13)

4/ (1.22)

7/ (2.13)
$2 /(1.72)$

$17 /(14.66)$

$1 /(0.86)$ 


\begin{tabular}{|c|c|c|c|c|}
\hline Layia & & $11 /(3.11)$ & $5 /(1.52)$ & \\
\hline Marrubium & $2 /(1.82)$ & $3 /(0.85)$ & & \\
\hline Plantago & & $3 /(0.85)$ & $13 /(3.96)$ & $1 /(0.86)$ \\
\hline Poaceae & $2 /(1.82)$ & $8 /(2.26)$ & $6 /(1.83)$ & $3 /(2.59)$ \\
\hline Polygonum & & $6 /(1.69)$ & & \\
\hline Ribes & & $12 /(3.39)$ & & \\
\hline Senecio & $5 /(4.55)$ & $18 /(5.08)$ & $11 /(3.35)$ & $17 /(14.66)$ \\
\hline Solanaceae & & $3 /(0.85)$ & & \\
\hline Solidago & & & $8 /(2.44)$ & \\
\hline Tanacetum Type & & & $11 /(3.35)$ & $7 /(6.03)$ \\
\hline Thalictrum & & $3 /(0.85)$ & & \\
\hline Trifolium & & $2 /(0.56)$ & $6 /(1.83)$ & \\
\hline Viola & $2 /(1.82)$ & & & \\
\hline Xanthium & $1 /(0.91)$ & $16 /(4.52)$ & $17 /(5.18)$ & $6 /(5.17)$ \\
\hline Zinnia Type & & & $8 /(2.44)$ & \\
\hline Cryptogramma & & & & $1 /(0.86)$ \\
\hline Botrychium & & & $3 /(0.91)$ & \\
\hline Dicranum & & & & $1 /(0.86)$ \\
\hline Didymodon & $2 /(1.82)$ & $6 /(1.69)$ & $11 /(3.35)$ & \\
\hline Dryopteris & $5 /(4.55)$ & $16 /(4.52)$ & $9 /(2.74)$ & \\
\hline Hypnum & $8 /(7.27)$ & $6 /(1.69)$ & & $1 /(0.86)$ \\
\hline Lycopodium & & $3 /(0.85)$ & & \\
\hline Osmunda regalis & $1 /(0.91)$ & & & $4 /(3.45)$ \\
\hline Pteridium & & $25 /(7.06)$ & $15 /(4.57)$ & $10 /(8.62)$ \\
\hline Selaginella & & & $2 /(0.62)$ & \\
\hline Sphagnum & $3 /(2.73)$ & $1 /(0.28)$ & & \\
\hline Woodwardia & & $7 /(1.98)$ & $8 /(2.44)$ & $1 /(0.86)$ \\
\hline Unidentifiable & $12 /(10.91)$ & $37 /(10.45)$ & $12 / 3.67)$ & $10 /(8.62)$ \\
\hline Identifiable & $1 /(0.91)$ & & $4 /(1.22)$ & $4 /(3.45)$ \\
\hline Totals & $110 /(100)$ & $355 /(100)$ & $328 /(100)$ & $116 /(100)$ \\
\hline
\end{tabular}


Table 4, Contd.

Pollen Counts and Percentages from Fort Vancouver

Taxa
Abies
Acacia
Carya
Fraxinus
Juniperts
Larix
Picea
Pinus
Populus
Pseudotsuga
Quercus
Rosaceae
Tsuga
Achillea
Actaea
Ambrosia
Apiaceae
Aster
Bidens
Borago
Brassicaceae
Calendula Type
Caryophyllaceae
Cereales
Cheno/Am
Fenestrate 22-29
Fenestrate $30-39$
Cynara
Dahlia Type
Daphne
Equisetum
Euphorbia
Lamiaceae
Liliaceae
Marrubium
Plantago
Poaceae
Rumex
Sagittaria
Saxifraga
Senecio
Solanaceae

422

Samples, Lot Numbers

$425 \quad 433 \quad 431$

$3 /(0.95)$

$2 /(0.63)$

$5 /(1.58)$

$4 /(1.26) \quad 3 /(2.88) \quad 7 /(2.31)$

$4 /(1.26) \quad 2 /(1.92) \quad 12 /(3.96) \quad 4 /(3.81)$

$4 /(1.26) \quad 10 /(3.30)$

$6 /(5.71)$

$7 /(2.21)$

$1 /(0.96) \quad 8 /(2.64)$

$8 /(2.52)$

$1 /(0.96)$

$5 /(1.58)$

$6 /(1.89)$

$1 /(.96)$

$2 /(0.63)$

$6 /(1.89)$

$2 /(1.92)$

$5 /(1.65)$

$1 /(0.95)$

9/ (2.84)

$3 /(2.89)$

$6 /(1.98)$

$4 /(1.26)$

$4 /(3.85)$

$12 /(3.96) \quad 4 /(3.81)$

$3 /(2.86)$

$1 /(0.33)$

$1 /(0.96)$

$1 /(0.96)$

$3 /(0.95) \quad 3 /(2.88)$

$6 /(1.98)$

$14 /(4.42)$

$32 /(10.09)$

$8 /(7.692)$

$23 /(7.59)$

$20 /(6.60) \quad 6 /(5.71)$

$7 /(2.21)$

$11 /(3.63)$

$2 /(1.90)$

$4 /(1.26)$

$20 /(6.31)$

$19 /(5.99)$

$17 /(16.35)$

$7 /(2.31)$

$18 /(5.94) \quad 12 /(11.43)$

$3 /(0.99)$

$6 /(1.98)$

$6 /(1.98)$

$11 /(3.47)$

$1 /(0.95)$

$7 /(2.31)$

$1 /(0.95)$

$1 /(0.95)$

$1 /(0.95)$

$11 /(3.47) \quad 5 /(4.81)$

9/ (2.97)

4/ (1.32)

9/ (2.97)

$3 /(1.90)$

$2 /(1.90)$ 


$\begin{array}{lllll}\begin{array}{l}\text { Solidago } \\ \text { Tanacetum Type }\end{array} & 2 /(0.63) & & & 1 /(0.95) \\ \begin{array}{l}\text { Thalictrum } \\ \text { Typha }\end{array} & 4 /(1.89) & 4 /(3.85) & 11 /(3.63) & \\ \text { Xanthium } & & & 11 /(3.63) & \\ \text { Zinnia Type } & 11 /(3.47) & 3 /(2.88) & & 4 /(3.81) \\ \begin{array}{l}\text { Cryptogramma } \\ \text { Didymodon }\end{array} & 15 /(4.73) & & & \\ \text { Dryopteris } & 12 /(3.79) & & & 2 /(1.90) \\ \text { Hypnum } & 13 /(4.10) & 6 /(5.77) & 7 /(2.31) & 5 /(4.76) \\ \text { Lycopodium } & 7 /(2.21) & 2 /(1.92) & 11 /(3.63) & 5 /(4.76) \\ \text { Ophioglossum } & 3 /(.95) & & & 2 /(1.90) \\ \text { Osmunda regalis } & 5 /(1.58) & & 4 /(1.32) & \\ \text { Pteridium } & 12 /(3.79) & 12 /(11.54) & 15 /(4.95) & 7 /(6.67) \\ \begin{array}{l}\text { Selaginella } \\ \text { Sphagnum }\end{array} & 3 /(.95) & & & 2 /(1.90) \\ \text { Woodwardia } & 7 /(2.21) & 2 /(1.92) & 9 /(2.97) & 3 /(2.86) \\ \text { Unidentifiable } & 8 /(2.52) & 4 /(3.85) & & 2 /(1.90) \\ \text { Identifiable } & 15 /(4.73) & 12 /(11.54) & 19 /(6.27) & 13 /(12.38) \\ \text { Totals } & 4 /(1.26) & 1 /(0.96) & 7 /(2.31) & 2 /(1.90) \\ & 317 /(100) & 104 /(100) & 303 /(100) & 105 /(100)\end{array}$


Table 4, Contd.

Pollen Counts and Percentages from Fort Vancouver

\begin{tabular}{|c|c|c|c|c|}
\hline \multicolumn{5}{|c|}{ Samples, Lot Numbers } \\
\hline Taxa & 441 & 464 & 484 & 497 \\
\hline Abies & & $4 /(2.74)$ & & \\
\hline Acacia & & $2 /(1.37)$ & & $3 /(1.05)$ \\
\hline Alnus & & $5 /(3.42)$ & & $4 /(1.39)$ \\
\hline Juniperus & & & $3 /(2.38)$ & \\
\hline Larix & & $6 /(4.11)$ & & $8 /(2.79)$ \\
\hline Pinus & & & $14 /(11.11)$ & $8 /(2.79)$ \\
\hline Pseudotsuga & & $4 /(2.74)$ & $4 /(3.17)$ & \\
\hline Quercus & & & $4 /(3.17)$ & $3 /(1.05)$ \\
\hline Rosaceae & & & & $2 /(0.70)$ \\
\hline Taxus & & & & $6 /(2.10)$ \\
\hline Thuja & & $5 /(3.42)$ & & \\
\hline Tsuga & & & $6 /(4.76)$ & $8 /(2.79)$ \\
\hline Vaccinium & & & $2 /(1.59)$ & \\
\hline Ambrosia & & $5 /(3.42)$ & & \\
\hline Asarum & & & $2 /(1.59)$ & \\
\hline Aster & $2 /(3.64)$ & $11 /(7.53)$ & & \\
\hline Borago & & & & $3 /(1.05)$ \\
\hline Cereales & & & $2 /(1.59)$ & \\
\hline Cheno/Am & $1 /(1.82)$ & $8 /(5.48)$ & $10 /(7.94)$ & $18 /(6.27)$ \\
\hline Fenestrate $22-29$ & $1 /(1.82)$ & $8 /(5.48)$ & $16 /(12.70)$ & $28 /(9.76)$ \\
\hline Fenestrate $30-39$ & $1 /(1.82)$ & $4 /(2.74)$ & & $7 /(2.33)$ \\
\hline Equisetum & $9 /(16.36)$ & $14 /(9.59)$ & $6 /(4.76)$ & $18 /(6.27)$ \\
\hline Layia & & & & $6 /(2.10)$ \\
\hline Liliaceae & & $2 /(1.37)$ & & \\
\hline Marrubium & & & & $3 /(1.05)$ \\
\hline Plantago & & & & $9 /(3.14)$ \\
\hline Poaceae & $2 /(3.64)$ & $2 /(1.37)$ & & \\
\hline Polygonum & $1 /(1.82)$ & $3 /(2.10)$ & $3 /(2.38)$ & \\
\hline Saxifraga & & $3 /(2.10)$ & & \\
\hline Senecio & $2 /(3.64)$ & & & $17 /(5.92)$ \\
\hline Solanaceae & & & & $6 /(2.10)$ \\
\hline Solidago & $2 /(3.64)$ & & & $12 /(4.18)$ \\
\hline Tanacetum Type & & & $4 /(3.17)$ & $4 /(1.39)$ \\
\hline Thalictrum & & $4 /(2.74)$ & & \\
\hline Trifolium & $1 /(1.82)$ & & & \\
\hline Xanthium & & $7 /(4.79)$ & $5 /(3.97)$ & $10 /(3.48)$ \\
\hline Zinnia Type & & & & $3 /(1.05)$ \\
\hline Dicranum & & $6 /(4.11)$ & & \\
\hline Didymodon & $3 /(5.45)$ & & $12 /(9.52)$ & $8 /(2.79)$ \\
\hline Dryopteris & $3 /(5.45)$ & $6 /(4.11)$ & $1 /(0.79)$ & $12 /(4.18)$ \\
\hline Hypnum & & $4 /(2.74)$ & & \\
\hline Lycopodium & $2 /(3.64)$ & & & $4 /(1.39)$ \\
\hline
\end{tabular}


Ophioglossum

Osmunda regalis

Pteridium

Sphagnum

Woodwardia

Unidentifiable

Totals

$\begin{array}{llll} & 4 /(2.74) & 4 /(3.17) & 4 /(1.39) \\ & 3 /(2.10) & & 8 /(2.79) \\ 11 /(20.00) & 7 /(4.79) & 8 /(6.35) & 19 /(6.62) \\ 5 /(9.10) & & & 12 /(4.18) \\ & 6 /(4.11) & 4 /(3.17) & 12 /(4.18) \\ 9 /(16.36) & 13 /(8.90) & 16 /(12.70) & 22 /(7.67) \\ 53(100) & 146(100) & 126(100) & 287(100)\end{array}$


Table 4, Contd.

\begin{tabular}{|c|c|c|c|c|}
\hline \multirow[b]{2}{*}{ Taxa } & \multicolumn{4}{|c|}{$\begin{array}{c}\text { Pollen Counts and Percentages from Fort Vancouver } \\
\text { Samples, Lot Numbers }\end{array}$} \\
\hline & 551 & 534 & 536 & 538 \\
\hline Abies & $2 /(0.60)$ & $4 /(1.28)$ & & \\
\hline Alnus & & $20 /(6.41)$ & $6 /(1.95)$ & $9 /(2.95)$ \\
\hline Carya & & & $1 /(0.32)$ & \\
\hline Castanopsis & & & & $1 /(0.98)$ \\
\hline Citrus & & & $1 /(0.32)$ & \\
\hline Juniperus & & & $3 /(0.97)$ & \\
\hline Larix & $9 /(2.69)$ & $3 /(0.96)$ & $4 /(1.30)$ & \\
\hline Morus & & & & $11 /(3.61)$ \\
\hline Picea & & $5 /(1.60)$ & $3 /(0.97)$ & $4 /(1.31)$ \\
\hline Pinus & $8 /(2.40)$ & $19 /(6.09)$ & $6 /(1.95)$ & $5 /(1.64)$ \\
\hline Populus & & & & $3 /(0.98)$ \\
\hline Pseudotsuga & & $6 /(1.92)$ & $4 /(1.30)$ & $2 /(0.66)$ \\
\hline Quercus & $6 /(1.80)$ & $8 /(2.56)$ & $2 /(0.65)$ & $4 /(1.31)$ \\
\hline Rosaceae & & $4 /(1.28)$ & $4 /(1.30)$ & $4 /(1.31)$ \\
\hline Salix & & & $1 /(0.32)$ & $5 /(1.64)$ \\
\hline Taxus & $4 /(1.20)$ & & & \\
\hline Thuja & & & & $3 /(0.98)$ \\
\hline Tsuga & $15 /(4.49)$ & $11 /(3.53)$ & $5 /(1.62)$ & $1 /(0.33)$ \\
\hline Ulmus & & & & $1 /(0.33)$ \\
\hline Ambrosia & $10 /(2.99)$ & $2 /(0.64)$ & $5 /(1.62)$ & $5 /(1.64)$ \\
\hline Anthemis & & & & $1 /(0.33)$ \\
\hline Apiaceae & & $5 /(1.60)$ & $2 /(0.64)$ & $2 /(0.66)$ \\
\hline Apocynum & $5 /(1.50)$ & & & \\
\hline Aquilegia & & $2 /(0.64)$ & & $3 /(0.98)$ \\
\hline Artemisia & & $1 /(0.32)$ & & \\
\hline Aster & $18 /(5.40)$ & & & \\
\hline Bidens & $6 /(1.80)$ & & & $1 /(0.33)$ \\
\hline Brassicaceae & $9 /(2.69)$ & $2 /(0.64)$ & & $5 /(1.64)$ \\
\hline Calendula Type & $5 /(1.50)$ & & & \\
\hline Carex & & & $1 /(0.32)$ & \\
\hline Caryophyllaceae & & $3 /(0.96)$ & & \\
\hline Centaurea & & $1 /(0.32)$ & $3 /(0.97)$ & \\
\hline Cerastium & & & & $2 /(0.66)$ \\
\hline Cereales & & $2 /(0.64)$ & $4 /(1.30)$ & \\
\hline Cheno/Am & $21 /(6.29)$ & $4 /(1.28)$ & $4 /(1.30)$ & $4 /(1.31)$ \\
\hline Fenestrate 22-29 & $45 /(13.47)$ & $81 /(25.96)$ & $101 /(32.79)$ & $75 /(24.59)$ \\
\hline Fenestrate 30-39 & $17 /(5.10)$ & $15 /(4.81)$ & $34 /(11.04)$ & $35 /(11.48)$ \\
\hline Finestrate $40-45$ & & $4 /(1.28)$ & $1 /(0.32)$ & $1 /(0.33)$ \\
\hline Daphne & & & $1 /(0.32)$ & \\
\hline Eleocharis & & & & $1 /(0.33)$ \\
\hline Equisetum & $22 /(6.59)$ & $12 /(3.85)$ & $22 /(7.14)$ & $20 /(6.56)$ \\
\hline Eriogonum & & & $1 /(0.32)$ & \\
\hline
\end{tabular}




\begin{tabular}{|c|c|c|c|c|}
\hline Helianthus & & & & $1 /(0.33)$ \\
\hline Humulus & & & $1 /(0.32)$ & $3 /(0.98)$ \\
\hline Iridaceae & $2 /(0.60)$ & $2 /(0.64)$ & $2 /(0.65)$ & \\
\hline Lamiaceae & & & $3 /(0.97)$ & \\
\hline Layia & $7 /(2.10)$ & & & \\
\hline Liliaceae & & $2 /(0.64)$ & & $2 /(0.66)$ \\
\hline Marrubium & $7 /(2.10)$ & & & \\
\hline Nicotiana & & $1 /(0.32)$ & & \\
\hline Papaver & & $4 /(1.28)$ & & \\
\hline Phaseolus & & & $1 /(0.32)$ & \\
\hline Plantago & & $25 /(8.01)$ & $3 /(0.97)$ & \\
\hline Poaceae & $5 /(1.50)$ & $9 /(2.88)$ & $4 /(1.30)$ & $9 /(2.95)$ \\
\hline Portulaca & & & & $2 /(0.66)$ \\
\hline Ribes & & $5 /(1.60)$ & $2 /(0.65)$ & $4 /(0.66)$ \\
\hline Rumex & & & $4 /(1.30)$ & $2 /(0.66)$ \\
\hline Senecio & $11 /(3.29)$ & $11 /(3.53)$ & $6 /(1.95)$ & $11 /(3.61)$ \\
\hline Solanaceae & & $3 /(0.96)$ & $7 /(2.27)$ & \\
\hline Solidago & $8 /(2.40)$ & $4 /(1.28)$ & $i$ & \\
\hline Trifolium & & & $2 /(0.65)$ & $1 /(0.33)$ \\
\hline Xanthium & $10 /(2.99)$ & $2 /(0.64)$ & & $6 /(1.97)$ \\
\hline Zinnia Type & $8 /(2.40)$ & & & \\
\hline Cryptogramma & & & & $1 /(0.33)$ \\
\hline Didymodon & $12 /(3.59)$ & & $4 /(1.30)$ & \\
\hline Dryopteris & $11 /(3.29)$ & $1 /(0.32)$ & $6 /(1.95)$ & $3 /(0.98)$ \\
\hline Hypnum & & $4 /(1.28)$ & & $2 /(0.66)$ \\
\hline Lycopodium & $4 /(1.20)$ & $1 /(0.32)$ & $2 /(0.65)$ & $6 /(1.97)$ \\
\hline Pteridium & $19 /(5.69)$ & $8 /(2.56)$ & $10 /(3.25)$ & $11 /(3.61)$ \\
\hline Selaginella & & & $3 /(0.97)$ & \\
\hline Sphagnum & & $3 /(0.96)$ & $5 /(1.62)$ & $6 /(1.97)$ \\
\hline Unidentifiable & $22 /(6.59)$ & $9 /(2.88)$ & $16 /(5.19)$ & $22 /(7.21)$ \\
\hline Identifiable & $6 /(1.80)$ & $3 /(0.96)$ & $4 /(1.30)$ & $5 /(1.64)$ \\
\hline Totals & $334 /(100)$ & $312 /(100)$ & $308 /(100)$ & $305 /(100)$ \\
\hline
\end{tabular}


Table 4, Contd.

Pollen Counts and Percentages from Fort Vancouver

\begin{tabular}{|c|c|c|c|c|}
\hline Taxa & 540 & 542 & 544 & 546 \\
\hline Abies & & $4 /(1.33)$ & $7 /(2.27)$ & \\
\hline Alnus & $7 /(2.33)$ & & & \\
\hline Berberis & $3 /(1.00)$ & & & \\
\hline Castanopsis & $5 /(1.67)$ & & $4 /(1.30)$ & \\
\hline Citrus & & $2 /(0.66)$ & & \\
\hline Fraximus & & $2 /(0.66)$ & & \\
\hline Juniperus & $9 /(3.00)$ & $3 /(1.00)$ & & \\
\hline Larix & $7 /(2.33)$ & $3 /(1.00)$ & $5 /(1.62)$ & $2 /(1.69)$ \\
\hline Murus & $4 /(1.33)$ & $9 /(3.00)$ & & \\
\hline Picea & $8 /(2.67)$ & $5 /(1.67)$ & $7 /(2.27)$ & \\
\hline Pinus & $6 /(2.00)$ & $8 /(2.67)$ & $7 /(2.27)$ & \\
\hline Populus & $5 /(1.67)$ & $3 /(1.00)$ & $10 /(3.25)$ & $1 /(0.85)$ \\
\hline Pseudotsuga & $5 /(1.67)$ & $8 /(2.67)$ & $3 /(0.97)$ & $9 /(7.63)$ \\
\hline Quercus & $5 /(1.67)$ & $2 /(0.66)$ & & \\
\hline Rosaceae & $4 /(1.33)$ & $2 /(0.67)$ & & \\
\hline Salix & & & & $2 /(1.69)$ \\
\hline Thuja & & $3 /(1.00)$ & $6 /(1.95)$ & \\
\hline Tsuga & $8 /(2.67)$ & $4 /(1.33)$ & $1 /(0.32)$ & $4 /(3.39)$ \\
\hline Achillea & & & $3 /(0.97)$ & \\
\hline Ambrosia & $8 /(2.67)$ & $7 /(2.33)$ & $8 /(2.60)$ & $2 /(1.69)$ \\
\hline Apiaceae & $3 /(1.00)$ & $3 /(1.00)$ & & \\
\hline Aquilegia & $4 /(1.33)$ & & & \\
\hline Aster & & & $6 /(1.95)$ & \\
\hline Bidens & $15 /(5.00)$ & $2 /(0.67)$ & & \\
\hline Brassicaceae & & $4 /(1.33)$ & & \\
\hline Calendula Type & & $1 /(0.33)$ & & \\
\hline 'Cereales & & $1 /(0.33)$ & $4 /(1.30)$ & \\
\hline Cheno/Am & $8 /(2.67)$ & $3 /(1.00)$ & & \\
\hline Fenestrate $22-29$ & $46 /(15.33)$ & $73 /(24.33)$ & $41 /(13.31)$ & $8 /(6.78)$ \\
\hline Fenestrate 30-39 & $12 /(4.33)$ & $23 /(7.67)$ & $16 /(5.91)$ & \\
\hline Fenestrate $40-45$ & & & $9 /(2.92)$ & \\
\hline Daphne & & $2 /(0.67)$ & & \\
\hline Equisetum & $15 /(5.00)$ & $13 /(4.33)$ & $30 /(9.74)$ & $26 /(22.03)$ \\
\hline Euphorbia & & $2 /(0.67)$ & & \\
\hline Helianthus & & $3 /(1.00)$ & & \\
\hline Humulus & & & $3 /(0.97)$ & \\
\hline Iridaceae & $5 /(1.67)$ & $3 /(1.00)$ & & \\
\hline Lamiaceae & & & $3 /(0.97)$ & \\
\hline Marrubium & & $2 /(0.67)$ & & \\
\hline Menyanthes & & & & $2 /(1.69)$ \\
\hline Plantago & $9 /(3.00)$ & $7 /(2.33)$ & $13 /(4.22)$ & \\
\hline Poaceae & $5 /(1.67)$ & $5 /(1.67)$ & $3 /(0.97)$ & $4 /(3.39)$ \\
\hline
\end{tabular}

Samples, Lot Numbers

$3 /(1.00)$

$5 /(1.67)$

$2 /(0.66)$

$2 /(0.66)$

9/ $3 /(1.00) \quad 3 /(1.00)$

$7 /(2.33) \quad 3 /(1.00)$

$4 /(1.33) \quad 9 /(3.00)$

$8 /(2.67) \quad 5 /(1.67) \quad 7 /(2.27)$

$6 /(2.00) \quad 8 /(2.67) \quad 7 /(2.27)$

$5 /(1.67) \quad 3 /(1.00) \quad 10 /(3.25) \quad 1 /(0.85)$

$5 /(1.67) \quad 8 /(2.67) \quad 3 /(0.97) \quad 9 /(7.63)$

Rosaceae

Thuja

Tsuga

Achillea

Ambrosia

Apiaceae

Aquilegia

Aster

Bidens

Brassicaceae

Calendula Type

$8 /(2.67)$

$1 /(0.33)$

$6 /(1.95)$

$3 /(0.97)$

$(2.60)$

$2 /(1.69)$

$3 /(1.00) \quad 3 /(1.00)$

$4 /(1.33)$

$46 /(15.33) \quad 73 /(24.33)$

$41 /(13.31)$

$8 /(6.78)$

Fenestrate 30-39

Fenestrate 40-45

Daphne

Equisetum

Euphorbia

Helianthus

Humulus

Iridaceae

Lamiaceae

Marrubium

Menyanthes

Poaceae

$5 /(1.67)$

$5 /(1.67)$

$13 /(4.22)$ 


\begin{tabular}{|c|c|c|c|c|}
\hline Polygonum & & $2 /(0.66)$ & $3 /(0.97)$ & $3 /(2.54)$ \\
\hline Portulaca & & $1 /(0.33)$ & & \\
\hline Ribes & & $2 /(0.66)$ & $4 /(1.30)$ & \\
\hline Saxifraga & & & $6 /(1.95)$ & \\
\hline Senecio & $12 /(4.00)$ & $14 /(4.67)$ & $9 /(2.92)$ & $1 /(0.85)$ \\
\hline Solanaceae & $4 /(1.33)$ & $2 /(0.66)$ & $5 /(1.62)$ & \\
\hline Solidago & & & & $1 /(0.85)$ \\
\hline Tribulus & $3 /(1.00)$ & & & \\
\hline Xanthium & $12 /(4.00)$ & $13 /(4.33)$ & $11 /(3.57)$ & $4 /(3.39)$ \\
\hline Zea mays & & & $1 /(0.32)$ & \\
\hline Zinnia Type & & & $8 /(2.60)$ & \\
\hline Cryptogramma & & & & $2 /(1.69)$ \\
\hline Dicranum & & $2 /(0.66)$ & $17 /(5.52)$ & $20 /(16.95)$ \\
\hline Didymodon & $3 /(1.00)$ & $6 /(2.00)$ & $1 /(0.32)$ & \\
\hline Diyopteris & $11 /(3.67)$ & $5 /(1.67)$ & $8 /(2.60)$ & $3 /(2.54)$ \\
\hline Hypnum & $3 /(1.00)$ & $2 /(0.66)$ & & \\
\hline Lycopodium & $10 /(3.33)$ & & $5 /(1.62)$ & $2 /(1.69)$ \\
\hline Osmunda regalis & & $2 /(0.66)$ & & \\
\hline Polystichum & & $1 /(0.33)$ & & \\
\hline Pteridium & & $9 /(3.00)$ & $8 /(2.60)$ & $11 /(9.32)$ \\
\hline Selaginella & $3 /(1.00)$ & & $4 /(1.30)$ & \\
\hline Sphagnum & $10 /(3.33)$ & $8 /(2.61)$ & $5 /(1.62)$ & $3 /(2.54)$ \\
\hline Woodwardia & $3 /(1.00)$ & & $2 /(0.65)$ & $2 /(1.69)$ \\
\hline Unidentifiable & $16 /(5.33)$ & $14 /(4.67)$ & $17 /(5.52)$ & $6 /(5.08)$ \\
\hline Identifiable & $4 /(1.33)$ & $5 /(1.67)$ & $5 /(1.62)$ & \\
\hline Totals & $300(100)$ & $300 /(100)$ & $308 /(100)$ & $118 /(100)$ \\
\hline
\end{tabular}




\section{Description of Recovered Taxa}

\section{Arboreal Vegetation}

Abies Pollen grains of this genus appeared in eight of the twenty-four samples with the greatest amount recovered from context 431 . Several species of fir grow naturally in the region surrounding Fort Vancouver (see Franklin and Dyrness 1969; Mattoon 1936: 27) and historical records cited in Appendix A of the Fort Vancouver Cultural Landscape Report (http://www.nps.gov) include firsthand accounts, which document the presence of this species in the vicinity of the fort.

Acacia Pollen grains of this genus appeared in four samples. Acacia is not native to the area. Acacia is insect-pollinated and grows naturally in the southern portion of the United States (Britton and Brown, Vol. I 1896: 254; Wodehouse 1965: 431). This species moderately produces pollen, but has a low dispersal rate (Davis http://www.geo.arizona.edu/palynology), perhaps indicating local vegetation. Historical records indicate that acacia seeds were present at Fort Vancouver in 1833 (http://www.nps.gov). Therefore, the recovered acacia pollen grains, albeit a minute representation in the pollen spectrum, possibly indicate that this species was grown within or in close proximity to the garden testing area. Acacia was planted as an ornamental and during colonial times gum arabic was bled from it and used for candymaking and as a medicinal ingredient (Sumner 2004: 227).

Alnus $\quad$ Pollen grains belonging to this genus were recovered from nine samples with the greatest amount representing $6.47 \%$ of the total counted pollen for the context recovered from sample 534. Alder grows naturally in the region surrounding Fort Vancouver (see Franklin and Dyreness 1969; Mattoon 1936:29) and is characterized as a 
fast-growing species at distressed sites (Tilman 1988: 214). Perhaps this is an indication of some type of a disturbance to the landscape in the immediate area. Studies (Larsen and MacDonald 1998) reveal positive correlations between fire and alder within a 5- year period following a peak in macroscopic charcoal. Interestingly, charcoal particles were observed in all Fort Vancouver samples. Alder is also widespread along streams and commonly found in swamps (Harlow 1957: 129), perhaps also indicating a moist immediate environment. Several recovered pollen grains measured larger than others perhaps indicating the presence of at least two distinct alder species (see Heusser 1969: 413).

Berberis Pollen grains identified to this genus were recovered from sample 540. Barberry was initially cultivated during the seventeenth century as a hedge and the berries from the plant were used to dress meat dishes and were also pickled for consumption (Sumner 2004: 123,166, and 337). There are several species belonging to the genus Berberis that are native to North America (Britton and Brown, Vol. II 1897: 89-90).

Carya Minute amounts of hickory pollen were recovered in two samples, 422 and 536. This genus is native to eastern North America (Britton and Brown, Vol. 1 1896: 484). Since hickory pollen is heavy, it tends to fall closer to its originating source perhaps indicating local vegetation. Hickory may have been grown at Fort Vancouver. Castanopsis Giant chinquapin grows naturally in Washington. A nominal amount of pollen grains identified to this genus were recovered from four samples perhaps indicating a background presence for this genus. 
Celtis Hackberry is native to North America (http://plants.usda.gov). A minute amount of pollen grains identified to this genus were recovered from one sample.

Citrus $\quad$ Minimal amounts of citrus pollen were found in samples 536 and 542. Citrus does not naturally occur in the Washington area and is both insect and windpollinated (Wright 2007: 12, website). The recovery of pollen grains identified to this genus implies that it was imported to the area and probably grown at the fort. Historical records and eyewitness accounts document that oranges, lemons, and nectarines were grown at Fort Vancouver in 1835, 1836 and 1841 (http://www.nps.gov).

Fraxinus Pollen grains identified to this genus were recovered from two samples. Ash is native to the area (Mattoon 1936: 46) and an eyewitness account by Rev. Samuel Parker places white ash (Fraxinus latifolia) in the vicinity of Fort Vancouver (http://www.nps.gov).

Juniperus Several species of juniper are native to the area (Mattoon 1936: 46). The recovery of pollen grains identified to this genus was quite common. Juniper was represented in ten samples.

Larix Larch frequently appeared in the pollen record as it was represented in nineteen samples. Larch prefers moist habitats and is naturally found in swampy woods and around the margins of lakes in the region (Britton and Brown, Vol. I 1896: 54), perhaps indicating a moist environment in the general region.

- Moraceae Pollen grains identified to this family were recovered from five contexts with the highest percentages of total pollen counted for this genus appearing in samples 538 and 542. Species such as mulberry (Morus) and figs (Ficus) belong to this family and are not native to the region. Historical records indicate that figs were grown 
probably in the garden area (http://www.nps.gov). The presence of Ficus in the palynological record is uncommon and generally due to soil samples that were in association with fallen figs or a nearby Ficus tree (Bush and Rivera 2001: 364). Picea Spruce pollen grains appeared in twelve samples. Several species of spruce are naturally located in the region (Heusser 1978: 297-298; Mattoon 1936: 46). Historical documents and archaeology verify that a spruce mill was located on the premises in the early $20^{\text {th }}$ century (http:/www.nps.gov). The recovered spruce pollen grains complement the record.

Pinus $\quad$ Several species of pine are indigenous to the area (Heusser 1978: 297298). Pine pollen grains were present in eighteen samples and most likely represent background and regional vegetation. Historical records also indicate that pine was observed in the area during the Fort Vancouver occupation (http://www.nps.gov). Populus Species such as cottonwood (Populus deltoides) and quaking aspen (Populus tremuloides) are native to the region (Kapp et al. 2000: 77). Pollen grains identified to this genus were recovered in eleven samples and most likely represent background vegetation. Historical records from the Fort Vancouver period mention that some species of poplar were referred to as "Balm of Gilead" (http://www.nps.gov). The resin from both poplar and fir trees was used as an ingredient in herbal remedies to cure a variety of illnesses (Sumner 2004: 254).

Pseudotsuga Douglas fir as mentioned, "dominates modern successional stands" in the region. Pollen grains identified to this genus were recovered in twenty samples and in eight of these samples, represented a higher percentage of the total counted pollen than other arboreal species for any one sample. 
Quercus Poilen grains identified as oak were present in fourteen samples.

Historical accounts document that several species of oak were present in the vicinity of Fort Vancouver (http://www.nps.gov) and are growing on the property today.

Rosaceae This family comprises roughly 1200 species consisting of herbs, shrubs, and trees (Britton and Brown, Vol. II 1897: 194-254). Minimal amounts of Rosaceae pollen were recovered during the pollen analysis; however, pollen identified to this

- family was found in half of the samples submitted for analysis. Because many species belonging to this family are insect pollinated, pollen is poorly dispersed, which may account for the low pollen grain recovery rate; however, insect-pollen also denotes local vegetation. Therefore the recovered Rosaceae pollen grains may indicate that species belonging to this family were grown throughout or within the garden testing area.

Historical records report that many fruit species belonging to the Rosaceae family such as apples, peaches, plums, cherries, pears, strawberries, and apricots as well as roses were grown in the Fort Vancouver garden and orchard areas (http://www.nps.gov).

Salix Negligible amounts of willow pollen appeared in five samples. Several species of willow are native to the area (Mattoon 1936: 28-29).

Taxus Several species of yew, for example the Pacific yew (Taxus brevifolia), are indigenous to the region (http://plants.usda.gov). Pollen grains identified to this genus were recovered in three samples.

Thuja Pollen grains identified to this genus were recovered from five samples. Several species belonging to this genus are native to Washington (Mattoon 1936: 27). Tsuga Pollen grains identified to this genus were represented in fifteen samples and most likely comprised background and regional vegetation. 
Ulmus Elm is not native to the region (http://plants.usda.gov). A trivial amount of pollen identified to this genus appeared in one sample.

Vaccinium Blueberry and cranberry are native to western North America and were historically reported in the vicinity of Fort Vancouver (http://www.nps.gov). Several of these species prefer moist soils (Britton and Brown, Vol. II 1897: 575-580) perhaps further supporting that wetland environments existed within or near the fort.

\section{Non-Arboreal Vegetation}

Actaea Pollen grains identified as baneberry only appeared in sample 433. A couple of species belonging to this genus are native to western North America (Britton and Brown, Vol. I 1896: 55-56).

Ambrosia and Xanthium Ragweed and cocklebur or burweed appeared in twentytwo of the twenty-four samples. These species are considered to be markers of cultivation and are portrayed as "fugitive" or "invader" species that readily and initially colonize disturbed environments (Elzinga 1988: 374-375; Faegri et al. 1989: 182-184; Kelso and Beaudry 1990: 68) and are common among cultivated fields, open soils, meadows, and pastures (Britton and Brown, Vol. III 1898: 297-298; Brown 1976: 182, 186; Page and Weaver 1974: 206). Because ragweed and cocklebur or burweed are wind pollinated, they provide more of a regional as well as local vegetation type. Ragweed and cocklebur or burweed were well represented in the Fort Vancouver pollen spectrum perhaps documenting ongoing agricultural practices as well as a disturbed, open, regional landscape.

Apiaceae Weedy and economic taxa such as carrot and parsley are included in this family. Queen Anne's Lace (Daucus carota), naturalized from Europe for example, 
serves as both a garden ornamental, but it also occurs naturally as an invasive weed in fields and waste places (Britton and Brown, Vol. II 1897: 510). Many species identified to this family, for example Cow Parsnip (Heracleum lanatum), prefer moist soils (Britton and Brown, Vol. II 1897: 514). Historical documentation regarding Fort Vancouver states that vegetables such as curled parsley, carrots, and parsnips were grown there (http://www.nps.gov). Pollen identified to this family was present in seven samples with more than an incidental amount recovered in sample 425. Many species identified to this family are insect-pollinated indicating local vegetation.

Apocynum cannabinum Pollen grains identified as Indian hemp only appeared in two samples. This species is commonly present in fields and thickets (Britton and Brown, Vol. III 1898: 3).

Aquilegia Columbine was only present in three samples, Historical documentation lists several references to red columbine (Aquilegia formosa) as growing in the vicinity of Fort Vancouver (http://www.nps.gov). Perhaps this species was cultivated for aesthetic purposes; however, columbine also grows wild.

Asarum Pollen grains identified to this genus only appeared in two samples. Ginger is indigenous to the northwest (http://plants.usda.gov) and has been used as a medicine and as a seasoning for foods during colonial times (Sumner 2004: 190, 340$341)$.

Borago Species belonging to this genus are native to Europe and naturally occur in North America in waste places after having escaped from cultivation (Britton and Brown, Vol. III 1898: 67-68). Alkanet was extracted from the roots of some species and used as 
red dye (Leighton 1970: 256-257). Minute amounts of Borago appeared in three samples.

Brassicaceae The Mustard Family comprises many species, which are predominantly native to Europe, Asia and northern Africa (Britton and Brown, Vol. II 1897: 118). The family represents both weedy and economic taxa. Pepperweed (Lepidium), for example, is a naturally occurring weed (Britton and Brown, Vol. II 1897: 110-112). Historical documentation identifies several species of cabbage; radish, turnip, broccoli, and mustard were grown at Fort Vancouver (http://www.nps.gov). Minimal amounts of pollen identified to the Brassicaceae family were found in nine pollen samples with more than an incidental amount registered for several of these samples especially since many of these species are insect-pollinated.

Carex and Eleocharis Many species of sedge identified to both genera are commonly found in swamps, bogs, marshes, ponds, streams, wet woods, and along shores; however, some species prefer woody areas, thickets, and dry soils (Britton and Brown, Vol. I 1896: 248-256, 292-360). Pollen grains identified as Carex were only present in two samples. Carex represented approximately $3 \%$ of the total pollen counted for sample 334 , which was taken from a root cellar floor. Interestingly, a high amount of Equisetum and a minimal amount of Eleocharis, another genus of sedge, were also recovered from this context. Minute amounts of pollen grains identified as Eleocharis were also found in samples 401 and 538.

Caryophyllaceae Pollen grains identified to the "Pink Family" were recovered from four samples. Carnations, pinks, and sweet william belong to this family and were grown in colonial American gardens (Sumner 2004: 190). Weedy taxa such as white campion 
(Lychnis alba) also belong to this family and frequently inhabit meadows and waste places (Britton and Brown, Vol. II 1897: 13-15).

Cereales European-introduced cereals, besides indicating settlement, are also economic species and possess implications regarding diet and commerce. Historical records indicate that cereal grasses such as early Angus oats (Avena), winter wheat (Triticum), and rye (Secale), were grown at Fort Vancouver (http://www.nps.gov) from the early years of the fort throughout its occupation. One entry makes note that rye was the only crop to have survived a flood one year. Minimal amounts of pollen grains identified as cereal grass were recovered from seven samples. Most species grouped as such except rye are self-pollinated; therefore, their pollen grains do not fall far from their originating point (Davis 1969: 420; van der Veen: 1992: 8), and not a great quantity of pollen is released until the plants are threshed (Kelso 1994a: 17). European-introduced cereal pollen is found on respective grain, chaff, straw, and grain products (Kelso 1998: 54; see also Grieg 1982: 59). The recovery of European-introduced cereals signifies "local human activities involving grain, grain products or grain waste" (Kelso 1998: 54; see also Bradley et al. 1983: 75). It is probable that cereal pollen was deposited at Fort Vancouver because it was grown and most likely processed there.

Chenopodiaceae/Amaranthaceae (Cheno/Am) Pollen grains identified as either goosefoot or pigweed were recovered from twenty-one samples. These species are predominately wind-pollinated weedy taxa that thrive in open spaces, cultivated soils, dry soils, and wastelands and can also be found in woods and thickets (Britton and Brown, Vol. I 1896: 569-593; Page and Weaver 1974: 209; Wodehouse 1965: 410-421). The presence of these species in so many Fort Vancouver samples supports an open regional 
environment and probable agricultural activities, which historical documentation verifies were ongoing in the immediate sampled area.

Compositae, Liguliflorae Pollen grains were identified as Liguliflorae due to their fenestrate sculpturing and were separated out into three categories based on grain size. The majority of species categorized as Liguliflorae are native to Europe, but there are several species considered indigenous to North America (Britton and Brown, Vol. III 1898: 262-282). Fenestrate pollen grains were recovered from every Fort Vancouver sample; however grains only measuring from $22 \mu \mathrm{m}$ to $29 \mu \mathrm{m}$ were recovered from sample 546, which predates the Hudson Bay Company occupation. Several fenestrate pollen types measuring in this range are native to the Northwest, whereas some cultivated species such as lettuce (Lactuca) and others generally measure over $30 \mu \mathrm{m}$. Chicory (Cichorium intybus), with the leaves of this species cooked for greens or used in salads (Page and Weaver 1974: 181) measures from about 35 to $53 \mu \mathrm{m}$.

Compositae, Tubuliflorae Pollen grains identified to this category were well represented and recovered from every sample except 335 . Several different species were identified in this analysis. Historical records possibly list yarrow (Achillea) as growing in the vicinity of Fort Vancouver (http://www.nps.gov). Pollen grains identified to this genus appeared in five of the samples. Yarrow commonly grows in open areas, grassy fields, and waste places, but it was also cultivated as a curative herb during colonial times (Page and Weaver 1974: 154; Sumner 2004: 34-35). Perhaps yarrow was grown at Fort Vancouver for the same purpose. A minute amount of pollen was identified as Anthemis. Chamomile was used as a spice and in medicinal teas (Sumner 2004: 35, 176). Artemisia was found in one sample. Several species belonging to this genus were introduced to 
North America; however, mugwort (Artemisia vulgaris) may be native to the Northwest Territory (Page and Weaver 1974: 207). This species as well as other species belonging to this genus are known to flourish in fields and waste places (Britton and Brown, Vol. III 1898: 461-468; Page and Weaver 1974: 207). Numerous species belonging to the genus Aster are native perennials and grow in a variety of habitats (Britton and Brown, Vol. III 1898: 356-382; Page and Weaver 1974: 164). Some species are attractive enough to be grown in gardens, but this practice was more common in England than it was in the United States (Page and Weaver 1974: 164). Pollen grains identified as Aster appeared in seven Fort Vancouver pollen samples with the greatest frequency occurring in sample 551. Interestingly no aster pollen grains were recovered from sample 546, which dates to before the Hudson Bay Company occupation. Several beggar-ticks (Bidens) species are indigenous to the western portion of the United States (Britton and Brown, Vol. III 1896: 436-440). This weedy plant likes to grow in wet soils, but it has also been found on drier soils and is present in fields, gardens, waste places, along ponds and streams (Page and Weaver 1974: 205; Britton and Brown, Vol. III 1898: 436-440). Pollen grains identified as Bidens were recovered from five samples.

Pollen identified as a marigold type (Calendula) was recovered from seven samples. Marigolds were imported to North America and were cultivated as early as 1642 in Dutch New Netherlands (Taylor 1996: 19). Pollen grains resembling an artichoke type (Cynara) were recovered from two samples. Pollen grains identified as sunflower (Helianthus) were recovered from five samples. Helianthus is native to North America and grows in a variety of habitats (Britton and Brown, Vol. III 1898: 421-429). The roots of Jerusalem artichoke (Helianthus tuberosus) were consumed by many Native 
American groups (Moerman 1998: 259) and American colonists (Sumner 2004: 87-88) as well. Sunflowers, members of the Helianthus genus, were regularly grown as ornamentals in North America and historical documentation makes reference to sunflowers in the vicinity of Fort Vancouver (http://www.nps.gov).

- Pollen grains resembling a Dahlia type were recovered from one sample, but at an amount equal to $6 \%$ of the total amount of pollen counted for that sample. Interestingly, pollen grains resembling a Zinnia type represented approximately $5 \%$ of the total pollen counted for the same sample. Pollen grains identified to this type were present in a total of five samples, while pollen identified to daisy tidytips (Layia) were recovered in four samples. Since both dahlias and zinnias are insect-pollinated, pollen grains dispersed by these species would have landed nearby their point of origin. Dahlias were extremely popular in the early nineteenth century (Sumner 2004: 328; Weishan and Roig 2004: 38). Documentary evidence suggests that dahlia seeds were present at Fort Vancouver in 1833 as well as roses and "many other pretty flowers" (http://www.nps.gov).

Pollen grains identified to the weedy Senecio genus were recovered from twenty samples and were generously present in samples 334 and 392. Many species of Senecio occur naturally in western North America (Britton and Brown, Vol. III 1898: 475) and are an invader species. Another weedy genus, Solidago was identified in nine samples. There are approximately 85 species of Solidago that are predominately native to North America (Britton and Brown, Vol. III 1898: 331-347). Pollen grains identified as a Tansy type (Tanacetum) were recovered from seven samples. Tansy leaves were consumed, used for flavoring, used as a vermifuge and an insecticide (Sumner 2004: 100, 185 , and 232). 
Daphne Daphne is an introduced species to North America

(http://plants.usda.gov). Small amounts of pollen identified to this genus were recovered from four samples.

Equisetum Pollen grains identified as Equisetum appeared in all twenty-four samples and was well represented in many of them. Field horsetail (Equisetum arvense) grows in sandy soils along roadways (Britton and Brown, Vol. I 1896: 36). Scouring-rush

(Equisetum hymale) grows in wet environments along the shores of rivers and lakes

(Britton and Brown, Vol. I 1896: 38). The rough stems of scouring-rush (Equisetum

hymale) were used to scour pots, pans, and floors (Britton and Brown, Vol. I 1896: 38;

Sumner 2004: 298).

Eriogonum A trivial amount of buckwheat was recovered from one sample.

Eriogonum is comprised of indigenous herbaceous species predominately from the western United States (Britton and Brown Vol. I: 542-546).

Euphorbia Spurge occurs naturally in western parts of North America (Britton and Brown, Vol. II 1898: 370). Minute amounts of spurge were recovered from two samples. Humulus Pollen grains identified as hop appeared in eight samples. Historical documentation from the Fort Vancouver occupation mentions hops (http://www.nps.gov). Common hop grows naturally throughout the United States (http://plants.usda.gov). Hops were also cultivated and brewed with barley to make ale and other beverages (Sumner 2004: 60-61).

Iridaceae A minimal amount of pollen grains identified to the Iris Family were recovered from eleven samples. Some species of iris grow naturally in North America and prefer wet soils as irises can be commonly found in swamps, marshes, river shores, 
and along streams (Britton and Brown, Vol. I 1996: 448-452). Irises were also cultivated (Taylor 1996: 16, 98; Sumner 2004: 338). Historical records indicate that field irises were present in the vicinity of Fort Vancouver (http://www.nps.gov).

Lamiaceae Pollen grains identified to this family, not inclusive of horehound (Marrubium), were recovered in four samples. Many taxa belonging to this family are insect-pollinated thereby indicating local vegetation types. Both weedy and economic species are included in this family. Horehound (Marrubium) was recovered in six samples. This species has been used as a remedy to clear up "severe mucus congestion" and a tea was made out of it (Heinerman 1988: 191; Lewis and Elvin-Lewis 1977: 307). Liliaceae Insect-pollinated, vegetable and flower species are included in this family. Historical documentation lists several types of onions and leeks that were grown at Fort Vancouver (http://www.nps.gov). Lilies graced numerous gardens throughout North America. In the 1800 s there were over sixty-eight types of lilies available in seed catalogues with species native to the western U. S. appearing by the mid 1800s (Adams 2004: 254-260). Pollen grains identified to this family were recovered in seven samples. Nicotiana Tobacco belongs to the Solanaceae family. A small amount of tobacco pollen was found in one sample and since this species is insect-pollinated, its presence may indicate local vegetation. Nicotiana was smoked by many indigenous North American groups at ceremonial activities and they used it for medicinal purposes (Moerman 1998: 354-358). European Americans also smoked tobacco and utilized it in teas for medicinal purposes (Sumner 2004: 248-249). 
Papaver Poppies are native to both Europe and western North America (Britton and Brown, Vol. II 1897: 99). A nominal amount of pollen grains identified to this genus were found in one sample.

Phaseolus The genus is comprised of approximately thirty native New World species (Sauer 1993: 73). Beans were commonly grown in colonial gardens and prepared in a number of recipes (Sumner 2004: 78-79). Fort Vancouver historical records verify that beans were cultivated in 1834 (http://www.nps.gov). A minute amount of pollen identified to this genus was recovered from one sample.

Plantago This genus is comprised of naturalized and indigenous species that are associated with settlement because they flourish on packed soil of yards and paths, waste places and fields (Britton and Brown, Vol. III 1898: 206-210; Page and Weaver 1974: 212). Pollen grains identified as plantain appeared in seventeen Fort Vancouver samples and represented over $5 \%$ of the total counted pollen for two of them, perhaps indicating an occupied landscape.

Poaceae Fort Vancouver historical records verify that in addition to Europeanintroduced cereals, a variety of wild grasses were cultivated at the site (http://www.nps.gov). Wild grass pollen was recovered from eighteen samples, but never represented more than $4 \%$ of the total counted pollen for any one sample. Other historical studies yield significantly higher amounts of grass pollen indicating grass covered surfaces (see Kelso 1994b; Mrozowski et al. 1989) and further demonstrate that the recovered wild grass pollen from Fort Vancouver is too low to suggest grass cover and is not a sufficient quantity to verify whether or not the garden paths were covered 
with grass. Nevertheless, grass pollen grains were recovered from these areas supporting the presence of grass in the vicinity.

Polygonum Pollen grains identified as knotweed minimally appeared in five samples. Both naturalized and indigenous herbs are included in this genus with some species preferring wet soils, while others flourish within waste places (Britton and Brown, Vol. I 1996: 554-567; Wodehouse 1965: 404).

Portulaca A small amount of pollen identified to this genus was recovered from two samples. Many species of Portulaca, a flowering herb, prefer to inhabit fields and wastes places and are indigenous to the New World (Britton and Brown, Vol. II 1897: 4-6). Members of this genus are used as a food source and ornamental planting (Page and Weaver 1974: 189). Many species of Portulaca are insect-pollinated and may indicate local vegetation.

Ribes Several species of currants are native to western North America (Britton and Brown, Vol. II 1897: 187-192). Minimal amounts of pollen identified as currants were recovered from nine samples. According to historical records, a few types were cultivated at Fort Vancouver (http://www.nps.gov). Since currants are insect-pollinated, perhaps the recovered pollen indicates that they were grown nearby.

Rumex The genus Rumex is comprised generally of weedy taxa. Rumex is windpollinated and represents regional vegetation. Rumex minimally appeared in four samples.

Sagittaria Pollen grains identified to this genus were only recovered in one sample. Many species of this genus such as arrowhead (Sagittaria latifolia) grow in shallow water. 
Saxifraga Minimal amounts of pollen identified to this genus were recovered from five samples. Many species of this genus prefer to inhabit rocky dry soils, while others grow in wet environments (Britton and Brown, Vol. II 1897: 170-176).

Solanaceae Species belonging to the Nightshade family are predominantly insectpollinated. Pollen grains identified as Solanaceae were recovered in eleven samples. A variety of vegetation types native to North and South America are included in this family (Britton and Brown, Vol. III 1898: 137). Species such as ground cherry (Physalis virginiana) grow wild and were consumed as food and used as a medicinal remedy by Native Americans as well as American colonists (Heiser 1969: 108-109; Moerman 1998: 395-396). Many other edible taxa belong to the Solanaceae family. Historical documentation from Fort Vancouver reports that potatoes (Solanum sp.) were grown there (http://www.nps.gov).

Thalictrum Pollen grains identified to this genus were recovered from five samples. Several species of meadow rue are native to the Pacific Coast (Britton and Brown, Vol. II 1897: 86).

Trifolium Farmers in New England as early as the seventeenth century sowed their lands with imported grasses, which included red clover (Trifolium pretense) (Romani 1996: 33). Red clover was commonly grown for fodder (Britton and Brown, Vol. II 1897: 276) and can be considered as an economic species. Historical documentation from Fort Vancouver contains several entries of clover especially for the earlier years of occupation (http://www.nps.gov). Pollen grains identified as Trifolium were recovered from six samples. 
Typha Pollen grains identified to this genus were minimally recovered from one sample. Species such as the broad-leaved cat-tail (Typha latifolia) thrive in marshes throughout North America (Britton and Brown, Vol. I 1896: 62).

Viola Members of this genus consist of widely distributed insect-pollinated shrubs and herbs (Britton and Brown, Vol. II 1897: 445; Wodehouse 1965: 442-444). Heartsease (Viola tricolor) was cultivated as an ornamental as well as for medicinal use (Sumner 2004: 321). Pollen grains identified to this genus were present in two samples. Zea mays Maize is considered an economic taxon. One maize pollen grain with identification based on measurement of grain size, pore, and annulus was recovered from sample 544. Historical records indicate that maize or "Indian corn" was grown during Fort Vancouver's first years as entries for this crop were listed from 1825 through 1832 (http://www.nps.gov). Like European-introduced cereal pollen, maize pollen grains do not settle far from their point of origination indicating that maize was probably grown or processed in close proximity to the garden testing area.

\section{Mosses and Ferns}

Several types of mosses and ferns were identified in all twenty-four Fort Vancouver pollen samples. Six moss and six fern genera were recovered. Several types of fern that were identified in this analysis prefer moist environments such as swamps and marshes as well as grassy woods and meadows. Pollen grains identified as woodfern (Dryopteris) and brackenfern (Pteridium) appeared in twenty-one samples. Species belonging to these genera are considered to be invader species. Western brackenfern (Pteridium aquilinum) for example readily colonizes altered environments and cultivated fields and is "fire-adapted" 
(http://www.fs.fed.us/database/feis/plants/fern/pteaqu/all.html). As mentioned, charcoal particles were observed in every Fort Vancouver pollen sample. Higher amounts of brackenfern suggest an open landscape (Heusser 1978: 303-304). This species was also used in Europe for animal bedding (Dimbleby 1985: 144).

\section{Conclusion}

The pollen analysis conducted on twenty-four soil samples extracted from the Fort Vancouver garden testing area represent a mixture of many native arboreal and understory vegetation types that are common to both the Puget sound and Tsuga heterophylla vegetation zones. Nevertheless, a number of introduced, naturalized, and economic taxa were also identified. For the samples possessing a density, which exceeded 1000 grains of pollen per gram of soil thereby qualifying the findings from these samples to be suitable for reconstructing environmental vegetation, a landscape dominated by non-arboreal vegetation was revealed (see Table 5 and Table 6 ). Arboreal pollen never exceeded $26 \%$ of the total counted pollen or TCP for any one sample. This

Table 5

Percentages of Vegetation Types for Samples Possessing a Pollen Grain Density > 1000 grains of pollen per gram of soil

\begin{tabular}{|l|l|l|l|l|l|l|l|l|}
\hline Vegetation Type & $\begin{array}{l}\text { Sample } \\
\mathbf{3 3 4}\end{array}$ & $\begin{array}{l}\text { Sample } \\
\mathbf{3 8 9}\end{array}$ & $\begin{array}{l}\text { Sample } \\
\mathbf{4 2 0}\end{array}$ & $\begin{array}{l}\text { Sample } \\
\mathbf{4 1 9}\end{array}$ & $\begin{array}{l}\text { Sample } \\
\mathbf{4 2 2}\end{array}$ & $\begin{array}{l}\text { Sample } \\
\mathbf{4 3 3}\end{array}$ & $\begin{array}{l}\text { Sample } \\
\mathbf{4 9 7}\end{array}$ & $\begin{array}{l}\text { Sample } \\
\mathbf{5 5 1}\end{array}$ \\
\hline Arboreal & $21 \%$ & $18 \%$ & $20 \%$ & $17 \%$ & $16 \%$ & $14 \%$ & $14 \%$ & $13 \%$ \\
\hline Non-Arboreal & $54 \%$ & $62 \%$ & $52 \%$ & $64 \%$ & $56 \%$ & $58 \%$ & $48 \%$ & $65 \%$ \\
\hline Mosses \& Ferns & $16 \%$ & $13 \%$ & $18 \%$ & $14 \%$ & $22 \%$ & $19 \%$ & $31 \%$ & $14 \%$ \\
\hline Unidentifiable/Identifiable & $8 \%$ & $7 \%$ & $10 \%$ & $5 \%$ & $6 \%$ & $9 \%$ & $7 \%$ & $8 \%$ \\
\hline Totals & $100 \%$ & $100 \%$ & $100 \%$ & $100 \%$ & $100 \%$ & $100 \%$ & $100 \%$ & $100 \%$ \\
\hline
\end{tabular}

Values Rounded to Nearest Whole Number. 
Table 6

Percentages of Vegetation Types for Soil Column Samples

\begin{tabular}{|l|l|l|l|l|l|l|l|}
\hline Vegetation Type & $\begin{array}{l}\text { Sample } \\
\mathbf{5 3 4}\end{array}$ & $\begin{array}{l}\text { Sample } \\
\mathbf{5 3 6}\end{array}$ & $\begin{array}{l}\text { Sample } \\
\mathbf{5 3 8}\end{array}$ & $\begin{array}{l}\text { Sample } \\
\mathbf{5 4 0}\end{array}$ & $\begin{array}{l}\text { Sample } \\
\mathbf{5 4 2}\end{array}$ & $\begin{array}{l}\text { Sample } \\
\mathbf{5 4 4}\end{array}$ & $\begin{array}{l}\text { *Sample } \\
\mathbf{5 4 6}\end{array}$ \\
\hline Arboreal & $25 \%$ & $14 \%$ & $18 \%$ & $26 \%$ & $19 \%$ & $16 \%$ & $15 \%$ \\
\hline Non-Arboreal & $65 \%$ & $69 \%$ & $64 \%$ & $54 \%$ & $63 \%$ & $61 \%$ & $43 \%$ \\
\hline Ferns/Mosses & $6 \%$ & $10 \%$ & $9 \%$ & $14 \%$ & $12 \%$ & $16 \%$ & $37 \%$ \\
\hline Unidentifiable/Identifiable & $4 \%$ & $7 \%$ & $9 \%$ & $6 \%$ & $6 \%$ & $7 \%$ & $5 \%$ \\
\hline Totals & $100 \%$ & $100 \%$ & $100 \%$ & $100 \%$ & $100 \%$ & $100 \%$ & $100 \%$ \\
\hline
\end{tabular}
Values Rounded to Nearest Whole Number.

*Sample 546 does not have a densily > 1000 grains of pollen per gram of soil; however, it was included because it represents the deepest recovered sample for the soil column. Data from this sample was not used for environumental reconstruction.

high percentage was only reached in sample 540 of the soil column, which coincided with an occupation of the site by the U. S. Army prior to both the WW I and Spruce Mill occupations. Non-arboreal pollen maintained percentages ranging from $48 \%$ to $69 \%$ of the total counted pollen for all samples containing a density above 1000 pollen grains per gram of soil, while ferns and mosses comprised percentages ranging from $6 \%$ to $31 \%$.

The domination of non-arboreal pollen spanned from the Hudson Bay Company's occupation to modern day even though sample 534 , which reflected a more recent pollen composition, revealed a higher percentage of arboreal pollen. Percentages of ferns and mosses decreased during this period.

Upon closer inspection of recovered non-arboreal and Rosaceae pollen grain totals, some interesting observations can be made (Table 7 and Table 8 ). Weedy taxa

Table 7

Percentages of Non-Arboreal \& Rosaceae Vegetation Types for Samples Possessing a Density $>1000$ Grains of Pollen per Gram of Soil

\begin{tabular}{|c|c|c|c|c|c|c|c|c|}
\hline $\begin{array}{c}\text { Non-Arboreal } \\
\text { Vegetation } \\
\text { Types }\end{array}$ & $\begin{array}{c}\text { Sample } \\
\mathbf{3 3 4}\end{array}$ & $\begin{array}{c}\text { Sample } \\
\mathbf{3 8 9}\end{array}$ & $\begin{array}{c}\text { Sample } \\
\mathbf{4 2 0}\end{array}$ & $\begin{array}{c}\text { Sample } \\
\mathbf{4 1 9}\end{array}$ & $\begin{array}{c}\text { Sample } \\
\mathbf{4 2 2}\end{array}$ & $\begin{array}{c}\text { Sample } \\
\mathbf{4 3 3}\end{array}$ & $\begin{array}{c}\text { Sample } \\
\mathbf{4 9 7}\end{array}$ & $\begin{array}{c}\text { Sample } \\
\mathbf{5 5 1}\end{array}$ \\
\hline Liguliflorae & $1 \%$ & $17 \%$ & $9 \%$ & $22 \%$ & $12 \%$ & $10 \%$ & $13 \%$ & $19 \%$ \\
\hline Cheno/Am & $1 \%$ & $\mathbf{3} \%$ & $2 \%$ & $4 \%$ & $4 \%$ & $8 \%$ & $6 \%$ & $6 \%$ \\
\hline $\begin{array}{c}\text { Ambrosia \& } \\
\text { Xanthium }\end{array}$ & $1 \%$ & $2 \%$ & $6 \%$ & $5 \%$ & $6 \%$ & $2 \%$ & $3 \%$ & $6 \%$ \\
\hline Senecio & $11 \%$ & $2 \%$ & $5 \%$ & $3 \%$ & $3 \%$ & $3 \%$ & $6 \%$ & $3 \%$ \\
\hline $\begin{array}{c}\text { Equisetum \& } \\
\text { Sedges }\end{array}$ & $24 \%$ & $5 \%$ & $10 \%$ & $4 \%$ & $6 \%$ & $6 \%$ & $6 \%$ & $6 \%$ \\
\hline
\end{tabular}




\begin{tabular}{|c|c|c|c|c|c|c|c|c|}
\hline Wild Grasses & 0 & $2 \%$ & $2 \%$ & $2 \%$ & 0 & 0 & 0 & $2 \%$ \\
\hline Tubuliflorae & $3 \%$ & $8 \%$ & $3 \%$ & $12 \%$ & $17 \%$ & $8 \%$ & $8 \%$ & $16 \%$ \\
\hline Rosaceae & $1 \%$ & 0 & $1 \%$ & $3 \%$ & $2 \%$ & 0 & $1 \%$ & 0 \\
\hline $\begin{array}{c}\text { European- } \\
\text { introduced } \\
\text { cereal }\end{array}$ & 0 & 0 & $1 \%$ & 0 & $1 \%$ & 0 & 0 & 0 \\
\hline Apiaceae & 0 & $2 \%$ & 0 & 0 & $1 \%$ & 0 & 0 & 0 \\
\hline Solanaceae & $2 \%$ & $2 \%$ & $1 \%$ & 0 & 0 & 0 & $2 \%$ & 0 \\
\hline Lamiaceae & 0 & $2 \%$ & $1 \%$ & $3 \%$ & 0 & $2 \%$ & $1 \%$ & $2 \%$ \\
\hline Brassicaceae & $2 \%$ & $2 \%$ & $1 \%$ & 0 & 0 & 0 & 0 & $3 \%$ \\
\hline Trifolium & 0 & $1 \%$ & $1 \%$ & $2 \%$ & 0 & 0 & 0 & 0 \\
\hline $\begin{array}{c}\text { Remaining } \\
\text { Non-Arboreal }\end{array}$ & $8 \%$ & $14 \%$ & $9 \%$ & $7 \%$ & $4 \%$ & $19 \%$ & $2 \%$ & $2 \%$ \\
\hline
\end{tabular}

Values Rounded to Nearest Whole Number.

Table 8

\section{Percentages of Non-Arboreal and Rosaceae Pollen Types for Soil Column Samples}

\begin{tabular}{|l|l|l|l|l|l|l|l|}
\hline $\begin{array}{l}\text { Non-Arboreal } \\
\text { Vegetation } \\
\text { Types }\end{array}$ & $\begin{array}{l}\text { Sample } \\
\mathbf{5 3 4}\end{array}$ & $\begin{array}{l}\text { Sample } \\
\mathbf{5 3 6}\end{array}$ & $\begin{array}{l}\text { Sample } \\
\mathbf{5 3 8}\end{array}$ & $\begin{array}{l}\text { Sample } \\
\mathbf{5 4 0}\end{array}$ & $\begin{array}{l}\text { Sample } \\
\mathbf{5 4 2}\end{array}$ & $\begin{array}{l}\text { Sample } \\
\mathbf{5 4 4}\end{array}$ & $\begin{array}{l}\text { *Sample } \\
\mathbf{5 4 6}\end{array}$ \\
\hline Liguliflorae & $32 \%$ & $\mathbf{4 4 \%}$ & $\mathbf{3 6 \%}$ & $20 \%$ & $\mathbf{3 2} \%$ & $22 \%$ & $7 \%$ \\
\hline Cheno/Am & $1 \%$ & $1 \%$ & $1 \%$ & $\mathbf{3} \%$ & $1 \%$ & 0 & 0 \\
\hline $\begin{array}{l}\text { Ambrosia \& } \\
\text { Xanthium }\end{array}$ & $1 \%$ & $2 \%$ & $4 \%$ & $7 \%$ & $7 \%$ & $6 \%$ & $5 \%$ \\
\hline Senecio & $4 \%$ & $2 \%$ & $4 \%$ & $4 \%$ & $5 \%$ & $3 \%$ & $1 \%$ \\
\hline $\begin{array}{l}\text { Equisetum \& } \\
\text { Sedges }\end{array}$ & $4 \%$ & $7 \%$ & $7 \%$ & $5 \%$ & $4 \%$ & $10 \%$ & $22 \%$ \\
\hline Wild Grasses & $3 \%$ & $1 \%$ & $3 \%$ & $2 \%$ & $2 \%$ & $1 \%$ & $3 \%$ \\
\hline Tubuliflorae & $2 \%$ & $1 \%$ & $1 \%$ & $5 \%$ & $2 \%$ & $6 \%$ & $1 \%$ \\
\hline Rosaceae & $1 \%$ & $1 \%$ & $1 \%$ & $1 \%$ & $1 \%$ & 0 & 0 \\
\hline $\begin{array}{l}\text { European- } \\
\text { introduced } \\
\text { cereals and } \\
\text { maize }\end{array}$ & $1 \%$ & $1 \%$ & 0 & 0 & 0 & $2 \%$ & 0 \\
\hline Apiaceae & $2 \%$ & $1 \%$ & $1 \%$ & $1 \%$ & $1 \%$ & 0 & \\
\hline Solanaceae & $1 \%$ & $2 \%$ & 0 & $1 \%$ & $1 \%$ & $2 \%$ & 0 \\
\hline Lamiaceae & 0 & $1 \%$ & 0 & 0 & $1 \%$ & $1 \%$ & 0 \\
\hline Brassicaceae & $1 \%$ & 0 & $2 \%$ & 0 & $1 \%$ & 0 & 0 \\
\hline Trifolium & 0 & $1 \%$ & 0 & 0 & 0 & 0 & 0 \\
\hline $\begin{array}{l}\text { Remaining } \\
\text { Non-Arboreal }\end{array}$ & $13 \%$ & $3 \%$ & $4 \%$ & $5 \%$ & $5 \%$ & $9 \%$ & $4 \%$ \\
\hline
\end{tabular}

542

* Sample 546 does not have a density > 1000 grains of poilen per gram of soil; however, it was included because it represents the deepest recovered sample for the soil column. Data from this sample was not used for environmental reconstruction.

including many invader species were represented by pollen grains identified as

Liguliflorae, Cheno/Am, Ambrosia and Xanthium, Senecio, Equisetum, and wild grasses

represented a significant portion of the non-arboreal vegetation totals. Tubuliflorae 
Compositae pollen was also well represented with members of this grouping comprising weedy taxa as well as cultivated vegetables and flowers. These findings indicate that weedy taxa most likely not only dominated regional non-arboreal vegetation, but also dominated local non-arboreal vegetation as well. Interestingly, for the soil column samples, numbers of Liguliflorae were much higher than they were for the other samples taken from the garden testing area with the highest percentages correlating with the portion of the column located in closer proximity to the ground surface.

Liguliflorae Compositae pollen is not as susceptible to deterioration and generally preserves well because of its fenestrate sculpturing and as a result, even in a decayed condition, is still recognizable (Dimbleby 1985: 144-145). Therefore, an overrepresentation of fenestrate pollen in the soil column samples, as compared to the samples taken from other areas of the garden, may indicate that preservation differed across the garden areas. However, high levels of Liguliflorae may also reflect specific habitats as "very high percentages of "Liguliflorae" pollen have been recorded in humandisturbed habitats" (Davis, http://www.geo.arizona.edu/palynology/pid00029.html). In applying this observation to the Fort Vancouver pollen study, the samples from the soil column with the highest percentages of fenestrate pollen are samples 538, 536, and 534, which are associated with the most recent occupations of the site. A dramatic rise in fenestrate pollen is initially seen in the pollen spectrum from sample 546, which dates to before 1824, to samples 544 and 542 that are associated with the Hudson Bay Company and early U. S. Army occupations perhaps reflecting ongoing activities associated with the landscape between and during these two occupations in the region. Also during this period, most arboreal species decreased except pine and pollen identified as Morus. 
Citrus pollen appeared for the first time as well as increased amounts of weedy taxa such as Ambrosia, Xanthium, and Senecio and pollen identified to the Brassicaceae, Lamiaceae, and Solanaceae families. Wild grasses remain steady and Europeanintroduced cereals initially appeared in the pollen record.

The pollen assemblage of sample 540 is interesting. This sample represents the post Hudson Bay Company occupation and the continued U. S. Army occupation. At this time the amount of fenestrate pollen decreased; however, pollen identified as Tubuliflorae increased. Amounts of Ambrosia and Xanthium remained stable and pollen grains identified as Cheno/Am increased. Interestingly, pollen identified as Equisetum continued to decrease as well as recovered pollen belonging to the Brassicaceae and Lamiaceae families and European-introduced cereals. Pollen identified as mosses and ferns all increased except Pteridium, which dramatically decreased at this time possibly indicating a reduction in burning over the region. Many species of arboreal pollen increased at this time except pollen identified as Morus. By the mid 1800 s historical documentation states that the amount of land associated with cultivation had decreased from earlier times (http://www.nps.gov), perhaps this change in the use of the landscape from agricultural fields that were associated with the Hudson Bay Company occupation to how the U. S. Army utilized the area is reflected in the pollen spectrum.

Sample 538, which is associated with W W I and the spruce mill occupations, reflected a decrease in many arboreal taxa except Salix, which is known to populate disturbed areas. At this time, smaller sized fenestrate pollen and wild grasses also increased. Even though the samples closest to the ground surface reflect high amounts of fenestrate pollen, samples 536 and 534, which are associated with more modern times, 
revealed increases in many arboreal taxa as well as wild grasses, and weedy taxa such as Plantago, Senecio, and Solidago.

The pollen analysis of the Fort Vancouver samples touches upon, which vegetation types were probably grown at Fort Vancouver. The analysis revealed that specific economic taxa such as European-introduced cereal pollen and maize were most likely cultivated at the fort because pollen grains identified to both categories were recovered from a sample associated with the fort's occupation and other samples associated with the same occupation contained minimal amounts of cereal pollen. The examination also verified that wild grasses were present in the immediate area, but were inconclusive in regards to whether or not the garden paths were surfaced with grass. Regardless of the smaller amounts of recovered wild grass pollen from the samples, these findings do not refute the historical record, but cannot corroborate it. Pollen grains were also recovered for many insect-pollinated families and genera, which included cultivated species, such as Solanaceae, Lamiaceae, Rosaceae, and others; however, weedy species are also associated with these categories making it difficult to definitively conclude what species were cultivated and which were wild. Regardless, these families and genera are indicative of local vegetation, whether wild or cultivated.

A number of imported genera such as Acacia, Citrus, and others were also recovered in the pollen analysis. Since these genera are not indigenous to the Washington area and are insect-pollinated, their presence probably denotes local vegetation that was most likely cultivated at Fort Vancouver. Numerous pollen grains were also identified to vegetation categorized as Liguliflorae Compositae and resembled pollen grains from a variety of flowering taxa and herbs such as yarrow, aster, marigold, 
sunflower, beggar-ticks, dahlia, and zinnia. Perhaps these species were cultivated at the fort.

The majority of pollen grains represented in the local pollen rain for a cultural landscape are considered to be generally non-arboreal (Kelso 1994a: 11). Faegri and others (1989: 179) define a cultural landscape as a "mosaic of plant communities directly or indirectly influenced by the activities of man" with people directly influencing environments through "plant cultivation, animal husbandry, and technical utilization of resources" as well as habitation sites. Many genera and species identified in the pollen analysis of sediments extracted from the garden testing area at Fort Vancouver describe an active, lived landscape, one that appears to have been shaped by ongoing human land management strategies that began prior to the Hudson Bay Company occupation and continued through succeeding occupations at a varying rate. 


\section{References}

Adams, R. J. and J. K. Morton

1974 An Atlas of Pollen of the Trees and Shrubs of Eastern Canada and the Adjacent United States, Part II, Ulmaceae to Rosaceae, Department of Biology, Waterloo, Ontario: University of Waterloo.

Bradley, J. W., N. DePaoli, N. Seasholes, P. McDowell, G. Kelso, and J. Schoss 1983 Archaeology of the Bostonian Hotel Site, Occasional Publications in Archaeology and History \#2. Boston, MA: Massachusetts Historical Commission.

Britton, N. L. and Hon. A. Brown 1898 An Illustrated Flora of the Northern United States, Canada and the British Possessions: From Newfoundland to the Parallel of the Southern boundary of Virginia, and from the Atlantic Ocean Westward to the 102D Meridian, Vol. III, Apocynaceae to Compositae, Dogbane to Thistle. New York: Charles Scribner's Sons.

1897 An Illustrated Flora of the Northern United States, Canada and the British Possessions: From Newfoundland to the Parallel of the Southern boundary of Virginia, and from the Atlantic Ocean Westward to the 102D Meridian, Vol. II, Portulacaceae to Menyanthaceae, Portulaca to Buckbean. New York: Charles Scribner's Sons.

1896 An Illustrated Flora of the Northern United States, Canada and the British Possessions: From Newfoundland to the Parallel of the Southern boundary of Virginia and from the Atlantic Ocean Westward to the 102D Meridian, Vol. I, Ophioglossaceae to Aizoaceae, Ferns to Carpet-Weed. New York: Charles Scribner's Sons.

Brown, L.

1976 Weeds in Winter. New York: W. W. Norton \& Company.

Bryant Jr., V. and S. A. Hall

1993 "Archaeological Palynology in the United States: A Critique." American Antiquity 58(2):277-284.

Bush, M. B. and R. Rivera

2001 "Reproductive Ecology and Pollen Representation Among Neotropical Trees."

Global Ecology \& Biogeography 10:359-367.

Davis, M. B.

1969 "Climatic Changes in Southern Connecticut Recorded by Pollen Deposition at Rogers Lake.” Ecology 50(3):409-422.

Dimbleby, G. W.

1985 The Palynology of Archaeological Site. London: Academic Press Inc. 
Dincauze, Dena F.

2000 Environmental Archaeology: Principles and Practice. Cambridge: Cambridge University Press.

Dorset, E.

2008 "Personal Communication."

Elzinga, W. J.

1988 "Short-term Vegetation Changes on an Abandoned Mining Site as Determined by

Pollen Analysis." American Midland Naturalist 120(2):371-379.

Erdtman

1943 An Introduction to Pollen Analysis. New York: The Ronald Press Company.

Faegri, K., J. Iversen, P. E. Kaland, and K. Krzywinski

1989 Textbook of Pollen Analysis, 4th ed., Caldwell, NJ: The Blackburn Press.

Franklin, J. F. and C. T. Dyrness

1969 Vegetation of Oregon \& Washington, U.S.D.A. Forest Service Research Paper

PNW-80. Portland, Oregon: U.S. Department of Agriculture, Pacific Northwest Forest and Range Experiment Station.

Gleason, H. A. and A. Cronquist

1964 The Natural Geography of Plants. New York \& London: Columbia University

Press.

Grieg, J.

1982 "The Interpretation of Pollen Spectra from Urban Archaeological Deposits." In Environmental Archaeology in the Urban Context, ed. A. R. Hall and H. K. Kenward,

Research Report No. 43, London: Council for British Archaeology.

Hall, S.

1981 "Deteriorated Pollen Grains and the Interpretation of Quaternary Pollen

Diagrams." Review of Paleobotany and Palynology 32:193-206.

Harlow, W. M.

1957 Trees of Eastern and Central United States and Canada. New York: Dover

Publications, Inc.

Heinerman, $\mathrm{J}$.

1988 Heinerman's Encyclopedia of Fruits, Vegetables, and Herbs. West Nyack, NY:

Parker Publishing Company.

Heiser Jr., C. B.

1969 Nightshades: The Paradoxical Plants, San Francisco: W. H. Freeman and Company. 
Heusser, C. J.

1978 "Modern Pollen Rain in the Puget Lowland of Washington." Bulletin of the Torrey Botanical Club 105(4):296-305.

1969 "Modern pollen spectra from the Olympic Peninsula, Washington." Bulletin of the Torrey Botanical Club 96(4):407-417.

Kapp, R. O., O. K. Davis and J. E. King

2000 Pollen and Spores, $2^{\text {nd }}$ ed., Illustrated by Richard C. Hall, College Station, TX:

The American Association of Stratigraphic Palynologists Foundation.

Kapp, R. O.

1969 Pollen and Spores. Dubuque, lowa: William C. Brown Company.

Kelso, G. K. and M. C. Beaudry

1990 "Pollen Analysis and Urban Land Use: The Environs of Scottow's Dock in $17^{\text {th }}$, $18^{\text {th }}$, and Early $19^{\text {th }}$ Century Boston." Historical Archaeology 29:61-81.

Kelso, G. K.

1998 "Pollen Analysis of the Feature 4 Privy at the Cross Street Back Lot Site, Boston, Massachusetts." Historical Archaeology 32(3):49-62.

1994a "Management summary, Phase III Palynological Data Recovery, Pollen Analysis of the Boston Mill Pond Site (Bos-HA-14) Boston, Massachusetts," Appendix D. In Archaeological Data Recovery: The Mill Pond Site (Bos-HA-14) Boston-Massachusetts, prepared by Charles D. Cheek and Joseph Balicki, February 2000. West Chester, PA: John Milner Associates Inc.

1994 b "Palynology in Historical Rural-Landscape Studies: Great Meadows, Pennsylvania." American Antiquity 59(2):359-372.

King, J. E., W. E. Klippel, and R. Duffield

1975 "Pollen Preservation and Archaeology in Eastern North America." American Antiquity 40(2):180-19.

Larsen, C.P.S. and G. M. MacDonald

1998 "Fire and Vegetation Dynamics in a Jack Pine and Black Spruce Forest Reconstructed Using Fossil Pollen and Charcoal." The Journal of Ecology 86(5):815828.

Leighton, A.

1970 Early American Gardens: "For Meate or Medicine." Amherst: The University of Massachusetts Press. 
Lewis, W. and M. P. F. Elvin-Lewis

1977 Medical Botany: Plants Affecting Man's Health. New York: John Wiley \& Sons, Inc.

Mattoon, W. R.

1936 Forest Trees and Forest Regions of the United States, U.S. Department of Agriculture Miscellaneous Publication Number 217. Washington, D.C.: United States

Department of Agriculture.

McAndrews, J. H., A. A. Berti, and G. Norris

1973 Key to the Quaternary Pollen and Spores of the Great Lakes Region, Royal Ontario Museum Life Sciences Miscellaneous Publication. Toronto: The Royal Ontario Museum.

Moerman, D. E.

1998 Native American Ethnobotany. Portland, Oregon: Timber Press.

Moore, P. D. and J. A. Webb

1978 An Illustrated Guide to Pollen Analysis. Halsted Press, a Division of John Wiley \& Sons Inc., New York.

Moore, P. D., J. A. Webb, and M. E. Collinson

1991 Pollen Analysis, Second Edition. Oxford: Blackwell Scientific Publications.

Mrozowski, S. A., E. L. Bell, M. C. Beaudry, D. B. Landon, and G. K. Kelso 1989 "Living on the Boot: Health and Well Being in a Boardinghouse Population." World Archaeology 21(2):298-319.

Page, N. M. and R. E. Weaver Jr.

1974 Wild Plants in the City, reprinted from Arnoldia Vol. 34, No. 4. Jamaica Plain, Massachusetts: Arnold Arboretum of Harvard University.

Pearsall, D. M.

2000 Paleoethnobotany: A Handbook of Procedures, $2^{\text {nd }}$ ed. San Diego, CA: Academic Press.

Romani, Jr., Daniel A. 1996 "Our English Clover-grass Sowen Thrives Very Well": The Importation of English Grasses and Forages into Seventeenth-Century New England." In Plants and People, the Dublin Seminar for New England Folklife Annual Proceedings 1995, ed. Peter Benes, Boston, Boston University.

Sauer, J. D.

1993 Historical Geography of Crop Plants: A Select Roster. Boca Raton, Florida: CRC Press, Inc. 
Sumner, J.

2004 American Household Botany: A History of Useful Plants 1620-1900. Portland, Oregon: Timber Press, Inc.

Taylor, R. L.

1996 Plants of Colonial Days. Mineola, NY: Dover Publications, Inc.

Tilman, D.

1988 Plant Strategies and the Dynamics and Structure of Plant Communities.

Princeton, NJ: Princeton University Press.

Trigg, H. B., D. Landon, E. Newman, and A. Hancock

2003 "Archaeobiological Materials Analyses." In Supplementary Excavations at the

Kirk Street Agents' House, Lowell National Historical Park, Lowell, Massachusetts, ed. William A. Griswold, Occasional Publications in Field Archaeology, Number 2, pp. $27-$ 41. Lowell, MA: National Park Service.

Van der Veen, Marijke

1984 Crop Husbandry Regimes: An Archaeobotanical Study of Farming in Northern England, $100 \mathrm{BC}-\mathrm{AD} 500$, Sheffield Archaeological Monographs 3, Sheffield: J. R.

Collis Publications, University of Sheffield, Department of Archaeology and Prehistory.

Weishan, M. and C. Roig

2004 From a Victorian Garden: Creating the Romance of a Bygone Age Right in your own Backyard. New York: Penguin Group Inc.

Wodehouse, R. P.

1965 Pollen Grains: Their Structure, Identification and Significance in Science and Medicine, New York and London: Hafner Publishing Company.

Websites

http:/cals.arizona.edu/pubs/crops/az1441/az1441.03.pdf. "Pollination of W. Murcott Afourer Mandarins" in Citrus Research Report (P-153) October 2007, Wright, G. C., 1213.

http://plants.usda.gov. USDA Plant Database. Accessed throughout 2008.

http://www.fs.fed.us/database/feis/plants/fern/pteaqu/all.html. Accessed: March 14, 2008.

http://www.geo.arizona.edu/palynology/pid00029.html. University of Arizona Pollen Database, Liguliflorae (Compositae). Accessed: March 13, 2008.

http://www.geo.arizona.edu/palynology/polonweb.html. University of Arizona Pollen Database. Accessed: throughout 2007 and 2008. 
http://www.nps.gov. Fort Vancouver: Cultural Landscape Report (Vol. 1, Appendices A, B, D, and G). Accessed: October 27, 2007. 


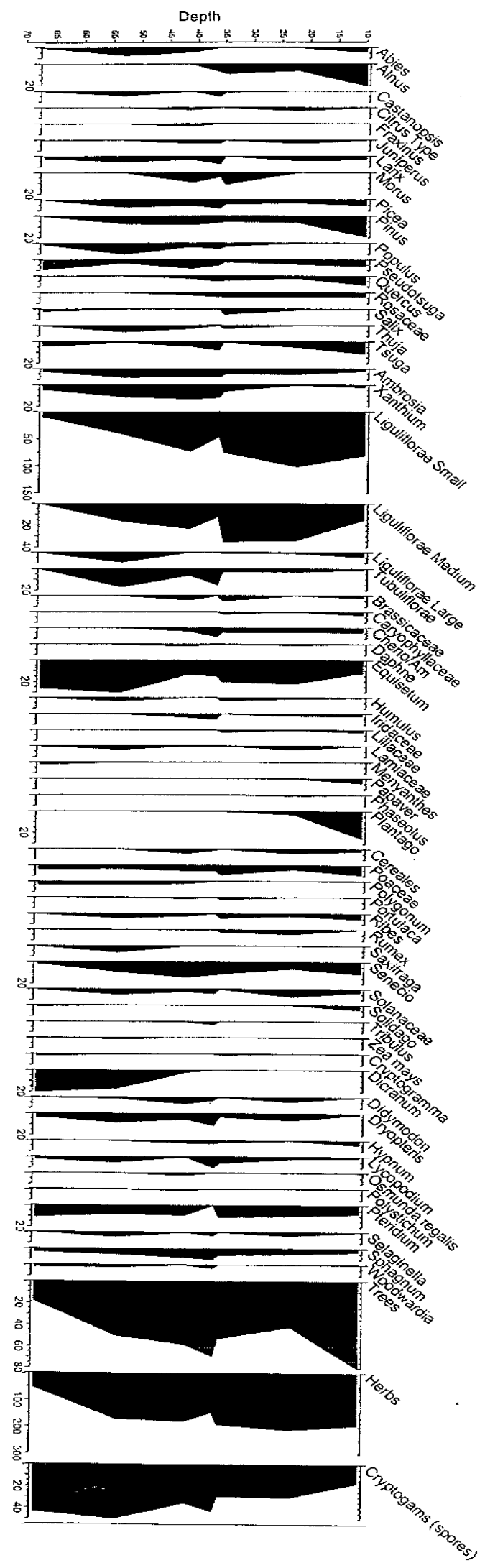




\section{APPENDIX G}

A Pollen Analysis of a Hudson's Bay Company

Non-Garden Provenience, Fort Vancouver, Washington 


\title{
A Pollen Analysis of a Hudson's Bay Company Non-garden Provenience, Fort Vancouver, Washington
}

\author{
Prepared For: \\ Elaine Dorset \\ Fort Vancouver National Historic Site \\ 612 E. Reserve Street \\ Vancouver, WA 98661 \\ Submitted By: \\ Susan A. Jacobucci and Heather B. Trigg \\ Andrew Fiske Memorial Center for Archaeological Research at \\ The University of Massachusetts Boston \\ 100 Morrissey Blvd \\ Boston, MA 02125
}

Cultural Resources Management Study No. 41

January 2011 


\section{Introduction}

The Andrew Fiske Memorial Center for Archaeological Research at the University of Massachusetts Boston conducted a palynological analysis on six contiguous soil samples that were collected from the Fort Vancouver site. The samples were recovered from a location associated with the Hudson Bay Company's occupation that is situated in close proximity to what is today Fort Vancouver's Visitors Center, which is scheduled to undergo extensive renovations in the near future (Dorset 2010 Pers. Comm.). In particular, the selected sample collection site is of a non-garden provenience, located east of a circa 1849 wheat field (Dorset 2010 Pers. Comm.). Not much is known as to how the Hudson Bay Company utilized this space; nonetheless, after their occupation the collection site's former landscape underwent numerous modifications. From the mid to late $19^{\text {th }}$ century the site served first as the location of the U.S. Army Vancouver Arsenal, then after 1878, the Department of Columbia reconfigured the area with roads and constructed new buildings while moving others; the buildings were removed with the Department's abolishment around 1913 and ultimately the site was left open and vacant (Dorset 2010 Pers. Comm.).

The goal of the current pollen study of the non-garden provenience is twofold. The results of this examination are desired chiefly for comparisons to findings of a previous pollen analysis of soil samples that were collected from various locations associated with the Fort Vancouver "garden-testing area"' (see Jacobucci 2008). Archaeologists are eager to see what vegetation differences exist between the two contexts which would allow us to characterize a garden context. Also archaeologists hope the analysis of the non-garden provenience would provide information as to how the Hudson Bay Company utilized this space. In particular, this 
study attempts to identify the types of vegetation that existed on the collection site before the Hudson Bay Company's occupation, specifically if the area was formerly a meadow or tree covered, and when the agricultural field to the west of the collection site was developed. This current pollen analysis addresses these issues and augments the archaeological and historical records of Fort Vancouver.

Pollen recovered from an archaeological site is a mixture of local and regional background pollen rain as well as pollen which came from deliberately used plants by site inhabitants. The reconstruction of vegetation communities using pollen analysis is problematic and requires cautious interpretation because pollen produced by different taxa are differentially preserved and the identification of specific plants especially to species is difficult. The survival of pollen grains and spores is rather dependant on environmental conditions, variations of plant taxa pollen production and dispersal strategies, and the resistance of their pollen grains and spores to decay. Finally, it is difficult to identify the recovered pollen to species or even genus using microscopy because many taxa look morphologically similar. All of these factors affect our ability to identify former vegetation (Bryant and Hall 1993:281; Dincauze 2000:345-346; Faegri et al. 1989:11-38, King et al. 1975:181; Moore and Webb 1978:109-118; Pearsall 2000:251-252). Nevertheless, recovered pollen allows us to recreate a partial although biased vegetation history that was molded by various forces such as climate, human occupation, and land management strategies (Bradley et. al 1983; Brugam 1978; Davis 1969; Kelso and Beaudry 1990; Kelso 1998; Jacobucci et al. 2007; Oldfield 1978; Pearsall 2000:265-269, 324). By uncovering the impact that human activities have on vegetation, and through understanding how pollen grains and spores arrive at a site, palynology also helps archaeologists answer questions about site function by identifying "task-specific" areas (Cahill et al. 1991:66; Kelso et al. 2006; 
Pearsall 2000:274). We can expect the samples from Fort Vancouver to contain a mixture of

local and regional background pollen rain from trees and weeds in addition to pollen from plants that were deliberately grown or utilized there especially since the site from which the soil samples came from was not a closed environment such as the interior of a structure.

\section{Methods}

Location of Site within the Natural Pollen Spectrum

Fort Vancouver is situated in the southeastern section of the state of Washington, to the north of the Columbia River between the Cascade Mountains located to its east and the Coast Mountain ranges to the west. The site is positioned in the Puget Sound vegetational area and is surrounded by the Tsuga heterophylla vegetation zone (Franklin and Dyrness 1969: 38). Many vegetation types common to both zones were identified in this current pollen analysis as they were in the examination of samples extracted from the garden testing area at Fort Vancouver (Jacobucci 2008). Arboreal vegetation prevalent to the Puget Sound and Tsuga heterophylla vegetation zones consists predominantly of gymnosperms. Douglas fir (Pseudotsuga menziesii) dominates modern successional tree stands with western hemlock (Tsuga heterophylla), and western red cedar (Thija plicata) present in fluctuating amounts (Heusser 1978: 297). Western white pine (Pinus monticola) is frequently represented and prefers fairly open forest habitats; while Sitka spruce (Picea sitchensis) is negligibly present in flood plains and inhabits areas near river mouths (Heusser 1978: 298). Beach or lodgepole pine (Pinus contorta) is sometimes locally present in plentiful quantities and grand fir (Abies grandis) is scarce (Heusser 1978: 297298). Hardwoods such as red alder (Alnus rubra), giant chinquapin (Castanopsis chrysophylla), and bigleaf maple (Acer macrophyllum) are rare in the region, but are better represented at newly disturbed sites (Franklin and Dyrness 1969: 56). Black cottonwood (Populus trichocarpa), 
Oregon ash (Fraxinus latifolia), and willow (Salix sp.) sporadically appear in the region and are usually associated with major water courses, while Pacific madrone (Arbutus menziesii) and Oregon white oak (Quercus garryana) are situated at lower elevations (Franklin and Dyrness 1969: 56; Heusser 1978: 298).

The understory vegetation community characteristic of lower slopes and stream terraces of the Tsuga heterophylla vegetation zone is composed of exceptionally "lush understory shrubs, dicotyledonous herbs, and ferns" (Franklin and Dyrness 1969: 60). Vegetation such as blueberry (Vaccinium spp.), western woodfern (Dryopteris linnaeana), spinulose woodfern (D. spinulosa var. dilatata), pioneer violet (Viola glabella), brackenfern (Pteridium), and mosses are present in these environments (Franklin and Dyrness 1969: 60; Gleason and Cronquist 1964: 357; Heusser 1978: 299). Franklin and Dyrness (1969: 61-63) discuss vegetation successional patterns that occur after episodes of environmental disturbance such as a devastating fires or logging. Right after such an event, the first growing season consists of sparse vegetation cover, which is usually comprised of survival species from the original stand, followed during the second year by annual herbaceous invader species such as woodland ragwort (Senecio sylvaticus), which generates vast quantities of small, windborne seeds (Franklin and Dyrness 1969:61). After the second year, but before shrubs such as alder and California blackberry (Rubus ursinus) among others take hold, further weedy species such as fireweed (Epilobium anglustifolinm), bull thistle (Cirsilum vulgare) and western brackenfern (Pteridium aquilinitum) flourish (Franklin and Dyrness 1969: 61).

\section{Contexts}

The six soil samples were collected in 2010 by archaeologists from Fort Vancouver National Historic Site (see Table 1). The samples are dated to the historic period and were collected from a site situated near what is today Fort Vancouver Visitors Center and roughly 516 
$\mathrm{m}$ from the northeast corner of the previously sampled garden which is the closest known proximity of introduced garden plants (Dorset 2011,2010 Pers. Comm.) (Figure 1). In particular the sample collection site is located approximately $632 \mathrm{~m}$ from the location in the southern part of the garden where samples from the "garden-testing area" were recovered (Dorset 2011 Pers. Comm.). Five of the samples for the current examination were collected as a column sample from the north wall of a $50 \mathrm{~cm}$ shovel test pit (ST 10-02) (Dorset 2010 Pers. Comm.). The last column sample situated the deepest from the ground surface (ST 10-02-Pollen 6) was collected from the floor of the shovel test pit after roughly $2 \mathrm{~cm}$ of soil were first scraped off; while, the modern surface sample (ST 10-02-Pollen 1) was collected from an area on the ground surface situated roughly $30 \mathrm{~cm}$ southwest of the shovel test pit (Dorset 2010 Pers. Comm.). This modern sample was collected for comparative purposes (Pearsall 2000:288).

Table 1

Proveniences of the Fort Vancouver Washington Pollen Samples

\begin{tabular}{|c|c|c|c|}
\hline Sample Number & Level & Strat & cm Below Surface \\
\hline ST 10-02-Pollen 1 & Surface & 0 & 0 \\
\hline ST 10-02-Pollen 2 & 1 & 1 and 2 & 10 \\
\hline ST 10-02-Pollen 3 & 2 & 3 Upper & 20 \\
\hline ST 10-02-Pollen 4 & 2 & 3 Lower & 28 \\
\hline ST 10-02-Pollen 5 & 3 & 4 & 38 \\
\hline ST 10-02-Pollen 6 & 4 & 5 & 45 \\
\hline
\end{tabular}

\section{Laboratory methods}

Approximately $30 \mathrm{~g}$ of sediment were processed for each sample. Soil samples were weighed before they were processed using standard pollen extraction techniques. That is the samples were treated with hydrochloric acid to remove carbonates, hydrofluoric acid, to remove silicates, and acetolysis to remove organics (see Moore and Webb 1978: 22-27; Pearsall 2000: 294-296). Two tablets containing a known number of identifiable exotic Lycopodium sp. spores 
(Batch Number: 483216) were added to each sample to assist in the calculation of pollen and spore density and concentration, and assess preservation (Hall 1981; Larsen and MacDonald 1998:819).

Several microscope slides of pollen residue were mounted in glycerol and prepared for each sample. The slides were scanned at $400 \mathrm{x}$ and $600 \mathrm{x}$ magnifications. Following direction provided by other studies (Bryant Jr. and Hall 1993: 281; Pearsall 2000: 303; Trigg et al. 2003: 35 ), a minimum of 300 pollen grains and spores were counted for each sample in addition to the Lycopodium tracer spores. Pollen grains were identified by comparing them to online images appearing on the web (www.geo.arizona.edu/palynology/polonweb.html; http://striweb.si.edu/roubik/), to a modern reference collection housed at the University of Massachusetts Boston, and to published sources (Erdtman 1943; Kapp 1969, Kapp et al. 2000; McAndrews et al. 1973; Moore and Webb 1978; Moore et al. 1991). Pollen grains too deteriorated, crumpled, torn, or distorted to identify were classified as "unidentifiable," while any pollen grains encountered that were in good physical condition, but could not be identified were classified as "identifiable."

Some pollen could only be identified to the family level although the majority were identified to genus. Few can be identified to species (Marshall 2008:221). Pollen identified to the Asteraceae family were categorized as individual genera whenever possible, but grouped for discussion purposes based on their mode of pollen production and dispersal. Pollen grains of the Liguliflorae-type have a fenestrate surface sculpturing and for this examination were grouped into two categories based on size. The Liguliflorae are insect pollinated and large quantities of this pollen type have been recovered from disturbed or anthropogenic environments (http://www.geo.arizona.edu/palynology/pid00029.html ). 
Several members of the Lycopodium genus are common to Washington (Britton and Brown 1896:40 43). Pollen grains identified as clubmoss (Lycopodium sp.) were easily distinguishable from the control spike tracer (Lycopodium sp.) based on larger size differences. Grass pollen grains smaller than $45 \mu \mathrm{m}$ are usually considered to be of a wild type (see Wodehouse 1965:310-319). Grass pollen grains between $45 \mu \mathrm{m}$ and $65 \mu \mathrm{m}$ are considered European-introduced cereals such as oats (Avena), rye (Secale), wheat (Triticum), and barley (Hordeum). Pollen produced by wild grasses and European-introduced cereals were recovered in this examination.

Many ornamental and economic plants and some weedy taxa are non-arboreal and are generally insect or self-pollinated (Faegri et al. 1989:186). These plants, as well as many Asteraceae classified as Tubuliflorae, such as sunflower (Helianthus), aster (Aster), marigold (Calendula) and ragwort (Senecio) with pollen from these taxa recovered in this examination, generate a smaller quantity of pollen thus their appearance in the pollen spectrum is generally limited (Faegri et al. 1989:186). Because the pollen grains of insect-pollinated taxa tend to be heavier (Faegri et al. 1989:13) and, in the case of herbaceous plants, are dispersed near the ground surface where wind velocities are reduced (Kelso 1994a:11; Moore and Webb 1978:111), they are infrequently incorporated in the pollen rain (Pearsall 2000:259). Therefore their presence in the pollen spectrum typically signifies local vegetation and environmental conditions (Kelso and Beaudry 1990:65). Numerous trees such as pine (Pinus) and oak (Quercus) and many common weeds such as ragweed (Ambrosia) and Cheno-Ams are wind-pollinated. These taxa produce large quantities of pollen and although they are often interpreted as reflecting regional vegetation (Kelso and Beaudry 1990:65; Moore and Webb 1978:109-114; Pearsall 2000:258-260), wind-pollinated weeds and trees may have grown in the immediate area. 
In order to reconstruct vegetation patterns, sufficient quantities of pollen are needed. Pollen can be differentially destroyed by taphonomic conditions and this is often reflected in the sedimentological record by low pollen densities. Pollen densities greater than 1000 grains of pollen and spores per gram of sediment are considered satisfactory for environmental reconstruction (Hall 1981). The pollen and spore densities for all six samples were calculated (Table 2). Densities were greater than 1,000 grains and spores/g for all. The density was greatest for the modern surface sample followed by Sample 3, which possessed the next highest.

Table 2

\section{Pollen and Spore Densities}

\begin{tabular}{|c|c|}
\hline Sample Number & $\begin{array}{c}\text { Density-pollen grains and } \\
\text { spores/grams of soil }\end{array}$ \\
\hline 1 & $20,991.90$ \\
\hline 2 & $5,161.94$ \\
\hline 3 & $8,643.11$ \\
\hline 4 & 3933.95 \\
\hline 5 & $4,751.60$ \\
\hline 6 & $3,148.40$ \\
\hline
\end{tabular}

\section{Results}

The pollen analysis of soil samples recovered from unit ST 10-2 and the modern surface sample revealed 55 distinct taxa or groupings in addition to the "identifiable," "non-identifiable" and "unknown palynomorph" categories (Table 3). A tally of the recovered pollen is included (Appendix A). The pollen data were entered into a computer database (Tilia 2.0). This database calculated percentages of the pollen and spores, and we generated a pollen and spore percent diagram included at the end of the report (Figure 2). Samples 1 through 6 were represented in sequence based on depth. A description of the recovered taxa follows. 
Table 3

Taxa Identified in Non-garden Provenience Samples, Fort Vancouver

\begin{tabular}{|l|l|}
\hline \multicolumn{1}{|c|}{ Scientific Name } & \\
\hline Arboreal taxa & \\
\hline Abies & Fir \\
\hline Acer & Maple \\
\hline Alnus & Alder \\
\hline Betula & Birch \\
\hline Castanea dentata & Chestnut \\
\hline Celtis & Hackberry \\
\hline Fabaceae-Acacia-Type & Bean family - Acacia Type - Acacia Tree \\
\hline Moraceae & Mulberry family \\
\hline Ostrya & Hophornbeam \\
\hline Picea & Spruce \\
\hline Pinaceae & Pine family \\
\hline Pinus & Pine \\
\hline Pseudotsuga & Douglas Fir \\
\hline Quercus & Oak \\
\hline SC-Salicaceae and Cupressaceae & Willow and Cypress family \\
\hline Tsuga & Hemlock \\
\hline & \\
\hline & \\
\hline Rosaceae & Rose family \\
\hline & \\
\hline & Either Arboreal \\
\hline Ambrosia & Ragweed \\
\hline Apiaceae & Carrot or Parsley family \\
\hline Artemisia & Sagebrush \\
\hline Aster & Aster \\
\hline Calendula & Marigold \\
\hline Cardluts & Musk Thistle \\
\hline Carex & Sedge \\
\hline Caryophyllaceae & Pink family \\
\hline Cheno/Am & Chenopodiaceae/Amaranthaceae \\
\hline Daphne & Daphne \\
\hline Equisetum & Horsetail \\
\hline Eupatorium & Thoroughwort \\
\hline Helicuthus & Sunflower \\
\hline Iris & Iris family \\
\hline Lamiaceae & Mint family \\
\hline Lamiaceae, Mentha & Mint \\
\hline Ligulifforae $>30 \mu \mathrm{m}$ & Liguliflorae \\
\hline Ligulifloraee $<30 \mu \mathrm{m}$ & Liguliflorae \\
\hline Liliaceae & Lily family \\
\hline & \\
\hline
\end{tabular}




\begin{tabular}{|l|l|}
\hline Scientific Name & Common Name \\
\hline Menyanthes & Buckbean \\
\hline Oxalis & Woodsorrel \\
\hline Phlox & Phlox \\
\hline Plantago & Plantain \\
\hline Poaceae & Grass Family, Wild Grasses \\
\hline Poaceae, Cereales & Grass Family, European-Introduced Cereal \\
\hline Polygonum & Knotweed \\
\hline Primulaceae & Loosestrife family \\
\hline Senecio & Ragwort \\
\hline Thalictrum & Meadow-rue \\
\hline Trifolium & Clover \\
\hline Utricularia & Bladderwort \\
\hline & \\
\hline & Mosses and Ferns \\
\hline Dicraniaceae & Moss \\
\hline Dryopteris & Wood-fern \\
\hline Hypnaceae & Moss \\
\hline Lycopodium sp. & Clubmoss \\
\hline Polypodium & Polypody \\
\hline Pottiaceae & Moss \\
\hline Sphagnum & Peat moss \\
\hline & \\
\hline
\end{tabular}

\section{Description of Recovered Taxa}

A description of the taxa identified through pollen analysis for all soil samples that were recovered from the Fort Vancouver including the modern samples follows. Data in this section includes the taxon's preferred habitat, possible species, culinary or medicinal uses, historical records as well as the likelihood the taxon represents a deliberate cultivated plant or background pollen rain. Taxa are discussed in groups based on whether they were trees and shrubs (arboreal), herbs (non-arboreal) or ferns/mosses. 


\section{Description of Recovered Taxa Arboreal}

Abies Small amounts of pollen identified to this genus appeared in three of the six samples. Firs inhabit boreal regions, but also grow in mountainous areas (Britton and Brown 1896:56), and are located besides streams and in swamps (Harlow 1957:68). Several species of fir grow naturally in the area surrounding Fort Vancouver (see Franklin and Dyrness 1969; Mattoon 1936: 27) and historical records cited in Appendix A of the Fort Vancouver Cultural Landscape Report (http://www.nps.gov) include firsthand accounts, which document the presence of this species in the vicinity of the Fort. Nevertheless since this genus is windpollinated, pollen can be transported great distances it is also probable that the presence of fir pollen could denote regional vegetation.

Acer A small amount of pollen identified as maple was recovered in Sample 4. Species such as bigleaf maple (Acer macrophyllum) grow sparsely in the subject area except in regions subject to landscape disturbance.

Alnus Pollen grains belonging to this genus were recovered in five of the six samples. Interestingly, high proportions of alder pollen were recovered in the modern surface sample and Sample 5 , representing approximately $10 \%$ and $5 \%$ of the total counted pollen respectively. Alder grows naturally in the region surrounding Fort Vancouver (see Franklin and Dyreness 1969; Mattoon 1936:29) and is characterized as a fast-growing species at distressed sites (Tilman 1988: 214). Alder is also widespread along streams and commonly found in swamps (Harlow 1957: 129), perhaps also indicating a moist immediate environment. Some of the alder pollen grains had four apertures and others had five probably indicating that at least two distinct alder species were represented (see Heusser 1969: 413). 
Betula Birch pollen was recovered in all samples. Several species of birch are indigenous to the subject area (http://plants.usda.gov) and historical records indicate that birch was present in the vicinity of Fort Vancouver during its operation (http://www.nps.gov). The presence of birch pollen probably represents background vegetation.

Castanea- Type A small amount of chestnut type pollen was recovered in Sample 2. It is possible that this pollen is tanoak (Lithocarpus sp.), which is very similar in appearance to chestnut pollen. Tanoak is indigenous to Oregon and California (http://plants.usda.gov).

Celtis Hackberry is native to North America (http://plants.usda.gov). A minute number of pollen grains identified to this genus were recovered in two samples.

Fabaceae, Acacia- Type $\quad$ Small amounts of pollen identified as an Acacia -type appeared in five samples, the modern sample and Samples 2, 3, 4, and 5. Acacia is not native to the area and grows naturally in the southern portion of the United States (Britton and Brown 1896: 254; Wodehouse 1965: 431). Since this taxa is insect-pollinated and moderately produces pollen, but has a low dispersal rate (http://www.geo.arizona.edu/palynology), it is most likely that acacia grew in close proximity to the subject area. Acacia pollen was also recovered in the previous examination of samples from the Fort Vancouver garden contest. Historical records indicate that acacia seeds were grown at Fort Vancouver in 1833 and were probably started under protective frames (http://wwww.nps.gov). Acacia was planted as an ornamental and during colonial times gum arabic was bled from it and used for candy-making and as a medicinal ingredient (Sumner 2004: 227). Perhaps the presence of Acacia- type pollen in the Fort Vancouver pollen spectrum can be attributed to the Fort's trading relationship with other entities including Hawaii as Acacia koa for example is native to Hawaii (http://plants.usda.gov). 
Larix Larch appeared in the pollen record, but was not represented in Sample 3 and a small amount was recovered from Sample 4, perhaps indicating land use intensification of the subject area during the period of time these two samples represent. Larch was a preferred wood for ship building and historical records indicate that a sawmill operation was in full force at Fort Vancouver by 1828 (http:www.nps.gov). It is possible that the reduction in larch in the pollen record in Samples 3 and 4 could be due to timber being harvested. Larch prefers moist habitats and is naturally found in swampy woods and around the margins of lakes in the region (Britton and Brown 1896: 54) and its presence in the palynological record could indicate a moist environment in the general region.

Moraceae Pollen grains identified to the Moraceae family were recovered in Samples 1 through 5, but not in Sample 6, which was the deepest layer of the soil column. Species such as mulberry (Mortus) and figs (Ficus) belong to this family and are not native to the region. Mulberries (Morus) were popular ornamental trees in the late sixteenth and early seventeenth centuries (Leighton 1986: 457). White mulberry (Morls alba) was prized for its cold hardiness (Adams 2004: 51). Because of physical similarities in pollen grains between pollen produced by mulberry and figs, it is difficult to distinguish one from the other. Historical records indicate that ligs were grown probably in the garden area under protective cover (http://www.nps.gov; Weishan 1999: 94). The presence of Ficus in the palynological record is uncommon and generally due to soil samples that were in association with fallen figs or a nearby Ficus tree (Bush and Rivera 2001:364). Perhaps mulberry trees or figs grew in close proximity to the sample collection site.

Ostrya Hophornbeam is not native to the area (Britton and Brown 1896:507). A small quantity of hophornbeam pollen was identified only in the modern sample. 
Pinaceae, Picea and Pinus Pollen grains identified as pine, spruce and deteriorated grains identified to the Pine family were recovered in all samples with the lowest proportion of these species recovered from Sample 4. Several species of spruce and pine are indigenous to the subject area (Heusser 1978: 297-298; Mattoon 1936: 46). As early as the 1700s a number of spruce species were popular for decorating ornamental grounds (Adams 2004:89-90). Historical records indicate that pine and spruce were observed in the area during the Fort Vancouver occupation and taxa such as sugar pine (Pimus lambertiana) for example were grown in the garden (http://www.nps.gov).

Pseudotsuga Ample amounts of pollen identified as Douglas fir were recovered in all six samples. The modern sample contained the most, as approximately $29 \%$ of the total counted pollen for this sample was comprised of Douglas fir pollen; however, all of the other samples contained anywhere from five to fourteen percent. Interestingly, a decrease in Douglas fir pollen can be seen from Sample 5 to Sample 4 with a further decrease to Sample 3 perhaps indicating intensive activity in the area as well as operation of a saw mill on the premises. An increase in Douglas fir pollen was recorded from Sample 3 to Sample 2, possibly indicating forest regrowth.

Quercus Small amounts of pollen were identified in the modern surface sample as well as Samples 3 and 6 . Historical accounts document that several species of oak were present in the vicinity of Fort Vancouver (http://wwiv.nps.gov) and grow on the property today.

SC (Salicaceae, Cupressaceae) Pollen identified to the "Willow" and "Cypress" families were identified in all samples. Pollen from these families were combined into the SC category because the grains are morphologically very similar. Taxa such as juniper (Jliniperus), cedar (Chamaecyparis), arborvitae (Thuja), cottonwood (Populus deltoids) and quaking aspen 
(Populus tremuloides) are included in this grouping. All of these taxa are native to the region (Kapp et al. 2000: 77; Mattoon 1936: 27, 46) and most likely represent background vegetation; however, historical records indicate that many of these grew on the fort and in the vicinity of it (http://www.nps.gov).

Tsuga A small amount of hemlock pollen was represented in all samples except Sample 5. The presence of hemlock pollen in the Fort Vancouver pollen spectrum likely represents background and regional vegetation as hemlock is wind-pollinated; however historical records indicate that hemlock grew at the Fort and/or in the immediate vicinity.

\section{Arboreal or Non-Arboreal Vegetation}

Members of the Rosaceae family are trees, shrubs, and herbs. For this examination, pollen identified to this family level was not grouped in either arboreal or non-arboreal categories.

Rosaceae Small amounts of pollen identified to the "Rose" family was recovered in Samples 3, 5, and 6. This family comprises roughly 1200 species (Britton and Brown 1897:194254). Because many "Rose" family taxa are insect-pollinated and their pollen is poorly dispersed, their presence in the pollen spectrum may indicate that these species grew in the area. Historical records indicate that a variety of taxa belonging to this family were grown at Fort Vancouver and most likely were concentrated in the garden and orchard area (http://www.nps.gov); however, many species belonging to this family grow wild, are indigenous to the area and not enough pollen identified to this family was recovered in the current examination that would suggest intentional cultivation. "Rose" family pollen was better represented in some of the previously analyzed garden context samples, for example, pollen 
identified to this family represented roughly $3 \%$ of the total counted pollen for Sample 419 perhaps indicating intentional cultivation (Jacobucci 2008).

\section{Non-Arboreal Vegetation}

Ambrosia Ragweed appeared in all six samples. This taxon is considered to be a marker of cultivation and a "fugitive" or "invader" species that readily and initially colonizes disturbed environments (Elzinga 1988:374-375; Faegri et al. 1989:182-184; Kelso and Beaudry 1990:68). Ragweed is common among cultivated fields, open soils, meadows, and pastures (Britton and Brown 1898:297-298; Brown 1976:182, 186; Page and Weaver 1974:206). Because ragweed is wind-pollinated, its presence may be indicative more of regional than local vegetation; nonetheless, its presence may also reflect local vegetation. Ragweed pollen did not represent more than $2 \%$ of the total counted pollen for any one sample. These findings are comparable to the pollen analysis of Fort Vancouver garden contexts (Jacobucci 2008).

Apiaceae A small amount of pollen identified to the "Carrot" family was recovered in Sample 5. Weedy and economic taxa such as carrot and parsley are included in this family. Queen Anne's Lace (Daucus carota), naturalized from Europe for example, serves as both a garden ornamental, but it also occurs naturally as an invasive weed in fields and waste places (Britton and Brown 1897: 510). Many species identified to this family, for example cow parsnip (Heracleum lanatum), prefer moist soils (Britton and Brown 1897: 514). Historical documentation regarding Fort Vancouver states that vegetables such as curled parsley, carrots, and parsnips were grown there (http://www.nps.gov). Many species identified to this family are insect-pollinated and indicate local vegetation, but it is common for a few pollen grains identified to this family to appear in pollen profiles because the plants are generally pervasive (http://www.geo.arizona.edu/palynology/pid00043.html). Pollen identified to the "Carrot" 
family was better represented in the garden context samples with more than an incidental amount recovered in one of them that would suggest intentional cultivation.

Asteraceae, (Compositae) Liguliflorae Pollen grains identified as Liguliflorae to the "Sunflower" family because of their fenestrate sculpturing were separated out into two categories based on grain size. The majority of species categorized as Liguliflorae are native to Europe, but there are several species indigenous to North America (Britton and Brown 1898:262-282). Several fenestrate pollen types measuring in the small range $(<30 \mu \mathrm{m})$ are native to the Northwest, whereas some cultivated species such as lettuce (Lactuca) and others generally measure over $30 \mu \mathrm{m}$. A moderate to large quantity of the smaller Liguliflorae pollen was recovered in all units with the most, approximately $20 \%$ of the total counted pollen recovered from Sample 3. Taraxacum or dandelion type plants generally inhabit fields and waste places (Britton and Brown 1898: 271), perhaps supporting agricultural activities, which took place at Fort Vancouver that are verified through historical records (http://www.nps.gov). A few samples analyzed in the previous pollen examination of the garden context contained moderate amounts of Liguliflorae pollen measuring over $40 \mu \mathrm{m}$, perhaps indicating intentional cultivation of economic and/or ornamental taxa. For example, over $4 \%$ of the total counted pollen for Sample 389 contained Liguliflorae pollen measuring over $40 \mu \mathrm{m}$ (Jacobucci 2008). Asteraceae (Compositae) Tubuliflorae Pollen grains grouped into this "Sunflower" family category were well represented in the Fort Vancouver non-garden pollen profile. This grouping includes pollen produced by such taxa as aster (Aster), goldenrod (Solidago), marigold (Calendula), musk thistle (Carduus), ragwort (Senecio), sagebrush (Artemisia), sunflower (Helianthus), and thoroughwort (Eupatorium), which were recovered in this examination. Interestingly, together these taxa represented less than $1 \%$ of the total counted pollen for the 
modern surface sample and the deepest sample (Sample 6) from the column profile; however, Samples 3 and 4 contained the greatest amount of pollen produced by these taxa with pollen from these taxa representing approximately $5 \%$ of the total pollen counted for these two contexts. A larger proportion of pollen identified as Tubuliflorae pollen were recovered in some of the garden contexts. For example Tubuliflorae pollen represented roughly $8 \%$ of the total counted pollen for Samples 389, 433, and 497, which were examined in the previous analysis; while greater amounts of this pollen type were recovered in Samples 419, 422, and 551, and represented approximately $12 \%, 17 \%$, and $16 \%$ of the total counted pollen respectively (Jacobucci 2008). Some of the recovered pollen included in this grouping for the previous examination were identified as tansy (Tanacetum), a zinnia- type and a dahlia- type indicating intentional cultivation of these plants.

Some Tubuliflorae species such as sagebrush (Artemisia vulgaris) which may be native to the Northwest Territory (Page and Weaver 1974: 207) and goldenrod flourish in fields and waste places (Britton and Brown 1898: 461-468; Page and Weaver 1974: 195, 207). Numerous species belonging to the genus Aster are native perennials and grow in a variety of habitats (Britton and Brown 1898: 356-382; Page and Weaver 1974: 164), but were also grown in gardens as ornamentals (Page and Weaver 1974: 164). Aster, goldenrod, and sagebrush pollen were recovered in Samples 2 through 6 of the non-garden context. Their presence corroborates with historic and archaeological evidence that indicates an open, deforested landscape at Fort Vancouver during its occupation. Small amounts of pollen identified to the weedy Senecio genus were recovered from Samples 2 and 5. Many species of Senecio occur naturally in western North America (Britton and Brown 1898: 475) with species such as Woodland ragwort 
(Senecio sylvaticus) colonizing recently burned areas within the first growing season only to become present in minute quantities in succeeding years (Franklin and Dyrness 1969: 61). Carex Pollen identified as sedges were recovered from all samples. Sedges are commonly found in swamps, bogs, marshes, ponds, streams, wet woods, and along shores; however, some species prefer woody areas, thickets, and dry soils (Britton and Brown 1896: 248-256, 292-360). The greatest quantity of sedge pollen was identified in Sample 3, which represented approximately $3 \%$ of the total counted pollen for that sample. Historic documentation indicates that some of the cultivated fields at Fort Vancouver were subjected to river flooding from time to time (http://www.nps.gov).

Caryophyllaceae Small amounts of pollen identified to the "Pink" family were recovered from three samples. Carnations, pinks, and sweet william are members of this family and were grown in colonial American gardens (Sumner 2004: 190); however, weedy taxa such as white campion (Lychnis alba) also belong to this family and frequently inhabit meadows and waste places (Britton and Brown 1897: 13-15). There was not enough pollen recovered that was identified to this family to suggest intentional cultivation.

Chenopodiaceae/Amaranthaceae (Cheno/Am) Pollen identified as either goosefoot or pigweed was recovered in all samples. The greatest amount of goosefoot or pigweed pollen was recovered in Samples 2 through 5 and respectively represented approximately $7 \%, 14 \%, 9 \%$, and $6 \%$ of the total counted pollen for these four contexts. Cheno/am pollen was recovered in comparable amounts from some of the previously analyzed garden contexts (Samples 433, 497, and 551) (Jacobucci 2008). Interestingly Cheno/am pollen was much better represented in the soil column from the non-garden context than pollen from these taxa were represented in the soil column from the garden context (Jacobucci 2008). These vegetation types are predominately 
wind-pollinated weedy taxa that thrive in open spaces, cultivated soils, dry soils, and wastelands and can also be found in woods and thickets (Britton and Brown 1896:569-593; Page and Weaver 1974:209; Wodehouse 1965:410-421). The presence of these species in the Fort Vancouver samples supports an open regional environment and probable ongoing agricultural activities, which historical documentation verifies were taking place in the immediate sampled area.

Daphne Daphne is native to Europe and Asia and escaped cultivation in the United States (Britton and Brown 1897:465). This genus is insect-pollinated, therefore, its identification in the Fort Vanouver pollen spectrum reflects its presence in the local vegetation. Small amounts of pollen identified to this genus were recovered in Samples 2 and 3.

Equisetum Pollen grains identified as Equisetum was well represented in all six samples. Field horsetail (Equisetum arvense) grows in sandy soils especially along roadways (Britton and Brown 1896: 36). Scouring-rush (Equisetum hymale) grows in wet environments along the shores of rivers and lakes (Britton and Brown 1896: 38). The rough stems of scouring-rush (Equisetum hymale) were used to scour pots, pans, and floors (Britton and Brown 1896: 38; Sumner 2004: 298). Historic documents describe indigenous people of the Fort Vancouver area collecting field horsetail (http://www.nps.gov), which verifies the presence of this taxon in the subject area.

Iris A minimal amount of pollen grains identified as iris was recovered from Sample 3. Some species of iris grow naturally in North America and prefer wet soils as irises can be commonly found in swamps, marshes, river shores, and along streams (Britton and Brown 1996: 448-452). Irises were also cultivated (Taylor 1996: 16, 98; Sumner 2004: 338). Historical 
records indicate that field irises were present in the vicinity of Fort Vancouver (http://www.nps.gov).

Lamiaceae and Mentha Small amounts of pollen identified to the "Mint" family were recovered in three samples, Samples 1,3, and 6. Many taxa belonging to this family are insectpollinated and their presence in the samples indicates local vegetation. Both weedy and economic species are included in this family.

Liliaceae Several species of lily are native to the area and inhabit dry woods as well as meadows and marshes (Britton and Brown 1896:416-418). Insect-pollinated, vegetable and flower species are also included in this family. Pollen identified to the "Lily" family were identified in Samples 2, 3, 5, and 6.

Menyanthes Pollen identified as buckbean (Menyanthes) was recovered in all samples except the modern surface sample. More than an incidental amount of buckbean pollen was recovered in Sample 4. Buckbean (Menyanthes trifoliata) is native to the subject area (http://plants.usda.gov), grows in bogs (Britton and Brown 1897:622) and was utilized by Native Americans as an analgesic and antiemetic and consumed as a food source (Moerman 1998:342343).

Oxalis Woodsorrel prefers woods and fields and is present in the subject area (Britton and Brown 1897:344-347). A small amount of wood sorrel pollen was recovered in Sample 3. Phlox Several types of phlox grow in Washington (http://plants.usda.gov) and are present in moist woods, along streams, and in thickets (Britton and Brown 1898:32-37). In the eighteenth century, several types of phlox were collected and cultivated for their flowers (M'Mahon 1806:461; Sumner 2004:323) and used for their medicinal properties (Moerman 1998:392). Phlox pollen was recovered in all samples except Sample 5. More than an incidental 
amount of phlox pollen was recovered in Samples 2 and 4. Phlox are insect-pollinated, thus denoting local vegetation.

Plantago Plantain is associated with settlement because they grow along paths and roadways (Page and Weaver 1974: 212). A small amount of plantain pollen was identified in Samples 2, 4, and 6.

Poaceae, wild Wild grass pollen was recovered in all analyzed samples, but amounts never exceeded $3 \%$ of the total counted pollen for any one sample with the highest amount recovered from the modern surface sample. This finding is in line with the results of the palynological examination of several contexts associated with the "garden testing area" as both the surface sample and an early twentieth century context from this previous examination contained the highest proportions of wild grass pollen (Jacobucci 2008). One of the objectives of the previous analysis was to verify if the Fort Vancouver garden paths were covered with grass; however the amount of recovered wild grass pollen from any Fort Vancouver context analyzed to date is too low to suggest grass cover in comparison to the significantly higher amounts of wild grass pollen recovered in other historical studies which advocate for grass covered surfaces (see Kelso 1994b; Mrozowski et al. 1989).

Poaceae, European-introduced cereal European-introduced cereal pollen was recovered in Sample 2. Most European-introduced cereals except rye are self-pollinated; therefore, their pollen grains do not travel far (Davis 1969:420; van der Veen:1992:8), and only a small quantity of pollen is released until the plants are threshed (Kelso 1994a:17). European-introduced cereal pollen is found on respective grain, chaff, straw, and grain products (Kelso 1998:54; see also Grieg 1982:59). The recovery of cereal pollen indicates "local human activities involving grain, grain products or grain waste" (Kelso 1998:54; see also Bradley et al. 1983:75) at the site. It is 
probable that cereal pollen was deposited in the sampled context because it was cultivated and processed nearby, which is supported by historical records (http://.www.nps.gov) and corroborates with findings from the palynological examination of contexts associated with the "garden testing area," which recovered small amounts of European-introduced cereal pollen in seven analyzed contexts (Jacobucci 2008).

Polygonum Pollen grains identified as knotweed appeared in four samples (Samples 1, 2, 5, and 6). Both naturalized and indigenous herbs are included in this genus with some species preferring wet soils, while others flourish within waste places (Britton and Brown 1996: 554567; Wodehouse 1965: 404).

Primulaceae Loosestrife (Lysimachia), a member of the Primulaceae family, is naturalized from Europe and is present in moist thickets (Britton and Brown 1897:587-589). A small quantity of pollen resembling loosestrife pollen was identified in the modern surface sample and Sample 6.

Thalictrum Some species of meadow rue prefer open places and sunny swamps, mountains and woods (Britton and Brown 1897:86-88). Several species of meadow rue are native to the Pacific Coast (Britton and Brown 1897: 86). A small quantity of meadow rue pollen was identified in the modern surface sample and Sample 3.

Trifolium Small amounts of clover pollen were recovered in the modern pollen surface sample as well as in Sample 3. Farmers as early as the seventeenth century sowed their lands with imported grasses and forage plants, which included red clover (Trifolium pretense) (Romani 1996:33). Clover was commonly used as green manure and part of a crop rotation system (Nelson 2007). Red clover, for example, was commonly grown for fodder (Britton and Brown 1897:276). Historical documentation from Fort Vancouver contains several entries of clover 
especially for the earlier years of occupation (http://www.nps.gov) and no doubt was incorporated in the pollen rain at Fort Vancouver.

Utricularia A small quantity of bladderwort pollen was recovered in the modern surface sample and Samples 3 and 5. Several species in this genus are indigenous to the subject area (http://plants.usda.gov).

\section{Mosses and Ferns}

Several types of mosses and ferns were identified in all six Fort Vancouver pollen samples. Five moss and two fern genera were recovered. Several types of fern that this analysis identified prefer moist environments such as swamps and marshes as well as grassy woods and meadows. A moderate amount of spores identified as woodfern appeared in all six samples. Species belonging to these genera are considered to be invader species with some species dominating the understory of wet regions in the Tsuga heterophyla vegetation zone (Franklin and Dyrness 1969: 60). The highest percentage of woodfern was recovered in Sample 6, which represented approximately $12 \%$ of the total counted pollen and spores.

Unknown Palynomorph Large amounts of an "unknown palynomorph" (Photograph 1) were recovered in all six samples, with the greatest quantity (nearly $31 \%$ of the total counted pollen), recovered from Sample 4. Small amounts of this type were identified in the examination of samples recovered from the "garden-testing area;" however, they were not included in the earlier report because at the time they were not considered to be pollen. Spores grouped in this category are similar in appearance to pollen produced by Acacia and Mimosa, which belong to the Fabaceae family and by vegetation included in the Hippocratea genus (Hippocrateaceae) in that grains are polyads; however, the "unknown palynomorph" appears to have verrucate sculpturing as some species of Hippocratea versus the psilate sculpturing of the Acacia-type, 
and has pore-like apertures on its cells. Numerous tree and shrubby species belong to the Mimosa genus and vines such as medicine vine (Hippocratea volubilis) belong to the Hippocratea genus, however, like Acacia, none of these genera are indigenous to the subject area. Acacias and silk trees (Mimosa) were used as ornamentals (Leighton 1986:387, 389). Thomas Jefferson grew sensitive plant (Mimosa pudica) and other types of Mimosa (Betts 1981: 8, 445, 449). Prairie acacia (Mimosa filiculoides also referred to as Acacia filiculoides) for example is a shrub that naturally occupies open areas from Missouri to New Mexico (Britton and Brown 1887: 254); nevertheless, sensitive plant is a flowering creeping annual that was introduced to Hawaii. It is probable that pollen identified as an "unknown palynomorph" type originated from shrubby or herbaceous plants because relatively high amounts of this type were identified in Samples, 3 and 4, which featured diminished percentages of arboreal vegetation.

\section{Discussion}

The thrust of the pollen analysis for the Hudson's Bay Company non-garden provenience Ivas for comparison to the previously analyzed garden proveniences from Fort Vancouver (Jacobucci 2008). Nevertheless important interpretive information was collected by examining the total spectrum of pollen, especially since all samples examined had adequate pollen and spore densities for environmental reconstruction. Such information helps describe the former background pollen rain as well as local vegetation that existed in the vicinity of the collection site at the time of Fort Vancouver's occupation and assists archaeologists in understanding how the Hudson Bay Company utilized their space and how the actions of the occupants impacted the vegetation of the area.

The pollen and spores recovered from the six soil samples represent a mixture of native arboreal, understory vegetation, herbs, mosses and ferns that are common to the Puget Sound 
vegetational area and the Tsuga heterophylla vegetation zone, plants not native to the subject area, plants that prefer moist environments, and economic taxa. Pollen identified to taxa such as Douglas fir dominated the proportion of recovered arboreal taxa; however, pollen produced by other trees such as alder, pine, and spruce were also well represented in some of the samples. Weedy taxa such as Cheno/Am and Liguliflorae pollen were well represented in all samples with an overwhelming proportion of these two taxa representing approximately $36 \%$ of the total counted pollen for Sample 3. Small amounts of pollen produced by plants that prefer moist environments such as bladderwort and buckbean were recovered in this study; while other taxa such as horsetail were well represented in all samples. Spores produced by ferns and mosses such as wood-fern and clubmoss, were identified with the greatest proportion of these types recovered in Samples 5 and 6. Small amounts of introduced and economic taxa were also recovered. For example small amounts of pollen identified as an Acacia-type were recovered from Samples 1 through 5; while a more moderate amount of "Mulberry" family pollen were recovered from these samples. A small amount of European-introduced cereal pollen was recovered from Sample 2 .

The pollen analysis also revealed a vegetation profile in transition no doubt affected by human agency (see Table 4). Percentages of pollen from trees and shrubs increased from Samples 6 to 5, decreased firom Samples 5 through 4 then increased to the top of the soil column. On the other hand, percentages of pollen produced by herbaceous vegetation were inversely proportionate to the percentages of pollen produced by arboreal taxa. The percentages of pollen produced by herbs decreased slightly from Samples 6 to 5, increased from Samples 5 to 3, then decreased from Sample 3 to the top of the soil column. Pollen produced by Douglas fir, larch, pine, and spruce, for example, taxa common to the Puget Sound and Tsuga heterophylla 
Table 4

Approximate Percentages of Major Vegetation Categories

\begin{tabular}{|c|c|c|c|c|c|}
\hline Samples & $\begin{array}{c}\text { Trees \& } \\
\text { Shrubs }\end{array}$ & Herbs & $\begin{array}{c}\text { Ferns \& } \\
\text { Mosses }\end{array}$ & $\begin{array}{c}\text { Unknown } \\
\text { Palynomorph }\end{array}$ & Unidentifiable/Identifiable \\
\hline 1 & $60 \%$ & $19 \%$ & $10 \%$ & $7 \%$ & $3 \%$ \\
\hline 2 & $39 \%$ & $36 \%$ & $8 \%$ & $11 \%$ & $6 \%$ \\
\hline 3 & $15 \%$ & $56 \%$ & $10 \%$ & $15 \%$ & $4 \%$ \\
\hline 4 & $11 \%$ & $45 \%$ & $11 \%$ & $29 \%$ & $4 \%$ \\
\hline 5 & $34 \%$ & $35 \%$ & $15 \%$ & $11 \%$ & $5 \%$ \\
\hline 6 & $18 \%$ & $34 \%$ & $15 \%$ & $23 \%$ & $7 \%$ \\
\hline
\end{tabular}

vegetation zones, revealed a notable decrease in the percentages of pollen identified to these tree types between Samples 5 and 4 and an increase at that time of weedy taxa such as Cheno/Am and Liguliflorae pollen, perhaps highlighting a period of intense land utilization which included the operation of a timber mill that no doubt contributed to deforestation of the Fort Vancouver area. A notable increase in percentages of pollen produced by these arboreal taxa was then observed between Samples 3 and 2, which probably reflects a period of reforestation of the area as a result of abandonment (See Table 5). Percentages of pollen identified to Cheno/Am and Liguliflorae taxa decrease between Samples 3 and 2. The decrease in herbaceous taxa at that

Table 5

A Comparison Over Time of Approximate Percentages of Douglas fir, Larch, Pine, and Spruce; Cheno/Am \& Liguliflorae Pollen, and Unknown Palynomorph

\begin{tabular}{|c|c|c|c|}
\hline $\begin{array}{c}\text { Sample } \\
\text { Numbers }\end{array}$ & $\begin{array}{c}\text { Percentage of the Total } \\
\text { Counted Pollen for Douglas } \\
\text { Fir, Larch, Pine, and Spruce }\end{array}$ & $\begin{array}{c}\text { Percentage of the } \\
\text { Total Counted Pollen } \\
\text { for Cheno/Am \& } \\
\text { Liguliflorae }\end{array}$ & $\begin{array}{c}\text { Percentage of the } \\
\text { Total Counted Spores } \\
\text { for Unknown } \\
\text { Palynomorph }\end{array}$ \\
\hline 1 & $42 \%$ & $8 \%$ & $7 \%$ \\
\hline 2 & $30 \%$ & $18 \%$ & $11 \%$ \\
\hline 3 & $8 \%$ & $36 \%$ & $15 \%$ \\
\hline 4 & $6 \%$ & $23 \%$ & $29 \%$ \\
\hline 5 & $17 \%$ & $17 \%$ & $11 \%$ \\
\hline 6 & $13 \%$ & $22 \%$ & $23 \%$ \\
\hline
\end{tabular}


time possibly indicates a change in activity in the subject area, which coincides with a period of reforestation supported by an increase in recovered arboreal pollen. There is a curious increase in arboreal pollen and decrease in herbaceous pollen from Samples 6 to 5. Of note are the high percentages of the "unknown palynomorph," which seem to mimic the trend for increasing percentages of pollen produced by weedy Cheno/Am and Liguliflorae taxa between Samples 6 and 4 and decreasing pollen percentages of these vegetation types between Samples 3 and 2. However, instead of percentages of spores identified to the "unknown palynomorph" category increasing between Samples 4 and 3 as pollen from Cheno/Am and Liguliflorae plants did, percentages of spores of the "unknown palynomorph" type significantly decrease (Figure 3). Perhaps this disparity will help define the vegetation type that produced this "unknown palynomorph."

Increasing pollen percentages from other weedy vegetation between Samples 6 through 4 also supports the hypothesis supported by historical records and archaeology for the increasingly active Fort Vancouver landscape at that time. Percentages of Asteraceae, Tubuliflorae pollen, for example also increased between these samples (see Table 5). Since taxa included in this grouping are predominately insect-pollinated, this finding indicates that local ground cover was most likely weedy with many of these taxa such as ragwort considered as invader species preferring to colonize fields and waste places. Many of these taxa grow in meadows but they also inhabit recently cleared landscapes. Historical records describe the site that would become Fort Vancouver as a three mile meadow susceptible to frequent river flooding at "the foot of a beautiful range of high prairie ground rising about thirty feet" (http://www.nps.org). Since all of the analyzed samples from the sediment core are cultural (Dorset 2010 Pers. Comm.) it is difficult to say from the samples analyzed for this current examination if the pre-Fort Vancouver 
landscape was tree covered or part of a meadow. Interestingly, arboreal pollen only represented $18 \%$ of the total pollen counted for Sample 6 clearly revealing that at least in the earliest years of the Fort Vancouver occupation, trees were not the dominant vegetation at the site. Instead, proportions of weedy taxa, mosses and ferns prevailed and represented approximately $55 \%$ of the total counted pollen at that time. Sample 6 depicts a relatively treeless landscape which may be as a result of ongoing Native American land maintenance and burning practices that are reported to have taken place in the northern part of Washington over the past 2,000 years (Weiser and Lepofsky 2009).

Wood-fern represented roughly $12 \%$ of the total counted pollen for Sample 6. Some types of wood-fern are considered to be invader species; however, others such as spreading or northern wood-fern (Dryopteris expansa) grow in moist to wet woods and along streambanks (http://www.biology.burke.washington.edu). A high incidence of wood-fern perhaps attests to local ground cover during the early Hudson Bay Company occupation and could support the existence of a former meadow. Unfortunately Sample 546, a pre-Fort Vancouver occupation sample which was analyzed in the previous pollen examination (Jacobucci 2008) had a pollen and spore density that was insufficient for environmental reconstruction. Pollen from arboreal species such as Douglas fir, larch, and willow and from weedy taxa such as small Liguliflorae and field horsetail and or scouring rush (Equisetum) and wood-fern were recovered in this sample (Jacobucci 2008).

Cheno/Ams are prevalent in cultivated soils and pollen from these taxa were well represented in Samples 2 through 6 in the current examination perhaps due to ongoing agricultural practices in the area which affected the vegetation spectrum. Percentages of ragweed pollen remain relatively consistent throughout the sampled soil profile with the 
Table 6

Percentages of Asteraceae, Tubuliflorae Pollen; Ambrosia; Wild Grasses; Europeanintroduced Cereals; and Cheno/Am

\begin{tabular}{|c|c|c|c|c|c|}
\hline $\begin{array}{c}\text { Sample } \\
\text { Number }\end{array}$ & $\begin{array}{c}\text { Percentages of } \\
\text { Asteraceae, } \\
\text { Tubuliflorae Pollen }\end{array}$ & $\begin{array}{c}\text { Percentages } \\
\text { of Ragweed } \\
\text { Pollen }\end{array}$ & $\begin{array}{c}\text { Percentages } \\
\text { of Wild } \\
\text { Grass } \\
\text { Pollen }\end{array}$ & $\begin{array}{c}\text { Percentages } \\
\text { of } \\
\text { European- } \\
\text { Introduced } \\
\text { Cereals }\end{array}$ & $\begin{array}{c}\text { Percentages } \\
\text { of } \\
\text { Cheno/Am }\end{array}$ \\
\hline 1 & $0.66 \%$ & $1.31 \%$ & $3.28 \%$ & 0 & $1.64 \%$ \\
\hline 2 & $3.00 \%$ & $1.67 \%$ & $1.00 \%$ & $0.67 \%$ & $7.00 \%$ \\
\hline 3 & $4.56 \%$ & $0.33 \%$ & $1.95 \%$ & 0 & $14.01 \%$ \\
\hline 4 & $5.26 \%$ & $1.97 \%$ & $0.33 \%$ & 0 & $8.88 \%$ \\
\hline 5 & $3.30 \%$ & $1.00 \%$ & $1.65 \%$ & 0 & $6.27 \%$ \\
\hline 6 & $0.98 \%$ & $1.63 \%$ & $0.65 \%$ & 0 & $4.58 \%$ \\
\hline
\end{tabular}

exception of Sample 3 in which percentages of ragweed pollen decreased from Sample 4.

However, ragweed pollen then increased from Samples 3 to 2. Interestingly, a small amount of European-introduced cereal pollen was only identified in Sample 2, perhaps indicating when the wheat field to the west of the sampled site location was utilized or that cereal pollen traveled that far. Percentages of wild grass pollen increased from Samples 4 to 3, and from Samples 2 to 1 perhaps indicating episodes of less activity on the Fort Vancouver landscape as increases in grass pollen is often correlated to more settled landscapes; however, not enough grass pollen was recovered in this examination to support this premise.

\section{Comparison Between Garden and Non-Garden Profiles}

In several ways the current analyzed pollen profile is similar to the pollen analysis of the Fort Vancouver "garden-testing area," which included a soil profile. Both examinations revealed periods of intense land usage which were characterized by lower amounts of arboreal pollen and the recovery of pollen from invader species and a period of arboreal reforestation specifically in samples located near the modern ground surface. Both examinations recovered Europeanintroduced cereal pollen and an acacia-type pollen; however the analysis of the "garden-testing 
area" also recovered pollen identified to other cultivated species such as a zinnia-type, citrus and a dahlia- type to name a few that were not present in samples collected from the non-garden provenience. The pollen examination of the "garden-testing area" also identified samples containing ample amounts of pollen identified to certain insect-pollinated taxa (such as a greater percentage of Apiaceae family pollen recovered in Sample 425 and Rosaceae family pollen recovered in Sample 419) (Jacobucci 2008) to suggest intentional cultivation. Tubuliflorae pollen types were recovered in both examinations; however, higher proportions of pollen identified to this category were recovered in several "garden-testing-area" contexts. For example pollen grouped into the Tubuliflorae category for three contexts (Samples 419, 422, and 551) which were examined in the previous pollen analysis exceeded $12 \%$ of the total pollen counted for these contexts (Jacobucci 2008).

Many of the same taxa such as Douglas fir, alder, pine, spruce, ragweed, Ligulifloraetypes, knotweed, and goldenrod among others were recovered in both examinations and probably represent background vegetation. Nevertheless, the analysis of the "garden-testing area" recovered almost twice as many identified taxa or groupings, several of which were associated with herbaceous possible cultivated or ornamental taxa such as citrus, a dahlia-type, tansy, and a zinnia-type that were not identified in the current analysis. Percentages of arboreal pollen for several of the non-garden contexts ranged from roughly $11 \%$ to $18 \%$ of the total counted pollen for Samples 3, 4, and 6 and from 34\% to $60 \%$ of the total counted pollen for Samples 1, 2, and 5; while for samples analyzed from the "garden-testing area," arboreal pollen ranged from approximately $13 \%$ to $21 \%$ of the total counted pollen for the majority of samples (Jacobucci 2008). The "garden-testing area" samples contained relatively consistent higher percentages of herbaceous pollen which represented anywhere from roughly $48 \%$ to $65 \%$ of the total counted 
pollen for these samples (Jacobucci 2008). Consistent lower arboreal pollen proportions coupled with higher percentages of herbaceous pollen for several of the "garden-testing area" contexts could indicate that the predominant vegetation cover for these "garden-testing area" contexts were herbaceous taxa. Both examinations identified an "unknown palynomorph;" however, an overwhelming amount of this type was recovered from the non-garden contexts. The "unknown palynomorph" type appears to anticipate weedy taxa and could be a sensitive indicator to landscape disturbance.

\section{Conclusion}

The pollen analysis of samples that were recovered from a non-garden provenience at Fort Vancouver served for comparisons to the pollen examination of contexts associated with the "garden-testing area." Even though there were many similarities between the two studies such as the recovery of pollen from the same taxa such as Douglas fir, birch, acacia, and Europeanintroduced cereals to name a few, pollen types that were not recovered in the current analysis such as citrus and a zinnia-type among others, and the consistent lower proportion of arboreal to higher proportion of herbaceous pollen especially for the "garden-testing area" contexts, is what distinguished the two examinations from one another. All samples analyzed in the current examination had sufficient pollen and spore densities to warrant environmental reconstruction and also touched upon what vegetation types existed in the regional and local landscape over time. Interestingly, generous amounts of an "unknown palynomorph" were recovered in the current analysis while only small amounts were identified in the previous examination. The current analysis as the former, revealed a highly utilized Fort Vancouver landscape during its occupation as well as a period of reforestation that was identified in modern surface samples. 


\section{References}

Adams, D. W.

2004 Restoring American Gardens: An Encyclopedia of Heirloom Ornamental Plants, 16401940. Portland Oregon: Timber Press, Inc.

Betts, E. M.

1981 Thomas Jefferson's Garden Book, 1766-1824: With Relevant Extracts from his Other Writings. Philadelphia: The American Philosophical Society.

Bradley, J. W., N. DePaoli, N. Seasholes, P. McDowell, G. Kelso and J. Schoss

1983 Archaeology of the Bostonian Hotel Site, Occasional Publications in Archaeology and History \#2, Chapter 4, pp. 67-, Boston, MA: Massachusetts Historical Commission.

Britton, N. L. and Hon. A. Brown

1898 An Illustrated Flora of the Northern United States, Canada and the British Possessions: From Newfoundland to the Parallel of the Southern boundary of Virginia, and from the Atlantic Ocean Westward to the 102D Meridian, Vol. III, Apocynaceae to Compositae, Dogbane to Thistle. New York: Charles Scribner's Sons.

1897 An Illustrated Flora of the Northern United States, Canada and the British Possessions: From Newfoundland to the Parallel of the Southern boundary of Virginia, and from the Atlantic Ocean Westward to the 102D Meridian, Vol. II, Portulacaceae to Menyanthaceae, Portulaca to Buckbean. New York: Charles Scribner's Sons.

1896 An Illustrated Flora of the Northern United States, Canada and the British Possessions: From Newfoundland to the Parallel of the Southern boundary of Virginia and from the Atlantic Ocean Westward to the 102D Meridian, Vol. I, Ophioglossaceae to Aizoaceae, Ferns to Carpet-Weed. New York: Charles Scribner's Sons.

Brown, L.

1976 Weeds in Winter. New York: W. W. Norton \& Company.

Brugam, R. B.

1978 "Pollen Indicators of Land-Use in Southern Connecticut." Quaternary Research 9:349362.

Bryant Jr., V. and S. A. Hall

1993 "Archaeological Palynology in the United States: A Critique." American Antiquity $58(2): 277-284$.

Bush, M. B. and R. Rivera

2001 "Reproductive Ecology and Pollen Representation Among Neotropical Trees." Global Ecology \& Biogeography 10:359-367. 
Cahill, J., K. Reinhard, D. Tarler, and P. Warnock

1991 "Scientists Examine Remains of Ancient Bathroom." Biblical Archaeology Review 17(3):62-69.

Davis, M. B.

1969 "Climatic Changes in Southern Connecticut Recorded by Pollen Deposition at Rogers Lake." Ecology 50(3):409-422.

Dincauze, D. F.

2000 Environmental Archaeology: Principles and Practice. Cambridge: Cambridge University Press.

Dorset, E.

2011 "Personal Communications."

2010 "Personal Communications."

Elzinga, W. J.

1988 "Short-term Vegetation Changes on an Abandoned Mining Site as Determined by Pollen Analysis." American Midland Naturalist 120(2):371-379.

Erdiman, G.

1943 An Introduction to Pollen Analysis. New York: The Ronald Press Company.

Faegri, K., J. Iversen, P. E. Kaland, and K. Krzywinski

1989 Textbook of Pollen Analysis, 4th ed., Caldwell, NJ: The Blackburn Press.

Franklin, J. F. and C. T. Dymess

1969 Vegetation of Oregon \& Washington, U.S.D.A. Forest Service Research Paper PNW-80. Portland, Oregon: U.S. Department of Agriculture, Pacific Northwest Forest and Range Experiment Station.

Gleason, H. A. and A. Cronquist

1964 The Natural Geography of Plants. New York \& London: Columbia University Press.

Grieg, J.

1982 "The Interpretation of Pollen Spectra from Urban Archaeological Deposits." In Environmental Archaeology in the Urban Context, ed. A. R. Hall and H. K. Kenward, Research Report No. 43, London: Council for British Archaeology.

Hall, S.

1981 "Deteriorated Pollen Grains and the Interpretation of Quaternary Pollen Diagrams." Review of Paleobotany and Palynology 32:193-206. 
Harlow, W. M.

1957 Trees of Eastern and Central United States and Canada. New York: Dover Publications, Inc.

Heusser, C. J.

1978 "Modern Pollen Rain in the Puget Lowland of Washington." Bulletin of the Torrey Botanical Club 105(4):296-305.

Jacobucci, S. A.

2008 "An Analysis of Pollen from Fort Vancouver, Washington," Cultural Resources Management Study No. 25. Report submitted to Vancouver National Historic Reserve, Vancouver, WA.

Jacobucci, S. A., H. B. Trigg, and S. W. Silliman

2007 "Vegetation and Culture on the Eastern Pequot Reservation: Interpreting Millennia of Pollen and Charcoal in Southeastern Connecticut." Northeast Anthropology, 74:13-39 (Printed in 2010).

Kapp, R. O.

1969 Pollen and Spores. Dubuque, Iowa: William C. Brown Company.

Kapp, R. O., O. K. Davis and J. E. King

2000 Pollen and Spores, $2^{\text {nd }}$ ed., Illustrated by Richard C. Hall, College Station, TX: The American Association of Stratigraphic Palynologists Foundation.

Kelso, G. K. and M. C. Beaudry

1990 "Pollen Analysis and Urban Land Use: The Environs of Scottow's Dock in $17^{\text {th }}, 18^{\text {th }}$, and Early $19^{\text {th }}$ Century Boston." Historical Archaeology 29:61-81.

1994a "Management summary, Phase III Palynological Data Recovery, Pollen Analysis of the Boston Mill Pond Site (Bos-HA-14) Boston, Massachusetts," Appendix D. In Archaeological Data Recovery: The Mill Pond Site (Bos-HA-14) Boston-Massachusetts, prepared by Charles D. Cheek and Joseph Balicki, February 2000. West Chester, PA: John Milner Associates Inc.

$1994 b$ "Palynology in Historical Rural-Landscape Studies: Great Meadows, Pennsylvania." American Antiquity 59(2):359-372.

Kelso, G. K., F. R. Dimmick, D. H. Dimmick, and T. B. Largy

2006 "An Ethnopalynological Test of Task-specific Area Analysis: Bay View Stable, Cataument, Massachusetts." Journal of Archaeological Science 33:953-960.

Kelso, G. K.

1998 "Pollen Analysis of the Feature 4 Privy at the Cross Street Back Lot Site, Boston, Massachusetts." Historical Archaeology 32(3):49-62. 
King, J. E., W. E. Klippel, and R. Duffield

1975 Pollen Preservation and Archaeology in Eastern North America. American Antiquity 40(2):180-190.

Larsen, C.P.S. and G. M. MacDonald

1998 "Fire and Vegetation Dynamics in a Jack Pine and Black Spruce Forest Reconstructed Using Fossil Pollen and Charcoal." The Journal of Ecology 86(5):815-828.

Leighton, A.

1986 American Gardens in the Eighteenth Century, "For Use or for Delight." Amherst: The University of Massachusetts Press.

M'Mahon, B.

1806 The American Gardener's Calendar; Adapted to the Climates and Seasons of the United States. Philadelphia: B. Graves.

Marshall, D. M.

2008 Ethnopalynology: Pollen Analysis in Land and Underwater Archaeology. Saarbrücken, Germany: VDM Verlag Dr. Müller Aktiengesellschaft \& Co. KG.

Mattoon, W. R.

1936 Forest Trees and Forest Regions of the United States, U.S. Department of Agriculture Miscellaneous Publication Number 217. Washington, D.C.: United States Department of Agriculture.

McAndrews, J. H., A. A. Berti, and G. Norris

1973 Key to the Quaternary Pollen and Spores of the Great Lakes Region, Royal Ontario Museum Life Sciences Miscellaneous Publication. Toronto: The Royal Ontario Museum.

Moerman, D. E.

1998 Native American Ethnobotany. Portland, Oregon: Timber Press.

Moore, P. D. and J. A. Webb

1978 An Illustrated Guide to Pollen Analysis. Halsted Press, a Division of John Wiley \& Sons Inc., New York.

Moore, P. D., J. A. Webb, and M. E. Collinson

1991 Pollen Analysis, Second Edition. Oxford: Blackwell Scientific Publications

Mrozowski, S. A., E. L. Bell, M. C. Beaudry, D. B. Landon, and G. K. Kelso

1989 "Living on the Boot: Health and Well Being in a Boardinghouse Population." World Archaeology 21(2):298-319.

Nelson, Lynn A.

2007 Pharsalia: An Environmental Biography of a Southern Plantation, 1780-1880. The University of Georgia Press: Athens \& London. 
Oldfield, F.

1978 "Pollen Analysis of Recent Sediments From Two Lakes Near Halifax, Nova Scotia." Pollen et Spores 20:1517-1530.

Page, N. M. and R. E. Weaver Jr.

1974 Wild Plants in the City, reprinted from Arnoldia Vol. 34, No. 4. Jamaica Plain, Massachusetts: Arnold Arboretum of Harvard University.

Pearsall, D. M.

2000 Paleoethnobotany: A Handbook of Procedures, $2^{\text {nd }}$ ed. San Diego, CA: Academic Press.

Romani, Jr., D. A.

1996 "Our English Clover-grass Sowen Thrives Very Well": The Importation of English Grasses and Forages into Seventeenth-Century New England." In Plants and People, the Dublin Seminar for New England Folklife Annual Proceedings 1995, ed. Peter Benes, Boston, Boston University.

Sumner, J,

2000 The Natural History of Medicinal Plants. Portland: Timber Press.

2004 American Household Botany: A History of Useful Plants, 1620-1900. Portland, Oregon: Timber Press.

Taylor, R. L.

1996 Plants of Colonial Days. Mineola, NY: Dover Publications, Inc.

Tilman, D.

1988 Plant Strategies and the Dynamics and Structure of Plant Communities. Princeton, NJ: Princeton University Press.

Trigg, H. B., D. Landon, E. Newman, and A. Hancock

2003 "Archaeobiological Materials Analyses." In Supplementary Excavations at the Kirk Street Agents' House, Lowell National Historical Park, Lowell, Massachusetts, ed. William A. Griswold, Occasional Publications in Field Archaeology, Number 2, pp. 27 41. Lowell, MA: National Park Service.

Van der Veen, Marijke

1984 Crop Husbandry Regimes: An Archaeobotanical Study of Farming in Northern England, 100 BC - AD 500, Sheffield Archaeological Monographs 3, Sheffield: J. R. Collis Publications, University of Sheffield, Department of Archaeology and Prehistory.

Weiser, A. and D. Lepofsky

2009 "Ancient Land Use and Management of Ebey's Prairie, Whidbey Island, Washington." Journal of Ethnobiology 29(2):184-212. 
Weishan, $M$.

1999 The New Traditional Garden: A Practical Guide to Creating and Restoring Authentic American Gardens for Homes of all Ages. New York: Ballantine Publishing Group.

Wodehouse, R. P.

1965 Pollen Grains: Their Structure, Identification and Significance in Science and Medicine, New York and London: Hafner Publishing Company.

Websites:

http://biology.burke.washington.edu/herbarium/imagecollection.php?Genus=Dryopteris\&Species zexpansa The Burke Museum of Natural History and Culture, University of Washington, Accessed December 2010.

http://plants.usda.gov Accessed throughout 2010.

http://striweb.si.edu/roubik/ Smithsonian Tropical Research Institute, David Roubik, Pollen and Spores of Barro Colorado Island, Accessed throughout 2010.

http://vwww.geo.arizona.edu/palynology/polonweb.html, University of Arizona Catalogue of Internet Pollen and Spore Images, Accessed throughout 2010.

http://www.geo.arizona.edu/palynology/pid00027.html, Acacia (Leguminosae), Accessed November 2010.

http://www.geo.arizona.edu/palynology/pid00029.html, Liguliflorae, (Compositae), Accessed November 2010.

http://wwww.geo.arizona.edu/palynology/pid00043.html, Apiaceae - Umbelliferae, Accessed November 2010.

http://www.nps.gov. Fort Vancouver: Cultural Landscape Report (Vol. 1, Appendices A, B, D, and G). Accessed December 2010. 
Appendix A, Raw Taxa Counts

\begin{tabular}{|c|c|c|c|c|c|c|}
\hline Taxa and/ or Groupings & Sample 1 & Sample 2 & Sample 3 & Sample 4 & Sample 5 & Sample 6 \\
\hline Abies & 2 & 3 & 0 & 0 & 1 & 0 \\
\hline Acer & 0 & 0 & 0 & 1 & 0 & 0 \\
\hline Alnus & 31 & 2 & 0 & 1 & 15 & 2 \\
\hline Betula & 6 & 3 & 2 & 2 & 4 & 3 \\
\hline Castanea & 0 & 2 & 0 & 0 & 0 & 0 \\
\hline Celtis & 0 & 1 & 0 & 0 & 2 & 0 \\
\hline Fabaceae-Acacia-Type & 2 & 1 & 1 & 1 & 2 & 0 \\
\hline Larix & 9 & 26 & 0 & 1 & 4 & 9 \\
\hline Morus & 5 & 1 & 6 & 3 & 11 & 0 \\
\hline Ostrya & 1 & 0 & 0 & 0 & 0 & 0 \\
\hline Pinaceae & 4 & 5 & 3 & 0 & 1 & 2 \\
\hline Picea & 10 & 8 & 3 & 2 & 6 & 3 \\
\hline Pinus & 18 & 10 & 6 & 1 & 9 & 3 \\
\hline Pseudotsuga & 88 & 41 & 14 & 17 & 31 & 31 \\
\hline Quercus & 2 & 0 & 1 & 0 & 0 & 1 \\
\hline $\mathrm{SC}$ & 7 & 12 & 9 & 10 & 17 & 7 \\
\hline Tsuga & 1 & 2 & 1 & 1 & 0 & 1 \\
\hline Rosaceae & 0 & 0 & 1 & 0 & 1 & 2 \\
\hline Ambrosia & 4 & 5 & 1 & 6 & 3 & 5 \\
\hline Apiaceae & 0 & 0 & 0 & 0 & 1 & 0 \\
\hline Artemisia & 0 & 0 & 0 & 8 & 1 & 1 \\
\hline Aster & 0 & 3 & 6 & 2 & 4 & 1 \\
\hline Calendula & 0 & 0 & 2 & 0 & 0 & 0 \\
\hline Carduus & 0 & 1 & 0 & 0 & 0 & 0 \\
\hline Carex & 2 & 4 & 8 & 3 & 6 & 2 \\
\hline Caryophyllaceae & 0 & 1 & 3 & 0 & 2 & 0 \\
\hline Cheno/AM & 5 & 21 & 43 & 33 & 19 & 14 \\
\hline Daphne & 0 & 2 & 3 & 0 & 0 & 0 \\
\hline Equisetum & 4 & 13 & 14 & 30 & 16 & 23 \\
\hline Eupatorium & 2 & 2 & 1 & 5 & 3 & 0 \\
\hline Helianthus & 0 & 2 & 0 & 0 & 0 & 2 \\
\hline Iris & 0 & 0 & 1 & 0 & 0 & 0 \\
\hline Lamiaceae & 1 & 0 & 1 & 0 & 0 & 1 \\
\hline Lamiaceae, Mentha & 0 & 0 & 1 & 0 & 0 & 0 \\
\hline
\end{tabular}




\begin{tabular}{|c|c|c|c|c|c|c|}
\hline Taxa and/ or Groupings & Sample 1 & Sample 2 & Sample 3 & Sample 4 & Sample 5 & Sample $\epsilon$ \\
\hline Ligulliflorae, small & 18 & 33 & 61 & 44 & 26 & 56 \\
\hline Ligulliflorae, large & 2 & 0 & 8 & 4 & 8 & 1 \\
\hline Liliaceae & 0 & 2 & 4 & 0 & 3 & 1 \\
\hline Menyanthes & 0 & 1 & 1 & 5 & 1 & 3 \\
\hline Oxalis & 0 & 0 & 1 & 0 & 0 & 0 \\
\hline Phlox & 1 & 6 & 1 & 5 & 0 & 4 \\
\hline Plantago & 0 & 1 & 0 & 1 & 0 & 1 \\
\hline Poa $<40 \mu \mathrm{m}$ & 10 & 3 & 6 & 1 & 5 & 2 \\
\hline Poa, Cerales & 0 & 2 & 0 & 0 & 0 & 0 \\
\hline Polygonum & 4 & 5 & 0 & 0 & 1 & 1 \\
\hline Primulaceae & 2 & 0 & 0 & 0 & 0 & 1 \\
\hline Senecio & 0 & 1 & 0 & 0 & 1 & 0 \\
\hline Solidago & 0 & 0 & 5 & 5 & 1 & 0 \\
\hline Thalictrum & 0 & 0 & 0 & 11 & 5 & 6 \\
\hline Trifolium & 1 & 0 & 1 & 0 & 0 & 0 \\
\hline Uticularia & 1 & 0 & 1 & 0 & 1 & 0 \\
\hline Dicraniaceae, Dicranum & 0 & 6 & 0 & 3 & 8 & 3 \\
\hline Dryopteris & 22 & 13 & 15 & 22 & 25 & 36 \\
\hline $\begin{array}{l}\text { Hypnaceae, } \\
\text { Plagiothecium }\end{array}$ & 0 & 0 & 0 & 1 & 0 & 0 \\
\hline Lycopodium sp. & 4 & 2 & 9 & 6 & 6 & 6 \\
\hline Polypodium & 1 & 0 & 0 & 0 & 1 & 0 \\
\hline Pottiaceae & 0 & 2 & 7 & 5 & 2 & 1 \\
\hline Sphagnum & 3 & 1 & 0 & 3 & 2 & 3 \\
\hline Spike & 18 & 72 & 44 & 114 & 79 & 133 \\
\hline Unknown Palynomorph & 23 & 32 & 47 & 104 & 33 & 76 \\
\hline Unidentified & 8 & 15 & 9 & 11 & 14 & 17 \\
\hline Identified & 1 & 4 & 0 & 4 & 1 & 7 \\
\hline Total & 305 & 300 & 307 & 362 & 303 & 338 \\
\hline
\end{tabular}


Figure 1. Map of Location of ST 10-02

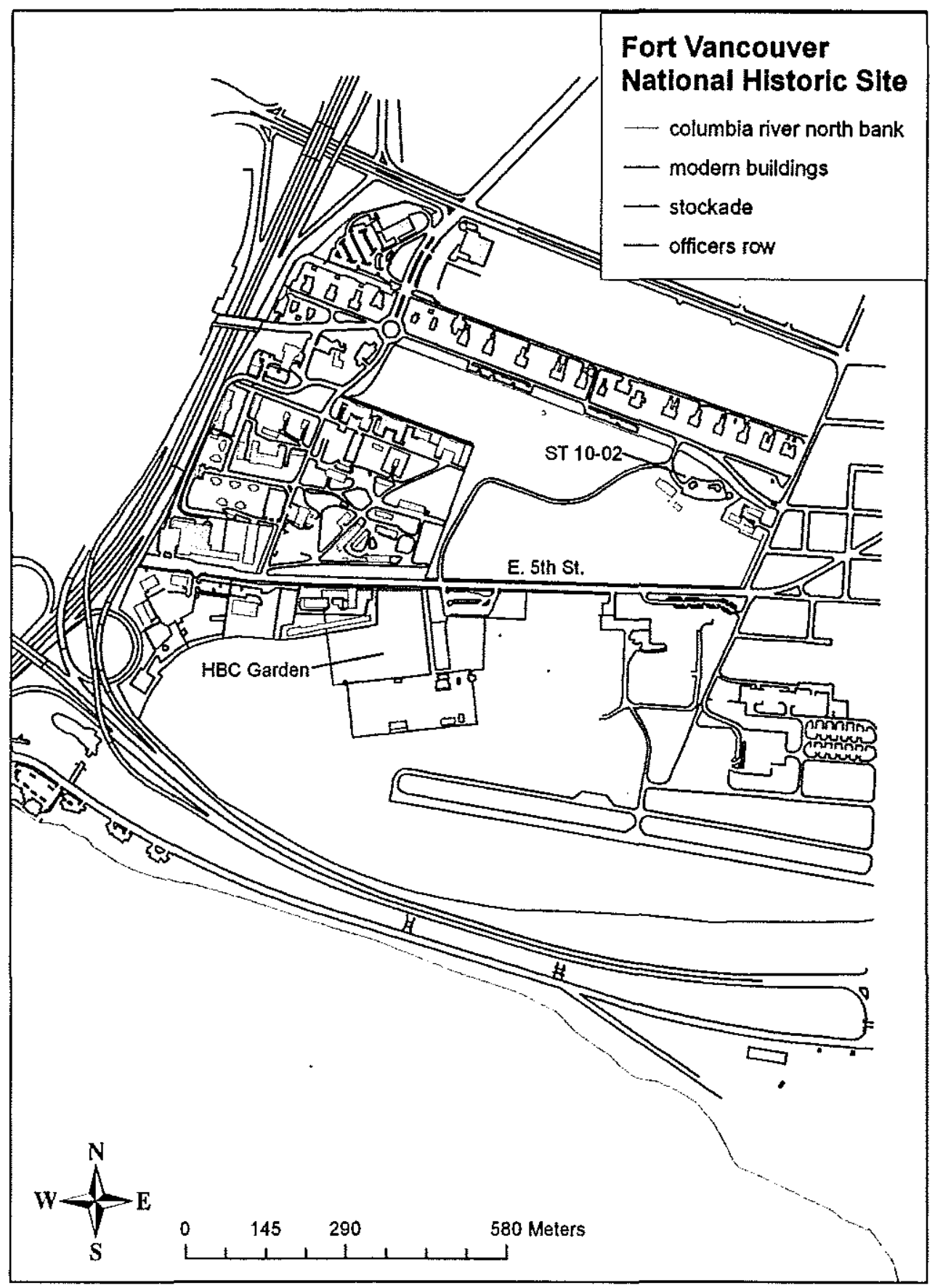


Figure 2. Pollen Percentage Diagram

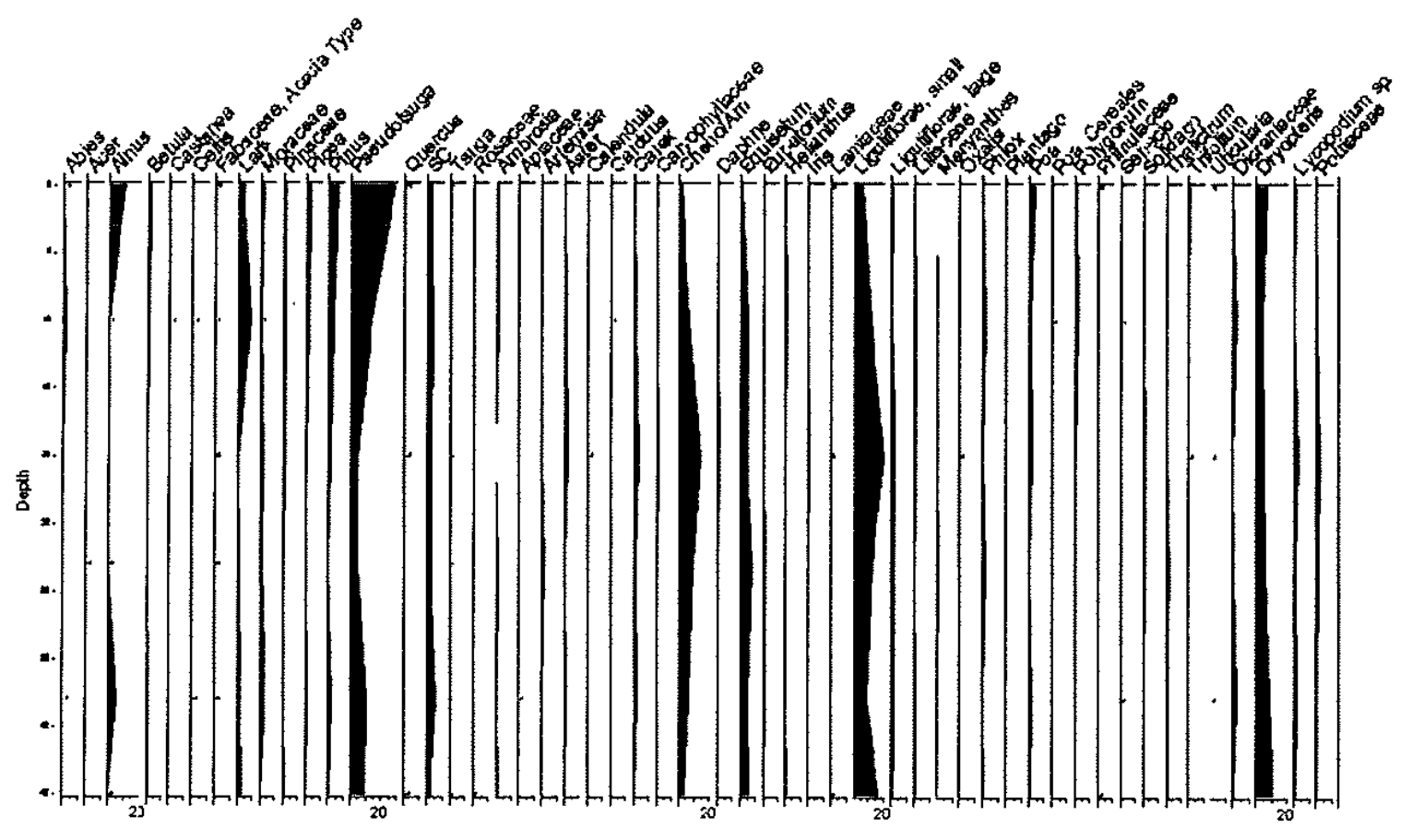


Figure 3. Percentage Diagram Including "Unknown Palynomorph"

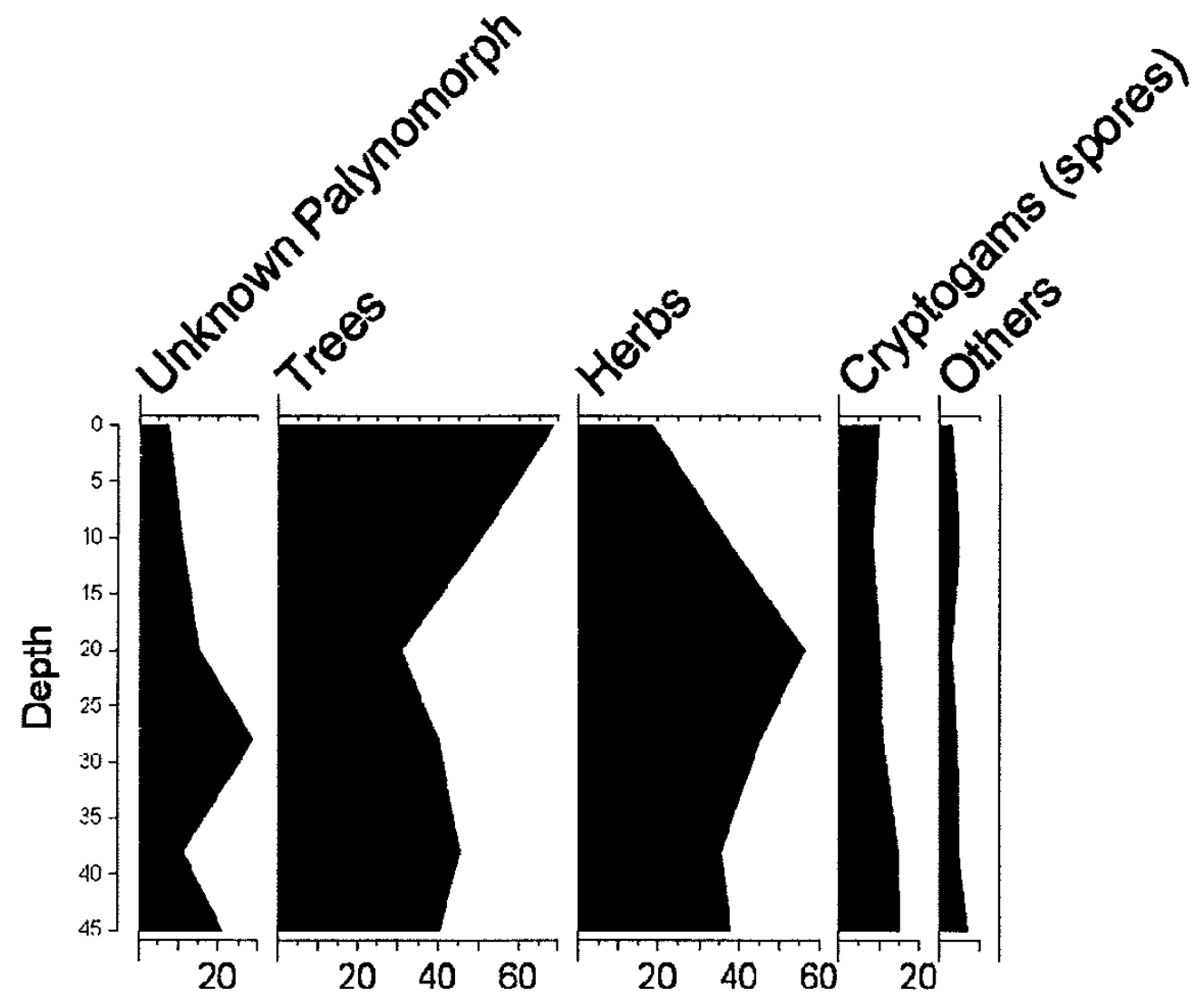


Photograph 1. "Unknown Palynomorph"

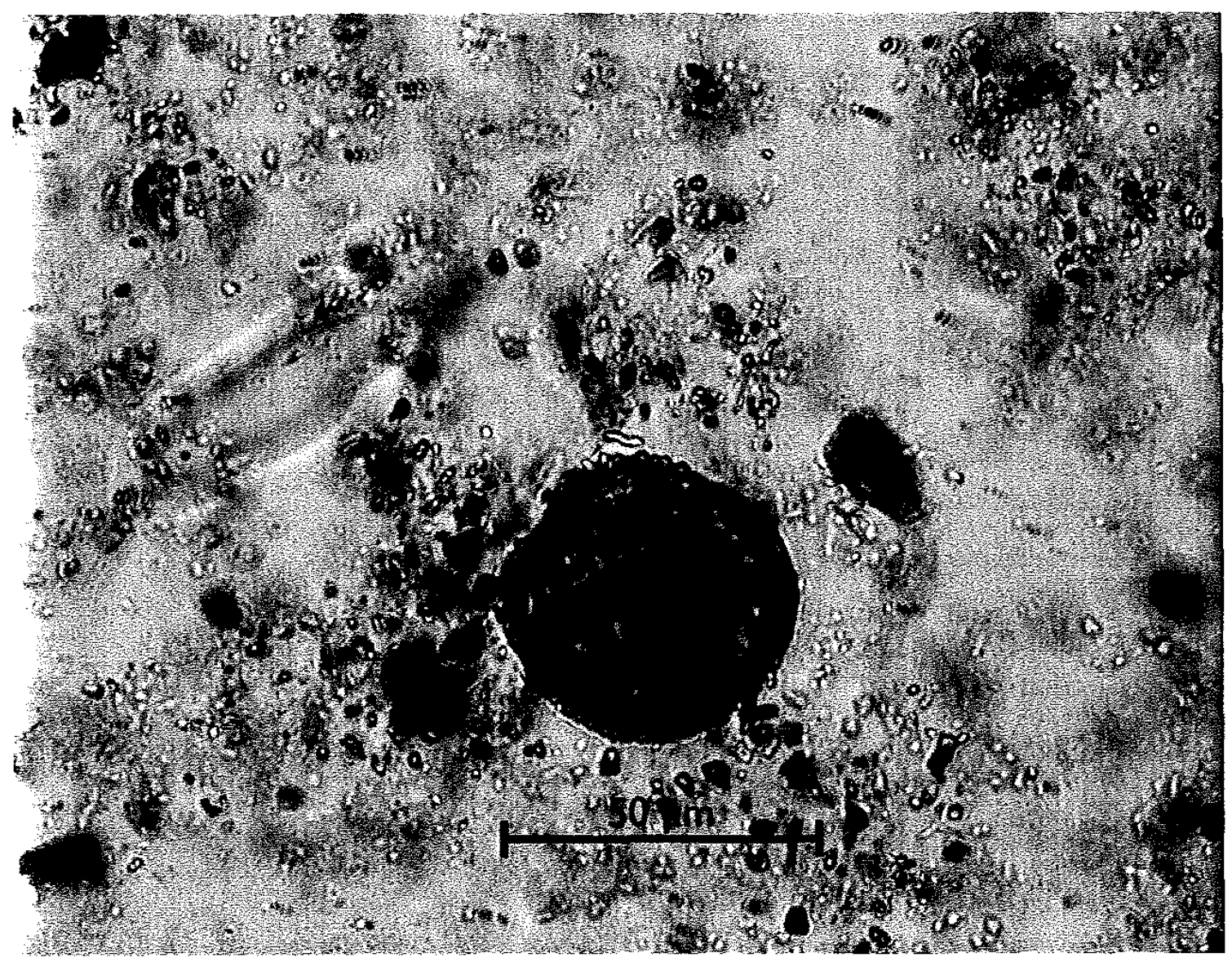




\section{APPENDIX H}

Macrobotanical Analysis of Hand-picked and Wetscreen Samples from Fort Vancouver, Washington 
Macrobotanical Analysis of Hand-picked and Wetscreen Samples from Fort Vancouver, Washington

\author{
by \\ Virginia S. Popper \\ Fiske Center for Archaeological Research \\ University of Massachusetts at Boston \\ Boston, Massachusetts
}

\author{
prepared for \\ Fort Vancouver National Historic Site - National Park Service \\ 612 E. Reserve St. \\ Vancouver, WA 98661
}

February 2, 2010 


\section{Methods and Results}

Thirty-four samples from the mid-nineteenth century garden at Fort Vancouver were sent for analysis. Wetscreen samples were sifted through a $2.00 \mathrm{~mm}$ sieve to separate out charcoal large enough for identification. Charcoal fragments smaller than $2 \mathrm{~mm}$ usually do not have enough diagnostic features for identification. All of the material was examined using an incident light binocular microscope (10-60x). The results are presented in Tables 1 and 2. Any identification that carried some uncertainty was indicated as $\mathrm{cf}$.

The samples contained seeds from a few economically important fruits: cf. Ficus carica (fig), Rubus sp. (blackberry/raspberry), and Sambucus sp. (elderberry). In addition, the samples had seeds from wild plants including Chenopodium sp. (goosefoot), Galium sp. (bedstraw), Fabaceae (legume family), two unknown seeds or fruit fragments and unidentifiable seed/fruit fragments. All of the wood and charcoal fragments were extremely small and most were too small to identify. Charcoal identified as "Conifer" had no visible resin ducts but were too small or distorted to rule out the presence of resin ducts. Those identified as "Conifer Type A" have small resin ducts in the late wood and could be from Douglas fir (Pseudotsuga menziesii), but again were too small for a secure identification. Indeterminate charcoal lacked diagnostic features for any type of classification. Other plant parts recovered include possible conifer cone bract fragments, a possible corm (underground stem) fragment, a legume-family pod fragment, grass stems and florets, bark, a bud fragment, and a very small thorn. Many of the samples contained rootlets, which are probably modern, and some contained small root fragments, grass stems and grass florets, which also look modern. Overall it seems that plant preservation is poor at the site. 
Most of the remains recovered from these samples are not carbonized. Plant material generally decomposes in a relatively short period of time after deposition, so uncarbonized plant remains are considered contamination by modern vegetation (Minnis 1981). Given the recent date of these deposits, it is possible that uncarbonized remains represent cultural deposits dating to the mid- $19^{\text {th }}$ century garden. However, the samples contain many rootlets and insect (non-plant) remains and extremely small wood and charcoal fragments, indicating a fair amount of disturbance of the deposits. Consequently, one should be cautious in the interpretation of the uncarbonized plant remains.

\section{Reference Cited}

Minnis, Paul E.

1981 Seeds in Archaeological Sites: Sources and Some Interpretive Problems. American Antiquity 46:143-1 
Table 2. Common Names and Notes for the Identified Macrobotanical Remains

\begin{tabular}{|l|l|l|}
\hline IDENTIFICATION & COMMON NAME & NOTE \\
\hline & & \\
\hline Chenopodium sp. & Goosefoot & \\
\hline Conifer & & \\
\hline Conifer Type A & & Possibly Douglas fir (Pseudotsuga menziesii) \\
\hline cf. Conifer cone bract frag. & & \\
\hline cf. Corm frag. & & $\begin{array}{l}\text { Modified, unbranching, underground stems } \\
\text { that serve food storage and reproductive } \\
\text { functions }\end{array}$ \\
\hline Fabaceae seed & & Very small seed comes from a wild legume \\
\hline cf. Fabaceae pod frag. & Legume family & \\
\hline cf. Ficus carica & Fig & \\
\hline Galium sp. & Bedstraw & \\
\hline Indeterminate charcoal & & \\
\hline Poaceae culms & Grass family & Small stems \\
\hline Poaceae floret & Grass family & Part of flower, no seed \\
\hline Rubus sp. & Blackberry/rasberry & \\
\hline Sambucus sp. & Elderberry & \\
\hline
\end{tabular}

